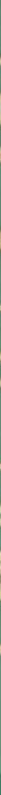

Media, Culture and Social Change in Asia

\title{
MEDIA, INDIGENEITY AND NATION IN SOUTH ASIA
}

Edited by

Markus Schleiter and Erik de Maaker

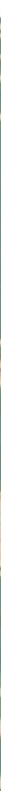




\section{Media, Indigeneity and Nation in South Asia}

How do videos, movies and documentaries dedicated to indigenous communities transform the media landscape of South Asia? Based on extensive original research, this book examines how in South Asia popular music videos, activist political clips, movies and documentaries about, by and for indigenous communities take on radically new significances. Media, Indigeneity and Nation in South Asia shows how in the portrayal of indigenous groups by both 'insiders' and 'outsiders' imaginations of indigeneity and nation become increasingly interlinked. Indigenous groups, typically marginal to the nation, are at the same time part of mainstream polities and cultures. Drawing on perspectives from media studies and visual anthropology, this book compares and contrasts the situation in South Asia with indigeneity globally.

Markus Schleiter is Lecturer in the Institute of Ethnology at Münster University, Germany.

Erik de Maaker is Assistant Professor in the Department of Cultural Anthropology and Development Sociology at Leiden University, The Netherlands. 


\section{Media, Culture and Social Change in Asia}

Series Editor: Stephanie Hemelryk Donald

Editorial Board:

Gregory N. Evon, University of New South Wales

Devleena Ghosh, University of Technology, Sydney

Peter Horsfield, RMIT University, Melbourne

Chris Hudson, RMIT University, Melbourne

Michael Keane, Curtin University

Tania Lewis, RMIT University, Melbourne

Vera Mackie, University of Wollongong

Kama Maclean, University of New South Wales

Laikwan Pang, Chinese University of Hong Kong

Gary Rawnsley, Aberystwyth University

Ming-yeh Rawnsley, School of Oriental and African Studies, University of London

Jo Tacchi, Lancaster University

Adrian Vickers, University of Sydney

Jing Wang, MIT

Ying Zhu, City University of New York

The aim of this series is to publish original, high-quality work by both new and established scholars in the West and the East, on all aspects of media, culture and social change in Asia.

\section{Digital China's Informal Circuits}

Platforms, Labour and Governance

Elaine Jing Zhao

The Early Transnational Chinese Film Industry, 1897-1937

Yongchun Fu

\section{Urban Culture in Pre-war Japan}

Adam Thorin Croft

\section{Media, Indigeneity and Nation in South Asia}

Edited by Markus Schleiter and Erik de Maaker

\section{Love Stories in China}

The Politics of Intimacy in the Twenty-First Century

Edited by Wanning Sun and Ling Yang

For a full list of available titles please visit: www.routledge.com/Media-Cultureand-Social-Change-in-Asia-Series/book-series/SE0797 


\section{Media, Indigeneity and Nation in South Asia}

\section{Edited by Markus Schleiter and Erik de Maaker}


First published 2020

by Routledge

2 Park Square, Milton Park, Abingdon, Oxon OX14 4RN

and by Routledge

52 Vanderbilt Avenue, New York, NY 10017

Routledge is an imprint of the Taylor \& Francis Group, an informa business

(C) 2020 selection and editorial matter, Markus Schleiter and Erik de Maaker; individual chapters, the contributors

The right of Markus Schleiter and Erik de Maaker to be identified as the authors of the editorial material, and of the authors for their individual chapters, has been asserted in accordance with sections 77 and 78 of the Copyright, Designs and Patents Act 1988.

With the exception of Chapter 1, no part of this book may be reprinted or reproduced or utilised in any form or by any electronic, mechanical, or other means, now known or hereafter invented, including photocopying and recording, or in any information storage or retrieval system, without permission in writing from the publishers.

Chapter 1 of this book is available for free in PDF format as Open Access from the individual product page at www.routledge.com. It has been made available under a Creative Commons Attribution-No Derivatives 4.0 license.

Trademark notice: Product or corporate names may be trademarks or registered trademarks, and are used only for identification and explanation without intent to infringe.

British Library Cataloguing-in-Publication Data A catalog record for this book has been requested

Library of Congress Cataloging-in-Publication Data

A catalog record for this book has been requested

ISBN: 978-1-138-35467-8 (hbk)

ISBN: 978-0-429-42464-9 (ebk)

Typeset in Times New Roman

by Apex CoVantage, LLC 


\section{Contents}

List of figures viii

Notes on contributors $\quad \mathrm{x}$

Acknowledgements $\quad$ xv

1 Introduction: screening indigeneity and nation 1

ERIK DE MAAKER AND MARKUS SCHLEITER

\section{PART I}

Vernacular popular culture: movies and music videos

2 Himachali indigeneity: Gaddi music VCDs and expressions of belonging

ANJA WAGNER

3 'Manbhum' videos and their many contours: contexts, contents, and the comic mode as a subversive form MADHUJA MUKHERJEE

4 Films, flirts, and no dances: a village video night and the circulation of popular Santali VCDs among Birhor people in India 
PART II

Politicising indigeneity: video clips and movies

6 Primitive accumulation and "primitive" subjects in postcolonial India: tracing the myriad real and virtual lives of mediatised indigeneity activism

UDAY CHANDRA

7 Giving voice? Experiences of collaboration on indigenous video-making projects

RADHIKA BORDE

8 From clanships to cyber communities: India's Northeast in the digital age

DAISY HASAN

9 Projecting and rejecting indigeneity: 'From Bangladesh with Love'

CARMEN BRANDT

\section{PART III}

Documenting and fictionalising indigeneity

10 Made in India: ethnographic films beyond visual anthropology

GIULIA BATTAGLIA

11 Critiquing stereotypes? Documentary as dialogue with the Garo

ERIK DE MAAKER

12 YouTube and the rising trend of indigenous folk dance: the case of the sakela dance of the Rai in Nepal and their diaspora

13 Identity, indigeneity, and cultural props: portraying the Tai-Ahoms in two Assamese films based on the legend of Joymati 
14 Polyandry, sexuality and the (mis)representation of indigenous women on Indian screens. The film Sonam:

The Fortunate One

MARA MATTA

15 Afterword: meditations on media in digital times 266 ROBIN JEFFREY

Index 


\section{Figures}

1.1 Munna Bhai, Santali music video and film producer at Sur Sangeet Films, in his VCD shop

1.2 On stage at the regional film festival Jharkhand Cine Award, organised by the All India Santali Film Association (AISFA), in Jamshedpur in May 2013

2.1 VCDs produced in Kangra District, Himachal Pradesh, featuring images of Gaddi people on the cover

3.1 Le samla sadher tomato: Taste, Taboo and Tomato

3.2 'Huchke niye puchke dili re': Between folk humour and grotesque realism

4.1 Birhor tola (subvillage) of Durdura, Mayurbhanj, Odisha in $2007 \quad 67$

4.2 Video night at a family's courtyard in a tola with predominantly Santal residents, near to the Birhor tola, Durdura, 2007

4.3 Chandra Tudu during the interview conducted in 2011

4.4 VCD cover of Santali film Chorok Chikan (2005)

4.5 VCD cover of Santali film Achchha Thik Geya (2008)

4.6 Birhor and Santal people dancing together at a village dance in Durdura, 2007

8.1 An image of Nido Taniam that was used to mobilise a call for justice

8.2 A still from the Shillong Chamber Choir's 'Just One' Music Video

9.1 Carmen Brandt and Shibly Sadik

9.2 Joy and Lisa in Cox's Bazar

9.3 Lisa on Bengali New Year's Day dressed in a traditional sari

10.1 2008 Delhi International Ethnographic Film Festival (DIEFF) banner

10.2 Audience listening to the seminar 'Practicing the Craft, Crafting the Practice' hosted by Delhi University during the 2008 DIEFF - among the audience, Saba Dewan and David MacDougall

10.3 Invited participants at the seminar 'Practicing the Craft, Crafting the Practice' hosted by Delhi University during 
the 2008 DIEFF. Speakers include (left to right) Sanjay Kak, Rahul Roy, Judith MacDougall, Nandini Bedi and Reena Mohan. 175

10.4 Cover of the book: A Portrayal of People: Essays on Visual Anthropology in India (Singh and DasGupta 1987)

10.5 Cover of the book: Visual Anthropology and India:

Proceeding of a Seminar (Singh 1992)

10.6 Cover of the book: Visual Anthropology in India and Its Development (Sahay 1993)

13.1 Xorai in Agarwala's Joymoti used for offering to gods 231

13.2 Xorai in Borah's Joymati used for offering paan-tamul 232

13.3 Jaapis as background decoration in Agarwala's Joymoti 233

13.4 Jaapis as headwear in Borah's Joymati 233

13.5 Dragons as background decoration in Borah's Joymati 234

13.6 Gamosa offered before the priests in Borah's Joymati 235

13.7 Clothing worn by members of the Tai-Ahom community during a cultural event in Sonari, Chraideo, Upper Assam 235

13.8 Clothing worn by members of the Tai-Ahom community at a religious event in Patsako, upper Assam region

13.9 Video still from a video posted on YouTube showing a Tai-Ahom demonstration to demand ST status; demonstrators wear traditional clothing as a marker of identity 


\section{Notes on contributors}

Arzuman Ara, The English and Foreign Languages University, Shillong Campus

Arzuman Ara teaches English at the English and Foreign Languages University, Shillong campus, Northeast India. She has been associated with studies in the fields of literary studies, language pedagogy, mass communication and journalism, gender studies and humanities. She has been a visiting fellow at Oakton Community College, Illinois, USA, and at North-Eastern Hill University, Shillong, India. She received the Barkataki Journalism Award in 2004 in Assam, India. She has published both in India and abroad and has also translated poetry volumes. Her academic interest lies in critical theory and cultural studies and she is a committed feminist. She has completed research in areas including partition narratives, critical pedagogy, tribal poetry and South Asian narratives. She has developed course materials for teaching the English language and comparative literature. In her studies of films, she focuses on visual analyses, especially of works by female directors.

Giulia Battaglia, Sorbonne Nouvelle Paris 3/École des Hautes Études en Sciences Sociales (EHESS), Paris

Giulia Battaglia is a researcher in anthropology of visual/art/media practices specialised in documentary film in India. Her work is interdisciplinary and draws from a range of academic fields, including visual/media anthropology, documentary studies, visual and material cultures, art and anthropology, Indian cinema, cultural studies, and film history. Since receiving her $\mathrm{PhD}$ from the School of Oriental and African Studies (SOAS), University of London, she has worked as a lecturer and researcher in various departments of anthropology, media, art and social sciences as well as in cultural institutions in England and in France. At present, she lives in Paris and works there in the fields of anthropology, arts and media in association with the laboratoire de recherche IRMECCEN, Université Sorbonne Nouvelle (Paris 3) and the laboratoire de recherche LAIOS/IIAC at the École des Hautes Études en Sciences Sociales (EHESS). For the latter, she is also responsible for a funded international project at the intersection of arts and social sciences, entitled "L'invention des formes de représentation à l'ère de la mondialisation". Her first monograph, Documentary Film in India: an Anthropological History, was published by Routledge in 2018 . 


\section{Radhika Borde, Charles University, Prague}

Radhika Borde is a researcher at the Department of Social Geography and Regional Development at the Charles University in Prague, and is a steering committee member of an IUCN specialist group (the specialist group on the Cultural and Spiritual Values of Protected Areas). She is also the editor of the group's newsletter. Radhika has a PhD from Wageningen University in the Netherlands. She has worked as an activist in India and continues to support grassroots-level, indigenous-led rural initiatives. She has researched and published on social movements against mining, indigenous religiosity, indigenous media, indigenous women's movements in India and place-attachment in immigrant populations.

\section{Carmen Brandt, University of Bonn}

Carmen Brandt has been junior professor at the Department for South Asian Studies of the Institute for Oriental and Asian Studies at the University of Bonn, Germany, since January 2017. She obtained a Magister degree in Languages and Cultures of Modern South Asia, Indology, and Communication and Media Studies from the Martin Luther University Halle-Wittenberg, Germany, where she later received her doctorate in Languages and Cultures of Modern South Asia. Her doctoral research focused on the representation in fictional and non-fictional sources in Bengali and English of the itinerant groups in Bengal known as 'Bedes'. Her thesis The 'Bedes' of Bengal: Establishing an Ethnic Group through Portrayals was published by LIT Verlag, Berlin. In her current research project, she is investigating the sociopolitical dimensions of script in general, multiscriptality, and script invention and revival, particularly among ethnolinguistic minorities in contemporary South Asia. Central to this research is the comparative analysis of case studies from various regions in Bangladesh, India and Pakistan, where she regularly conducts fieldwork. Apart from sociolinguistics, she is interested in identity politics in contemporary South Asia in general, and more specifically in the influence of global development and rights discourses on the formation of local identities.

\section{Uday Chandra, Georgetown University, Qatar}

Uday Chandra is an assistant professor at Georgetown University, Qatar. His research interests lie at the intersection between agrarian studies, postcolonial theory, political anthropology and South Asian history. His forthcoming monograph Negotiating Leviathan traces how the notion of 'tribe' has co-evolved with modern state-making processes in South Asia and beyond.

\section{Erik de Maaker, Leiden University}

Erik de Maaker (PhD, Leiden) is a researcher and lecturer at the Institute of Cultural Anthropology and Development Sociology at Leiden University in the Netherlands. He studied anthropology in Amsterdam and Leiden, and in his $\mathrm{PhD}$ dissertation, he took the changing religious practices of the Garo as a starting 
point for an analysis of social and economic transformation in upland Northeast India. His current research focuses on the redefinition of land as a resource, as well as processes of place-making in the extended eastern Himalayas. This includes the redefinition and re-appreciation of 'traditional' cultural ideas and practices ('heritage') and their growing importance in terms of ethnicity, indigeneity and nation. Methodologically, the material and performative dimensions of culture are central to his research. Work at the peripheries of post-colonial states has raised his interest in the growing importance of Asia's borders, and he is one of the founders of the Asian Borderlands Research Network (https://iias.asia/ research/asian-borderlands-research-network). Erik has published in a range of academic journals and edited volumes, and is preparing a monograph on the modernisation of 'custom', community and relatedness in upland Northeast India. For more details on his research and publications, see https://leidenuniv.academia. edu/ErikdeMaaker

\section{Daisy Hasan, University of Westminster, London}

Daisy Hasan is currently managing "Creative Interruptions: grassroots creativity, state structures and disconnections as a space for "radical openness" - an arts and activism research project at Brunel University, London. She also coordinates the Chevening South Asia Journalism Programme at the University of Westminster, London. She has researched and taught at the universities of Leeds, Cardiff and Swansea. She has worked with All India Radio and was a founder member of the splitENDS media co-operative in Shillong where she worked on a series of short films and video projects. She was awarded a Ford Foundation International Fellowship to do a PhD in Media Studies in Swansea. She also received the BBC's Jasvinder Singh Memorial Fellowship to pursue postgraduate study at the AJK Mass Communication Research Institute, Jamia Millia Islamia. Her first novel The To-Let House (Tara Books, 2010) was longlisted for the 2008 Man Asia Literary Prize and shortlisted for The Hindu Literary Prize, 2010.

\section{Robin Jeffrey, National University of Singapore}

Robin Jeffrey is a visiting research professor at the Institute of South Asian Studies, Singapore. His most recent book, written with Assa Doron, is Waste of a Nation: Garbage and Growth in India (Harvard University Press, 2018). He and Doron also wrote The Great Indian Phone Book (2013). Robin is the author of India's Newspaper Revolution (2000). He taught for 25 years at La Trobe University in Melbourne and worked twice at the Australian National University in Canberra. He lives in Melbourne.

Akshaya Kumar, Indian Institute of Technology (IIT), Indore

Akshaya Kumar is Assistant Professor at the School of Humanities and Social Sciences, Indian Institute of Technology, Indore. He completed his PhD with a 
Screen studentship at the University of Glasgow in Film and Television Studies. $\mathrm{He}$ is currently finishing a manuscript provisionally titled "Provincializing Bollywood: Bhojpuri Cinema in a Comparative Media Crucible". His essays have appeared in Social Text, Television and New Media, South Asia: Journal of South Asian Studies and various other journals.

\section{Mara Matta, Sapienza University of Rome}

Mara Matta is a senior researcher in South Asian Studies and Assistant Professor of Modern Literatures of the Indian Subcontinent at the Department of Oriental Studies at Sapienza University of Rome, Italy. She studied at the University of Napoli 'L'Orientale', East Anglia University (UK), Sichuan University and Tibet University (PRC), and Dhaka University (Bangladesh). She is on the editorial boards of several international journals. Her research interests cover Himalayan and South Asian indigenous literatures and cinemas, Asian theatre, media and communication, migration and diaspora, indigeneity and minorities' rights, and subaltern and gender studies. She has published two books, one on political theatre in Nepal entitled Nepal: A Theatre for Better Reasons (Fuorilinea Ed, Rome 2015) and one on the representation of Tibet in world theatre, Scena Tibet, (Fuorilinea Ed, Rome 2013). She is currently working on two projects: a coedited book on Asian mobilities and arts, and a monograph on Kalpana Chakma's Diary. She has also contributed various articles to international journals and as book chapters. Mara is a member of the Network for the Promotion of Asian Cinemas (NETPAC, Delhi and Colombo) and of the Archive of Migrant Memories (AMM, Rome).

\section{Madhuja Mukherjee, Jadavpur University, Kolkata}

Madhuja Mukherjee (Associate Professor) teaches in the Department of Film Studies, Jadavpur University, Kolkata, India. Madhuja's research focuses on industrial history, regional networks, technological transformations, genre, stars, urban cultures and historiography. Recently she has researched and published on sound, music and voice in Indian films. She is currently working on digital practices and new exhibition circuits. Madhuja has published extensively in reputable scholarly journals; she is the author of the book New Theatres Ltd. (Pune: NFAI, 2009), editor of Aural Films, Oral Cultures (Kolkata: JU Press, 2012), Voices of the Talking Stars (Delhi/Kolkata: Sage/Stree, 2017), and co-editor of Popular Cinema in Bengal (Routledge, forthcoming). Her work in film is not limited to the field of academia. She co-wrote the internationally acclaimed film Qissa (2013), and her directorial debut, Carnival (2012), has been screened at several international festivals. Madhuja received a fellowship for arts leadership during 2013-14, and her multi-media installations have been shown at renowned galleries and in international programmes. She is currently working on her second graphic novel The Dog Star, supported by IFA, Bangalore. As the principal initiator of the art platform TENT, Kolkata, Madhuja has organised the annual TENT 'Little Cinema International Festival' for experimental films and art since 2014. 


\section{Markus Schleiter, Münster University}

Markus Schleiter teaches social anthropology and media anthropology at the Institute of Ethnology, Münster University, Germany. Prior to this, he was an affiliated scholar at the Frobenius Institute in Frankfurt am Main and at the International Institute of Asian Studies, Leiden, the Netherlands, where he did research about 'indigenous' communities in South Asia with reference to popular indigenous films of South Asia as well as indigenous everyday culture and religion, and governmental developmental work. Furthermore, he has published on forms of ethnographic writing in South Asia. He has conducted more than three years of ethnographic field studies with the Birhor and Santal people. In 2013, he initiated a collaborative archive of Santali VCDs that is maintained by the Frobenius Institute, Frankfurt am Main and the Media Lab at the Department of Film Studies, Jadavpur University, Kolkata.

\section{Anja Wagner}

Anja Wagner is a social anthropologist from Germany, specialised in environmental anthropology and the anthropology of place. Further key interests are media anthropology and visual representation, as well as the anthropology of gender. She has conducted ethnographic fieldwork among the Gaddi people in Himachal Pradesh, North India. Anja has worked as a lecturer in social anthropology at the University of Münster and has taught at the University of Heidelberg's South Asia Institute. She studied social anthropology and economics at the Free University in Berlin and received her postgraduate degree in social anthropology from the University of Heidelberg.

\section{Marion Wettstein, University of Bern}

Marion Wettstein is an anthropologist, ethnographer, social scientist of religion and curator who takes a comparative approach in studying religious, performative and material practices between Europe and Asia. With her regional focus on the extended eastern Himalayas, she completed her dissertation on textile traditions in Northeast India at the University of Zurich in 2011. Her current research project examines ritual dance and performative traditions in eastern Nepal. She is a postdoctoral assistant at the Institute for the Science of Religion and Central Asian Studies at the University of Bern, Switzerland. Major publications include Naga Textiles: Design, Technique, Meaning and Effect of a Local Craft Tradition in Northeast India (2014) and Naga Identities: Changing Local Cultures in Northeast India (2008). 


\section{Acknowledgements}

This volume expands upon a larger body of academic writing on critical approaches to indigeneity and nation in South Asia that has emerged over the last two decades. The initial idea for this book dates back to 2008, as the outcome of a workshop that was held at the International Institute of Asian Studies (IIAS), Leiden University ("'Tribes', Traditions and the State: Reconsidering social practices of 'tribal' development in India"). After some delay, the project gathered further shape at two workshops in Zürich in 2014 during the 23rd bi-annual European Conference on South Asian Studies (ECSAS). The conference included the panel "Video varieté: The cultures and forms of new visual media in South Asia", while parallel to the conference the workshop "'Tribes' on Screen: Mediatizing South Asian Indigeneity" was held at the Ethnographic Museum of the University of Zürich. Other contributions have their origins in presentations given at the Frobenius Institute at the University of Frankfurt, which has also supported the project extensively and provided travel funds.

Many people have contributed to the realisation of this book. We are grateful to the two anonymous reviewers of the Routledge "Media, Culture and Social Change" series for their comments, encouragement and valuable suggestions. We also wish to thank Chandan Baskey, Helene Basu, Deepak Beshra, Christiane Brosius, Birbaha Hansda, Shyamranjen Hembram, Anne Koth, Lallianpuii, Lotte Hoek, Lidia Guzy, Frank Heidemann, Karl-Heinz Kohl, Sukurmani Murmu, Rajni Palriwala, Melvil Pereira, Manon Osseweijer, Patricia Spyer, Willem van Schendel and our contributors. We are particularly indebted to Pip Hare, who took care of the English language editing of the various contributions. We are grateful to the German Research Foundation (DFG) for their sustained support and for providing funding for travel and copyediting. Financial support for this project has also been made available through Leiden University's profile area Asian Modernities and Traditions (AMT), the Dutch National Science Foundation (NWO), the Indian Council for Social Science Research (ICSSR) and Leiden University's Institute of Cultural Anthropology and Development Sociology. Last but not least, this volume could not have been realised without the support of the Institutes of Ethnology of Heidelberg University and Münster University, particularly during the final stages of the work.

Münster and Leiden, January 2019. 
$\because$ Taylor \& Francis Taylor \& Francis Group http://taylorandfrancis.com 


\title{
1 Introduction
}

\section{Screening indigeneity and nation}

\author{
Erik de Maaker and Markus Schleiter
}

\section{Media at the fringe}

At a weekly market in a remote, rural district of the Indian state of Meghalaya, a vendor is offering bootleg VCDs of the latest Hindi movies for sale. In addition, she sells disks of movies and music videos in Garo, Assamese, Bengali and other local languages. Movies and music videos are also available for download onto memory cards or for wireless transfer via Bluetooth onto smartphones. Prices are low because copyright is not an issue, so even people on a very tight budget can afford to make purchases. Music and films offer the vendor's customers a delightful world of pleasure and entertainment, but also provide them with the opportunity to listen to new voices that are politically engaged and culturally committed. In this locality, accessing music and videos via the internet is also becoming increasingly affordable for a wide public. Audiovisual media have not only become omnipresent as consumable entertainment, often mixed with political messages, but also as a medium of self-expression: important events are captured for posterity on mobile phones, shared among family and friends and sometimes displayed on Facebook.

Not so long ago, watching movies, music videos and documentaries required televisions or projectors that were not necessarily easily available in the extensive rural areas of South Asian countries such as India, Pakistan, Bangladesh and Nepal. In large parts of these rural hinterlands, where landlines never gained much ground and electricity cannot be taken for granted, the increasing affordability of video, smartphone technology and internet access constitutes nothing less than a revolution. As advanced digital technology and connectivity become available at ever lower rates (sometimes even apparently free of charge), with mobile networks competing to provide the best services, digital media technologies now reach some of the otherwise least connected parts of South Asia. These technological and commercial developments also create opportunities for new producers to enter the formerly closed arena of the entertainment industry; producers who often have particular political and cultural messages to convey, and who may increasingly challenge the hegemony of commercially produced cinema and documentary (Figure 1.1).

Most South Asian countries are dominated by hegemonic majorities, and it is not uncommon to hear evolutionary notions of 'civilisation' invoked to legitimise their position vis-à-vis groups or communities that are socio-economically and/or 


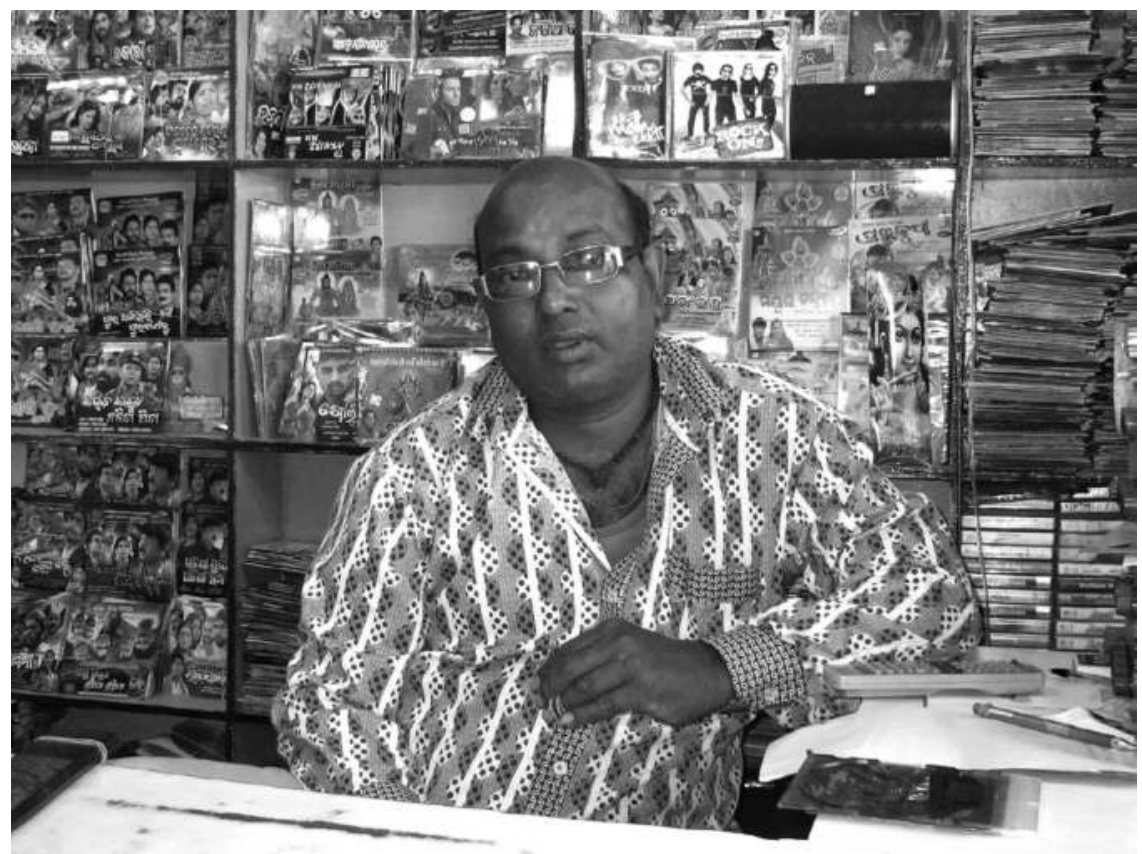

Figure 1.1 Munna Bhai, Santali music video and film producer at Sur Sangeet Films, in his VCD shop

Source: Photograph by Markus Schleiter

culturally marginalised (Bates 1995; Dirks 2001). In attempting to claim 'the nation' for themselves, the former tend to marginalise the latter, if they do not ideologically locate them outside its confines altogether (Chatterjee 1993). Among the most excluded are those whom the language of governance refers to as 'tribal' communities. Such groups may often be perceived as 'first people', the heirs of 'original' settlers and/or 'indigenous'. Economically deprived and socially excluded, these groups have historically not had access to mainstream media. Yet now they are at the forefront of transformations in the media landscape within which, until recently, they had barely been acknowledged as potential audiences, let alone producers. Often numerically relatively small, these communities constitute niche audiences both culturally and linguistically. Economies of scale used to restrict if not preclude the production of media specifically addressing such groups. At the same time, small-scale local media producers in South Asia had to struggle to gain any access to production facilities, as did people belonging to tribal communities. At best, the latter featured as the topic or object of ethnographic documentary films that emphasised their cultural distinctiveness (see Battaglia and de Maker, this volume) or were depicted by mainstream cinemas as citizens who were not truly part of the nation as imagined by majorities (see Matta, this volume). 
In the past two decades, however, the reduced costs of video equipment, editing and dissemination have made the production of movies and music videos that directly address these niche audiences commercially viable. Likewise, it has become economically feasible for people belonging to culturally marginalised communities to shoot and disseminate their own documentary material, which they engage with, challenge, or, at times, more or less paraphrase the kinds of narratives that were formerly almost exclusively constructed and owned by 'outsiders'. How have these new media been adopted and adapted by South Asia's tribal groups, as well as by other communities that perceive themselves as indigenous? And in what ways do these new modalities of representation transform perspectives on indigeneity and its place within nations?

This volume draws its inspiration from perspectives that have developed over the last few decades in media anthropology. These include seminal works such as Bourdieu's (1993) analysis of cultural production, Larkin's (2008) study of the impact of media technologies on cultural form and Ginsburg's (1995a, 2002) work on indigenous media. Methodologically, the volume relies heavily on ethnography; each of the contributions is grounded in qualitative research. Most of the chapters are based upon data that their authors collected while doing long-term research. Typically, such research involves building up lasting relationships with one's interlocutors, learning about their ideas, attitudes and practices by accompanying them in everyday life. Taken together, the various contributions explore how media that is made for audiences deemed indigenous is produced, shared, and viewed or 'consumed'. The chapters explore the social and political impact of old and new media technologies and media content in relation to the (re)formulation, contestation and (re)definition of mediatised representations of indigeneity, and how this bears upon perceptions and conceptualisations of nation in South Asia.

\section{Indigeneity and nation in South Asia}

In South Asia, marginalised minority groups that are believed to be descendants of 'original' inhabitants tend to be referred to as Adivasi ('first people') in India, pahari ('hill people') or upojati ('those outside the nation') in Bangladesh, janajati ('nation') in Nepal, and 'those of a marginal qaum' ('nation') in Pakistan. ${ }^{1}$ All in all, these communities comprise no small number of people. In India, the largest of the South Asian states, members of these various groups taken together in 2011 numbered at least 104 million, according to the country's latest population census, which was held in that year (Census 2011). In Nepal, an estimated nine million people come under such categorisation (Carrin, Kanungo and Toffin 2014). Precise figures for other South Asian nations are not available. Across the various South Asian states, the English term 'tribe' is also used to refer to these groups. 'Tribe' was introduced by the erstwhile British colonial administration to label groups that were believed to be marginal to 'mainstream society' and thought to exist outside both caste hierarchies and the pre-colonial states of the subcontinent.

In accordance with a rigid understanding of social structure, the erstwhile British colonial administration sought to chart, enumerate and map the South Asian 
population, an endeavour which involved creating extensive listings and descriptions of the various tribes, cataloguing their ethnographic traits and ranking them in terms of 'civilisational hierarchy' (Pels 2000). British colonial policy sought to divide the population along lines of religion, caste and tribe in order to weaken the pre-colonial political fabric and facilitate the imposition of colonial rule (Cohn 1984; Appadurai 1993). Shaken by the events of 1857 , known variously as the 'Indian mutiny' or the 'first war of Indian independence', efforts to gather firsthand knowledge about South Asian communities intensified (Dirks 2006). Colonial administrators and army officers alike wrote extensively, describing the physical appearance and cultural characteristics of 'native' communities. These developments coincided with the foundation of anthropological societies in London and in South Asia itself, which disseminated the recently compiled ethnographic reports. In addition to administrative and military personnel, scholars (often former administrators or military personnel) and missionaries contributed their observations and interpretations to anthropological journals, which became the foundation of ethnographic writing on the minority communities of South Asia. Many ethnographic reports were primarily concerned with the identification of cultural traits, including attire, festivities, kinship and group-specific beliefs and rituals. Tribal communities were - at least historically - rarely believed to adhere to mainstream religions, and were often assumed to have a non-hierarchical social organisation (Xaxa 2008; Rycroft and Dasgupta 2011). Current conceptualisations of so-called tribal groups, and their positioning as indigenous people, continue to bear the marks of these early attempts at social categorisation, and this volume explores how such notions are manifested in contemporary visualisations of indigeneity and nation in South Asia.

Throughout South Asia, differences between tribal and non-tribal communities tend to be interpreted in a cultural and a hierarchical sense (Heidemann and Wolf 2014). Construed by South Asia's majorities as 'noble savages' or the living ancestors of 'modern' humans, the tribal groups of South Asia tend to be seen as backward and primitive (Dirks 2001). To this day, people belonging to tribal communities frequently face exclusion and discrimination, resulting in political marginalisation and economic deprivation. In many cases, traits initially identified by colonial ethnographers have become incorporated into the self-identifications of the groups concerned, which in turn find expression in new performative contexts, such as state-sponsored cultural festivals (DuBois et al. 2011). Ancestral rituals become staged performances, divorced from former religious contexts, and photographs showing heritage objects or community members wearing folkloristic tribal attire are circulated as hallmarks of tribalness printed on calendars, T-shirts and other mass-produced commodities. Such reproduction of cultural vignettes may appear far removed from earlier contexts, but frequently offers people from the communities concerned a way of relating their present to their past (de Maaker 2013). Cultural vignettes and customary practices, ever subject to reinterpretation, continue to shape gender roles, social relationships and political networks.

The policies imposed to counter the discrimination faced by tribal communities vary between the distinct South Asian states. Whereas most states do not have 
extensive provisions to counter discrimination, the Indian state has devised extensive policies to improve the political and socio-economic status of disadvantaged groups (Middleton 2015). In India, preferential discrimination is allocated according to 'schedules' (listings, hence 'Scheduled Tribes' or 'STs') based on categorisations of communities carried over from the colonial era. The listings are specific for each of the states and union territories of India, and a group that is listed as ST in one state will not necessarily be listed as such in a neighbouring state. Preferential discrimination measures range from reserved 'seats' in education and in elected bodies, exclusive access to a given number of government jobs, and at times exclusive rights to own and trade land as well as reduced tax obligations. Communities categorised as 'Scheduled Castes' (SC) and 'Other Backward Classes' (OBC) qualify for similar benefits. Scheduled Castes include Dalits or Harijans, who face structural deprivation and discrimination based upon their position within caste hierarchy. The same holds, albeit to a slightly lesser extent, for 'Other Backward Classes'. The implementation of these schemes has given rise to a complex administrative machinery, particularly in regions such as Northeast India or the mountainous areas of Odisha in central India, in which people with a tribal background constitute a high percentage of the population. Given the substantial benefits offered by preferential treatment, these policies have contributed to the fortification and reification of community-based indigenous identities (Van Schendel 2011; Middleton 2015). Elsewhere in South Asia policies of affirmative action bring less concrete benefits, but even there 'tribe' and the 'indigenous slot' have become firmly established political and social categories (Karlsson 2003).

Worldwide, indigeneity emerged as an important notion in the 1980s, with NGOs striving to advance the interests and rights of 'indigenous people' on a global level. Audiences in both the Global North and the Global South seem convinced by claims made on the basis of indigeneity. The concept initially gained traction within discourses on citizenship and nation in 'white settler' countries such as Australia, Canada and the United States of America. There, descendants of those who had inhabited the land before the arrival of European colonisers began to identify themselves as 'first people' in political struggles over natural resources and citizenship rights. 'Firstness' translated into primordial claims to the natural resources of what were regarded as ancestral lands that were being appropriated by mining companies and state governments. In the extensive lawsuits that followed, cultural bonds to land and landscape expressed in myths and rituals were cited and contributed to the success of substantial land claims. In 2007, the global recognition of indigeneity was testified to in the 'Declaration on the Rights of Indigenous Peoples' by the United Nations (Merlan 2009).

In India, organisations that represent tribal or Adivasi communities claim that descendants of a region's 'original' inhabitants should have first rights to ancestral land and the resources it harbours (Baviskar 2006; Karlsson and Subba 2006). Often, such claims are primarily advanced to ward off or at least contest attempts made to 'grab' land and resources by the state and/or the neo-liberal ventures it increasingly encourages and facilitates (as in the case of the Niyamgiri Movement versus the Vedanta Resources mining corporation; see Borde, this volume). Yet, 
inevitably, claims based upon ancestry implicitly identify other residents of the same territory as the descendants of later settlers, who are then denied equal rights to land and resources (Vandekerckhove 2009; Ghosh 2006). If indigenous claimmaking is successful, as in the parts of India's Northeast that are dominated by tribal groups, it can result in the further political and legal marginalisation of people who are unable to advance such primordial claims to any land (Baruah 2003). Claiming indigenous rights based upon ancestral occupation has proven highly problematic in contexts other than 'white settler' countries, and South Asia is a prime example.

The global rise of indigeneity has been part of broader environmentalist discourse that gained influence from the 1980s onwards (Muehlebach 2001). Earlier, indigeneity had primarily been attributed in South Asia based upon the cultural distinctiveness of tribes. Since then, as a consequence of growing concerns about deforestation, mining and pollution, indigenous people have come to be perceived as ecological guardians (ibid.). In South Asia, this has led to a reframing of tribal groups as people who are intrinsically close to nature (Shah 2007). Political activists contrast such peaceful groups with the brute force of states and neo-liberal capitalism, as can be seen in the video 'We Shall Not Leave Our Village' ('Gaon Chodab Nahin'), the audience reception of which Uday Chandra analyses in Chapter 6. The video presents the Indian state as a brutal aggressor that attacks harmonious indigenous village life, with policemen beating up villagers while unscrupulous politicians enforce their resettlement to make way for mining companies. Yet invoking indigeneity can be a two-edged sword: characterising communities as intrinsically close to nature implies that they are distant from civilisation, apparently untouched by modernity and contemporary society. All too often such groups are represented as the living survivors of an earlier phase of human evolution, isolated and timeless. Rather than debunking stereotypes, political movements that champion indigeneity, tribalness or adivasiness tend to contribute to the reification of all the cultural characteristics typically associated with such groups, not always to positive effect.

The success of indigenous claim-making has triggered new research by social scientists, inspiring new contributions in terms of anthropological theory. The political dimensions of indigeneity have attracted particular attention. It has been noted that the effectiveness of political assertions of indigeneity is to a substantial degree defined by a group's positioning vis-à-vis the state, and the political and administrative mileage that claiming indigenous status may potentially translate into (Murray Li 2010; Kohl 2006). Yet research has also questioned conceptualisations of indigeneity that are limited to distinct, 'closed' groups. In the Caribbean context, Maximilian Forte $(2005,2010)$ argued with reference to adoptive kin relationships and cosmopolitan forms of a Caribbean global indigeneity that indigenous belonging can create an inclusiveness that transcends narrow definitions of community and nation. Likewise, scholars working in South Asia have cited examples in which indigenous movements have brought together and united multiple groups or communities (Ghosh 2006; Steur 2017).

In South Asia, social science research along these lines sustains an engaged debate on the relevance and implications of the term tribe. Researchers' various 
contributions reveal that the debate on tribe is inextricably intertwined with efforts made since independence (and before) by politically dominant groups to define mainstream society in South Asia as a high civilisation, rooted in the courtly cultures of the early states of the north and the south, that is allegedly superior to what are perceived as the folk cultures at its margins. Revealingly, the governments of South Asia's post-colonial states refuse to categorise tribal groups as indigenous people - arguing instead that in principle all their citizens are indigenous (Muehlebach 2001). As mentioned in the previous section, this argument is plausible when considered in view of the notion of indigeneity in states such as Australia, Canada and the USA. As early as the 1940s, G.S. Ghurye (1963 [1943]) argued that the state-defined distinction of castes and tribes could not be justified on sociological grounds. One of his opponents was the self-taught anthropologist Verrier Elwin, who maintained that tribals should be seen as set apart from the rest of society and cherished as the custodians of unique cultural traditions that were not only distinct from but actually superior to both the Indian and European mainstream (Elwin 1988 [1964]). On the one hand, determined efforts continue to be made to argue the case for valorising tribe, emphasising the exceptionality, uniqueness and great cultural value of tribal customs and practices (Singh 2002; Pfeffer and Behera 2005). On the other hand, there has been a steady stream of contentions that tribe in South Asia is ultimately an artificially constructed social category, the product of a colonial worldview. Historians such as Bates (2007) and Misra (2011) have effectively debunked the alleged isolation of indigenous communities, while social anthropologists such as Shah (2010) and Karlsson (2011) have critically examined indigenous peoples' supposed exclusive relationship with nature.

\section{Beyond indigenous media}

Before the digital revolution, people who were economically and socially disadvantaged rarely had access to media production facilities, and it was an important emancipatory development when this began to change from the 1980s onwards. Camcorders became available on the consumer market, enabling real-life events to be recorded by people who had never before been able to do so. Anthropologists like Faye Ginsburg heralded the potential of these developments to enable the kind of groups that had traditionally been the subjects of films to produce their own narratives. New media could serve as "new vehicles for internal and external communication, for self-determination, and for resistance to outside cultural domination" (Ginsburg 1995a, 256). In this and later work, Ginsburg argued that indigenous filmmaking had emerged globally, in the 1980s and 1990s, as a critical response to films made about indigenous communities by 'outsiders'. Thus, indigenous filmmaking was seen to reflect protagonists' desire to tell 'their own story' (Ginsburg 1995b, 2011). This empowerment or agency is also stressed by Wilson and Steward, who observe

the shift in the past few decades to the command of mass media technologies by Indigenous peoples as they have appropriated the technologies of the 
dominant society and transformed them to their own uses in order to meet their own cultural and political needs.

These and other publications on indigenous media (for example, Villarreal [2017]), proceed from what can perhaps best be termed a consolidated understanding of such groups, which assumes that all their members have common interests and a shared identity.

Focusing on South Asia, the current volume extends this discourse in two directions. First, it critically assesses the ways in which indigeneity is articulated in the context of encompassing hegemonic nations. Rather than assuming that indigenous groups have been - at least historically - isolated, we approach indigeneity and indigenous (self-)identification as processual, i.e., actively constituted in dialogue with the respective nation-state, wider South Asian understandings of community and global understandings of indigeneity. Here, we also draw on Anderson (1991), whose seminal work emphasised the constitutive role of media in fostering notions of belonging or dissociation, essential to the 'imagining' of communities as cohesive identities. Second, and in line with recent attempts to extend understandings of indigenous media beyond film and video (Sreberny-Mohammadi and Mohammadi 1994; Lempert 2018), the contributions look beyond vernacular cinema to address music videos, documentaries and social media, all of which are relevant to the production and perception of indigeneity in the South Asian region.

We do not assume that the messages conveyed by media are unambiguous or immutable, or that the ideas and values of a given cultural environment are shared by all who inhabit it. Rather, drawing on Bourdieu's (1979) approach to cultural practice, we consider culture to be the ongoing outcome or 'product' of interactional patterns that continuously serve to confirm, alter or even contradict everyday normativity. This implies that it is less media content, as such, but rather people's engagement with it and interpretation of it that determines what it may bring about (Basu 2005; Bräuchler and Postill 2010). According to Mazzarella (2004), audiovisual media, like rituals, costumes, buildings or behavioural patterns, provide 'projection surfaces' that allow people to express and reflect upon their own conceptualisations of society, whereby they continually reformulate, alter, challenge and contradict their notions of culture anew. In a seminal contribution, Mankekar (1999) showed how viewers of television soaps could simultaneously "submit" to and "resist" representations relating to gender and the nation. Media portrayals can be interpreted in widely diverging ways, as Wagner (this volume) shows in relation to representations of Gaddi people in music videos from Himachal Pradesh, and Mukherjee (this volume) explores in the case of 'Manbhum' videos from West Bengal.

With this emphasis on circulation and interpretation, our volume has three foci. First, it foregrounds everyday practices of media consumption and production, that is, on-the-ground ethnographic engagement with media users as well as cultural producers. How do newly available media technologies transform trajectories of production and circulation of indigenous media? How are conceptualisations of indigeneity visualised? Second, the perspective is widened to provide analyses of the circulation and transformation of media across distinct levels of scale. For 
example, how do small-scale or grassroots media feed into global media, and vice versa? What are producers inspired by, and how do they serve as an inspiration for others? Third, this book examines the 'framing' or articulation of culture, community and ethnicity, in order to explore divergent and convergent interpretations or 'readings' of media content. The contributions to this volume engage with these questions through a wide range of ethnographic case studies.

\section{South Asian media as cultural fields of production}

In South Asia, the production of music videos, movies, political videos, documentaries and other audiovisual media for and by minority groups can be seen as part of a broader process of the "cculturalisation' of media" (Fornäs 1995). Fornäs apparently used this term to refer to "changing conditions of cultural agency" or "new distributions of cultural recognition" (Couldry 2012, 23), i.e., the tailoring of media content to appeal to specific 'culturally' defined audiences, rather than to a more general South Asian public. In Cassette Culture (1993) Peter Manuel showed how the spread of the audio cassette from 1983 onwards led to a boom in regional music production across India. This regional music was disseminated as cassettes of both folk songs and pop music. By 1991, 'regionalised' music comprised a market share of $40 \%-60 \%$, whereas previously pan-Indian music production had dominated. According to Manuel, cassette technology had managed to decentralise music production because it enabled recording by small-scale "cottage producers", ending the oligopoly of the large Indian music producers. In their pioneering essays (first published shortly after World War II), Horkheimer and Adorno (2000 [1947]) had argued that mass media would always be in the hands of the elite, who would use media at least in part to suppress the political consciousness of common people. However, their analysis was largely rooted in the assumption that the means to produce and disseminate media would always be centralised. Manuel's work showed that the omnipotence of large music corporations was easily broken down once technological innovations made the decentralised production of audio cassettes possible. In a similar vein, Robin Jeffrey (2000) analysed the 'newspaper revolution' that was enabled by the economic liberalisation of India in the 1990s (Rao 2010; Udupa 2015). These developments led to a massive increase in the volume of advertisements included in newspapers, which in turn fostered the emergence of new, commercially viable vernacular language editions of newspapers and led to higher circulation figures for all newspapers taken together. In rural areas, notably, this expanded and democratised the public sphere. Nalin Mehta (2008) has made a similar argument with respect to cable TV and satellite TV channels. Until the early 1990s, India only had state-owned television channels. Their programming was a direct result of media policies formulated by the central government. The liberalisation of television broadcast licensing and the subsequent emergence of satellite and cable TV networks resulted in a tremendous increase in commercial local and regional language shows, reducing the popularity and influence of the previously dominant all-India programmes.

More recently, decentralised or 'small media' (Sreberny-Mohammadi and Mohammadi 1994) have become even more important. With the gradual but steady expansion 
of mobile communication networks, which now increasingly reach formerly neglected rural areas, video and music distribution via mobile phones has gained ground. In addition, and just as significantly, both telephone handsets and mobile data are becoming ever more affordable, even for low-income families. The distribution of digital files via mobile networks or so-called dedicated download shops makes the piracy of copyrighted materials, which was already previously widespread, ubiquitous. The internet also facilitates easy sharing of videos via social media such as Facebook and YouTube, creating yet more ways by which media can circulate. These social media platforms transcend geographical distances, allowing people who have migrated to cities or abroad to stay in touch with their 'home' communities.

Media produced across distinct levels of scale, for local, national or international audiences, do not operate in strictly separate realms. On the contrary - they draw inspiration from each other. Such creative exchange has been the most extensively researched in the field of cinema. Filmmakers have been found to adapt and transpose narratives and visual forms between films intended for regional, national or global audiences. This results in what Rachel Dwyer and Divia Patel (2002) have termed, with reference to Bollywood, a hybrid mise-en-scène, in which the traditional and the modern come together. In a pioneering study, Ganti (2012) has shown how filmmakers in India produce adaptations of Hollywood films to suit the tastes of a pan-Indian if not pan-South Asian market. In the process, they 'enhance' and transform the original films' moral framing and add new storylines that cater to their intended audience's expectations regarding multi-narrative story-telling (Brosius and Butcher 1999; Gopalan 2002). Further studies have examined how other successful film formulas have been appropriated by one regional or national context from another. For instance, Hoek (2014) traces how the storylines of Telugu films from Hyderabad have been transferred to popular Bangladeshi films produced in Dhaka. In other words, even when filmmakers target specific regional or national audiences, they derive their strategies and draw inspiration to a large extent from wider South Asian and even global movie-related networks (Pandian 2015; Booth and Shope 2014; Schleiter 2017).

Reciprocal relationships maintained between producers of music videos, movies, political videos and documentaries who focus on indigenous groups in South Asia are evident, for instance, in their involvements with regional, national as well as pan-South Asian and global mainstream media. When these interwoven contexts of production are taken into account, media production processes clearly transcend the kinds of hierarchies between minorities and majorities and their concomitant dichotomies of dominance and resistance that are often perceived as unshakeable. Foregrounding the locatedness of media produced for ethnic and linguistic minority groups allows us to highlight in this volume the regionalisation and 'culturalisation' of media content. At the same time, such a perspective enables examination of how filmmakers' and media producers' locatedness is situated within a wider 'social field' of media production. Social field is understood here in Bourdieu's sense, as a social network that connects professionals across a variety of (media) environments as well as regional zones. The people within such a social field are not only connected by what they share and appreciate, but also by what they reject (Bourdieu and Johnson 1993). 
The contributions to Media, Indigeneity and Nation in South Asia focus upon media genres that can be broadly divided into three categories. Each of the three parts of the book is dedicated to one of these: (1) popular entertainment, (2) political activism and (3) documentaries and feature films. The first part relates to movies and music videos that have been primarily made for the purpose of entertainment and relate to the self-identifications of the audiences targeted. The second part analyses political videos that have been produced with the aim of highlighting and promoting what are regarded as key cultural themes. The final part deals with documentaries and with feature films that more or less formally engage with cultural classification and categorisation.

\section{Vernacular popular culture: movies and music videos (Part I)}

The first part of this book focuses on the production of 'small-scale' movies and music videos, and their circulation among regionally or ethnically defined audiences. Thousands of small-scale production houses have sprung up across South Asia to make movies in hundreds of regional languages such as Bodo, Santali, Oraon and Khasi, catering to audiences totalling at least 150 million people in India alone (Figure 1.2). These regionalised entertainment industries output a great

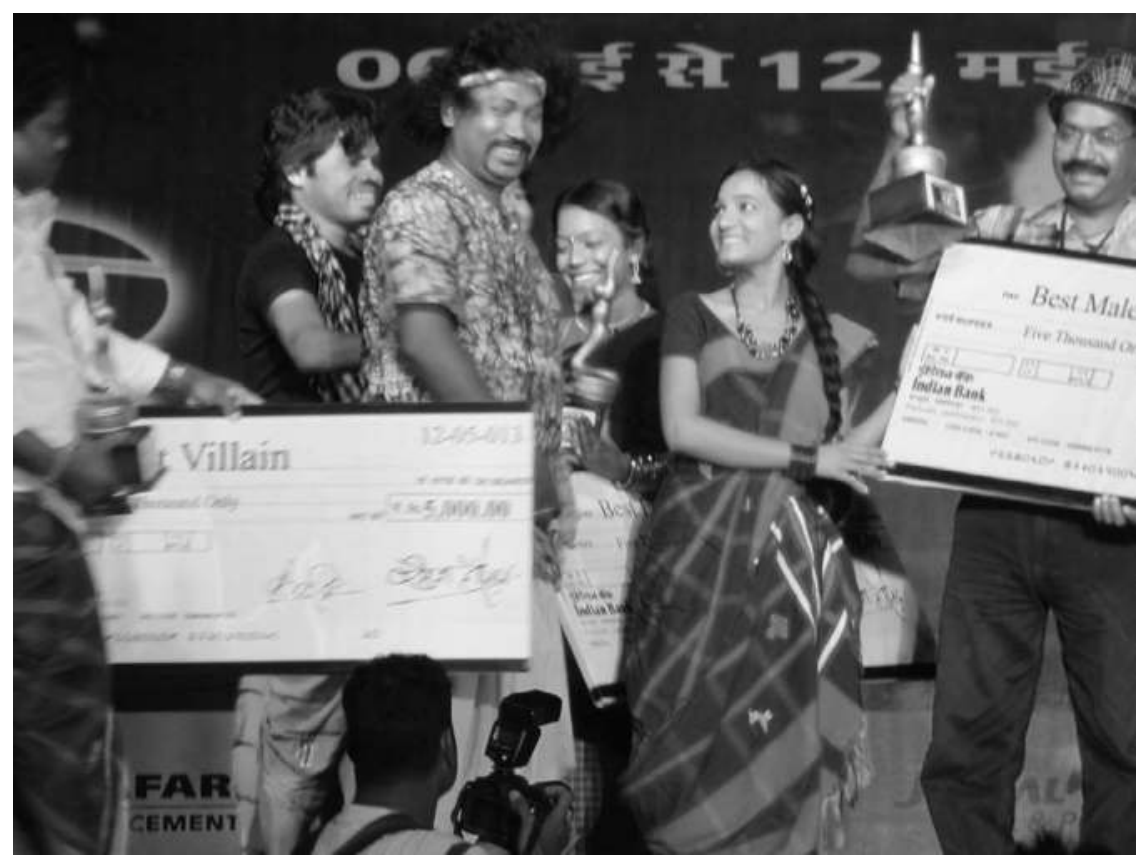

Figure 1.2 On stage at the regional film festival Jharkhand Cine Award, organised by the All India Santali Film Association (AISFA), in Jamshedpur in May 2013

Source: Photograph by Markus Schleiter 
variety of media content, in terms of both narrative style and themes addressed. Nor is there a uniform pattern by which the movies and music videos produced circulate among their target audiences. Gaddi music videos, as shown by Wagner, are specifically created for a single linguistic community and region. The circulation of Santali language VCDs, by contrast, is not at all limited regionally but stretches thousands of kilometres from Northern Odisha and Jharkhand in India to Nepal and Bangladesh (Schleiter 2014). In addition to the ethnic Santali audiences for whom they are primarily produced, the movies reach not only an audience of up to six million speakers of Santali, but are also watched by people from other indigenous groups, such as the Munda and Ho.

The chapters included in this part explore how mainstream and regional media draw on each other for inspiration. As mentioned in the earlier section, in order to increase circulation, producers of small-scale movies and music videos often adapt successful storylines from South Asia's mainstream cinema, elaborating on them in terms of both content and style. In so doing, they take visual markers such as costume, landscape or festivities that are traditionally or stereotypically associated with certain indigenous communities and combine them with recent trends in popular culture - such as hairstyles, fashion or pop music - from South Asia's mainstream or from elsewhere in the world. The authors of the chapters in this part examine how the producers of movies and music videos interpret and shape ideas about indigeneity, and how this can contribute to a reformulation of existing perceptions of ethnicity and culture, while also creating new ones.

How video narratives can contribute to the valorisation of indigeneity becomes evident from Wagner's research among the Gaddi of Himachal Pradesh. VCD albums that feature songs as well as short clips of religious rituals are popular with Gaddi audiences. The videos include visual markers that articulate a Gaddi identity, such as sheep herding and the Himachali mountains. Traditionally, the Gaddi are shepherds, which is how they were classified in colonial ethnographies. Taking on Adams' (1994) concept of 'virtual identity', Wagner argues that these markers are combined to produce a highly condensed and mediatised visualisation of Gaddiness that is seen to be more 'real' and more 'Gaddi' than most Gaddis' everyday lives are. Moreover, this 'virtual identity' opens up multiple possible ways of identifying as Gaddi, from a traditional shepherd's lifestyle to a specifically Gaddi modernity. In addition, images of extensive grasslands or high mountains refer not only to being Gaddi, but also to a sense of belonging to the state of Himachal Pradesh. The VCDs featuring music videos as well as short clips of religious rituals thus inspire various interpretations of indigeneity, rather than a narrow definition of Gaddi culture.

While Gaddi VCDs offer both entertainment and informative content, West Bengal's Manbhum videos are of a subversive nature. Manbhum videos, produced by an industry that is spread across Purulia district, are feature length and comprise a series of short episodes interspersed with songs and dances. In her examination of Manbhum videos, Mukherjee argues that they contest both Bollywood 
blockbusters and mainstream Bengali cinema by cultivating an often deliberately amateurish stance and a cinematic style of grotesque realism. Mukherjee reads the 'comic' quality of Manbhum video as an attack on social hierarchies comparable to Mikhail Bakhtin's (1984) readings of 'folk humour' and 'carnival'. According to her analysis, the appeal of Manbhum videos derives at least partly from their ability to challenge the status quo, which implies that as popular media they are certainly more than trivial entertainment.

Shifting towards spectatorship, Schleiter provides an ethnographic analysis of a 'video night' held by a Birhor community in rural Odisha. People attend such events not only for the videos but also because they enjoy spending time with their kin and peers, cementing relationships. Schleiter rejects the idea that the films screened represent the intrusion of 'modernity' into a supposedly passive 'timeless' village, and shows instead how collectively watching movies through the night fills the cultural space formerly occupied by village dances. He shows how village residents have appropriated VCDs to fit established cultural practices, which he takes as evidence of the extent to which the circulation of modern mass media (such as Santali VCDs) has become an integral part of everyday ('modern') Birhor life. The village video nights exemplify how 'modernity' is actively assimilated by a community, creating new forms of spectatorship based upon earlier cultural patterns.

The mainstay of the South Asian entertainment industry has historically been cinema, which has been organised on a linguistic basis. While the Hindi cinema industry (most famous for its 'Bollywood' offshoot) is no doubt the most formidable, and Tamil and Bengali cinema are also well known, there are many other cinematic production realms that are less known internationally but nonetheless well established. One of these is Bhojpuri cinema, which in terms of circulation has always catered to both regional and supra-regional audiences (Tripathy 2012). Kumar investigates its appeal by examining film content and screening infrastructures, as well as their relevance to local politics. The films are regarded as 'vulgar' and are famous for showing 'loose' women, depicting sexuality in ways that contrast sharply with the chasteness of Bhojpuri women upon which family honour notoriously depends. Families, and especially the middle classes, do not consider the run-down cinema halls of rural Bihar in which the films are projected to be respectable places to visit. Consequently, the cinema halls are almost exclusively lower class masculine spaces, in which the explicit content of the films can be consumed outside the realm of the family. The films offer aspiring movie stars the hope of social ascent through stardom. Young men invest in their own videos in return for a chance to act, co-financing the industry. Becoming a singer or dancer means that one has risen above and beyond one's local and rural environment. Film stars are regularly part of larger stage shows that include singers and occasionally erotic dance performances. Kumar argues that by successfully combining vulgarity, stardom and stage to attract a diverse lower class male audience, Bhojpuri cinema reveals itself as something of far more consequence than 'just' an indigenous media undertaking. 


\section{Politicising indigeneity: video clips and movies (Part II)}

Economic development in India frequently puts pressure on resources owned or managed by marginalised minorities. When companies or government agencies attempt to acquire land, for example for mining, this is often met by protests. If protesters can claim that indigenous rights are under threat, their cause tends to gain legitimacy in the eyes of NGOs, politicians and the general public in South Asia and internationally. In order to mobilise popular support, videos are often disseminated in which the indigeneity of those threatened is emphasised. Such videos, typically produced by NGOs, are circulated via YouTube and other social media sites that enable video sharing. The choice of language (predominantly Hindi and English) used in such videos suggests that these expressions of political struggle typically target South Asia's educated urban audiences, if not a global middle class.

First, to maximise impact, such videos tend to portray indigenous communities as marginalised and deprived, at the mercy of the whims of multinational corporations and of the policy makers who provide the legal and rational framework that enables those corporations to operate. The conflation of neo-liberal capitalism and the state is often illustrated by images of villagers' protests being met by police violence, as in the infamous lathi-charges in which protestors are beaten up with long bamboo sticks. Second, in keeping with the global environmental discourse mentioned earlier, such clips portray indigenous groups as eco-spiritual custodians of the 'natural' environment in which they live. This is typically done by contrasting romanticised images of village life in the midst of an untouched natural landscape with footage showing enormous destructive machines of industrial exploitation. One of the most successful protest campaigns conducted along these lines to date has been that against bauxite mining by the Vedanta company in Southern Odisha (Borde 2017). A short video produced by Survival International ${ }^{2}$ was instrumental in convincing general audiences and politicians in both India and Europe that Vedanta's activities should be curtailed, and ultimately legal action was taken (Nicholas 2009). The downside, however, of campaigns that invoke such stereotypical images of 'natural' indigenous people is that they can reinforce preconceptions of indigenous 'backwardness', resulting in further exclusion and discrimination as described in the contribution by Hasan included in this part.

Brandt's contribution shows that an emphasis on people's relationships to place is not only found in videos produced to further indigenous causes, but can also serve visual imaginaries of 'nation'. For example, the movie Bideśin $\bar{\imath}$ - From Bangladesh with Love (Sadik 2005) showcases the natural beauty of a variety of landscapes of Bangladesh, as well as the ancient ruins located there. Presented this way, history and landscape become emblematic of the identity of the Bangladeshi nation. This should not come as a surprise: after all, the very concepts of indigeneity, ethnicity and nation all centre on the relationships of dedicated groups of people to place.

The audience reception of a political video that achieved high viewing ratings within India, Gaon Chodab Nahin (We Shall Not Leave Our Village) (Sasi 2008), 
is the topic of the chapter by Uday Chandra. The clip, a sung narrative of the resistance of indigenous people in central India against commercial enterprises and corrupt politicians, has been watched both by people from the minority groups concerned and by activists in a wide variety of settings. The village audiences with whom Chandra watched the clip did not object to its depiction of villagers as indigenous 'eco-lovers', even though they considered it an unrealistic idealisation of their culture. Rather than envisioning a life close to nature, the villagers were looking forward to a share in the benefits of development. By contrast, middle class audiences belonging to the same community were more critical, reporting that they found the romantic depictions of indigeneity 'primitivising' (see also de Maaker, Chapter 11). Furthermore, diverse groups such as NGO activists and even Maoists praised the video, but for very different reasons. According to NGO activists, the clip advocated alternative development strategies, whereas the Maoists saw it as a tool that could inspire resistance and win support for their revolutionary movement. One reason why the video could successfully elicit so many different interpretations was that it did not refer to a single indigenous community, but to a more inclusive aggregate of indigenous and low-caste communities, as well as other marginalised and deprived groups, who it portrayed as collaboratively resisting neo-liberal and state exploitation.

The reception of politically motivated videos is also central to the chapter by Radhika Borde, in which she focuses on the producers of such material. In her contribution, she reflects on her own experiences as the manager of the media cell of an NGO that supports indigenous people in Jharkhand in their struggles to prevent mining companies from taking their land. Borde worked with a trained filmmaker of indigenous origin on the production of a small number of video clips. The filmmaker, of the Ho community, felt uncomfortable with the NGO's approach to using media for political activism. He would have preferred to use the camera to convey the beauty of the everyday lives of members of his community, showing activities such as dancing or the pleasure taken in drinking rice beer. His interests proved irreconcilable with the tasks assigned by the NGO, however, which proceeded from its director's conviction that the most emotive images would be ones that documented the repression of indigenous people by state forces such as the police. Borde recounts how the filmmaker was too intimidated to stand up to his colleagues - many of whom had a background in the caste population and did not belong to the Ho community concerned - and therefore withdrew from the job. The NGO's explicit decision to hire an indigenous filmmaker ultimately created a situation in which rather than giving subalterns a voice, as it claimed, it simply dictated what that voice should say.

Visual narratives that portray indigenous communities may fall in line with, reinforce or counter stereotypes held by the general public. This pertains not just to carefully crafted videos created by trained professionals, but also to postings on Facebook and other social media. Through these social media, Hasan explores audiences' engagement with events relating to India's Northeast. India's majorities primarily associate the Northeastern region with indigenous communities and cultural traits that are often summarily denigrated with reference to rumoured 
practices such as the consumption of dog meat, or the 'loose' character of women. Representations of the region in social media can reinforce existing stereotypes about indigenous communities, but more often result in their redefinition. Following McDuie-Ra (2012), Hasan argues that a shared Northeastern identity is gaining ground as a new kind of cosmopolitanism, most notably among people from the region who now reside elsewhere in India. Social media thus facilitate the emergence of a public sphere that enables identities to be refashioned and shared, and counter-hegemonic discourses to be formulated.

Concluding this part, Brandt explores the visualisation of the Bangladeshi nation in the movie Bideśinī: From Bangladesh with Love. The film never circulated outside Bangladesh although a foreign release had originally been planned. In this Bengali language film, in which Brandt was the lead actress, a Bengali man introduces a foreign woman to the country and its people. The movie attempts to offer an alternative to the global image of Bangladesh as a nation of poverty and underdevelopment. Rather than encountering such issues, the female lead character meets people who are satisfied, confident and happy, despite being poor. These attributes stand in sharp contrast to the egoism and lack of interpersonal connections that she and another foreign character in the movie are accustomed to in the USA. In short, the movie contrasts a simple, good and harmonious Bangladeshi village life with the loneliness and lack of commitment to social relationships deemed characteristic of the Western world. As such, the film can be perceived as self-orientalising, i.e., the Bangladeshi producer orientalises Bangladesh for a Bengali audience, and the visual nationalism used to do so shares commonalities with stereotypical representations of indigenous communities.

\section{Documenting and fictionalising indigeneity (Part III)}

Filmmakers have been attracted by indigenous cultures and traditions since the early years of cinema, as seen, for example, in Flaherty's Nanook of the North (1998 [1922]). In South Asia, ethnographic documentaries have shaped mainstream audiences' imaginations of people that appeared not only different, but also 'simple', 'pure', 'timeless' and hence traditional (Béteille 1998). Audiences' self-identifications as 'modern' in opposition to such portrayals reinforces a cultural hierarchy that has almost unavoidably been part and parcel of the reception of ethnographic films worldwide. Ethnographic filmmaking, as well as ethnography more generally, has its roots in attempts to explain exotic 'others': often people who lived in nonindustrialised societies that utilised technologies considered analogous to those employed in Europe's stone ages (Fabian 1983). In the colonial era, this perspective provided the 'scientific' basis for an evolutionary theory of culture that positioned Western civilisation at the pinnacle of a hierarchy of development. Hence the colonial powers presented themselves as 'naturally' superior to the people they subjugated, while indigenous societies were regarded as the least developed of all. This evolutionary perspective on culture was instrumentalised to present colonial rule as more paternalistic than exploitative and has remained an undertone in the 
post-colonial era, informing government policies geared towards the 'upliftment' of 'backward' indigenous communities (Xaxa 2016). Cultural evolutionism is now increasingly dismissed as misguided and politically incorrect in South Asia and worldwide, certainly by anthropologists and ethnographic filmmakers. Nonetheless, its tropes continue to be alluded to in films and journalism that emphasise a contrast between the postulated 'modernity' of viewers and the traditions that are foregrounded in order to mark a portrayed group or community as indigenous.

Documentary films differ from fictional ones in that viewers generally expect them to represent 'reality' rather than imaginative stories. Documentary filmmakers use certain techniques to establish their authority and convince viewers that the narratives presented are factual and based on real life (Nichols 2016). Ethnographic filmmakers have, at least historically, often extended such an aura of factuality by claiming that their films are rooted in scientific research. Non-professional videographers using consumer equipment tend to mimic documentary film conventions if they make recordings intended to represent aspects of their own lives (Wilson and Stewart 2008b). Dissemination of such amateur videos via the internet has radically changed and extended the kinds of audiences the videos can reach, making them available to growing diasporas within South Asia and abroad (Wettstein, Chapter 12). Audiovisual material can be shown and shared on social media such as YouTube and make a vital contribution to the visibility of minority cultures, both for the self-identification of members of such communities and for outsiders. Even though this does not necessarily debunk existing stereotypes, it does imply a change of format and voice, if only because these new forms of audiovisual documentation are first and foremost created for people belonging to the communities concerned.

The technological developments of the last decade have also made the production of fiction films a financially viable enterprise for new categories of producers, who cater specifically to audiences considered too small or 'niche' by larger industrial players. Parallel to the spread of literacy and the emergence of written literature in minority languages, fiction films set in indigenous societies have also become increasingly common. While such movies can put forward alternative perspectives, it proves almost impossible not to refer to stereotypical notions of indigenous culture, if only to help mainstream audiences relate to the cultural content. The contributions to this part reveal that local audiences do not necessarily seem disturbed by such cultural stereotypes, which may even be seen to provide necessary cultural and political affirmation of their communities' existence (de Maaker, Chapter 11).

Analysing the development, over time, of films identified as ethnographic in India, Giulia Battaglia shows that modes of funding and of dissemination have been formative for contemporary understandings of anthropological documentaries. In the eyes of critical filmmakers, she argues, the close association of at least some ethnographic filmmakers with government-sponsored agencies has discredited the genre. On the one hand, anthropologists working for government-funded institutions view such films primarily as a continuation of practices of 'documenting' indigenous cultures that have developed over the last century. On the other 
hand, some independent documentary filmmakers, especially those from South Asia itself, argue that makers of ethnographic films that foreground performative and material culture are complicit with government policies, since they fail to show the exploitation and deprivation inflicted upon indigenous communities. In other words, it appears impossible for documentary filmmakers in South Asia, as elsewhere, to avoid abetting certain preconceived agendas. For those who make documentary films that explore the lifeworlds of indigenous people, it seems difficult not to strengthen existing stereotypes. This holds both with respect to emphasising cultural distinctiveness and to exposing the effects of exploitation by corporations and the state, which may lead to portrayals in which communities appear to be hapless victims of 'modernity'.

Documentary films are not just made 'about' people; they also involve their protagonists. In his chapter, de Maaker analyses how members of Northeast India's Garo community engage with being the subject of documentary films. He notes that even though public intellectuals have critiqued documentary films about indigenous communities for exoticising and othering those portrayed, people who belong to the groups themselves have rarely voiced such criticism. In the case of the Garo, ethnographic films produced several decades ago continue to be screened and contribute to shared ideas about what constitutes Garo culture. Typically, such films focus on village life and imply that 'the Garo' are a unified, 'traditional' community, rather than representing the substantial differences in terms of class, education and religious background that have come to characterise the community. Some urban, educated, middle class Garo, however, express ambivalence towards these ethnographic films. But even those who are apprehensive about being 'traditionalised' value the films as cultural records of 'past' Garo customs. Given that the individuals who represent what urban Garo regard as their cultural past are alive and well today, the reificatory and objectifying approach towards culture that typically characterises such documentary films ends up challenging the extent to which Garo modernity has actually been attained. The protagonists of the films, by contrast, are proud to consider themselves the guardians of 'true' and 'ancient' Garo culture. They do not mind whether the films reinforce existing stereotypes. While acting out the roles designated by filmmakers is a source of amusement and not taken too seriously, both protagonists and the wider Garo audience acknowledge the (political) need to produce 'objectifications' of customs that can effectively communicate the cultural distinctiveness of the Garo to audiences within India and worldwide.

Creating audiovisual documentary records is common practice these days, as it is among the Rai of Eastern Nepal and Rai diaspora who feature in Wettstein's chapter. Over the last decade, hundreds of professional and amateur filmmakers have made video clips of the circular sakela dance, which is performed in a group as part of a ritual festival and, recently, also in other contexts. Sakela videos are shared on social media such as YouTube, where they are becoming increasingly popular, both in Nepal and among the Rai diaspora. Wettstein observes how nonritual performances of the dance in competitions and staging it for the camera has led to certain elements being emphasised, and notes the standardising effect of 
video records against which subsequent performances may be judged. The growing popularity of sakela is due, in part, to the mobilisation of ethnicity sparked by separatist parties in Nepal. Rai political actors use videos in which sakela dancing plays a prominent role to emphasise the cultural distinctiveness of the Rai and to rally support for demands for the creation of an autonomous Kirat Rai homeland within Nepal. The messages that viewers of these clips read in their visual content are revealed by the comments posted beneath the clips on YouTube. Wettstein argues that the YouTube videos and the comments posted contribute to a reinterpretation of the sakela dance, as well as to the broader political discourse on Rai ethnicity.

Shifting from documentary narratives to the documentary quality of feature films, Ara's contribution analyses a change in the way that props are used in two filmed adaptations of the Assamese legend Joymati. Over the past century, identity politics have come to dominate Assamese politics. The popular Assamese legend of Joymati tells the story of a princess who sacrificed her life to save her husband and his kingdom. Comparing two versions of the historical drama filmed in 1935 and in 2006, Ara notes a shift between the films' subtexts from pan-Assamese nationalism combined with an implicit anti-colonialism to the assertion of a more narrowly defined indigenous Tai-Ahom identity. Ara traces how the symbolism of the objects used and costumes worn in the films subtly underscore these agendas, and in doing so she draws attention to the non-verbal dimensions of cultural narratives and how these can be conveyed through objects and their stagings.

In South Asia, it is not uncommon that the honour of an entire family, if not a community, is seen to depend upon the chastity of its women. Where the legend of Joymati is a historical example of this trope, Mara Matta's contribution focuses on contemporary interpretations of female gender and sexuality. The first feature film made among the Brokpa of Arunachal Pradesh tells the story of a woman named Sonam. The film, which was shot with non-professional actors, focuses on the polyandric practices of the Brokpa. Brokpa women are presented as naturally inclined to 'indulge' in sexual intercourse with more than one partner. But rather than depicting polyandry as a culturally embedded relational arrangement, the film's narrative sentences Sonam to an unfortunate and untimely death, which viewers are implicitly directed to interpret as a just punishment for her 'sinful' life. In this way, Matta argues, interpretations of female chastity and monogamy as virtuous, which go virtually unchallenged among the South Asian mainstream, are projected by the filmmaker onto the Brokpa community. Such a misrepresentation of the lifeworlds of indigenous women is, according to Matta, by no means exceptional in cinema, but rather a further disappointing example of the extent to which mainstream normativity is projected onto cultural minorities.

\section{Reinterpretations, fragmentations, divergences}

The contributions to this volume reveal how new digital media technology has extended the scope and reach of media production to include people belonging to deprived and marginalised communities. The transformation of trajectories of production and circulation has been radical; for example, social media enable the 
creation and maintenance of online transnational communities that bring together 'home' communities and national and global diasporas. Such processes of change are ongoing, and as the coverage and affordability of internet access in the rural hinterlands continues to increase, ever more opportunities emerge for accessing and sharing audiovisual media.

The changing dynamics of media production and dissemination have redefined interactions between producers and audiences across different levels of scale. Although technological change has been game changing, the research presented here indicates that current tendencies towards the 'culturalisation' of media are grafted on processes of transformation that have been long since underway. The recent transformations of the media landscape follow patterns reminiscent of the vernacularisation of music cassettes in the 1980s, as well as the "newspaper revolution' and the diversification of TV networks in the 1990s. In these examples, narrowing products' linguistic and cultural framing enabled producers to reach out to new (niche) audiences. The contributions to this book suggest that media producers who identify with indigenous groups draw inspiration from mainstream music, cinema and documentary production. Global influences become most visible in the strategic framing of politicised indigeneity, for example, when parallels are drawn between South Asia's indigenous communities and other such groups worldwide.

The transformation of the media landscape has contributed to reinterpretations of notions such as culture, community and ethnicity. In South Asia, marginal and deprived groups, notably 'tribals', increasingly identify themselves in terms of indigeneity. Inherent to the notion of indigeneity are two assumptions that have contradictory implications for the politics of representation. On the one hand, the privileged relationship to nature attributed to indigenous communities places them on a (moral) ecological high ground vis-à-vis mainstream communities. On the other hand, the postulated archaic origins of indigenous knowledge and isolationist social organisation characterises indigenous communities as primitive and nonmodern, and hence inferior in terms of social hierarchy. In other words, vulnerability and victimhood are set against magnitude and agency. In this way, indigeneity appears in implicit opposition to an imagined hegemonic cultural 'mainstream', which in South Asian contexts tends to be equated with the respective nation. Indigeneity, as it is manifested in movies, music videos, political video clips and documentaries, is subject to a variety of interpretations. Political video clips generally emphasise the marginalisation, deprivation and proximity to nature of indigenous communities, while entertainment media tend to allude to stereotypes that have their origins in colonial era ethnography. Stereotypical representations that were once rejected for being outdated and inaccurate are now increasingly embraced, since they can prove vital in substantiating politically (and economically) motivated claims to unique tribal identities. Yet the various contributions also show that seemingly stereotypical visualisations of indigeneity are open to interpretation on behalf of consumers as well as producers. We hope that the explorations of media production, circulation and appreciation provided in the chapters that follow will help to inspire rethinking of the ever-changing complex interrelationships between media, indigeneity and nation in South Asia. 


\section{Notes}

1 Parts of this paragraph have been based upon "Indigeneity as a Cultural Practice: 'Tribe' and the State in India"; the introduction to a focus section of the IIAS Newsletter on 'Indigenous India' written by de Maaker and Schleiter (2010).

2 Mine: Story of a Sacred Mountain (Nicholas 2009), a 15-minute film produced by Survival International in support of a campaign by Dongria Kondh of Odisha to prevent Vedanta Resources Plc from acquiring a concession for an open-pit bauxite mine on their ancestral land. Narrated by the well-known British actress Joanna Lumley and distributed via the internet, the film appears to have made a significant contribution to the exceptionally successful campaign. See www.survivalinternational.org/films/mine, accessed on 9.12.2018.

\section{References}

Adams, Vincanne. 1994. Tigers of the Snow and Other Virtual Sherpas. Princeton: Princeton University Press.

Anderson, Benedict. 1991. Imagined Communities: Reflections on the Origin and Spread of Nationalism. London: Verso.

Appadurai, Arjun. 1993. "Number in the Colonial Imagination." In Orientalism and the Postcolonial Predicament: Perspectives on South Asia: 44th Annual South Asia Seminar: Papers, edited by Carol Breckenridge and Peter van der Veer. Philadelphia: University of Pennsylvania Press.

Bakhtin, Mikhail M. 1984. Rabelais and His World. Bloomington, IN: Indiana University Press.

Baruah, Sanjib. 2003. "Citizens and Denizens: Ethnicity, Homelands, and the Crisis of Displacement in Northeast India." Journal of Refugee Studies 16 (1): 44-66. doi: 10.1093/jrs/16.1.44.

Basu, Helene. 2005. "Practices of Praise and Social Constructions of Identitiy: The Bards of North-West India.” Archives de Sciences Sociales des Religions 130: 81-105.

Bates, Crispin. 1995. "Lost Innocents and the Lost of Innocence: Interpreting Adivasi Movements in South Asia." In Indigenous Peoples of Asia, edited by R.H. Barnes, Andrew Gray and Benedict Kingsbury, 103-119. Ann Arbour: Association of Asian Studies.

Bates, Crispin. 2007. Subalterns and Raj: South Asia Since 1600. Abingdon: Routledge.

Baviskar, Amita. 2006. “The Politics of Being 'Indigenous'.” In Indigeneity in India, edited by B.G. Karlsson and Tanka Bahadur Subba. London: Kegan Paul.

Béteille, André 1998. "The Idea of Indigenous People.” Current Anthropology 39 (2): 187-192.

Booth, Gregory D., and Bradley Shope. 2014. More Than Bollywood: Studies in Indian Popular Music. Oxford: Oxford University Press.

Borde, Radhika. 2017. "Differential Subalterns in the Niyamgiri Movement in India." Interventions 19 (4): 566-582. doi: 10.1080/1369801X.2017.1293553.

Bourdieu, Pierre. 1979. Outline of a Theory of Practice. Cambridge: Cambridge University Press.

Bourdieu, Pierre, and Randal Johnson. 1993. The Field of Cultural Production: Essays on Art and Literature. Cambridge: Polity Press.

Bräuchler, Birgit, and John Postill. 2010. Theorising Media and Practice. Oxford: Berghahn Books.

Brosius, Christiane, and Melissa Butcher. 1999. Image Journeys: Audio-Visual Media and Cultural Change in India. New Delhi: Sage. 
Carrin, Marine, Pralay Kanungo, and Gerard Toffin. 2014. Politics of Ethnicity in India, Nepal and China. New Delhi: Primus Books.

Census. 2011. "Census of India 2011." Office of the Registrar General \& Census Commissioner, Ministry of Home Affairs, Government of IndiaCensus of India. www.censusindia. gov.in/2011census/population_enumeration.html.

Chatterjee, Partha. 1993. The Nation and Its Fragments. Princeton: Princeton University Press.

Cohn, Bernard S. 1984. The Census, Social Structure and Objectification in South Asia. København: Soertryk.

Couldry, Nick. 2012. "The Fate of Culturalization, or Reflections on Johan Fornäs Library." In Senmoderna Reflexioner Festkrift till Johan Fornäs, edited by Erling Bjurström, Martin Frederiksson, Ulf Olsson and Ann Werner, 17-24. Linköping: Linköping University Electronic Press.

de Maaker, Erik. 2013. "Performing the Garo Nation? Garo Wangala Dancing between Faith and Folklore." Asian Ethnology 72 (2): 221-239.

de Maaker, Erik, and Markus Schleiter. 2010. "Indigeneity as a Cultural Practice: 'Tribe' and the State in India." IIAS Newsletter (53): 16-17.

Dirks, Nicholas B. 2001. Castes of Mind: Colonialism and the Making of Modern India. Princeton, NJ and Chichester: Princeton University Press.

Dirks, Nicholas B. 2006. The Scandal of Empire: India and the Creation of Imperial Britain. Cambridge, MA and London: The Belknap Press of Harvard University Press.

DuBois, Fletcher, Erik de Maaker, Karin Polit, and Marianne Riphagen. 2011. "From Ritual Ground to Stage." In Ritual, Media and Conflict, edited by Ronald L. Grimes, Ute Hüsken, Udo Simon and Eric Venbrux, 35-61. New York: Oxford University Press.

Dwyer, Rachel, and Divia Patel. 2002. Cinema India: The Visual Culture of Hindi Film. London: Reaction Books.

Elwin, Verrier. 1964. The Tribal World of Verrier Elwin. Bombay: Oxford University Press.

Fabian, Johannes. 1983. Time and the Other: How Anthropology Makes Its Object. New York: Columbia University Press.

Flaherty, Robert J. 1998 [1922]. Nanook of the North. New York: Citerion Collection.

Fornäs, Johan. 1995. Cultural Theory and Late Modernity. London: Sage Publications.

Forte, Maximilian C. 2005. "Extinction: The Historical Trope of Anti-Indigeneity in the Caribbean." Caribbean Amerindian Studies 6 (4), August 2004-August 2005: 1-24.

Forte, Maximilian C. 2010. Indigenous Cosmopolitans: Transnational and Transcultural Indigeneity in the Twenty-First Century. New York: Peter Lang.

Ganti, Tejaswini. 2012. Producing Bollywood: Inside the Contemporary Hindi Film Industry. Durham: Duke University Press.

Ghosh, Kaushik. 2006. "Between Global Flows and Local Dams: Indigenousness, Locality, and the Transnational Sphere in Jharkhand, India." Cultural Anthropology 21 (4): 501534. doi: 10.1525/can.2006.21.4.501.

Ghurye, Govind Sadashiv. 1963 [1943]. The Scheduled Tribes (The Aboriginees So-Called and Their Future). Bombay: Bhatkal.

Ginsburg, Faye. 1995a. "Mediating Culture: Indigenous Media, Ethnographic Film, and the Production of Identity." In Fields of Vision: Essays in Film Studies, Visual Anthropology, and Photography, edited by L. Devereaux and R. Hillman. Berkeley: University of California Press.

Ginsburg, Faye. 1995b. "The Parallax Effect: The Impact of Aboriginal Media on Ethnographic Film.” 11 (2): 64-76. doi: 10.1525/var.1995.11.2.64. 
Ginsburg, Faye. 2002. "Screen Memories: Resignifying the Traditional in Indigenous Media." In Media Worlds: Anthropology on New Terrain, edited by Faye Ginsburg, Lila Abu-Lughod and Brian Larkin, 39-57. Berkeley: University of California Press.

Ginsburg, Faye. 2011. "Native Intelligence: A Short History of Debates on Indigenous Media and Ethnographic Film." In Made to Be Seen: Perspectives on the History of Visual Anthropology, edited by Marcus Banks and Jay Ruby, 234-255. Chicago: University of Chicago Press.

Gopalan, Lalitha. 2002. Cinema of Interruptions: Action Genres in Contemporary Indian Cinema. London: British Film Institute.

Heidemann, Frank, and Richard K. Wolf. 2014. "Indigeneity, Performance, and the State in South Asia and Beyond." Asian Ethnology 73 (1-2): 1-18.

Hoek, Lotte. 2014. Cut-Pieces: Celluloid Obscenity and Popular Cinema in Bangladesh. New York: Columbia University Press.

Horkheimer, Max, and Theodor W. Adorno. 2000 [1947]. "Kulturindustrie: Aufklärung als Massenbetrug." In Dialektik der Aufklärung: Philosophische Fragmente, edited by Max Horkheimer and Theodor W. Adorno, 146-204. Frankfurt am Main: Fischer.

Jeffrey, Robin. 2000. India's Newspaper Revolution: Capitalism, Technology and the Indian-Language Press, 1977-99. London: Hurst \& Company.

Karlsson, Bengt G. 2003. "Anthropology and the 'Indigenous Slot': Claims to and Debates about Indigenous Peoples' Status in India.” Critique of Anthropology 23 (4): 403-423.

Karlsson, Bengt G. 2011. Unruly Hills: A Political Ecology of India's Northeast. New York: Berghahn Books.

Karlsson, Bengt G., and Tanka Bahadur Subba. 2006. Indigeneity in India. London: Kegan Paul.

Kohl, Karl-Heinz. 2006. "Coming Back to One's Own: What Happens to Tradition in NeoTraditionalist Movements?" In The Making and Unmaking of Differences, edited by Richard Rottenburg, Burkhard Schnepel and Shingo Shimada, 97-106. Bielefeld: Transcript Verlag.

Larkin, Brian. 2008. Signal and Noise: Media, Infrastructure, and Urban Culture in Nigeria. Durham: Duke University Press.

Lempert, William. 2018. "Indigenous Media Futures: An Introduction.” Cultural Anthropology 33 (2): 173-179. https://doi.org/10.14506/ca33.2.01.

Mankekar, Purnima. 1999. Screening Culture, Viewing Politics: An Ethnography of Television, Womanhood, and Nation in Postcolonial India. Durham: Duke University Press.

Manuel, Peter. 1993. Cassette Culture: Popular Music and Technology in North India. Chicago: University of Chicago Press.

Mazzarella, William. 2004. "Culture, Globalization, Mediation.” Annual Review of Anthropology 33 (1): 345-367. doi: 10.1146/annurev.anthro.33.070203.143809.

McDuie-Ra, Duncan. 2012. Northeast Migrants in Delhi: Race, Refuge and Retail. Amsterdam: Amsterdam University Press.

Mehta, Nalin. 2008. Television in India: Satellites, Politics, and Cultural Change. London: Routledge.

Merlan, Francesca. 2009. "Indigeneity Global and Local." Current Anthropology 50 (3): 303-333. doi: 10.1086/597667.

Middleton, Townsend. 2015. The Demands of Recognition: State Anthropology and Ethnopolitics in Darjeeling. Stanford: Stanford University Press.

Misra, Sanghamitra. 2011. Becoming a Borderland: The Politics of Space and Identity in Colonial Northeastern India. New Delhi: Taylor \& Francis. 
Muehlebach, Andrea. 2001. "'Making Place' at the United Nations: Indigenous Cultural Politics at the U.N. Working Group on Indigenous Populations." Cultural Anthropology 16 (3): 415-448. doi: 10.1525/can.2001.16.3.415.

Murray Li, Tania. 2010. "Indigeneity, Capitalism, and the Management of Dispossession." Current Anthropology 51 (3): 385-414. doi: 10.1086/651942.

Nicholas, Toby. 2009. Mine: Story of a Sacred Mountain. London: Survival International.

Nichols, Bill. 2016. Speaking Truths with Film: Evidence, Ethics, Politics in Documentary. Oakland: University of California Press.

Pandian, Anand. 2015. Reel World: An Anthropology of Creation. Durham: Duke University Press.

Pels, Peter. 2000. "The Rise and Fall of the Indian Aborigines: Orientalism, Anglicism, and the Emergence of an Ethnology of India, 1833-1869." In Colonial Subjects: Essays on the Practical History of Anthropology, edited by Peter Pels and Oscar Salemink, 82-116. Ann Arbor: The University of Michigan Press.

Pfeffer, Georg, and Deepak Kumar Behera. 2005. "Tribal Situation in India: An Introduction." In Contemporary Society: Tribal Studies (Vol VI: Tribal Situation in India), edited by Georg Pfeffer and Deepak Kumar Behera, ix-xvii. New Delhi: Concept Publishing Company.

Rao, Ursula. 2010. News as Culture: Journalistic Practices and the Remaking of Indian Leadership Traditions. New York: Berghahn Books.

Rycroft, Daniel J., and Sangeeta Dasgupta. 2011. The Politics of Belonging in India: Becoming Adivasi. Abingdon: Taylor \& Francis.

Sadik, Shibly. 2005. Bideśinī: From Bangladesh with Love. Bangladesh.

Sasi, Karivannoor P. 2008. Gaon Chodab Nahin ("We Shall Not Leave Our Village"). India.

Schleiter, Markus. 2014. "VideoCD Crossovers: Cultural Practice, Ideas of Belonging and Santali Popular Films." Asian Ethnology 73 (1-2): 181-200.

Schleiter, Markus. 2017. "Der Pop-Hit Injurious to Health: Musikschaffende, indigene Traditionen und kulturelle Praktiken des Flirtens am Beispiel eines Santali-Videosongs aus Indien.” In Soziale Ästhetik, Atmosphäre, Medialität: Beiträge aus der Ethnologie, edited by Philipp Zehmisch, Ursula Münster, Jens Zickgraf and Claudia Lang, 161-174. Münster: LIT.

Shah, Alpa. 2007. "The Dark Side of Indigeneity: Indigenous People, Rights and Development in India." History Compass (5/6): 1806-1832.

Shah, Alpa. 2010. In the Shadows of the State: Indigenous Politics, Environmentalism, and Insurgency in Jharkhand, India. Durham and London: Duke University Press.

Singh, Kumar Suresh. 2002. People of India: Introduction. New Delhi: Oxford University Press.

Sreberny-Mohammadi, Annabelle, and Ali Mohammadi. 1994. Small Media, Big Revolution: Communication, Culture, and the Iranian Revolution. Minneapolis: University of Minnesota Press.

Steur, Louise. 2017. Indigenist Mobilization: Confronting Electoral Communism and Precarious Livelihoods in Post-Reform Kerala, (Dislocations Series \#20). New York and Oxford: Berghahn Books.

Tripathy, Ratnakar. 2012. "Music Mania in Small-Town Bihar: Emergence of Vernacular Identities." Economic and Political Weekly 47 (22): 58-66.

Udupa, Sahana. 2015. Making News in Global India: Media, Public, Politics. Cambridge: Cambridge University Press.

Vandekerckhove, Nel. 2009. "We Are Sons of This Soil: The Dangers of Homeland Politics in India's Northeast." Critical Asian Studies 41 (4): 523-548. 
Van Schendel, Willem. 2011. "The Dangers of Belonging: Tribes, Indigenous Peoples and Homelands in South Asia." In The Politics of Belonging in India: Becoming Adivasi, edited by Daniel J. Rycroft and Sangeeta Dasgupta, 19-43. Oxon: Routledge.

Villarreal, Gabriela Zamorano. 2017. Indigenous Media and Political Imaginaries in Contemporary Bolivia. Lincoln: University of Nebraska Press.

Wilson, Pamela, and Michelle Stewart. 2008a. Global Indigenous Media: Cultures, Poetics, and Politics. Durham: Duke University Press.

Wilson, Pamela, and Michelle Stewart. 2008b. "Indigeneity and Indigenous Media on the Global Stage." In Global Indigenous Media: Cultures, Poetics, and Politics, edited by Pamela Wilson and Michelle Stewart, 1-35. Durham: Duke University Press.

Xaxa, Virginius. 2008. State, Society, and Tribes: Issues in Post-Colonial India. Delhi: Pearson Longman.

Xaxa, Virginius. 2016. "Tribes and Indian National Identity: Location of Exclusion and Marginality.” Brown Journal of World Affairs 23 (1): 223-237. 
$\because$ Taylor \& Francis Taylor \& Francis Group http://taylorandfrancis.com 


\section{Part I}

Vernacular popular culture

Movies and music videos 
$\because$ Taylor \& Francis Taylor \& Francis Group http://taylorandfrancis.com 


\title{
2 Himachali indigeneity \\ Gaddi music VCDs and expressions of belonging
}

\author{
Anja Wagner
}

\section{Prelude}

Visit to a family home in a Kangra village. I am invited into the grandest room, in which guests are received. A plastic chair is arranged for me. Tea is offered. Before the mother disappears into the kitchen to prepare the tea, she tells her eldest child to turn on the TV for me. Other children from the neighbouring houses crowd in. The children insert a music video CD (VCD) into the player. "This is one of our Gaddi songs", they say. I am waiting for the tea to arrive; I look at the videos and watch the children watching me.

Scenes like this were a regular experience during my fieldwork in Himachal Pradesh. It was common practice to play TV or music videos to entertain guests, especially first-time visitors who were not yet well known, while the obligatory cup of tea was being prepared. Knowing that I was interested in the Gaddi people and their practices, people took particular care to play music videos in the Gaddi dialect for me, particularly ones featuring the nuāla (a Gaddi worship ritual for the god Shiva), and they took me to other families' houses where they knew such VCDs were to be found.

In this chapter, I examine music VCDs featuring the music of Himachal Pradesh, and more specifically I consider the representation of the Gaddi people in these VCDs based on an analysis of the content of VCDs featuring Gaddi religious songs and of wider Himachali folk music VCDs, as well as on ethnographic fieldwork that I carried out in western Himachal Pradesh between 2006 and 2008. The images of the Gaddi constructed in the music videos - established first and foremost through costume and landscape - provide an exemplary case study for a debate on the mediatisation of indigeneity. Figure 2.1 shows a selection of covers of music VCDs that feature Gaddi people. The images draw on notions of the Gaddi as indigenous and at first sight appear to offer an essentialist reading of what indigeneity is about. However, closer examination of definitions of indigenous and "tribal" reveals that categorising the Gaddi as such is not as simple and straightforward as those seemingly stable labels might suggest. The case of the Gaddi and their campaign to obtain Scheduled Tribe status (cf. Kapila 2008) exemplifies the complicated politics of belonging in India, of which media representations, including those circulated in association with folk music, form a part 


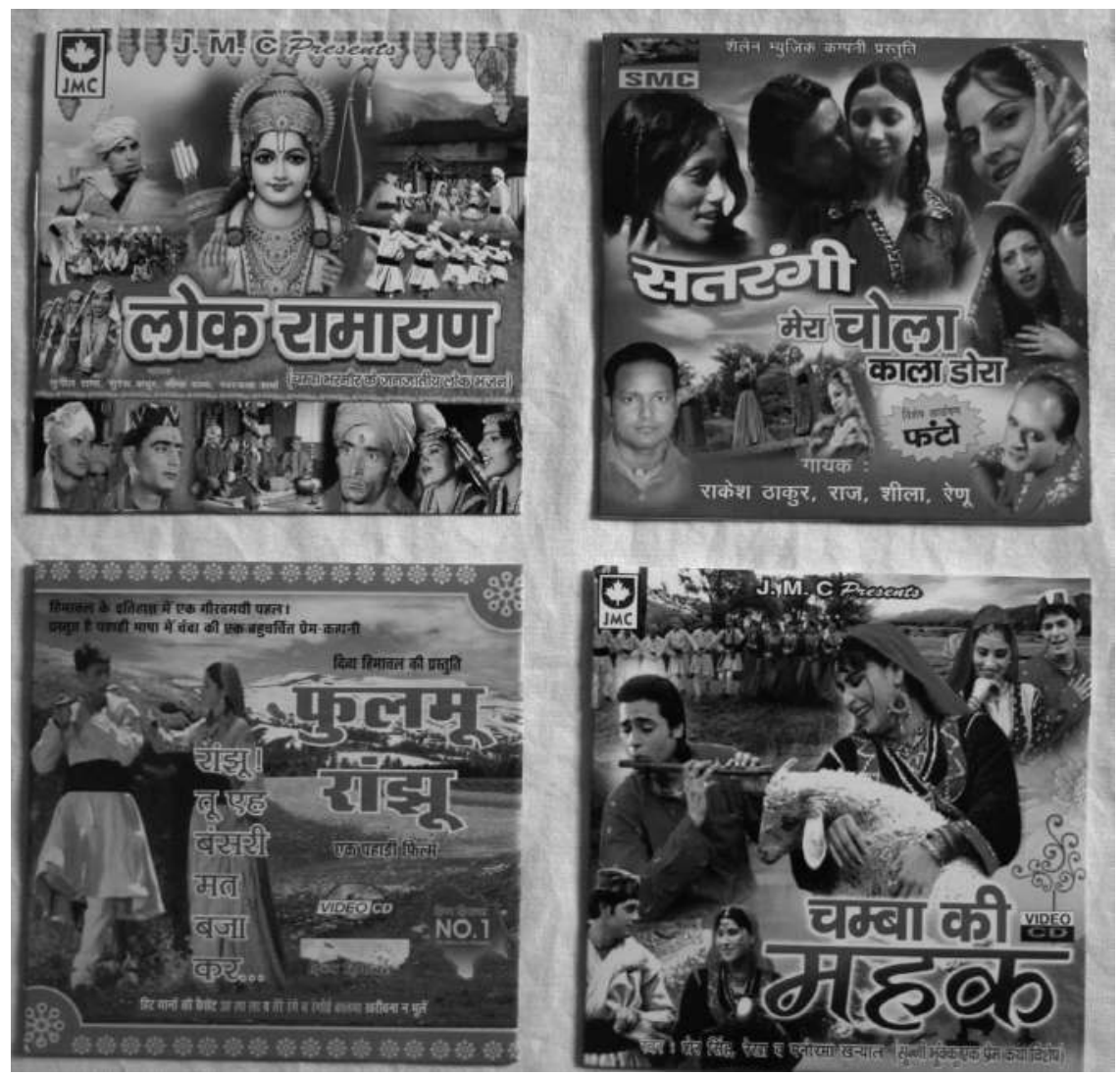

Figure 2.1 VCDs produced in Kangra District, Himachal Pradesh, featuring images of Gaddi people on the cover

Source: Photograph by the author

(Manuel 1993). Gaddi representations in VCDs thus show the ambivalence and complexity inherent to the mediatisation of indigeneity. Based on my ethnographic fieldwork, I will look at media practices connected to these VCDs and their images to ask, first, how the Gaddi identity presented can be read in a more fluid and flexible understanding. To avoid an essentialist reading, I will introduce Adams' concept of a "virtual" identity (1996). Second, with respect to the politicised debate on indigeneity in India, I will show how the virtual identity presented in the VCDs allows for multiple identifications. Moreover, I argue that Gaddi representations in Himachali music videos can be seen as a double indigenisation, since not only the Gaddi, but also Himachal Pradesh itself is already presented as local in these videos - in contrast to a mainstream North India. Or rather, Himachal Pradesh is represented as rural and thus at least implicitly differentiated 
from an urbanity associated with cities such as Chandigarh, New Delhi, or the larger cities of Punjab. Introducing the notion of double indigenisation, I ask whether the VCDs might reveal expressions of belonging that create a Himachali indigeneity rather than a merely Gaddi one.

\section{Gaddi music VCDs}

To open my discussion on the imagery of music VCDs, I will take a music VCD from Himachal Pradesh called Lok Rāmāyan (Folk Ramayana), which offers a popular rendering of the story of Rama (Gupta 2007). ${ }^{1}$ The songs on the VCD are devotional songs sung in Gaddi dialect. Lok Rāmāyan was produced in the Kangra Valley by the locally relatively widely circulated Jayanti Mata Cassette label (JMC). The VCD opens with an explanation of the content of the music videos. A speaker explains in Hindi that the VCD is about the nuālä; he describes when the nuālā is performed and explains that although the nuālā is an act of worship for Shiva, songs dedicated to Rama and Krishna are also sung during a nuālā in addition to the songs in Gaddi sung for Shiva. Hence, the first song on the VCD is the classical nuālā opening song that addresses the god Shiva. The songs that follow are Ramayana songs in Gaddi recounting the story of Rama. The speaker concludes by wishing viewers enjoyment of a very special Gaddi religious practice. With its introductory explanation, the VCD clearly addresses a wider audience than one comprised solely of Gaddi people familiar with the nuāala, while at the same time offering a very accurate and detailed portrayal of a practice that is cherished as an important part of Gaddi culture by Gaddi people themselves.

The speaker's introduction is accompanied by images from the Mani Mahesh Yatra. The Mani Mahesh Yatra is a large annual pilgrimage to the seat of Lord Shiva: Mount Kailash in the Bharmaur sub-district of Chamba. Several hundred thousand pilgrims set out each year to take a holy bath in the high-altitude lake beneath Mount Kailash's peak. The pilgrimage is especially popular among Gaddi people, but Gaddi are not the only pilgrims who undertake the journey. In the video footage, common pilgrims and Gaddi celās (oracles) are shown on their way up into the mountains. Celās, in this case, are men who are possessed by the god Shiva and act as his spokespersons while they are possessed. The celās shown in the video perform the pilgrimage wearing Gaddi male attire; colā and dorā. The colā is a thick, white gown made from sheep's wool with a flared skirt that ends above the knees. It is secured at the waist by a ḍorā: a thick black woollen cord. The ḍorā is about five or six metres long and almost completely covers the waist and stomach. As well as the pilgrims, images of the landscape are shown: a waterfall, a river with large grey rocks in its bed, and the snow-covered triangular peak of Mount Kailash of Bharmaur. These images alternate with footage from a nightly nuālā celebration performed on the veranda and in the courtyard of a family home: participants, musicians, and a priest sitting on the crowded veranda, and dancers in the slate-roofed courtyard in front of the house.

The subsequent songs and videos on the VCD are set during a nuālā performance. Most tracks start with a shot of the musical performers of the nuālā who, 
seated on the veranda, sing devotional songs in Gaddi dialect. The musicians are all male, as is usual in nuālā rituals. Two men play barrel-shaped drums and one a thâlì-ghad̄a (brass plate on a clay pitcher). Two women wearing typical Gaddi women's clothing sit behind the musicians; they take turns to sing with the male musicians. The women wear nuāncarī (a long dress with a tight bodice and a flowing, red, flower-printed skirt). The nuāncarī is tied at the waist by a dorā and accompanied by a knee-long pink headscarf and silver jewellery (most notably a long, heavy necklace and a large headpiece on the forehead). The camera shots of the musicians alternate with close-ups of the female singers and are cross-cut with other religious images: a Brahman priest preparing the ritual space (which features a mandala: a figure representing the universe made from flour and a garland of white wool above the mandala with flowers representing Shiva's seat on Mount Kailash); the priest's acts of worship during the night vigil (including offering certain foods at the mandala, blowing on a conch shell, ringing a small brass bell, reciting mantras); images of participants seated on the veranda; footage showing the Mani Mahesh Yatra; pictures of the god Shiva; statues of Lord Rama; and mountain scenes with villages or temples. The most prominent motifs in terms of frequency and length, however, are dance scenes. A group of male and female performers is shown wearing the quintessentially Gaddi attire of colā (men) and nuāncarī (women). The dancers perform Gaddi folk dances. The camerawork draws attention to dance steps and formations. The dance scenes are shot against two backgrounds: in the courtyard where the nuālā is performed and on a grassy stretch of land, the wasteland and pastureland at the outskirts of a village. In the latter scene, shots featuring dancers on green grass are intercut with shots filmed with forest and pine trees in the background. A further image which appears in several tracks shows a flute player, seated on the veranda as well as sitting in the wasteland.

The key feature that identifies the performers as Gaddi is their clothing, which is known as "traditional" Gaddi dress. This clothing underscores an understanding of the Gaddi as "tribal", pastoralists, and a mountain people (see later). This conceptualisation of the Gaddi is further corroborated by the landscapes shown in the videos: green grass, trees, and mountains. The chosen background thus not only places the Gaddi within the natural environment of Himachal Pradesh, but also follows stylistic conventions found in local Gaddi VCDs, Himachali folk music productions, and Bollywood dance scenes - in which green grass, pine trees, and mountain views represent the beauty of the Himalayas (cf. Wagner 2013) and serve as a background for romantic scenes, especially in the case of Bollywood productions.

In comparison to the portrayal of Gaddi people in Himachali folk music VCDs that I have discussed elsewhere (ibid.), in this Gaddi production, great care is taken to draw attention to the congruence of costumes and the typical ornaments and jewellery that are usually worn in combination on festive occasions: the female dancers' costumes are complemented by pink headscarves and heavy silver jewellery, and in close-ups of a male dancer his golden earrings are repeatedly shown. In addition, the musicians' instruments are of the contemporary Gaddi nuālà style. 
A mixing of styles occurs, however, at a different level: the folk dances shown in the videos would usually be performed at village festivals rather than at a nuālā, where the dancing is usually more spontaneous and less clearly choreographed. In addition, participants at a nuālā generally wear salvār-kamīz (trousers and shirts worn across India), rather than quintessentially Gaddi clothing.

By means of such visual imagery, Lok Rāmāyan portrays the Gaddi as culturally distinct from the rest of India: not only in terms of their typical dress und ritual practice, but also as a mountain people living in close proximity to the natural environment. Like other VCDs, this one thus identifies the Gaddi as Himachal Pradesh's indigenous Other. ${ }^{2}$

\section{Virtual identity}

To come to terms with this visual representation of the Gaddi, I draw on Vincanne Adams' concept of "virtual Sherpas" (Adams 1996). Borrowing from Adams, I call the Gaddi constructed in these video clips virtual Gaddi. Adams uses the term virtual to circumvent a discussion about authenticity among the Sherpa (ibid., 10; 24). Attributing or denying authenticity implies a "distinction between authentic and inauthentic culture" (ibid., 11), whereby authenticity is bound to be lost. The discourse on authenticity rests upon an essentialist notion that certain core values or attributes constitute genuine Gaddi (or Sherpa) culture. That would mean viewing culture as a distinct entity that is, or rather should be, pure, unchanged, and unspoiled by outside influences. In contrast, the notion of a virtual identity allows for a flexible and fluid understanding of culture, in which culture is seen as a continuously changing force that mediates human interactions. Thus, Adams' notion of virtual identity is by no means "not real", but instead describes a condensed representation of singular attributes, which together create an identity that appears more real than its real forms (ibid., 20). As Adams notes on Sherpa images in Sherpa-Westerner interactions,

Virtual Sherpas are not seen, in this sense, as "almost real but not quite"; rather, virtual Sherpas are taken to be more "real" than reality itself. Those images become the simulations to which Sherpas in contact with Westerners strive to live up.

(Adams 1996, 20)

Many of my Gaddi friends and acquaintances referred to a topic similar to that of authenticity in relation to the VCD images: they mentioned tradition and customs (rîti-riwāz), or simply the English word "culture". The term tradition, like the term authenticity, is linked to an essentialist understanding of culture. The concept of a virtual identity as put forward by Adams enables an alternative reading of the VCDs: one that considers how the Gaddi are represented in the images without assuming that they have fixed, unambiguous identities.

The Gaddi in the VCD are virtual Gaddi in Adams' sense because they are portrayed, on the one hand, as more real than reality itself, yet, on the other hand, 
certain attributes are singled out and displayed in a condensed form, while much of the everyday reality of Gaddi people's everyday lives remains unseen. For example, Gaddi women wear the nuāncarī, large headscarves, and silver jewellery on certain festive occasions, particularly at weddings, and every woman is given such a dress when she marries. These days, however, the nuāncarī is not worn by women as everyday clothing. The colā, the white woollen gown worn by the male dancers, is typical male clothing, but is even less common than the women's nuāncarī: not all Gaddi men own one. Some men wear a colā on the occasion of their retirement celebration, and it is also worn by the groom's aide at a wedding. In the past it was worn by shepherds in the mountains. Despite being worn only occasionally, the costumes in the videos are considered by Gaddi people and by others in the region to be typical Gaddi dress. Thus, the video makes reference to what is perceived as Gaddi culture and as such singles out what is uniquely Gaddi in contrast to the "culture" of other population groups in Kangra. In this way, as well as through the dances performed and songs sung, the VCD does what it promises in its introduction: it shows the audience a snippet of Gaddi social and religious practices, in a special, condensed way.

In addition, these images of the Gaddi make reference to what is known as the "typical" Gaddi way of life - and here the notion of virtual becomes even more fitting: throughout Himachal Pradesh and neighbouring Punjab, the Gaddi are commonly known to be transhumant pastoralists - the shepherds travel with their flocks of sheep and goats between the Shivalik foothills on the Himachal-Punjab border in winter and the Himalayan high pastures in summer. During migration time, Gaddi flocks are a common sight on the roads of Himachal to this day. Formerly, Gaddi families also used to migrate seasonally between summer villages in Bharmaur and winter villages in Kangra, where they cultivated crops. Every Gaddi family, even those who took up permanent residence in Kangra several generations ago, can still name their former Bharmaur village (see Wagner 2013).

The name Gaddi, from Hindi "seat", in one sense refers to a language group, i.e., the speakers of a regional language, which is a dialect of Hindi. The name Gaddi is also regionally identified with the Chamba sub-district of Bharmaur, which is considered the homeland of the Gaddi - although the Gaddi are said to have migrated there from the plains. ${ }^{3}$ The term Gaddi also designates a caste group ( $\left.j \bar{a} t \bar{\imath}\right)$, referring primarily to Gaddi of the Kshatriya varna (social stratum), but includes Gaddi Brahman and, depending on the context, may include or exclude Gaddi lower castes who also speak the language. My research and argument in this chapter refers to Gaddi Kshatriya. ${ }^{4}$ Gaddi are Hindu, and worship Shiva in particular. In their rituals, Gaddi sacrifice sheep and goats. The nuālā ritual, which forms the background of the songs in the VCD, is key to Gaddi religious practice. In this respect, Gaddi stand out from other Scheduled Castes or "tribes" in India, which in popular and academic conceptualisations alike are generally believed to be non-Hindu and non-caste populations. The sacrifice of animals, however, fits with preconceptions about indigeneity; but is also not unusual among Hindus in the Himalayan region.

The virtual identity created in VCD images crystallises a Gaddi identity that appears definitive but is only one aspect of contemporary Gaddi life. While 
some Gaddi families still own flocks and their men perform the transhumant migrations, many other Gaddi men have taken up jobs in the army, as schoolteachers, taxi drivers, or construction workers, and so on. In the area where I conducted my fieldwork, parents were keen to educate their sons and daughters in schools and colleges. At the same time, most people continue to identify with shepherding images, despite following other professions themselves. In addition, my interview partners often cited rituals such as the nuālā in selfrepresentations of being Gaddi. However, these rituals do not set Gaddi people apart in the context of the college, workplace, or village duties. I understand music videos as presenting a virtual identity that opens up a space for multiple identifications: identifications that may be held simultaneously or alternate according to context.

In sum, the Gaddi in the video are also virtual Gaddi because they represent a reality that is highly valued, but not lived by the majority of Gaddi people. While Gaddi continue to be Gaddi (the importance of the mountains and Gaddi rituals is one example, see Wagner 2013), their cultural distinctiveness from the rest of the population in Kangra as marked by seasonal migration and transhumance is becoming less pertinent in everyday life. Nonetheless, the depiction of the Gaddi as distinct and distinctly "tribal" can be traced from colonial literature to contemporary books on Himachal Pradesh, to Himachali music and Gaddi VCDs (ibid.).

\section{How Gaddi fit into the "indigenous slot"}

A debate on the mediatisation of indigeneity in the Indian context will necessarily engage with the terminological triad of "indigeneity/indigenous", "tribe/tribal", and "Adivasi". The example of the Gaddi, who are recognised as a Scheduled Tribe within two districts of Himachal Pradesh, illustrates the terminological problems central to this discussion.

For Willem van Schendel, the question of terminology - whether we talk about "indigenous" or "tribal" - is important because these denominations

influence everyday practices: tens of millions of people in South Asia believe themselves (or others) to be tribal, and others identify themselves as indigenous people. How anthropologists, politicians and policy makers engage with these terms affects the structure, dynamics and futures of South Asian societies.

(van Schendel 2011, 19)

During my research in Himachal Pradesh, Gaddi people repeatedly insisted that the Gaddi are tribal and a Scheduled Tribe, but not backward - at least not any more. These statements already hint at the colonial legacy of the term "tribe". While " $[t]$ he tribe, for the colonial state, by the end of the nineteenth century, had become a definable 'object' with clearly demarcated characteristics, an entity that was seemingly concrete and identifiable" (Rycroft and Dasgupta 2011,3), it was 
"inevitably understood within the vocabularies of contrast" (ibid., 4). In colonial and early ethnographic classification, "tribes" were distinguished from "castes"; as hill or forest dwellers they were set in opposition to plains people, while in terms of religion, the contrast was aboriginal versus Hindu (ibid.). In van Schendel's words, the "tribe" in colonial administration thereby "became not so much a container of specific cultural traits [. . . but rather a term fixing a relationship of very unequal power" (van Schendel 2011, 21). This history of the "tribal" category is still visible in the definition of the category of Scheduled Tribe outlined in the Indian constitution, which lists the characteristics of communities that may be allocated Scheduled Tribe status as follows: "indication of primitive traits; distinct culture; shy of contact with the community at large; geographical isolation; and backwardness" (Ministry of Tribal Affairs 2015).

In contrast, the terms "indigeneity" or "indigenous" place less emphasis on the supposed homogeneity of group and more on a community's association with a specific place, often claiming rights to a place by virtue of having occupied it before a majority population that is regarded as having come later (cf. van Schendel 2011, 25-26). In India, rather than "indigenous", the term "Adivasi" introduced by Indian nationalists at the end of the colonial period (ibid., 22) - has come to replace the term "tribe" as the politically correct expression. As van Schendel points out, however, the idea of a contrast between "tribals" and the "modern" state remains persistent and with it an implicit association of "tribals" or "Adivasi" with "backwardness" (ibid.). And despite the widespread usage of "Adivasi", the classificatory category of Scheduled Tribe, which grants special rights and quotas, has kept the term "tribe" prominent in everyday language and practices. In relation to the Gaddi, the term "tribal" and the administrative and political classification Scheduled Tribe are used..$^{5}$ In relation to the Gaddi, "tribal" refers to a specific lifestyle that differs from that of other population groups, foremost through pastoralism. Here, it is important to heed van Schendel's reminder of the significance of not only academic but also everyday usage of terminology. Just as "tribal studies" and what is meant by "tribal" within anthropology varies according to the region concerned (see van Schendel 2011, 24), in administrative practice, too, the category of Scheduled Tribe, ascertained as it is by local actors in specific states and districts, reflects regional variations and even inconsistencies, or specific local constellations.

Scheduled Tribe status was granted to the Gaddi in Himachal Pradesh on a district basis, which led to the situation that the Gaddi were recognised in Chamba as a Scheduled Tribe from the time of independence, while in Kangra (formerly part of Punjab) Scheduled Tribe status was not granted until 2002. As Kriti Kapila writes on the Gaddi campaign for Scheduled Tribe status in Kangra:

The situation is a paradoxical one because it is as modernist, reformist, national citizens that the Gaddis affirm their right to negotiate with and be recognized by the state, in order to acquire the benefits that should rightfully accrue to them. And yet, at the same time, their actions as citizens involve them asserting their right to Scheduled Tribe status, with all that this entails 
in terms of the ambivalent connections to a traditional past and to a way of life that is increasingly portrayed as not-modern.

(Kapila 2008, 128)

In VCD imagery it is this notion of a different way of life that is portrayed. Here, indigeneity is constructed by emphasising cultural distinctiveness. This distinctiveness is marked by specifically Gaddi clothing that evokes the occupation of herding sheep, as well as by the background scenery: the green grass, which forges a link between Gaddi/shepherding/mountains to symbolise the Gaddi lifestyle as pastoralists. Furthermore, the imagery draws upon romantic notions of a simple, unspoiled way of life as well as presenting the Himalayas as a spiritually pure environment. In addition, the content of the videos supported by the introduction to the nuāla - shows some religious practices that are particular to the Gaddi. Again, cultural distinctiveness is established by the specifically Gaddi way of worshipping Shiva in the nuālā. Worshipping Shiva is a Hindu practice, yet, as the VCD's introductory voiceover claims - and as most Gaddi and non-Gaddi speakers from the region would corroborate - the nuâlā is particular to the Gaddi.

Here, VCD imagery claims an "indigenous slot" (Karlsson 2003) for the Gaddi it portrays within the Himachali landscape and for Gaddi who watch the VCDs. These images of the Gaddi are not restricted to devotional and folk music, but flow in and out of the political arena and thus have an important political dimension, as the Scheduled Tribe campaign in Kangra shows. Further, a closer look at the Gaddi's Scheduled Tribe status reveals that the definition of "tribal" upon which it rests is relational rather than essential. As Hindus with castes and even high-castes, Gaddi do not fit common conceptualisations of what being "tribal" means.

Again, I find Adams' notion of a virtual identity convincing as a way to come to terms with images of the Gaddi - visual and otherwise - in order to better understand how indigeneity is produced in such music videos. The idea of a virtual identity not only circumvents the inconsistencies inherent to labels like "tribal" or "Adivasi" and the problems of academic and administrative classifications that the Gaddi in many respects exemplify, but also facilitates exploration of the discursive space and space for negotiation and contextualisation that VCD images open up in relation to notions of the indigenous as well as to mainstream, multiple, and contextual identities. ${ }^{6}$

\section{Locating VCDs in India's mediascape}

At the time of my fieldwork in Himachal Pradesh and Chandigarh between 2006 and 2008, VCDs were very popular but not (yet) to be found in all family homes. Not only did Gaddi families play Himachali folk music VCDs featuring images of Gaddi people to show me Gaddi culture on multiple occasions during the initial stages of my fieldwork, as described in my opening vignette, so too did other families in Himachal Pradesh and Chandigarh (cf. Wagner 2013). That the VCDs were considered a suitable medium to inform me about Himachal Pradesh and the 
Gaddi indicated that my hosts, whether Gaddi themselves or not, viewed the images as representative.

The first time I watched songs from the VCD Lok Rāmāyan (described earlier) was during an informal visit to the house of a Gaddi family I knew. The husband was resting and watching the VCD. He and his wife pointed out to me the quality of the production and the beauty of the songs. Since I was especially interested in the nuālā as part of my research, I enquired later where I could buy the VCD for myself. Taking the VCD to a family I regularly stayed with, I watched it several times with my hosts, their neighbours, and their relatives. We would gather cosily around the TV, initially with about ten people sitting on the bed, a couple on plastic chairs, and children and elder women on mats on the floor. Two daughters-in-law might stop by the TV on their way up to the kitchen, and the daughters-in-law of the extended family, as well as an unmarried son or the neighbour's sons, would often crowd into the doorway to watch. Depending on the chores they had to do in the house, different family members would stay for several songs, or at least one or two. When a certain neighbour or a relative from the adjoining village stopped by to visit, the mother of the family would ask me to bring out the VCD again. The VCD was judged to be an especially good production, and everyone appeared to enjoy the Gaddi songs and the visuals. Since it had been produced in a nearby village, viewers not only commented on the images and songs in general, but also tried to identify individual people and to trace their own relationships to them.

As a medium, VCDs are similar to audio cassettes and have come to replace them in North India. Compared to earlier audio and audiovisual media, as Peter Manuel (1993) has shown, the technology required to produce cassettes is much more accessible in terms of costs and infrastructure, which has enabled decentralised, regional production to flourish.

The pre-cassette recording industry had largely neglected many, if not most specific language areas of India. There appears to have existed no more than a handful of records representing the musics of Gharwal, Haryana, and Himachal Pradesh. Most records were in Hindi-Urdu [. . . ]. The pre-cassette record and film industry, on the whole, made little attempt to represent these "Little Traditions," concentrating instead on lingua-franca genres.

(Manuel 1993, 156)

Local Gaddi VCD productions (like their predecessors on cassette tapes) are one illustrative outcome of the regionalisation of the VCD market, and the ready availability of Gaddi dialect VCDs in Kangra and Chamba is in line with Manuel's observation that

the Pahari regions of Himachal Pradesh, although relatively densely populated, are linguistically so fragmented that cassette producers have tended to market tapes only in the dialect of the Kangra valley (which, of course, was itself neglected by the pre-cassette record industry).

(Manuel 1993, 162) 
Robin Jeffrey has described similar developments in the market for local language productions with regard to the spread of local language newspapers in India (2000).

One prerequisite for VCD consumption is the availability of a TV set. While VCDs can also be played on computers, at the time of my fieldwork most people watched them on relatively new TV sets and VCD recorders, which had been purchased and given, for example, by men to their wives and families at Diwali, or had been among the appliances given in dowry. ${ }^{7}$

All in all, VCDs are a medium with comparatively low barriers to consumption and production. Hence, like cassettes, they are able to create "new possibilities of musical and even socio-political discourse, by extending media control and access to an unprecedented variety of groups" (Manuel 1993, 259). In this sense, VCDs and cassettes show parallels to mobile phones as a medium of communication (cf. Doron and Jeffrey 2013), which have become widespread more recently than cassettes, but often only slightly later or even at the same time as VCDs in Kangra and Chamba.

As both television and landline phone connections had been strongly government-regulated, the liberalisation of both markets and the spread of satellite TV and mobile phones since the middle of the 1990s and the 2000s, respectively, led to an incredible rise in consumption and ownership of TV sets and phones (cf. Mehta 2008a for satellite TV and Doron and Jeffrey 2013 for mobile phones). In the case of satellite TV, this liberalisation was accompanied by a regionalisation of programming - similar to the developments in music recording and print media described earlier - and (especially in the case of news channels) led to a proliferation of regional news channels broadcasting in regional languages. This was a significant departure from the standard Hindi of Doordarshan's all-India news (see Mehta 2008a).

As Mehta reminds us, any new medium draws on or is adapted to existing social patterns of communication. Mehta argues that TV in India builds upon existing forms of expression. Despite the fact that globalisation was what brought satellite TV to India, satellite TV itself has quickly been "Indianised" (2008a, 6). Mehta points to the success of news channels as evidence for this. He argues that "a key factor in the rise and sustenance of Indian news television is that it forms a link with India's long dialogic and 'argumentative tradition' of heterogeneous debate" (Mehta 2008b, 35). In this context it is noteworthy that, especially in the realm of music, it is VCDs and not audio CDs that have become widely popular and have taken over from audio cassettes. On the one hand, the rise in VCD consumption has occurred simultaneously with increasing affordability and hence purchasing of TV sets, which could arguably explain the rise of VCDs. On the other hand, there seems to be a particular preference for the visual or a "visualist bias" in India (Pinney 1997, 109) that makes VCDs so successful as an audiovisual rather than just audio medium.

To sum up, the popularity of VCDs relates not only to the increased availability of equipment for playing them, but also to consumption patterns and similar developments that have taken place in television, newspapers, mobile phones, and 
cassettes. Since certain prerequisites must be met (TV, VCD recorder, electricity) for VCDs to be watched, the mediatisation of indigeneity cannot take place in isolation from regional and national developments. At the same time, the spread of so-called new media shows a trend towards regionalisation at least in terms of language and audience.

\section{Mediatising Himachali indigeneity}

According to Wilson and Stewart, in spite of a trend towards global marketing, "a good deal of Indigenous media is being produced for non-commercial purposes and beyond the reach of the mainstream media industries" (Wilson and Steward 2008, 2). While the Gaddi and Himachali music VCDs discussed in this chapter are produced for commercial purposes, they address a very local market. The images in the Gaddi VCDs are quite similar - although with important differences - to portrayals in more general Himachali music VCD productions that depict the Gaddi as "tribal", as mountain-dwellers, and place them on the "natural" side of Himachal Pradesh.

Indigenous media often must define themselves and their work against the idealized or stereotypical images that dominate the popular culture and discourses of mainstream societies. We often find such discourses situated in master narratives of evolution / progress in which Indigenous groups are seen as "simple," "primitive," or "backward".

(Wilson and Steward 2008, 14)

A further stereotypical image disseminated by dominant popular culture and socalled mainstream discourse can be found in Bollywood movies and their portrayal of the Himalayas and their inhabitants. As Philip Lutgendorf has argued, the Himalayas often serve as the backdrop for romantic fantasies in Bollywood films. "For one of the standard scenic locales of songs and dance sequences in mainstream Bombay films [. . .] is the mountainside as the venue for a love song" (Lutgendorf 2005, 29). According to Lutgendorf, the Himalayas stand not only for the abode and playground of the gods, but also for human communities known or rumoured to live a different way of life to communities in the plains, particularly with regard to the agency of women (ibid., 30-31). In addition, the common movie narrative of a love affair between an urban boy and a mountain girl plays on dichotomies such as the cosmopolitan versus the local, male versus female, and "modern civilization" versus "tradition" (ibid., 32). It thus evokes an understanding of the indigenous in line with that expressed, for example, in definitions of Scheduled Tribe status.

The Lok Rāmāyan VCD images do not corroborate these Bollywood stereotypes. Instead, they present an insider understanding of specifically Gaddi religious practices that are clearly highly cherished, hence worthy of introducing and explaining to a wider audience. Here, as with regional newspapers and music productions, a trend towards an appreciation of the local can be seen. By contrast, 
Bollywood's presentation of imagery of the Himalayas from a nationalised perspective often reveals a more ambivalent stance to what is represented as indigenous.

One remark I often heard expresses this ambivalence: "Yes, we are Gaddi, but we are not backward." One woman who assured me of this was a Brahman priest's wife from a small Bharmaur village, who proudly showed me pictures of her son's posh new flat in Mumbai when I visited her. Backwardness often seemed to be located elsewhere, even if it was apparently considered more Gaddi than nonbackwardness: many people advised me that if I wanted to find real Gaddi tribal culture, I would have to venture further up into the mountains, notably to the more remote and less accessible villages of Bharmaur.

In spite of this ambivalence, responses to the VCD imagery suggested that Himachali VCDs portray indigeneity in a positive way as typically Himachal, and as a virtual Himachali identity that Gaddi people can relate to and identify with. The images in Gaddi devotional VCDs or local folk music VCDs carry important meanings for Gaddi people by conveying a virtual Gaddi identity that people relate to and take pride in. The imagery of the Gaddi created in VCDs also relate to an intertextual network of images. A look at family photo albums and living room displays of photographs shows that pictures of people wearing Gaddi clothing, pictures of people against backdrops of mountains, grass, or high-altitude trees, and with sheep and goats are highly popular and cherished photographic motifs not least because they represent a way of life and a landscape that is highly prized (see Wagner 2013). The landscape, though it is their everyday surroundings, is lauded for its beauty and never taken for granted. For example, a young couple that I visited one time not only urged me to stay and eat with them, but also insisted, "Let's take a walk to the grounds before you leave. From there you have a beautiful view of the mountains". The mountains are not only revered for their visual appeal, but are also considered pleasing to the other senses, e.g., for their cool and quiet places (ibid.). These places are actively experienced on trips into the mountains, while visiting relatives, shepherds on high pastures, and deities at their temples (ibid.). With Mount Kailash at the centre of Bharmaur, the landscape is also famous for being the abode of the god Shiva.

Furthermore, VCDs - whether of Gaddi nuālā songs or Himachali folk music transport not only an image of the Gaddi, but also an image of Himachal Pradesh. Music VCDs and their visual images thus create not only a virtual Gaddi indigeneity but also a virtual Himachali one. This Himachal imagery is cherished by Gaddi and other Himachali groups, especially those who have migrated to cities such as Chandigarh, who identify with the images and relate to them as "our Himachal culture". If these VCD images function due to their "vocabularies of contrast" (Rycroft and Dasgupta 2011, 4), the Gaddi representations can be seen as a double indigenisation: not only do the Gaddi appear as the indigenous within Himachal, but Himachal Pradesh itself is presented as the local or rural in these videos vis-àvis the mainstream or urban India. This is how my Himachali acquaintances in Chandigarh presented Himachali folk music VCDs: as a display of their Himachali culture, the culture of their "village", which they described as distinct from that of 
Punjab or the "city". Himachal in this context is cherished as "our Himachal" by elders who have migrated to the city, as well as by young people who have grown up in Chandigarh. Thus, the virtual Gaddi created in those images mark differences between Gaddi (we) and Pahari (them), as much as they do between Himachali (we) and Plains/Punjabi (them) ${ }^{8}$

Imagery of Himachal and of a virtual Gaddi identity are also displayed on Facebook - a medium that has only recently become accessible with the spread of smartphones, and in my fieldwork area is mainly used by the young and college-educated, since 2010. ${ }^{9}$ The children and college students who introduced me to VCDs at the time of my fieldwork in Himachal have now grown up to become BA or MA graduates who own smartphones, which they use to comment and post images on Facebook. Gaddi clothing appears on Facebook, for example, worn by female relatives at a marriage, or in a photograph a young woman posted of her own wedding. These posts draw comments like "Apna culture Sab se best [sic]" ("our culture is the best of all") as well as compliments for the nice pictures. More common on Facebook are, however, images of a person in front of Himachal's incredibly steep mountains, in front of waterfalls, or young men on a motorcycle on a mountain road. Such photographs are taken on trips to villages in Bharmaur during the Mani Mahesh Yatra, on trips to visit temples or other holy places within the Dhauladhar mountain range, or on trips up to Triund, a famous hiking destination above Dharamshala that is popular among young locals and tourists. Frequent comments are awesome, nice pic, amazing view. ${ }^{10}$

In addition to pictures of oneself, a second type of Himachal images is posted, or rather "shared", on Facebook: Himachali road scenes. These mostly consist of buses negotiating extremely narrow roads next to deep ravines or making their way around landslides. The subtitles and comments salute Himachali bus drivers and praise them for being the best in India. The images are initially posted on professionally managed Facebook pages promoting Himachal Pradesh tourism, such as HuM HiMacHali HaI YaaR (We are Himachali, dude) or Kinnaur (which presents a district of Himachal Pradesh).

However, these images are only some of the pictures that users post on Facebook. This brings to mind what Mark Liechty has described as the negotiation of what it means to be "suitably modern" (Liechty 2003). Thus, the images are also about negotiating identity and, as Liechty has shown for Kathmandu, about finding a place between "tradition" and "modernity". Of all visual and digital media, this is particularly prominent on Facebook, where references to cultural identity and inherited belonging merge with images that position young people as part of a new lifestyle that had been unavailable to their parents' generation. Girls or young women post images of themselves wearing jeans, as customers in coffee shops; boys or young men pose proudly with motorbikes, and so on. These "new" images are posted alongside pictures of the Facebook users in front of Himachal's high, steep mountains. Such juxtapositions are not specific to Himachali Gaddi, but are also found on the pages of, for instance, young city-born Himachalis in Chandigarh who not only enjoy watching Himachali music VCDs but also post photographs 
of Himachali landscapes taken on trips to their home villages or share posts from professional sites.

Both VCD and Facebook images express a visual celebration of belonging that shows a trend towards a regionalisation that I refer to as a mediatisation of Himachali indigeneity. Here Himachal, as the indigenous, is presented as the distinct Other vis-à-vis the plains and urban metropolitan culture, mostly by emphasising its natural environment - its mountains, trees, and greenery - and its cultural practices, symbolised by local dress. At the same time, Himachal is no longer only known and admired for its natural beauty, its mountains, and as the abode of the gods. The state of Himachal Pradesh is also a producer of apples and energy, and a place for skiing and paragliding. Expressions of belonging here reveal a new Himachali indigenous self. As with the twofold development in the printed press identified by Jeffrey, whereby newspapers have been able to increase their readerships by diversifying to cater for regional languages while nationalising their content in terms of articles and advertisements $(2000,11)$, this Himachali indigeneity expresses a regional belonging of national citizens and of a generation that is partaking more and more frequently in technological developments, social media, and consumer culture. This shows that new media developments do not result in a devaluation of local identifications with one's region, the village, etc., even while they do contribute to the creation of wider national or supra-national communities. The result is a way of belonging that is both national and local at the same time - as presented on Facebook, in VCDs, and in local religious practice. The identity displayed, however, is a virtual identity. The images that convey a Himachali indigeneity play with crystalized motifs of what Himachal stands for. It is the more-than-real character of this mediatisation of indigeneity that allows for multiple identifications as an indigenous person and as a national citizen.

\section{Notes}

1 The cover of Lok Rāmāyan is shown in the upper left corner of Figure 2.1.

2 Or as one of several indigenous groups. Further groups are resident, for example, in the districts of Kinnaur or Lahul and Spiti.

3 There are two explanations for the meaning of Gaddi: the Gaddi are said to be Shiva's people - spatially and mythologically close to the god Shiva's seat in Bharmaur, Mount Kailash. Furthermore, Bharmaur town was the former seat of the king of Chamba.

4 There is little literature on Gaddi lower castes. The politics of recognition and belonging of Gaddi lower castes in Kangra has only recently been examined by Stephen Johnson in his $\mathrm{PhD}$ dissertation (2018).

5 Unlike other Scheduled Tribe groups in Northeast or Central India, the term Adivasi is not used in relation to the Gaddi. Neither do the Gaddi fit into an Adivasi-versus-mainstream constellation as the original inhabitants of a place. Gaddi people may claim to have been the first inhabitants of the Bharmaur region, but no priority of origin is claimed over other population groups of the Chamba district. In the Kangra district, Gaddi arrived as later settlers.

6 I do not use the term indigenous in the following as a description of the Gaddi community, but as an academic concept that enables discussion of the mediatisation of indigeneity. 
7 Generally, most homes in my fieldwork area were connected to mains electricity, with the exception of some in villages high up in the mountains. Homes without electricity did not operate electrical appliances like TVs. TV sets and VCD recorders were not owned by all families at the time of my fieldwork, although several families acquired new sets during that time. Some families owned old TV sets that were not compatible with VCD recorders.

8 Pahari, literally "of the mountains", refers to population groups of Himachal Pradesh who are speakers of Pahari dialects of Hindi. Pahari speakers are the majority population in Kangra. My interview partners in Himachal Pradesh and in Chandigarh distinguished between Himachal Pradesh and Punjab as states, while in terms of geography the opposition was phrased as the mountains or "hilly area" (Himachal) versus the plains (Punjab and larger North Indian plains region).

9 I draw my information from my observation of Facebook posts and comments between 2010 and 2016 by a user group aged between 18 and 40. As a Facebook participant, I have actively followed users online and observed their contacts' posts and comments over a length of time (see Boellstroff 2012 on ethnographic research on the internet). Ownership of smartphones and everyday use of Facebook only became widespread after the end of my fieldwork in the mountains.

10 The mountain images that I have seen so far have been mostly, although not exclusively, posted by male Facebook users. A comprehensive analysis of the gender dimension of these images, however, is beyond the scope of this chapter.

\section{References}

Adams, Vincanne. 1996. Tigers of the Snow and Other Virtual Sherpas. Princeton: Princeton University Press.

Boellstroff, Tom. 2012. "Rethinking Digital Anthropology." In Digital Anthropology, edited by Heather A. Horst and Daniel Miller, 39-60. London and New York: Berg.

Doron, Assa, and Robin Jeffrey. 2013. The Great Indian Phone Book: How the Cheap Cell Phone Changes Business, Politics, and Daily Life. Cambridge, MA: Harvard University Press.

Gupta, Atul. 2007. Lok Rāmāyaṇ: Cambā Bharmaur ke janjātīy lok bhajan. VCD, Kangra: Jayanti Mata Cassette (JMC).

Jeffrey, Robin. 2000. India's Newspaper Revolution: Capitalism, Politics and the IndianLanguage Press, 1977-99. London: Hurst.

Johnson, Steven C. 2018. "Tribal Margins: Dalit Belonging and State Recognition in the Western Himalayas.” PhD diss., Syracuse University. https://surface.syr.edu/etd/923.

Kapila, Kriti. 2008. "The Measure of a Tribe: The Cultural Politics of Constitutional Reclassification in North India." Journal of the Royal Anthropological Institute (N.S.) 14: 117-134.

Karlsson, Bengt G. 2003. "Anthropology and the 'Indigenous Slot': Claims to and Debates about Indigenous Peoples' Status in India.” Critique of Anthropology 23 (4): 403-423.

Liechty, Mark. 2003. Suitably Modern: Making Middle-Class Culture in a New Consumer Society. Princeton: Princeton University Press.

Lutgendorf, Philip. 2005. "Sex in the Snow: The Himalayas as Erotic Topos in Popular Hindi Cinema." Himalaya 15 (1-2): 29-37.

Manuel, Peter. 1993. Cassette Culture: Popular Music and Technology in North India. Chicago: University of Chicago Press.

Mehta, Nalin. 2008a. "Introduction: Satellite Television, Identity and Globalisation in Contemporary India." In Television in India: Satellites, Politics and Cultural Change, edited by Nalin Mehta, 1-12. London and New York: Routledge. 
Mehta, Nalin. 2008b. "India Talking: Politics, Democracy and News Television.” In Television in India: Satellites, Politics and Cultural Change, edited by Nalin Mehta, 32-61. London and New York: Routledge.

Ministry of Tribal Affairs. 2015. Scheduled Tribes: Introduction. www.tribal.nic.in/ Content/IntroductionScheduledTribes.aspx. Accessed on 4 January 2016.

Pinney, Christopher. 1997. Camera Indica: The Social Life of Indian Photographs. London: Reaktion Books Ltd.

Rycroft, Daniel and Sangeeta Dasgupta. 2011. "Indigenous Pasts and the Politics of Belonging." In The Politics of Belonging in India: Becoming Adivasi, edited by Daniel Rycroft and Sangeeta Dasgupta, 1-13. London and New York: Routledge.

van Schendel, Willem. 2011. "The Dangers of Belonging: Tribes, Indigenous Peoples and Homelands in South Asia." In The Politics of Belonging in India: Becoming Adivasi, edited by Daniel Rycroft and Sangeeta Dasgupta, 19-43. London and New York: Routledge.

Wagner, Anja. 2013. The Gaddi Beyond Pastoralism: Making Place in the Indian Himalayas. New York: Berghahn Books.

Wilson, Pamela, and Michelle Steward. 2008. "Introduction: Indigeneity and Indigenous Media on the Global Stage." In Global Indigenous Media: Cultures, Poetics, and Politics, edited by Pamela Wilson and Michelle Steward, 1-35. Durham and London: Duke University Press. 


\title{
3 'Manbhum' videos and their many contours
}

\author{
Contexts, contents, and the comic \\ mode as a subversive form
}

\author{
Madhuja Mukherjee
}

\section{Introducing Manbhum}

In this chapter, I look closely at the Manbhum video industry, which is based in Purulia district, West Bengal, India, and I focus on the narrative strategies of the videos that it produces. By presenting an overview of the small-scale production networks of these narrative and feature-length videos, along with the historical contexts of the locations of production, and by studying the contents and style of the videos, I read the Manbhum video industry in opposition to its big Other(s), which include Bollywood and 'respectable' Bengali language cinema. ${ }^{1}$ Indeed, while video industries have proliferated across the Global South over the last decade and are now widely accepted, videos produced from the margins of India have specific points of contestation, which I shall elaborate upon later. The content of Manbhum videos is drawn from local sources that are themselves in a state of flux, resulting in a compelling mix of contemporary as well as older forms of song, dance, and theatre; furthermore, they are also shaped by global 'video cultures' as they deal with issues of local production and circulation and negotiate emergent technologies. Consequently, I suggest, the videos often present self-conscious critiques of the ways that large-scale mainstream media products portray rural contexts. Many such productions are based upon popular tales and plots, often retold in new ways, which in the process reflect the spread of video cultures across wide geographical territories. Moreover, in the case of videos from the Purulia district (as well as other community-based productions such as Rajbangsi videos produced in North Bengal, and Santali (music) videos distributed in southern Bengal), their producers seek to reposition themselves in relation to Bengali mainstream and middle-class cinema. ${ }^{2}$ Hence, I argue, the issues at stake are not only the economic ramifications of the cultural products, but also the mobilisation of marginal culturesspecifically those of the "backward" castes/classes. ${ }^{3}$ Therefore, both the content and the production contexts of these videos are inextricably entwined with attempts to reclaim and redefine indigenous cultures, which - like all cultures, communities, and languages - are in a state of flux. The function of such (new) media products in relation to socio-political discontents is, hence, a key point of deliberation.

Our research on Manbhum videos helps us to address critical questions regarding community, culture, economy, language, landscape, and issues of re-presentation 
in contemporary media practices. Furthermore, while Manbhum and the Purulia area have been politically volatile, and the landscape and spoken language have often been excluded from typical Bengali narratives, I examine how the videos enable certain (fringe) communities, (rural) groups, and (working) peoples, who are marked by official categories such as "caste" and "tribe", to emerge forcefully and impertinently. ${ }^{4}$ What was denoted "Jangal Mahal" or forest territories during the colonial period is now the Purulia district of West Bengal state in eastern India. The majority of the district's indigenous people are categorised as so-called tribes. Political uprising in the Purulia area has a long history, beginning with the Chuar ('tribe') revolts in the mid-18th century. Manbhum district was formed in 1883, and during the high tide of nationalism Purulia joined the freedom movement in 1928; from 1930 to 1947 (until Indian independence) the situation remained politically charged. In 1956 Purulia was officially mapped within West Bengal, although its geography and demography could have perhaps led it to become part of Bihar. Located thus on the border between West Bengal and Bihar, Purulia retains its historical complexities. Indeed, since the late 1960s, with growing intensity since the turn of the millennium, Purulia has been a hotbed of far-Left guerrilla movements. In this chapter I do not propose, however, that the political movements shape the district's video cultures. Instead, I view the videos as a popular and active negotiation with elite Bengali culture and social marginalisation. As a consequence, I argue, the faces (of indigenous peoples) and bodies (of labouring classes) that have long been under-represented and unaccounted for, who were historically relegated to the margins (or spoken about by elite groups), as well as their cultural practices and ways of speaking, the vast pool of local stories, and 'unexplored' terrains, are now becoming accessible to us, in a renewed way, through these videos.

In this attempt to understand emergent video cultures and the stories they bring forth, I refer to wider debates on the significance of 'subcultures' vis-à-vis indigenous communities, which, I contend, have become all the more forceful now that digital tools have become easily accessible. My aim, therefore, is to revisit conceptual categories such as 'the mainstream' and 'mass' cultures, which may be compared with marginal and subcultural practices..$^{5}$ Therefore, by examining the growth of comparatively small film/video industries, which may be described as 'sub-regional' in relation to the existing frameworks of 'national' Hindi cinema and 'regional' Bengali films, I explore categories such as subculture and subcultural forms, alongside their modes of articulation. Through such explorations I hope to problematise certain widespread binaries like mainstream/alternative, mass/popular, high/low, production/reception, national/regional cinemas, and so on. To aid my study of a wide selection of feature-length videos, comprising in most cases of short comic skits and reworked versions of well-known (tushu) songs, I draw upon Mikhail Bakhtin's (1984) landmark readings of "folk humour", "grotesque realism", and "carnival". I specifically examine the "comic mode" of these videos as an engaging combination of age-old 'folk' forms and contemporary subjects, embracing both the 'popular' and the 'political'. In conclusion, I read Manbhum videos as subversive, since they effectively disturb the gravity of dominant narratives and the authority of big industrial systems and speak about the 
complexities of Manbhum's own space and place. In the process, I reason that with their robust irreverence towards hierarchy, the videos express a critical desire for political change and struggle over a Bhadralok notion of modernity. ${ }^{6}$

\section{Revisiting Manbhum through popular videos}

This chapter is based upon empirical research that was conducted under the aegis of the Media Lab, Department of Film Studies, Jadavpur University. ${ }^{7}$ The first phase of the research (a preliminary survey undertaken by Sadhan Mahato for the Media Lab) involved the collection of material (VCDs) in the Purulia District, as well as the recording of interviews with composer-producer Shankar Tara and singer-composer Kuchil Mukherjee. I conducted the second phase of the research, which included categorising the material in terms of genre and production details (year, location, personnel involved) and studying modes of reception. The latter included field trips to 'video halls' (in which videos are screened) in local areas and to production offices (e.g., that of Choice Videos in Kolkata) in order to research distribution mechanisms, patterns of reception, and viewership.

Manbhum - the term refers to both the location and the language/dialect/bhasavideos are by and large produced in, and circulate across, Purulia district; usually in the VCD format. These feature-length videos, which comprise a few short and popular skits interspersed with songs, first came into circulation and quickly became widely distributed in around 2003-2004. Their producers generally work with low budgets of less than INR 50,000 (usually INR 20,000-40,000, which is approximately USD 300-600) and employ local performers or performers from adjacent districts. The videos are often shot in outdoor locations, which are easily accessible (e.g., local parks or hillsides, locations near large lakes, paddy fields, marketplaces, temple premises, or factories, etc.). Rather than shooting in studios with purpose-built sets, interiors are usually shot in the homes of crew members or their friends and local people. The videos are commonly recorded using available light, making use of existing props and locally acquired costumes.

While the earliest videos were shot on Handycams and edited using two VCRs, more recent productions have been recorded on semi-professional cameras like the Sony PD 170 (a particularly well-known model that was also popular among documentary filmmakers) and are edited on PCs with freely downloadable editing software. Every month, about two to three new videos come on sale in the district's shops and markets and at melas (fairgrounds). Typically, they are screened in buses that cross the districts and/or in tea shops, which also serve as 'video halls', and at the time of certain local festivals, during the course of which small groups gather in the evenings. It was in one such tea shop in Jhalda town that I watched a series of videos on one rain-drenched evening in September 2012. The local audience, some of whom were sitting on the ground, were slightly self-conscious and a little hesitant to express their opinions on the content and style of the videos, although more or less everyone appeared to be enjoying them. Two of the comments made were imperative for me. While one elderly man exclaimed, "all this is a copy of Hindi cinema", another young man shyly added, "that's my sister-in-law's 
brother!" I noted that the videos repeatedly draw attention to production details (e.g., indicating formats and the names of producers, distributors, technicians and others), by means of text embedded in the video images. Often, they provide the phone numbers of crew members such as camerapersons, directors, and producers - signifying that they are available for further work opportunities.

Such material, I suggest, calls for a new approach to studying Indian film and video industries (including both independent films and B movies) since the production, distribution, and exhibition of these videos operates on a small scale, through informal and somewhat unorganised networks, resulting in the absence of any records or documentation of the videos, their processes of production, and viewership, etc. ${ }^{8}$ In addition, the inclusion of a series of popular plots, which are juxtaposed with diverse song-and-dance sequences, results in a loose narrative pattern and a non-linear story-telling style that is bereft of any structured beginning, middle, and end. Thus, the videos not only depict 'alternative' locations and situations, (local theatrical) performance styles, and 'low-end' techniques (as in the case of lighting, setting, or dubbing); they also highlight the unstable condition of dominant narrative cinema and reveal the ways in which conventional frameworks, genres, and styles can be contested by indigenous and variant audiovisual practices. Melis Behlil (2005) has addressed cinephilia and file-sharing with reference to new media practices, and D.N. Rodowick (2007) has written about the "virtual" after-lives of celluloid films in the digital context. In his influential study on the "Virtual Life of Film", Rodowick examines how digital tools have altered cinema's "aesthetic existence". He also highlights the ways that characteristics formerly associated with the "filmic image" (framing, exploration of depth of field, use of chiaroscuro lighting, etc.) are being "reworked, reappropriated, and recontextualized" through sampling and sequencing. ${ }^{9}$ In addition, Warren Buckland (2009), following David Bordwell et al. (1985), analyses emergent endeavours to complicate the narratives of Hollywood and European films and identifies certain recent films that have multi-focal narrative structures instead of classical linear ones. However, by focusing upon marginal media practices such as Manbhum videos, I hope to bring a fresh perspective to our understanding of new media cultures by exploring a field that is densely packed in terms of varied modes of engagement with technology, narrative strategies, and methods of circulation and consumption. ${ }^{10}$ Hence, I argue that digital tools are not only able to produce enhanced, clean, and sharp images and "puzzle films" as observed by Buckland, but that they can also enable heterogeneous processes of filmmaking that have seemingly democratised the global media landscape. ${ }^{11}$ Moreover, such videos draw attention to the fluidity of cultures and liminality of borders, as well as to the trajectories by which popular cultures are constantly being reclaimed, reinvented, and re-circulated.

The production and consumption of Manbhum video intersects with that of other videos produced and disseminated across different districts of the Indian states of Jharkhand, Odisha, and West Bengal. While the scope of this chapter does not allow me to comprehensively analyse the development of the multitude of small-scale video industries and narratives that have taken root across the Global 
South in the last decade or so, two crucial aspects of the emergent audiovisual cultures should be noted. First, recent research has been questioning the established cartography of India by focusing on the complexities of the 'region' and highlighting the diversity of economic conditions, community cultures, idioms, and topographies that coexist within the broad frame of the nation state. In the article, "Thiruvithamkoor, Malabar, Kerala: Speculations on the Regions in 'Regional Cinema"' (2015), for example, Ratheesh Radhakrishnan critiques the making of "regions" through language, geography, and cinema cultures, and reviews the efforts made to unify Kerala as a political unit. Likewise, my close reading of Manbhum videos disturbs the perception of cinema from Bengal as a unified, predominantly middle-class, and Bhadralok endeavour (see Gooptu (2010) on Bhadralok cinema), while at the same time problematising the representation of Bengal as consisting primarily of the Gangetic lowlands. ${ }^{12}$ Indeed, the videos reveal the vibrant presence of new vistas as well as of specific speech patterns and gestures that have remained unaccounted for in mainstream Bengali films. Manbhum videos make visible the limited views offered by Bengali films in particular, and Indian cinema in general, by demonstrating that 'films' can be produced (by local technicians without formal training) and circulated (amongst small groups and indigenous communities, or screened on TV sets in rural clubs, tea shops, and at informal gatherings, etc.) and may eventually re-tell the tales of the outer edges. Secondly, as I suggested earlier, analysing the material enables the generation of fresh knowledge about contemporary media practices by illustrating how newer technologies (e.g., video and the digital as opposed to celluloid) and techniques of production and distribution (independent of established theatres and broadcasters) and local narratives can disrupt the dominance of mainstream cinema and media cultures.

As will become evident in the interviews that are discussed later, the production of these videos is inextricably linked to both economic and cultural conflicts over prevailing (Bengali) cultural products, including films and music albums. For example, the videos appear to have developed in response to the mass distribution of disparate local musical forms (e.g., Tusu, Bhadu, Jhumur) marketed as allembracing 'folk'. Therefore, while Kolkata-based production houses such as Choice Videos (which also produces Santali films) play a crucial role in the reconstruction of indigenous musical patterns, companies based in Purulia, e.g., MVM (Malati Video Movies), control a large portion of the production of Manbhum videos. ${ }^{13}$ The contemporary Bengali film market, consequently, includes the production and reception of films and/or videos in (at least) three different dialects as well as other languages, including Hindi. In fact, while on one hand, music videos and narrative films in the Santali language are available in the south of West Bengal; on the other hand, Rajbangsi (the term refers to both community and dialect) videos produced in North Bengal and Assam travel across boundaries into Bangladesh. While the growth of Rajbangsi videos runs parallel to the increasing political agitation in the area, the viewership largely comprises immigrants, primarily from Bangladesh, which calls attention to the significance of such cultural transactions and to their relationship to the history of economic-political 
transformations in India. Moreover, as mentioned earlier, video cultures that stretch across borders can shed light on long-standing and complex histories of political marginalisation and problems of cultural re-presentation. As Schleiter points out,

Studies on tribes, ādivāsīs, or indigenous groups of India have largely ignored the questions central to this article: What determines the formation of such communities? And, more specifically, what role do the indigenous popular media play in shaping the outlook of their cultural identities? For a long time, research on the topic instead presupposed "indigenous" culture and ethnic belonging as primordially given.

(Schleiter 2014a, 191)

Hence, following Schleiter, who complicates the prevailing reading of 'Santali culture' as a single unit, I would like to suggest that contemporary viewers' interactions with videos can reveal new interpretations of politics and culture within Indian territories and among indigenous communities. The material that emerged during the research process prompts me to ask, Who actually speaks for the 'regions'?14 Or, adapting Dipesh Chakrabarty's (1992) well-known expression, Who speaks for the 'regional' present? I suggest that the video material and practices associated with it can help us to interrogate official political-cultural histories and examine the ways in which regions have been represented in popular media, as well as to reconsider the manner in which regional/national films have generally been studied. Stephen Hughes, for example, has pointed out that "regional language-based cinemas" have been broadly defined as "self-contained units [. . .] which collectively constitute Indian cinema as a whole". "However", Hughes adds, "linguistic/ethnic boundaries between the various cinemas of India have always been much more porous and contested than has been adequately recognized by scholars" (Hughes 2010, 214). In the following sections, therefore, I wish to demonstrate how Manbhum videos can help us bring such critical points to the fore, while I also locate Manbhum videos within the landscape of Indian cinema, and media and cultural studies.

\section{Video and new visual cultures}

The industries that produce videos have their own historical complexities, which are marked by years of tussle with the state. In fact, decades of political activism finally led to the Santali script and language being officially included in the eighth schedule of the constitution in 2008, and thus, the videos in the local dialect, which present local stories, have become a carrier of Santali histories and way of life. Moreover, the Rajbangsi video industry is overtly associated with ongoing political movements calling for a separate state and with demands for more power for Rajbangsi communities in the northern areas and the hills of Bengal. Producers of Santali language videos and Rajbangsi videos also organise their own local 'film' festivals in order to showcase and legitimatise their work. ${ }^{15}$ Similarly, the 
availability of Nepali films in Darjeeling, West Bengal, contributes towards the reworking of popular notions regarding Gorkha and Nepali identity, which is connected with the extended political agitations in the hills. ${ }^{16}$ Furthermore, Epsita Halder's (2010) project on popular Karbala narratives in 24 Parganas district, West Bengal, demonstrates how the cellphone-based circulation, among (Shia) Muslim communities, of media files from the Middle East, as well as recordings of local performances and songs, is contributing to the construction of a new Islamic identity. ${ }^{17}$ Consequently, what appears as an upsurge of digital video films may be regarded as a potent re-mapping of the nation with respect to its fractured history; ${ }^{18}$ and, as suggested earlier, studying the videos also points towards a new historiography of cinema in the regions, in opposition to the framing of 'regional cinemas' aligned with the political map of India. Furthermore, as discussed earlier, by means of these videos I hope to review the very materiality of 'cinema' as celluloid, since video and/or digital media have taken over as the format and technology used to record and disseminate alternative images of the territories. ${ }^{19}$

Manbhum videos, hence, should be closely looked at in the context of other digital and audiovisual practices that are currently burgeoning across the Global South. For example, Ali Nobil Ahmed's (2011) work on "Contemporary Pashto [pornographic] film and Cinema Culture", Farida Batool Syeda's (2012) research on "Mujra dance video CDs" and "present day Pakistani popular culture", along with Lotte Hoek's ongoing study of the extraordinary overlaps between cheap crime thrillers and traditional literary forms in Bangladesh, all examine such new media fields. ${ }^{20}$ Studies of indigenous video industries illustrate the complex nature of peripheral production systems, prevalent genres, audience cultures, and the manner in which these are interconnected with what I describe as "narratives of discontents". ${ }^{21}$ Daisy Hasan (2010), for example, demonstrates the ways in which art-house filmmakers in 2007 in Manipur, North-Eastern India, utilised (cheaply) available digital technology, while conversely, the scene was also activated by the production of popular music videos. Hasan shows how the situation brought together twofold tendencies (including both alternative films and more mainstream projects), and concludes: "[c]ontemporary commercial entertainment in the North-East, then, appears to combine several cultural influences strategically" (Hasan 2010, 42). ${ }^{22}$ Political tensions between the nation and the regions, as well as subjects relating to identity (involving issues of caste, religion, language, and location) also become crucial in Ratnakar Tripathy's (2007) article on Bhojpuri cinema, which examines the cultural undercurrents within 'backward' parts of India. According to Tripathy, these growing phenomena can inform us about transformations at local, regional, and national levels and reflect the pulsating dialogues vis-à-vis socio-political changes. In the following sections, accordingly, I enquire how video cultures present a dynamic correlation between a strong desire for political change, and audiovisual imaginings.

\section{Producing Manbhum narratives}

Cinema from Bengal, broadly speaking, has been analysed in relation to the history of the post-colonial state and problems of Bengali (Bhadralok) modernity (see, for 
example, Gooptu [2010]), but the interviews conducted for the Media Lab research raised certain key problems of studies on 'Bengali' cinema. As they discussed the themes and forms of Manbhum (music) videos, Kuchil Mukherjee (singer-producer) and Shankar Tara (composer-producer), drew our attention to language, dialect, and popular idioms, as well as to processes by which these have been appropriated by the more powerful and widely accepted 'Bengali' cultures (produced by the Bhadraloks from the big city). Shankar Tara, for instance, mentioned in his interview (recorded by Shadhan Mahato in Bengali, translated by me) that when he played a character from Purulia, the renowned star of the 1950s and '60s, Uttam Kumar, failed to speak in the Manbhum dialect or adopt its specific modes of expression. ${ }^{23}$ A different actor, Ajitesh Bandyopadhyay, who was from the region, performed the bhasha (dialect) more convincingly in another film. Bandyopadhyay's role in the concerned film, therefore, is perceived as a more authentic and acceptable portrayal of local intonations. Later, as he spoke about the waning of Manbhum imagination and contemporary videos, Tara insisted, "nothing is original now". In his opinion, locally and cheaply produced videos generally address poor people, who "do not earn more than fifty-sixty rupees [per day]" and like to "drink and watch these "quickies"". "But, what one can do?" he lamented, adding, "these days they produce vulgar stuff like Sadher Tomato [discussed later]".

Shankar Tara's comments raise imperative questions regarding what constitutes the larger framework of 'Bengali' cinema, and also point to the problems of the re-presentation of Manbhum in such films. More importantly, he questions contemporary Manbhum videos and highlights the ways in which local musical forms have been transformed and reproduced for a regional market, which is crisscrossed by other cultural products. Moreover, his comment - "nothing is original" - is crucial to my argument as it draws attention to the complicated nature of video production and reception. For example, in his analysis of modes of viewing Santali films, Markus Schleiter (2014b) has shown how reception practices are often embedded in the "meaningfulness of a 'traditional' dance night, and [how] this has led villagers to celebrate these films as a means of enjoying time together". "At the same time", Schleiter continues,

the villagers do expose the enduring nature of 'traditional' dances by comparisons with (the unworthiness of) 'video nights'. As such, film watching and 'traditional' practices in a village stand in a reciprocal reference to each other, and such media practice becomes part of supporting 'new media usage' as well as 'traditional' dance forms.

[2014b, 11, emphasis mine]

Schleiter's work underlines the paradoxical nature of participation in new media practices. In fact, both Shankar Tara and Kuchil Mukherjee (cited later) shed light on problematic subjects, like what constitutes "local" and "original" or "pure" cultures. Clearly, critical subjects of cultural re-presentation, as well as issues of 'culture', 'taste', 'music', and 'authenticity', are connected with manifold debates, which are generated both within and outside Manbhum. For instance, Kuchil 


\section{Madhuja Mukherjee}

Mukherjee, the veteran Jhumur performer, stresses the contexts and contents of such audiovisual products, and the matter of "vulgarisation" of Manbhum music and songs. Mukherjee laments:

These CDs [videos] sell like 'hot cakes' [... ] my son once got me one; I could not watch it at all. . . but [previously] our culture was endangered, [and] we needed new forms to survive.

Later, Mukherjee also described their shooting techniques:

Presently, we are working with small cameras, without reflectors or lights. For the night sequences, I just used bulbs [. . .] we shot in front of our houses.

Then, he quickly added:

[But] You see Jhumur was never a dance form [. . .] [as presented in the videos] yet, and we have to contemporize it now. ${ }^{24}$

Indeed, while the question of 'taste' ${ }^{25}$ is central in a number of conversations with local people, issues of reception are also raised, showing the precarious manner in which the video industries have expanded and continue to survive on the edge. Our Media Lab project illustrates the diversity of strategies deployed by the Manbhum video industry to hold its ground against large-scale production structures, despite its long history of political marginalisation and the gradual withering of local forms. These strategies include producing low-budget videos "cheaply [. . . ] with small cameras, without reflectors or lights" in order to "survive", and choosing specific genres, such as the comic mode, in an attempt to engage in a cogent dialogue with dominant cultures. ${ }^{26}$

In this chapter I would like to highlight some of the ways in which the desire for political change has been articulated through (digital) filmmaking and the various expressive forms that such articulations may assume. For instance, Ratnakar Tripathy, writing about Bhojpuri music videos and their resonances in the Hindi heartland, links the increasing popularity of such videos to aspirations for social mobility - fantasies that the videos seem to portray in the "vernacular". He concludes that such parallel regional industries

are dealing with a gigantic change that can be best expressed through the dynamic continuum: Hollywood cinema - Bombay cinema - Bhojpuri cinema. It is possible to talk about this continuum not simply as a theoretical construct with heightened relevance in the age of globalism, but a "real" experience from the audience's viewpoint [. . . [However] What is striking here is not the situation itself, but the depth to which it is uncovered. ... Even if we see Bombay and Bhojpuri films as part of a continuum, the moments of discontinuity and thematic magnification reveal unexplored terrains.

Tripathy $(2007,259)$ 
Following Tripathy, then, I would like to elaborate in the next section on how Manbhum videos have become a vehicle through which uneven social changes and political apprehensions are being voiced. I show how this new form of video "filmmaking" actually reveals "unexplored terrains", and how these videos effectively become a powerful tool for indigenous people to express a range of politicalcultural dissatisfactions, and to re-tell histories of social marginalisation.

\section{The matter of taste and tomato}

In the 1970s, the Birmingham Centre for Contemporary Cultural Studies was at the forefront of new approaches to the study of cultural industries, which relocated the subject of 'Culture' at the centre of debates. ${ }^{27}$ The methodology proposed by Stuart Hall, et al., have been discussed at length, arguably to exhaustion. ${ }^{28}$ Furthermore, despite contestations of the Cultural Studies model, the problem of seeing 'subcultures', as an alternative to 'mass-produced' cultural products has remained a pertinent topic, since it relates to studies of ongoing struggles of peripheral groups against socio-cultural relegation. Nonetheless, most studies of 'subcultures' have focused on urban practices ${ }^{29}$ (especially those of youth) and have posited such "subversive" practices as "alternatives". ${ }^{30}$ It is in this problematic context that I wish to evoke Mikhail Bakhtin's (1984) reading of "folk humour" and "grotesque realism" in an attempt to understand the heterogeneous field of Manbhum videos. The continued tussle over both the processes of production and the themes of cultural products that are facilitated by transformative media technologies provokes me to reconsider Manbhum videos in the light of two apparently oppositional tendencies: the persistence of folk traditions and the emergence of media technologies.

I wish to refer to the Manbhum video Le samla sadher tomato (produced around 2009) to elucidate the point (see Figure 3.1). Sadher tomato or "Favourite Tomato" (described as "vulgar" by Shankar Tara) opens with a sequence in which two actors perform as drunkards in a village, while cows, ducks, and bicycles cross the streets and the video frame. In the next sequence, one of the comedians squats next to a well and begins to sing and cry as he washes his clothes. His song narrates his woes, and the scene is intercut with images of the playback singer performing the same song in the open fields. I would like to argue that a video like this produces a unique assemblage by connecting three different performances, including the comic performance and the performance of the playback singer, juxtaposed with shots of the audience, who are either watching such performances directly and/or watching them as videos on televisions and VCD players. This multi-planed pattern of narration, which combines performances based on local plots with evidence of emergent technologies and shifting terrains of reception, creates rich and "activated texts" that are manifold accounts of social vicissitudes.

Later, another scene of Sadher tomato opens in a paddy field, and presents the story of a peasant couple whose young son is sick. This scene is shot through an appealing, although grainy and unstructured framing which generally 'covers' the action without overtly artistic framing. Afterwards, the story continues in the 


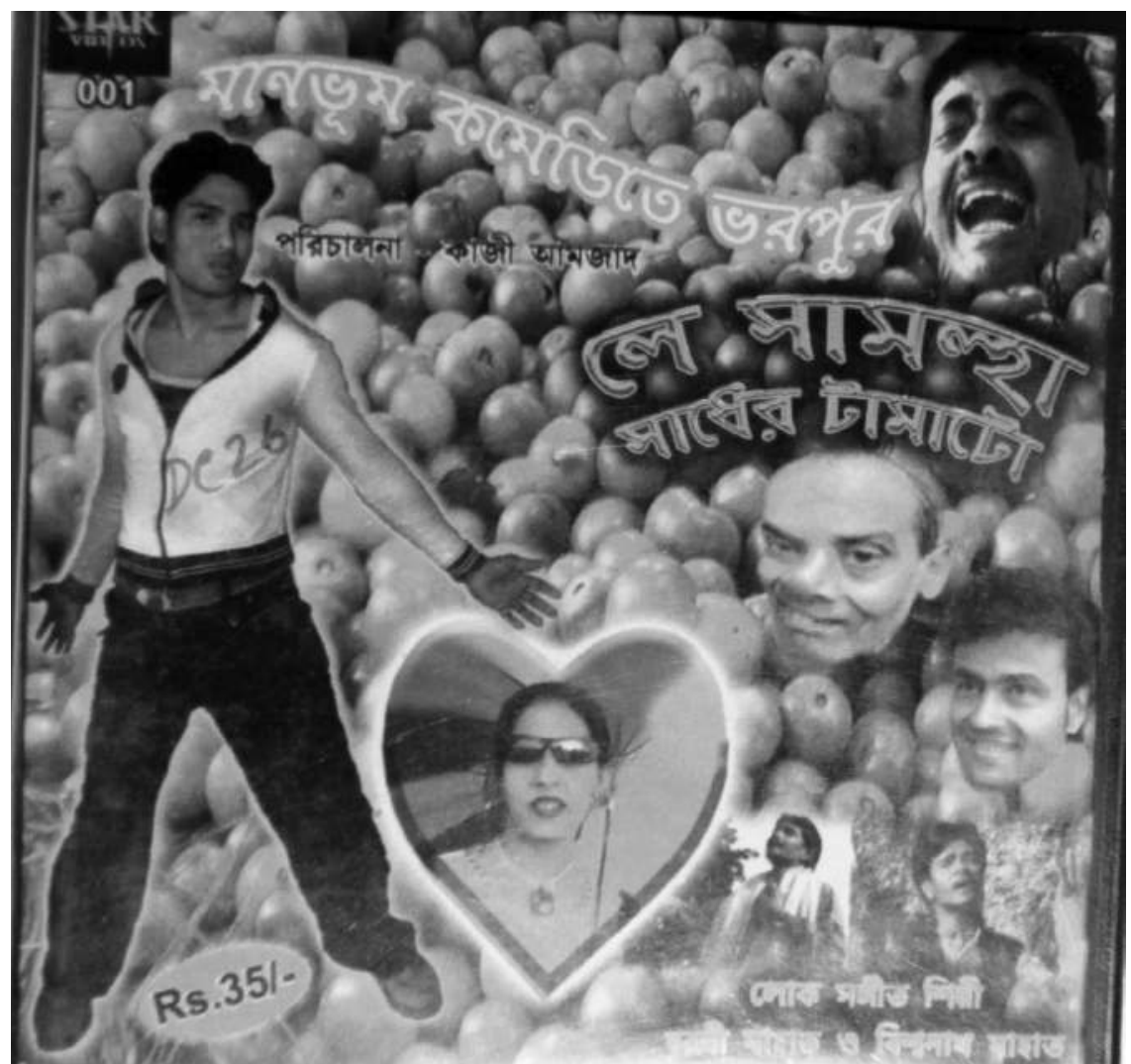

Figure 3.1 Le samla sadher tomato: Taste, Taboo and Tomato

couple's home. It transpires that the young boy has not eaten since the previous night. Then the scene is interrupted by the entrance of a shaman. He examines the boy and declares that he has been struck by a terrible malaise. But then the supposedly "possessed" patient recovers quickly as the shaman whispers to him. The shaman asks the boy what is on his mind, and is told, "I want a CD [DVD] player". The shaman breaks into laughter and reassures him that he will get one (just as the shaman will get his fee). The shaman exclaims, "[so] this is CD spirit!" In the next sequence, the father (Ali) and the young boy visit a rural market, where they buy a VCD player for 1,500 rupees and a VCD for 60 rupees. These sequences draw our attention to the location of Purulia, which lies on the border between Bengal and Bihar, and sees the circulation of a variety of consumer products as well as locally and extra-legally assembled consumer items. ${ }^{31}$ Thus, the 'CD-fever' story draws attention to the consumption of electronic devices and media in places that popular mainstream cinemas by and large portray as pristine villages untouched by technological developments. ${ }^{32}$ The production of such videos also points 
towards the cultural struggles through which the everyday lives of indigenous people, their narratives and voices of discontents surface via locally generated media products. Beyond the comic elements of such sequences, their self-reflective tone draws attention to the overlaps between apparently disparate cultural practices and testifies to the growing media cultures that are re-locating places like Manbhum within contemporary media fields.

Sadher tomato ends with a sequence that shows a group watching videos on a television, and then eating a feast together. This sequence, shot in the style of a home movie, appears to be a recording of an actual feast, which may have been added to the main video at a later date. And yet, the background to the shots of the ("backward caste") labourers eating biriyani (meat and rice) is a parched open field; a formidable backdrop that seems to recount the absences of Manbhum landscape in mainstream popular films. Sadher tomato shows how Manbhum videos can present an exceptional combination of actual accounts and anecdotes, as well as a tapestry of distinctive incidents and imaginaries.

To elaborate further on the above point, I would like to refer once again to Ratnakar Tripathy's argument:

the same population has shown its political sinews over the last two decades by challenging the hegemony of the upper castes through a number of movements and platforms as rallyist and voter. However, it is only with the rise of Bhojpuri films that it has found a certain cultural commonality and resonance in the regions of eastern Uttar Pradesh and Bihar.

(Tripathy 2007, 150-152)

Indeed, a similar argument may be put forward in relation to Manbhum films, since the stories of political-cultural abstruseness, which are being played out through the videos across Bengal's boundaries, become a sharp reminder of the unaddressed subjects of topography, idioms, and class/caste differences. Manbhum videos cannot be seen as a continuation or any clear-cut consequence of the specific (ultra-)Leftist political struggles in Bengal, Bihar, and Jharkhand. Nevertheless, subjects of political-cultural resistance are crucial to my analysis of the archetypal (performative) modes, plot types, comic elements, and musical compositions, which refigure in a compelling manner. Clearly, the videos bring up the experiences of 'tribes', 'caste' and communities and highlight the complications of dalit and adivasi experiences, which have remained marginalised for most of our cultural histories. ${ }^{33}$ Manbhum videos, in my understanding, not only produce alternative narratives, but also instigate persuasive debates concerning what characterises the regions, which, I suggest, are deeply fragmented in terms of places, peoples, languages, dialects, communities, work, gender, political histories, and cultural practices. These videos make it clear that there are many 'regional' cinemas, just as many regions (districts) exist within regions (provinces), and any thorough study of cinema from Bengal ought to include Manbhum, Santali, Rajbangsi videos, and others that function in parallel worlds, outside the networks of what has been studied as (contemporary) neo-Bhadralok cinema. ${ }^{34}$ 


\section{The comic mode and subversive videos}

The contexts and the contents of Manbhum videos allow me to raise critical questions concerning binaries like mainstream/alternative, high/low, production/reception, national/regional cinemas, etc. Many preceding studies concerned with 'mass' or 'popular' media or 'subcultures' have focused on urban contexts and youth cultures. But I would like to raise the following question: How we can read the 'comic mode' of Manbhum videos, through which a 'folk humour' resurges with carnivalesque vigour? While there has been little attention (in English) to the comic mode in cinema (and theatre) from Bengal, Sumanta Banerjee, who has written extensively on the persistence of popular culture in the face of long drawn out processes of modernisation and gentrification, has made the following observations about Bengali 'folk' cultures:

[w]ith the decline of the village economy and the beginnings of industry in nineteenth century Bengal, there was a regular exodus of poorer men and women from the countryside to Calcutta [Kolkata][... ]

These Bengali villagers brought with them into Calcutta the songs they inherited from rural folk culture with their own poetic rules, their own musical scales and rhythms. Along with their women, they not only kept alive the old folk culture in the squalor of the growing metropolis of Calcutta, but enriched it with new motifs borrowed from the surrounding urban scenes. The street literature of nineteenth century Calcutta - songs, dances, doggerels, theatrical performances, recitations - became a great melting pot of tradition and topicality.

(Banerjee 1989, 129-130)

Borrowing from Banerjee the notion of keeping folk forms "alive" and enriching them with "new motifs", I contend that the 'folk' culture and humour evoked in Manbhum videos has a long history of survival and travel; moreover, the videos can be collectively seen as a productive "melting pot" that brings together multiple cultural forms. Andrew Horton (1991) has written about the comic mode in cinema and discussed comedy and its "deconstructive spirit" at length. Furthermore, he writes about the "carnivalesque" energy in comedy and draws upon Mikhail Bakhtin's analysis of "pre-industrial" and "pre-capitalistic" cultures in the landmark work Rabelais and His World (1984). Bakhtin's ideological framework and his remarkable study of humour as a subversive force becomes crucial to my argument at this point, because the Manbhum videos, which are located within contemporary global flows of media cultures, also carry forceful traces of 'folk humour'.

In my concluding section, therefore, I read the specific comic mode of the Manbhum videos with reference to Bakhtin's (1984) framework. I use the analytical categories put forward by Bakhtin in this attempt to study the ways in which provincial slangs, expressions, farcical modes, and other prototypes have become a part of popular videos. The apparently unpremeditated images of the videos, 
unlike the digitally enhanced images of mainstream (Bengali and Bollywood) cinemas, seem to refer back to popular sources that have persisted over the years; especially those that are connected to various forms of 'folk' cultures. Hence, I examine the viewer's experience of what Bakhtin describes as (a) ritualistic spectacles (like song and dances), which are performed in specific locations; (b) comic verbal compositions, phrases or dialogues, and actions performed by certain characters or performers (whose faces become a feature of the comic form); and (c) specific physical and subversive acts directed towards hierarchy and various types of social structures (e.g., showing little or no reverence towards the dead).

As an example, the popular full-length video, Huchke niye puchke dili re (which can be roughly translated as "You promised but did not deliver", and was in circulation around 2005), includes a series of comic sequences (see Figure 3.2). The video opens in the interior of a house, showing a teenage boy humming a popular tune ("Pereet kore ne go sajani/ shomoye chole gele aar to pabi ni"; Fall in love my dear/Do not miss the chance). This cuts to a medium two-shot, which shows

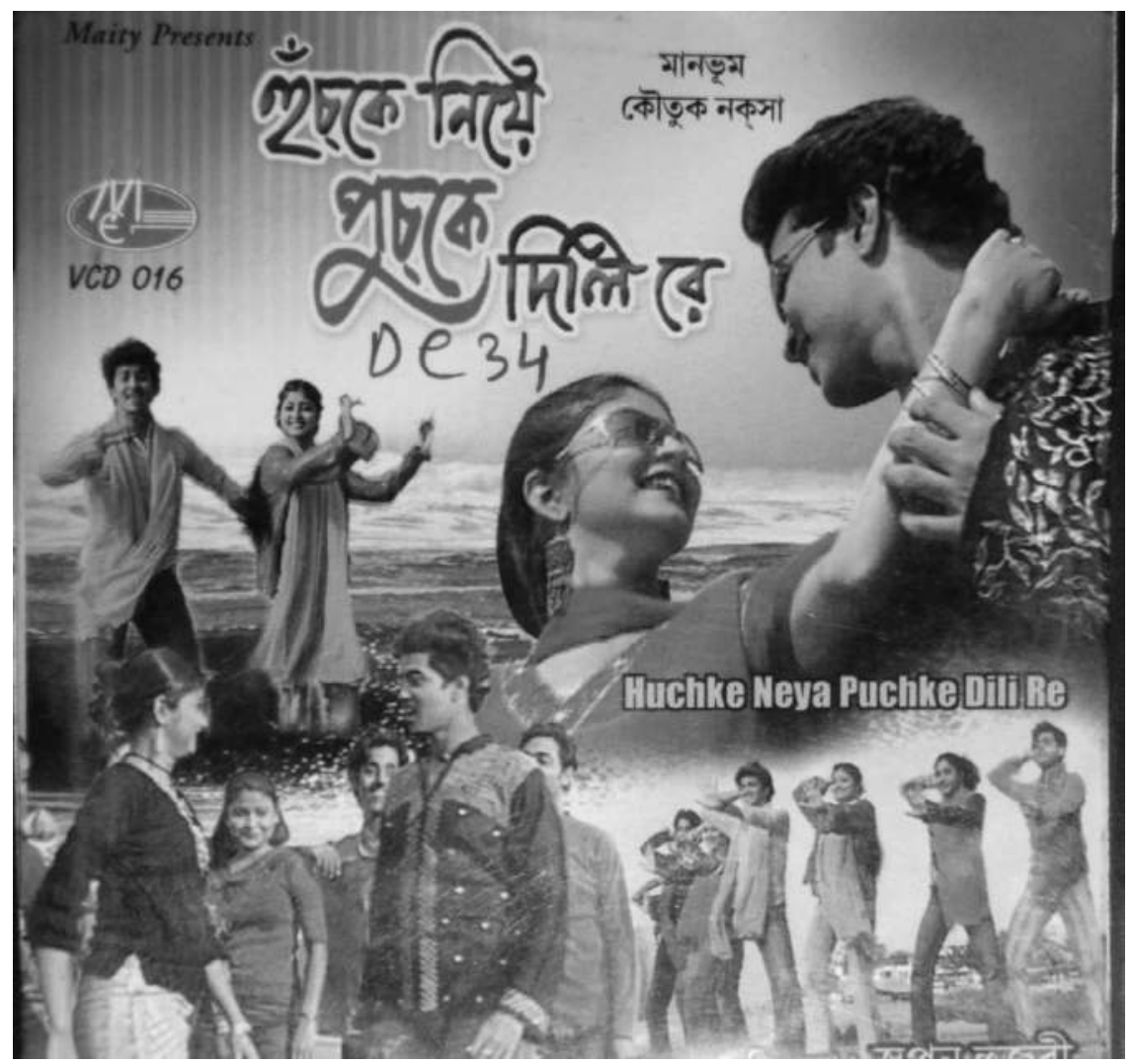

Figure 3.2 'Huchke niye puchke dili re': Between folk humour and grotesque realism 
the young lad with his sister, who is teaching him the entire song. Later, as they start dancing, the camera remains static and distant (long shot) when the boy's father enters the scene and enquires about his studies. Next, the father asks him to form sentences with the word "cow". "My father is a cow," replies the young man. This is just one example of the boisterous way that popular (and "vulgar") jokes, and various kinds of other subversive elements, including body movements and gestures, hold Manbhum videos together. It stands in opposition to the moral order of mainstream films. This approach to narrative may be read as what Bakhtin describes as

a completely different, non-official, extra ecclesiastical, and extra political aspect of the world, of man, and of human relations; they [pre-modern people] built a second world and a second life outside officialdom, a world in which all medieval people participate more or less.

(Bakhtin 1984, 6)

According to Bakhtin (1984), this alternative "second life" is founded on humour and laughter. Furthermore, it "belongs to the borderline between art and life. In reality, it is life itself, but shaped according to a certain pattern of play" (Bakhtin 1984, 7). The Manbhum videos, which are often watched at fairgrounds or in inbetween spaces like buses, function like "carnival", which has its own rules or "laws of its own freedom". A festive experience is inscribed within the videos and evoked in the collective acts of viewing. In fact, these videos disturb hierarchies: not only in social life, but also in the media and cultural industries, and invoke instead "second life of the people, who for a time [enter] the utopian realm of community, freedom, equality, and abundance" (Bakhtin1984, 9). Thus, "a special carnivalesque, marketplace style of expression [free, direct, and abusive] is formed" (Bakhtin 1984, 10). Certainly, in Sadher tomato, an extraordinary "marketplace" style of speech, and gestures that appear forthright and uninhibited, seem to liberate the viewer from the norms of social behaviour (bhadrota in Bengali) and civility. Moreover, the presence of an audience within the narrative itself shows that such laughter is not parody, since there is no negation, but is rather "festive laughter", directed at everyone.

In addition, the body, and various physical actions including eating and drinking, are prominent, while images of the body have exaggerated features. For instance, in the sequence in Sadher tomato in which the comedian, wearing an undershirt and lungi (wrap), squats and sings vigorously, the camera zooms in to his toothless mouth, producing a range of wide-angle distortions. Such framing, absent in mainstream films, creates a mise-en-scène of laughter. Bakhtin would describe such performances as "grotesque realism". "Grotesque realism" is about "lowering the high, spiritual, ideal", and includes the display of the lower part of the body. This body is the converse of the strictly perfect and finished product of a Bollywood star. ${ }^{35}$ The "true nature of grotesque cannot be separated from the culture of folk [and popular] humour" (Bakhtin 1984, 47). Likewise, "exaggeration, hyperbolism, excessiveness" are primary features of the grotesque form. 
Besides, the "grotesque" is not to be read as a displacement of repressed desires, but is rather a second or parallel world and life offered to its public. According to Bakhtin (1984, 123), "[1] aughter purifies [us] from dogmatism, from the intolerant and the petrified; it liberates from fanaticism and pedantry, from fear and intimidation, from didacticism, naiveté and illusion, from the single meaning, the single level". In my understanding, thus, besides producing an ethnographic charge (by shooting on location and by narrating local plots), the Manbhum videos become meaningful because of the manner in which they traverse the under-represented rocky terrains of Bengal, voice the 'rough and coarse' speech of Manbhum, and portray labouring bodies and/or unorganised workers, who remain conspicuously absent in middle-class cinemas. It liberates us from "didacticism, naiveté and illusion" and "from the single meaning" that such didacticism imposes on portrayals of social life in marginal areas.

Truly, with their fragmented plots and loud laughter, as well as through frames that present unexplored territories, figures, and speech, Manbhum videos appear like footnotes of our political-cultural histories, which comment on the problems of class, caste, languages, cultures, places, shared stories, and complicated patterns of social marginalisation. Thus, as I have illustrated in this chapter, the research conducted shows how these videos speak to the growing media cultures across the Global South and become both a means of recording local subjects, geographies, and voices (or speech), as well as a tool by which more critical objectives can be articulated. In addition, I have questioned conceptual categories like 'regional cinema' by exposing the complexities of how regions have hitherto been defined. Briefly, I asked what constitutes the regions, and in what ways indigenous people can raise their voices. I proposed that the videos become one of the modes of addressing the dualities of history and culture. Furthermore, such videos, which circulate alongside a wide range of practices and apparent dichotomies (such as traditional folk forms and industrial music videos, alternative and subcultures, popular and mainstream or commercial regional cinemas, TV and new media, local and global practices, as well as corporate networks and extra-legal trading of videos, etc.), disturb the existing frameworks of cinema studies and demand innovative and radical research questions. Reading the Manbhum videos' narratives with the aid of Bakhtin's (1984) formulations has helped me to interpret some of the subjects raised by the videos and pointed towards the need for more complicated approaches to studying the ways in which parallel modernities are being persistently explored, negotiated, and reworked.

\section{Notes}

1 On Bollywood, see Global Bollywood (Kavoori and Punathambekar 2008), and on the construction of "respectable" Bengali language cinema, see Bengali Cinema: An Other Nation (Gooptu 2010).

2 See Das (2009) on the political history of the formation of Rajbangsi 'tribes'.

3 This is the governmental terminology used to refer to disparate communities as 'castes' and 'tribes'. The groups are also referred to as 'reserved' categories.

4 See West Bengal District Gazetteers (Bhattacharya 1985). 
5 See Hall and Du Gay (1996).

6 See Larkin (1997).

7 As the joint coordinator of the Media Lab project, I have also supervised other research projects, including the sound cultures project, and conducted research on Kolkata-based film studios.

8 Tejaswani Ganti (2012) has shown that the Bollywood industry is also somewhat disorganised; with "kinship" structures and a reliance on existing protocols and practices often dominating production processes.

9 Also see Kracauer (1960) for a critical commentary on the celluloid medium and its forms.

10 See also Ji-hoon Kim (2009) and Charles R. Acland (2009).

11 An optimistic view of the 'digital revolution' was put forward by the Iranian filmmaker Samira Makmalbaf at Cannes Film Festival in 2000: "[t]hree modes of external control have historically stifled the creative process for a film-maker: political, financial and technological. Today with the digital revolution, the camera will bypass all such controls and be placed squarely at the disposal of the artist". For further discussion on this topic, see http:// collectiondevelopment.library.cornell.edu/mideast/makhms.htm [accessed on 23.8.2015].

12 See Madhuja Mukherjee (2011) on the production of a particular type of Bengal landscape through cinema.

13 My own research and documentary project (2002) on the urban-folk theatre 'Jyatra', which is popular across rural Bengal, revealed that many so-called folk products are, in fact, produced and regulated by companies based in Kolkata. Such production systems illustrate the ways in which urbanites imagine differences between the 'rural' and 'popular'. Thus, the local production of the videos becomes significant in relation to the question of who speaks for the "sub-terrains".

14 I allude to Spivak's infamous questioning in "Can the subaltern speak?"

15 I thank Tanusree Dey for sharing this information with me.

16 I thank Sradhanjali Tamang for sharing her research data with me.

17 See www.indiaifa.org/epsita-halder.html [accessed on 3.9.2015].

18 See Chatterjee (1997).

19 I am referring to early writings on the 'ontology' of cinema by Andre Bazin and Siegfried Kracauer and the ways in which they define the cinematic form. On contemporary audiovisual practices, see Marks (2000).

20 Ahmed presented a paper at a conference entitled "Media Morphologies: Infrastructures and Technologies in Art, Cinema, and Popular Culture" in September 2011 in Rotterdam. Syeda presented at the Conference "Arts and Aesthetics in the Globalising World", ASA 12, in April 2012 at JNU, Delhi. I presented a paper, upon which this chapter has been based, within the same panel.

21 See Haynes (2000) for a study of the video industry and horror genre in Nigeria.

22 Also see Kuotsu (2013) on popular videos of the region.

23 See Biswas (2000), on the star persona of Uttam Kumar and on aspects of post-colonial modernity in Bengal.

24 Kuchil Mukherjee can be seen performing Jhumur at www.youtube.com/watch? $\mathrm{v}=\mathrm{j} 11 \mathrm{R} 16 \mathrm{IE} 40$ [accessed on 28.1.2017].

25 Pierre Bourdieu has written extensively on "taste". He summarises:

[T] he capacity to confer aesthetic status on objects that are banal or even 'common' (because the 'common' people make them their own, especially for aesthetic purposes), or the ability to apply the principles of a 'pure' aesthetic to the most everyday choices of everyday life. [...]

[Moreover] The denial of lower, coarse, vulgar, venal, servile - in a word, natural enjoyment, which constitutes the sacred sphere of culture, implies an affirmation of the superiority of those who can be satisfied with the sublimated, refined, disinterested, gratuitous, distinguished pleasures forever closed to the profane.

(Bourdieu 1984, 5) 
26 See the documentary Supermen of Malegaon (2008) for a commentary on the comic mode in videos made in Maharashtra.

27 See Stuart Hall (1980).

28 See Fredric Jameson (1993).

29 See Kuan-Hsing Chen (1998).

30 See Andy Bennett (1999).

31 News features in recent years have reported the circulation of arms and huge quantities of ammunition in the district of Purulia.

32 See also Kaushik Bhowmik (2011) on the reframing of the Rajasthan landscape.

33 See Debesh Roy's monumental novel Barishaler jogen mandal (in Bengali), which deals with issues of caste and the lack of political change. It features the life and political journey of activist Jogendra Nath Mandal. See also Dwaipayan Sen's (2013) essay on Jogendra Nath Mandal.

34 See Bose and Chakravarty (2012) and Sangita Gopal (2012) for a closer reading of contemporary Bengali films. Gopal discusses the global ambitions of Bengali cinema.

35 Here I am referring to the sculpted and digitally corrected bodies of Bollywood stars; e.g., the recreation of Shahrukh Khan's body in films like Om Shanti Om (2007) and Fan (2016).

\section{References}

Acland, Charles R. 2009. "Curtains, Carts and the Mobile Screen." Screen 50 (1): 148-166.

Bakhtin, Mikhail. 1984. Rabelais and His World. Bloomington: Indiana University Press.

Banerjee, Sumanta. 1989. "Marginalization of Women's Popular Culture in Nineteenth Century Bengal." In Recasting Women: Essays in Colonial History, edited by Kumkum Sangari and Sudesh Vaid, 127-179. New Delhi: Zubaan.

Behlil, Melis. 2005. "Ravenous Cinephiles." In Cinephilia: Movies, Love and Memory, edited by Marijke de Valck and Malte Hagener, 111-124. Amsterdam: Amsterdam University Press.

Bennett, Andy. 1999. "Subcultures or Neo-Tribes? Rethinking the Relationship between Youth, Style and Musical Taste." Sociology 33 (3): 599-617.

Bhattacharya, Birendra Kumar. 1985. West Bengal District Gazetteers. Puruliya: State Editor, West Bengal District Gazetteers.

Bhowmik, Kaushik. 2011. "The Persistence of Rajasthan in Indian Cinema: One Region, So Many Views." Journal of the Moving Image 10: 13-39.

Biswas, Moinak. 2000. "The Couple and Their Spaces: Harano Sur as Melodrama Now." In Making Meaning in Indian Cinema, edited by Ravi S. Vasudevan. New Delhi: Oxford University Press.

Bordwell, David, Janet Staiger, and Kristin Thompson. 1985. The Classical Hollywood Cinema, Film Style and Mode of Production to 1960. London: Routledge.

Bose, Brinda, and Prasanta Chakravarty. 2012. "Kolkata Turning: Contemporary Urban Bengali Cinema, Popular Cultures and the Politics of Change." Thesis Eleven 113 (1): 129-140.

Bourdieu, Pierre. 1984. Distinction: A Social Critique of the Judgement of Taste. Cambridge, MA: Harvard University Press.

Buckland, Warren (ed.). 2009. Puzzle Films: Complex Storytelling in Contemporary Cinema. West Sussex: Wiley-Blackwell.

Chakrabarty, Dipesh. 1992. "Postcoloniality and the Artifice of History: Who Speaks for 'Indian' Pasts?.” Representations (37): 1-26.

Chatterjee, Partha. 1997. Our Modernity. Rotterdam and Dakar: Sephis \& Codesria. 
Chen, Kuan-Hsing (ed.). 1998. Trajectories: Inter-Asia Cultural Studies. London and New York: Routledge.

Das, Arup Jyoti. 2009. Kamatapur and the Koch Rajbanshi Imagination. Guwahati: Montage Media.

Ganti, Tejswani. 2012. Producing Bollywood: Inside the Contemporary Hindi Film Industry. New York: Duke University Press.

Gopal, Sangita. 2011. Conjugations: Marriage and Form in New Bollywood Cinema. Chicago, IL: University of Chicago Press.

Gooptu, Sharmistha. 2010. Bengali Cinema: An Other Nation. New Delhi: Roli Books.

Hall, Stuart. 1980. "Cultural Studies: Two Paradigms." Media, Culture and Society 2 (1): $57-72$.

Hall, Stuart, and Paul Du Gay (eds.). 1996. Questions of Cultural Identity. London: Sage.

Hasan, Daisy. 2010. "Talking Back to Bollywood: Hindi Commercial Cinema in the NorthEast." In South Asian Media Cultures: Audiences, Representations, Contexts for Arguments on the Mediated Scene, edited by Shakuntala Banaji, 29-50. London and New York: Anthem Press.

Haynes, Jonathan (ed.) 2000. Nigerian Video Films. Ohio: Ohio University Press.

Horton, Andrew. 1991. Comedy/Cinema/Theory. Berkley, California and Los Angeles: University of California Press.

Hughes, Stephen. 2010. "What Is Tamil about Tamil Cinema?" South Asian Popular Culture 8 (3): 213-229.

Jameson, Fredric. 1993. “On 'Cultural Studies'.” Social Text (34): 17-52.

Kavoori, Anandam P., and Aswin Punathambekar (eds.). 2008. Global Bollywood. New Delhi: Oxford University Press.

Kim, Ji-hoon. 2009. "The Post-Medium Condition and the Explosion of Cinema." Screen 50 (1): 114-123.

Kracauer, Siefried. 1960. Theory of Film: The Redemption of Physical Reality. Princeton: Princeton University Press.

Kuotsu, Neikolie. 2013. "Architectures of Pirate Film Cultures: Encounters with Korean Wave in 'Northeast' India.” Inter-Asia Cultural Studies 14 (4): 579-599.

Larkin, Brian. 1997. "Indian Films and Nigerian Lovers: Media and the Creation of Parallel Modernities." Africa 67 (3): 406-440.

Marks, Laura U. 2000. The Skin of the Film: Intercultural Cinema, Embodiment, and the Senses. Durham and London: Duke University Press.

Mukherjee, Madhuja. 2011. "The Story of Arri: Imagined Landscapes, Emergent Technologies and Bengali Cinema." Journal of the Moving Image 10: 61-80.

Radhakrishnan, Ratheesh. 2015. "Thiruvithamkoor, Malabar, Kerala: Speculations on the Regions in 'Regional Cinema'." BioScope: South Asian Screen Studies 6 (2): 126-144.

Rodowick, David Norman. 2007. The Virtual Life of Film. Cambridge, MA: Harvard University Press.

Schleiter, Markus. 2014a. "VideoCD Crossovers: Cultural Practice, Ideas of Belonging, and Santali Popular Movies." Asian Ethnology 73 (1-2): 181-200.

Schleiter, Markus. 2014b. "India's 'Indigenous' Cinemas. A Village Video Night and the Future of Santal 'Traditional' Dances.” IIAS Newsletter (67): 10-11. www.iias.nl/sites/ default/files/IIAS_NL67_1011.pdf. Accessed on 29 January 2017.

Sen, Dwaipayan. 2013. “An Absent-Minded Casteism?” Seminar 645 (May). www.indiaseminar.com/2013/645/645_dwaipayan_sen.htm. Accessed on 23 February 2017. 
Spivak, Gayatri Chakravorty. 1988. "Can the Subaltern Speak?" In Marxism and the Interpretation of Culture, edited by C. Nelson and L. Grossberg, 271-313. Basingstoke: Macmillan Education.

Tripathy, Ratnakar. 2007. "Bhojpuri Cinema: Regional Resonances in the Hindi Heartland." South Asian Popular Culture 5(2): 145-165.

\section{Filmography}

Amjad, K. (n.d.). Le samla sadher tomato [Video]. India: Manbhum bhasha. Hujuri, S. (n.d.). Huchke niye puchke dili [Video]. India: Manbhum Bhasha. Khan, F.A. (2008). Supermen of Malegaon [Documentary]. India: Hindi. 


\title{
4 Films, flirts, and no dances
}

\section{A village video night and the circulation of popular Santali VCDs among Birhor people in India}

\author{
Markus Schleiter
}

\section{A village video night ${ }^{1}$}

In April 2011, during the hot season, there was not much daily labour available in agriculture or construction for members of the Birhor indigenous group in the village of Durdura in the Indian state of Odisha (see Figure 4.1). As a result, people had a fair amount of spare time. Now and then, as I sat on the terrace of the room where I was staying for a month, I saw small parties of village residents passing by, going out to seek entertainment. They would leave the village for a drama show, a village theatre competition, or a wedding, not to return until the next day. At other times, many of the 80 inhabitants of the Birhor tola ${ }^{2}$ simply started the day by drinking mahua: a fairly strong sweet distillate made from the flowers of the mahua tree.

That month in Durdura, my host Gobora repeatedly told me that a few young unmarried men from the village, including the son of his elder brother, Raja, had asked whether I might give them 300 rupees (approx. USD 4.50) to organise a video night for the village. During my previous stays in this village in the Mayurbhanj district of Odisha, I had almost always refused to spend money on watching films together, offering instead to sponsor beer at dance nights. Back then, I wanted to learn more about dances, which I also enjoyed participating in. This time, however, I was planning to research Santali films and had brought lots of VCDs with me - so I was very keen for the TV set to be arranged.

The next day, when Raja himself told me, "Everybody in our tola wants to watch a video, please provide the TV set", I readily agreed to make a contribution towards the video night. A local TV lender from the neighbouring village arrived with his two assistants in the afternoon of the same day. The three middle-aged men transported the TV on the back of a bicycle and also brought a VCD player and a small collection of VCDs. Within an hour they had set up the equipment at the crossroads in the centre of the subvillage, the place where dances were held. A few hours later, approximately two hundred viewers of all ages and genders from the Birhor tola and the nearby Santal tola had already gathered on mats and blankets in front of the screen. The video night commenced soon after sunset with a VCD of Santali music videos, after which three Santali or Odiya films were screened, each lasting at least two hours.

What impressed me most was to see how some of the scenes moved the audience. A deep silence reigned during those moments of delight, when everybody's 


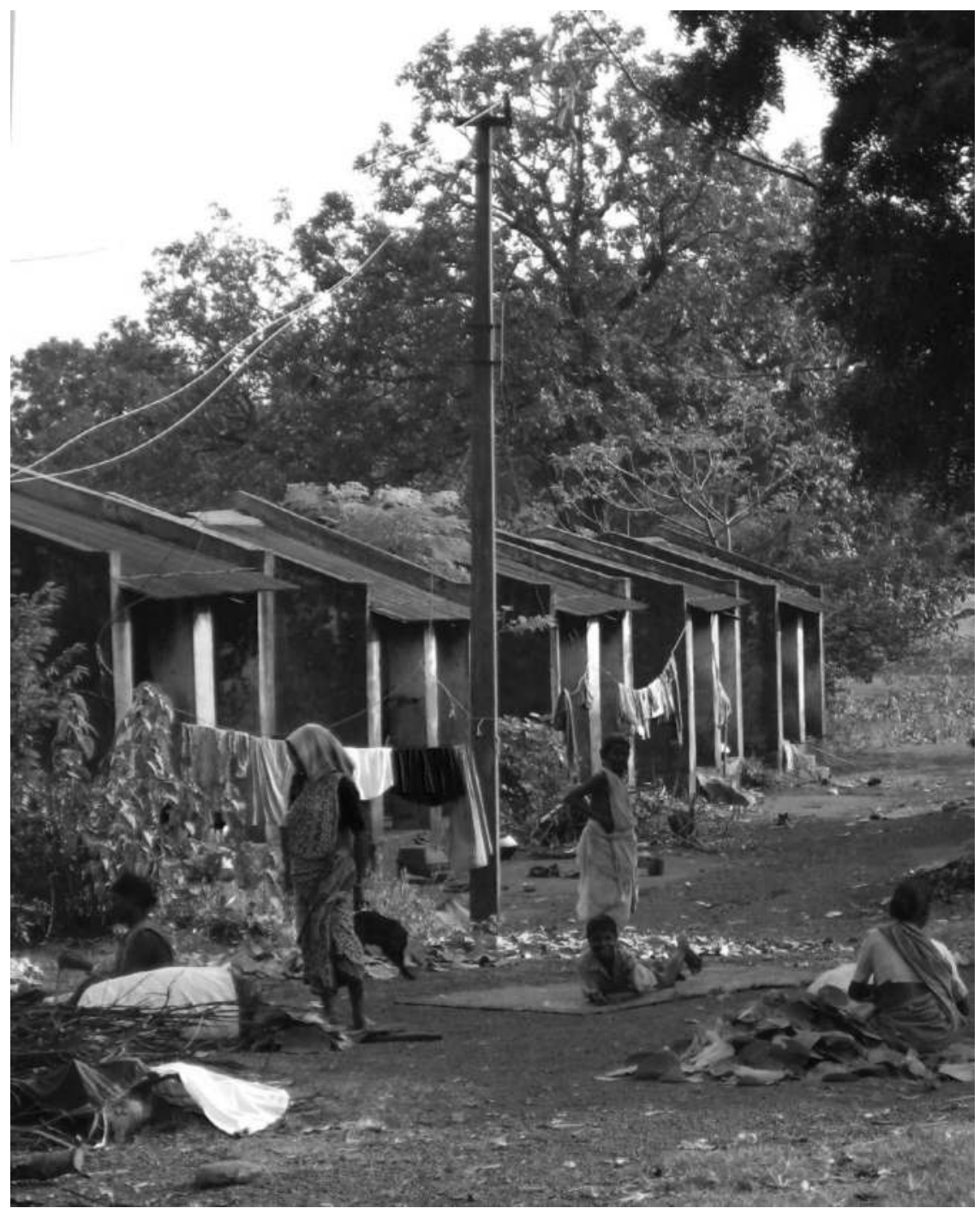

Figure 4.1 Birhor tola (subvillage) of Durdura, Mayurbhanj, Odisha in 2007

Source: Photograph by Markus Schleiter

gaze was fully concentrated on the screen. However, apart from the chance to watch Santali films, a video night might not seem like the most fascinating event for an anthropologist. People watched more or less silently, and those who expressed themselves out loud were strongly reprimanded. Hence, from my perspective, the screening became rather a long affair without much variation. I did my best to take part in my neighbours' occasional conversations, and also asked 


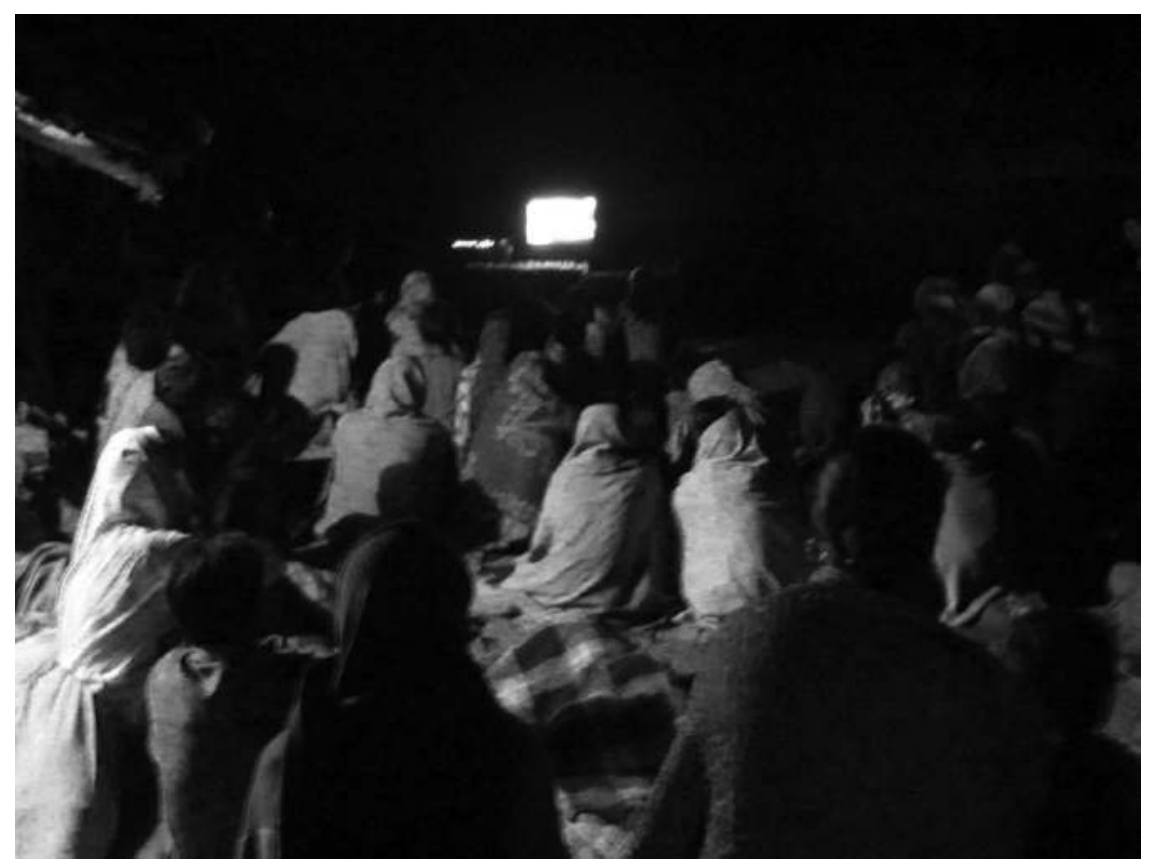

Figure 4.2 Video night at a family's courtyard in a tola with predominantly Santal residents, near to the Birhor tola, Durdura, 2007

Source: Photograph by Markus Schleiter

them about the films' stories. Now and then, I scrounged a bit of chewing tobacco. The song sequences were a welcome distraction. On the screen, a girl and six boys wearing jeans and sunglasses danced in the animated style that Bollywood's Salman had only managed in his younger days. A woman jokingly gave me a shove, and asked, “Are you drunk, or why aren't you talking to me anymore?" This was followed up the next morning, when she accused me, "Yesterday, you watched videos with me through the night. Now, you do not even look at me. At least you could offer me a glass of mahua."

As the night wore on, quite a large part of the audience, including my host Gobora, either went back to their homes or - wrapped in their blankets - drifted off to sleep on the spot. Nonetheless, the screening continued. Sometimes, when one VCD came to an end, the person who knew how to put in the next disc had to be woken up. As dawn broke, one last song compilation was watched and we were joined by some members of the village who had just woken up and come from their homes (for further ethnographic description of video nights, see Schleiter 2014a, 10-11).

In order to learn more about the villagers' tremendous interest in films, I conducted long interviews. On one of the first days of my stay, I spent an afternoon 
with an elderly couple in the nearby Santal tola. When the topic turned to VCDs, they immediately started to tell me about a video show that had been initiated by their neighbours a few days earlier in their shared courtyard, as part of the Chhatiar ceremony on the ninth day following their neighbours' baby's birth. The couple didn't just have positive things to say about films. The woman, in particular, started to complain about the video night, because it had denied her of an opportunity to dance. With everyone sitting in front of the TV, the video screening had made it impossible to dance Dong on that evening. Dong is a very popular type of dance that is only danced at a few particular ceremonies, such as weddings. Noticing my surprise at his wife's criticism of video shows, her husband offered a more reconciliatory position (see Figure 4.3$)^{\cdot 3}$

Dance will continue, it will never end. Some people may prefer video to dancing, that's up to them. Only the Birhor do mostly video shows. Now there is freedom: whatever you wish to do, you can do.

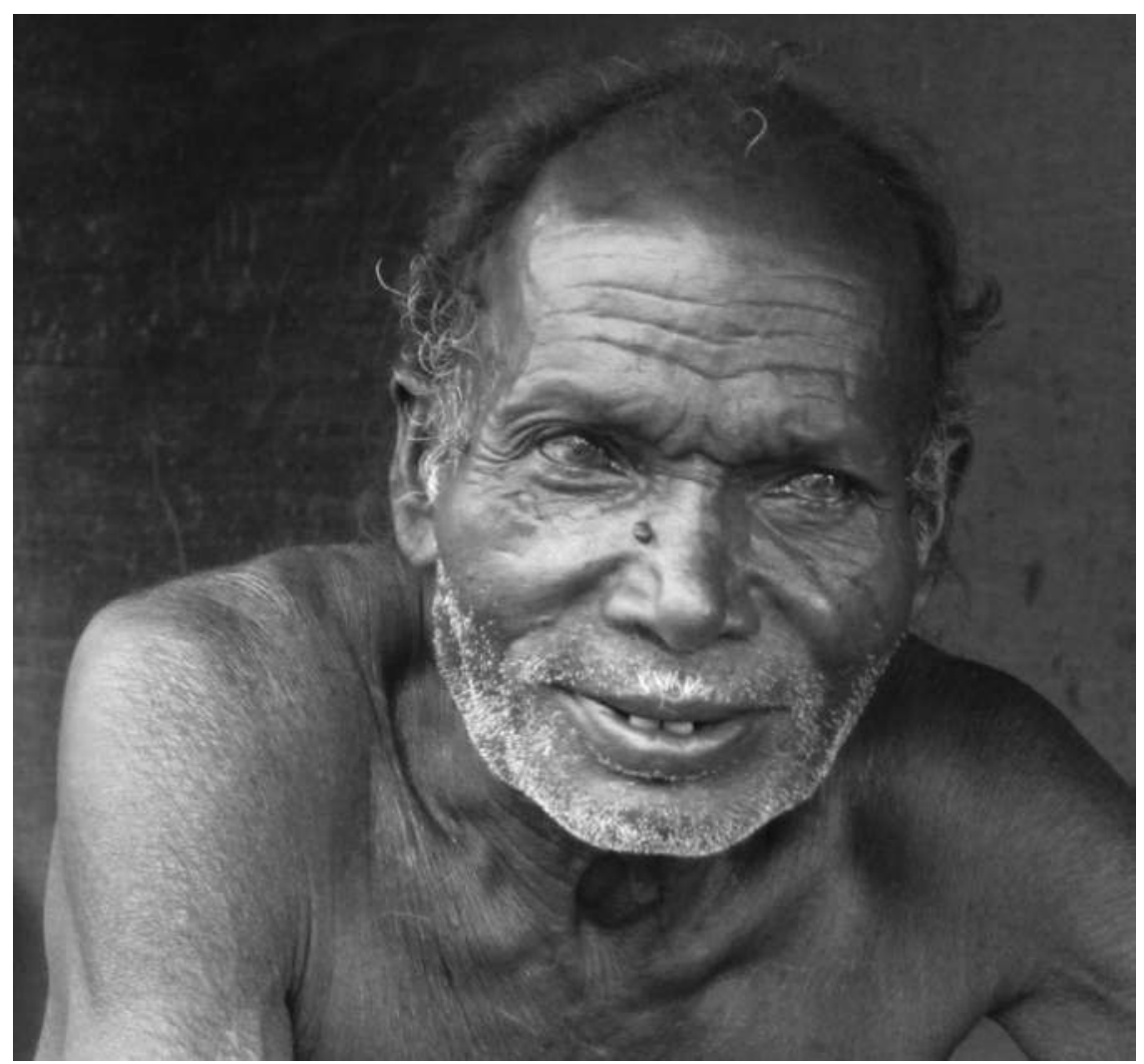

Figure 4.3 Chandra Tudu during the interview conducted in 2011

Source: Photograph by Markus Schleiter 
The man, almost 80 years old, took a deep drag on the cigarette I had given him, pausing to increase my curiosity before concluding his appraisal of these "modern" times:

Before, we had never seen tobacco, nor trousers, nor underwear. All these things have come, and now video is coming too.

(see Schleiter 2014a, 11, 2014b, 187)

$* * *$

Films and music videos in Santali - the Austro-Asiatic language of the Santal people, which has six million speakers - are popular indigenous media produced for rural people in the Indian states of Odisha, Jharkhand, and West Bengal. As well as members of the Santal indigenous group, ${ }^{4}$ many other communities with some knowledge of the Santali language such as the Munda, Ho, and Birhor are also fond of these movies. In 2017, an estimated 140 Santali films and 400 music video albums have been published as VCDs. In addition to distribution as VCDs, Santali films also reach their audiences in the form of cinema screenings, commercial village roadshows, YouTube videos, and digital files on the memory cards of mobile phones. Pirate copies comprise a significant share of VCD sales, and the majority of files are downloaded to mobiles. Since 2017, with the increasing affordability of $3 \mathrm{G}$ mobile internet in rural and urban areas of India thanks to extremely low-priced flat rates, streaming via YouTube looks set to replace VCDs as the preferred medium for accessing Santali songs and films - which is likely to result in a massive cut in revenues for their producers.

The dissemination of Santali films has emerged alongside an estimated one hundred regional film distribution networks that have grown within the past decade in South Asia, profoundly changing the media map and challenging the assumed predominance of Bollywood in the region (Hasan 2010; Wagner 2013; Schleiter 2014a, 2014b, 2017. See Jeffrey 2000; Hu 2005; Manuel 1993, 2012). These developments have been made possible by technological and economic factors such as the decrease in movie production costs due to the increased availability of consumer-priced digital camera technology adapted for professional shooting, as well as the easy accessibility of editing software on home computers. Authors have also claimed that the demand for and consequent proliferation of South Asian popular films has been intensified by their manifold references to 'modernity' and cinematic glamour. Cinema screenings are seen to offer a particularly appealing form of an extraordinary experience that lies beyond the realm of viewers' everyday culture - whether as a large event in a single-screen theatre or the trend-setting consumerism of the multiplex (Dickey 1993; Dwyer and Patel 2002; Srinivas 2002; Brosius 2005, 2010; Hughes 2010; Tripathy 2012; Hoek 2013; Pandian 2008, 2015).

However, as noted at the opening of this chapter, video nights in Durdura village in Odisha are not screened in a cinema but at the place in the village where dances and other community activities are held. This prompts the question of how 
video nights are embedded within the wider socio-cultural context in which the village is located. Counter to the view that technological and economic factors combined with the influx of modernity are the driving force behind the circulation of popular films in South Asia (Dickey 1993; Dwyer and Patel 2002; Pandian 2008; Hughes 2010), I propose that social and cultural factors from within a village provide the impetus for people to reach out to films. The commercially successful circulation of films and other cultural products thus becomes dependent on the capacity of the respective media to relate to everyday cultures and everyday life. Thus, I suggest that a significant aspect of media infrastructures is their "cultural margin". I use margin here analogously to its economic sense of a profit or price margin. Thus, the cultural margin of film circulation refers to the manifold interactions and cultural practices by which audiences/consumers actively engage with media and, consequentially, are just as much a part of media infrastructures as technological and economic factors are. Ultimately, recognising the definitive role of viewers and their culturally specific demands upon media enables me to offer a far more differentiated ethnography of village audiences than predominant representations in which they are reductively characterised as 'traditional' people - or, when they are granted a place within 'modernity' - as underprivileged mass consumers.

The idea that technological and economic developments underlie the circulation of mass media can be traced back to the critical thinking of the Frankfurt School. In a ground-breaking essay on the "culture industry" published nearly 70 years ago, Theodor W. Horkheimer and Max Adorno (2000 [1947]) put forward the idea that technological developments were enabling an economic elite to impose new mass media upon wider society. Since then, innumerable scholars and members of the public have joined the debate on whether and how the spread of mass media affects individuals and society, by turn heralding change, modernity, or the demise of social life as we know it (see McLuhan 1987; Horkheimer and Adorno 2000 [1947]; Ang 1985 [1982]; Mankekar 1999). More recently, the advent of globalisation theory, and particularly the notion of inexorable "global cultural flows", has instigated research in anthropology and media studies that focus on the localised appropriation of global signs (see Appadurai 1996; Kohl 2006). Interest in the influence of cultures and individuals upon media infrastructures themselves has been developing since the end of the past century, when new approaches in media anthropology began revealing the complex ways in which the circulation of regional media was developing in different directions to those of dominant global flows (see Ginsburg, Abu-Lughod and Larkin 2002). Brian Larkin, for example, described how Hausa youths' desire for an alternative modernity brought Bollywood to Nigeria (Larkin 1997; see Krings 2005). Further authors enquired into how regional social and cultural developments altered the spread and even introduction of new media (see Mehta 2008). In this context, technology and infrastructure were seen to be inseparable from culture, and researchers explored the ways in which media and their products were mediated as elements of cultural worlds (see Mazzarella 2004; Mukherjee 2011; Hoek 2013; Larkin 2013; Mankekar 2015; Röschenthaler and Schulz 2016; Udupa 2017). 
Building on these latter approaches, I will use my empirical findings to probe the extent to which an examination of cultural practices - patterns of interaction within the everyday culture of a setting - can enrich our understanding of the impact of media. Focusing on patterns of interaction, in particular, allows us to see individuals' articulations as a force that drives cultural change. According to Pierre Bourdieu (1987 [1980]), it is the expression of ideas and viewpoints within everyday interactions and negotiations that continuously constitutes and reiterates the 'culture' of a setting, while at the same time opening that 'culture' to potential change. Taking this further, William Mazzarella (2004; see also Sprenger 2006; Rao 2010; Bräuchler and Postill 2010; Hornbacher 2014) argues that mass media such as films become points of reference or "mirrors" in relation to which people confirm, negate, or rework ideas about culture - just as people reflect upon or mediate concepts of culture with reference to other media in the widest sense, such as rituals, interaction patterns, or travelling objects and ideas. Thus, discussing a film's content, for example, can inspire reflection upon one's own everyday culture, and may even incite desire for societal change. Less indirectly, discussions about conduct at events such as dances or video nights enable people to evaluate the current state of community life, expressing, for example, enthusiasm for new influences or nostalgia for the past.

The thoughts presented in this chapter are based on a one-month audience study in the Birhor tola of Durdura in April 2011, during which I built upon existing networks of acquaintances and findings from previous field stays in the same subvillage, which totalled 18 months over the past ten years. My language skills in Odiya, Birhor, and Santali were of help, along with the support of an Englishspeaking assistant of Santal origin for more complex conversations. I undertook participant observation focusing upon the cultural practices associated with films. I also conducted semi-structured interviews with film watchers in order to discover more about individual preferences with regard to Santali films and to complement my observations of everyday life. Furthermore, I had extensive discussions with people working in the Santali film industry and visited many of their workplaces, including recording studios in Cuttack and Baripada, film sets at various locations near Jamshedpur in Jharkhand, and distribution outlets in Kolkata.

It is worth noting at this point that the Birhor and Santal are two indigenous groups in India that have been portrayed in very different ways in ethnographic literature. To this day, the Birhor, with a current population of about 10,000, have been categorised as a "primordial" group that live as "hunters and gatherers" (see Dalton 1872; Roy 1978 [1925]; Adhikary 1984; Schleiter 2005; 2008; Fortier 2009; Nadal 2015). Not only have such classifications largely been abandoned within anthropology, criticised for implicitly portraying such groups as relicts of the past, but this one is inaccurate anyway. The Birhor's actual 'traditional' occupation is rope-making. The idea that the Birhor were "hunters and gatherers" was an erroneous interpretation of the fact that they lived in temporary settlements, in order to cope with fluctuating markets, and fabricated ropes from a fibre that they cut in the forest from the bauhinia creeper (Odiya: siali). The Santal, by contrast, are one of the largest indigenous groups in India and have generally been described 
as farmers noted for their skilled cultivation of barren lands (see Dalton 1872: 207-218). Furthermore, unlike Birhor people, researchers since colonial times have noted Santals' pride in their ethnic identity, as expressed in rituals, events, and everyday culture (Dalton 1872, 207-218; Archer 1974; Gautam 1977). What is more, many authors from the colonial era to recent times have noted that Santal people have always been open to (colonial) modernity (see Sherwill 1851; Archer 1974; Gautam 1977; Parkin 2000; Rycroft 2006; Carrin 2008, 2014; Choksi 2014; Schulte-Droesch 2014, 2018). Despite these apparent differences, however, most of the cultural factors described in the following that are relevant to my focus on film watching apply to both Birhor and Santal society. In most cases, therefore, I refer to both communities in the rest of this chapter.

\section{Filmmaker's choice}

"Villagers work hard, and afterwards they want to watch films to enjoy dream worlds, to feel like singing and dancing." That was how an assistant director working in the Santali film industry in Kolkata summarised rural Santal people's passion for popular films.

Baripada in Odisha, Jamshedpur in Jharkhand, and Asansol in West Bengal are the major production centres of the Santali film industry. The industry is, foremost, commercially driven, but movies are produced on extremely low budgets ranging from INR 150,000 to INR 400,000 per film (approx. USD 2,500 to USD 6,000). The only films to have budgets of INR 1,000,000 to INR 3,000,000 (approx. USD 15,000 to USD 45,000) are those destined for cinema release. Alongside travelling roadshows in villages, cinema is the most lucrative source of film financing. One consequence of the low budgets is a very tight shooting schedule. The production phase of an entire film is around 21 days, with two days at most to shoot a song. The distribution life cycle of a single Santali film is - as in other Indian cinema industries - maximised by successive releases. First, the film is advertised free of charge by trailers at the start of other VCDs produced by the same company. Next comes the release of a music video VCD featuring the film's songs, followed by cinema or roadshow screenings. After those screenings - sometimes even years later - the VCD of the full film is finally released. This means that songs are particularly important economically.

It is worth noting, as the assistant director's statement at the start of the paragraph might suggest, that in many cases those working for Santali film production companies are somewhat distanced from their rural target audiences. Many scripts are written by Santal writers, and the majority of film songs are composed and sung by Santal people. However, the producers, film directors, crews, and editors in this young industry often have an urban background, and some of them are not of Santal origin. Interestingly, the female lead roles in music videos are often performed by women from the wider population of the region. Given the meagre wages that low budgets impose, it is unsurprising that many people working in the industry are at the beginning of their careers and hope to use such movies to gain experience before ideally progressing to India's many bigger film industries. As a 


\section{Markus Schleiter}

result, contacts are maintained with other film industries, and it is common practice to copy or adapt both scripts and songs from films by other regional film productions.

The commercial basis of the industry, links to other film industries, and the idea that rural people seek unsophisticated entertainment (see Ganti 2002) may explain why most filmmakers choose to produce popular film narratives that follow the predominant narrative style of South Asian popular films (see Thomas 1985; Gopalan 2002; Morcom 2011; Basu 2011; Ganti 2012; Hoek 2013; Mahadevan and Jain 2017). Hence, a Santali film usually has a multi-narrative storyline with a love story running through the movie (see, for example, the big successes of the Santali film industry Chando Likhon [2003], Chorok Chikan [2005], or Achchha thik geya [2008]; see Figure 4.4 and Figure 4.5). A film will include four to five songs, which support the storyline and are presented in dance sequences. Most films also feature a social topic, such as the migration of Santals from villages to towns for labour. The main focus of the storyline, however, is on the male and female lead roles. The 'hero' is a morally upright character who protects the

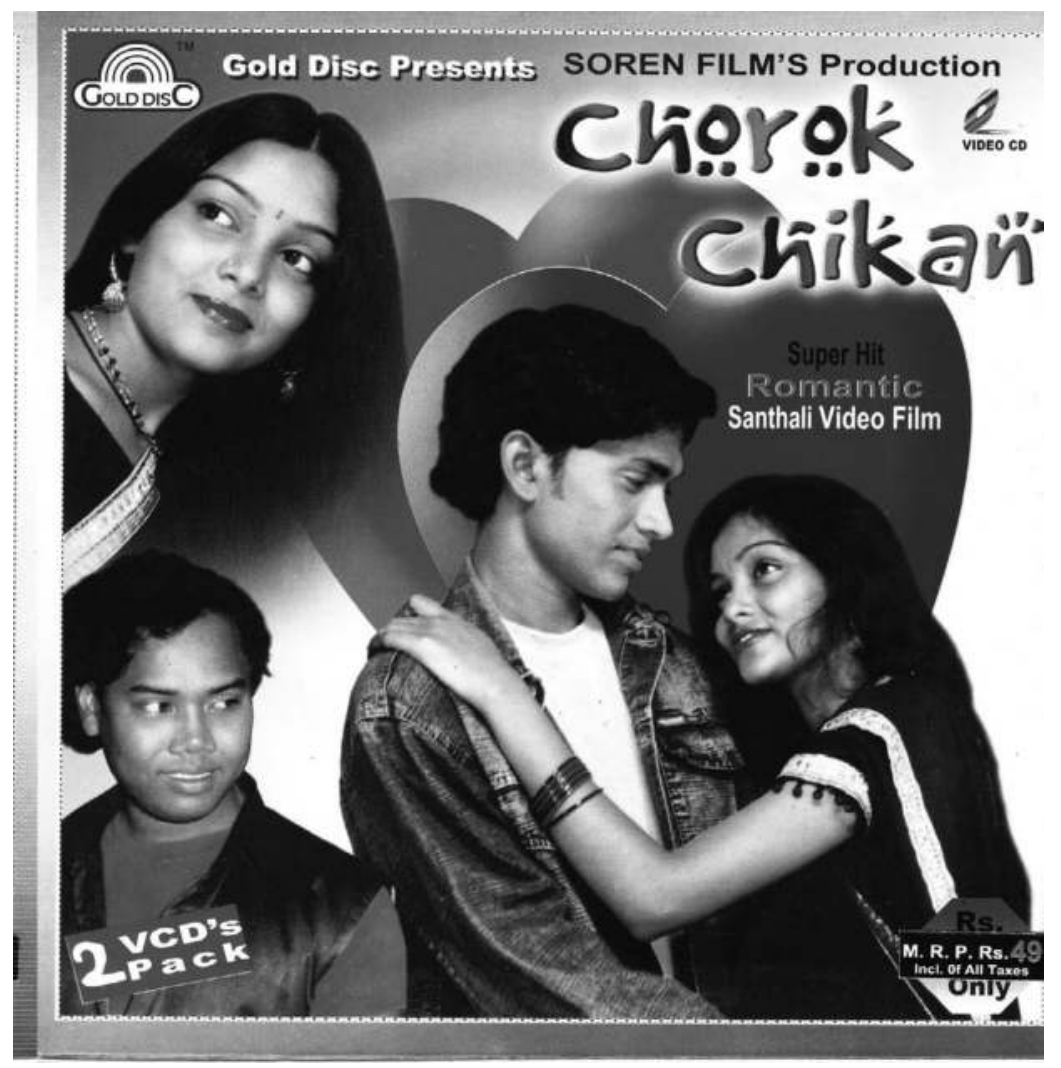

Figure 4.4 VCD cover of Santali film Chorok Chikan (2005) 


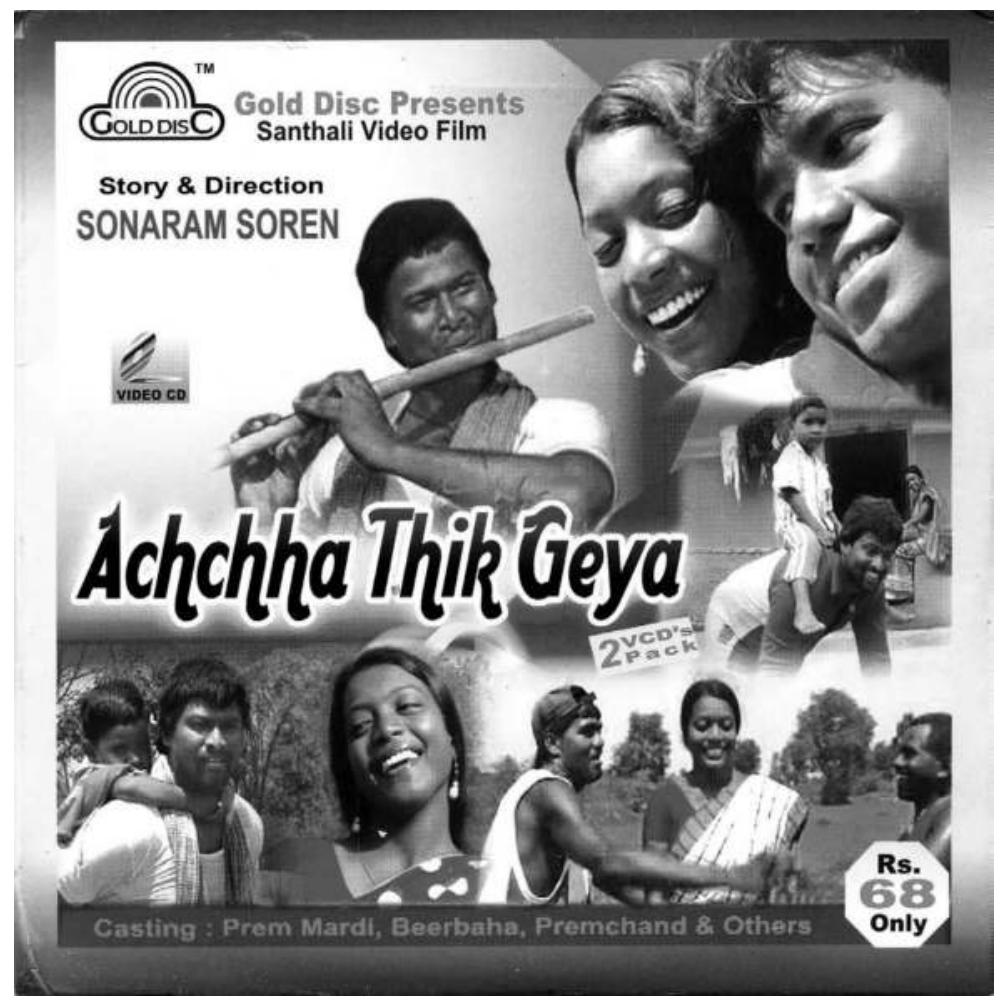

Figure 4.5 VCD cover of Santali film Achchha Thik Geya (2008)

'heroine'. Further typical characters are the hero's antagonist, the 'villain', and a comedian. The storyline thus resembles that of many Tamil or Telugu films as well as that of the predominant form of Hindi films from the 1950s to 1990s. It also reflects the viewing habits and expectations of village audiences accustomed to Odiya films as well as village theatre and drama shows.

\section{Love, sorrow, and revenge}

According to the film watchers I interviewed in the village of Durdura, star actors are not the main attraction of Santali films. Most actors were not even known by name, and judgement of a hero's role in a film was passed first and foremost in relation to his moral standing; dialogue and physical conduct came after. It was particularly the story (Hindi, Odiya: kahani, Santali, Birhor: kahni) that film watchers mentioned when asked what they enjoyed most in a film. Above all, people appreciated stories that unfold into twisted sub-plots to weave a web of interrelated problems. Such problems often arise out of the contradictory 
obligations of family, kin, and societal roles (an elder brother who has to care for his younger brother, for example) and are portrayed in different sections of the story that highlight the multiple roles played by a film's character. Many of my interviewees identified personally with the characters of films that featured topics and themes relating to major issues in their own lives (such as being an orphan, or fraternal conflicts that lead to the separation of a family).

Songs, portrayals of romance or suffering, action sequences, and endings in which revenge is achieved were further aspects cited as making a film particularly enjoyable to watch. The most popular love songs used beautiful allegories to express feelings and emotions in an indirect and thoughtfully elaborate way. The popularity of allegories is mirrored in their prevalence in folk songs. It is claimed that they are a part of Adivasi cultural traditions. As the basis of sad songs, allegories intensify the emotions evoked. Film watchers enjoy feeling sad and identifying with protagonists' sufferings (Odiya, Santali, Birhor: daya; Hindi: doya), which are an important aspect of many films. Finally, audiences enjoy action and particularly appreciate endings in which revenge is achieved; for example, when the villain is killed by the hero or heroine in a final fight, or the police arrive and take the villain to prison (see Gopalan 2002). Action scenes and revenge are enjoyed equally by men and women. Women told me that they appreciate seeing a good-looking, goodhearted male character successfully fighting to protect the heroine.

The fact that Odiya and Santali films were very popular in Durdura, while only a few individuals from the younger generation expressed an interest in Bollywood films, may be partly because many of the village's residents did not understand Hindi well enough to enjoy a Hindi movie. However, I see a clear connection between interviewees' lack of interest in Bollywood and their preferences for the kinds of narratives outlined above, which are a key element of most Santali productions. Some recent Bollywood productions have also successfully interwoven multiple narratives with social themes, for example, the 2011 box office success Singham by Rohit Shetty, or recent more realist Bollywood films set in small towns such as Mirza \& Juuliet (2017). Unlike Santali films, however, since the advent of Bollywood family drama in the 1990s, Hindi film narratives have until very recently predominantly focused on cinematic glamourisation (see Rajadhyaksha 2003; Dwyer and Pinto 2011), often at the cost of losing their former complexity, emphasis on social topics, and multi-narrative elaborateness. Such trends had not won favour among my interviewees in Durdura.

\section{Shared enjoyment}

When not watching films, residents of the Birhor tola like to spend evenings together dancing to drums, or simply singing, joking, and drinking together. Video nights like the one I attended are held at the place for dancing (Birhor, Santali: $a k h r a$ ) in the Birhor subvillage. At other times, screenings may be held in relation to family ceremonies in the nearby Santal subvillage, in which case they take place in the respective family's courtyard (see Figure 4.2). As mentioned by the elderly 
Santal woman cited in my introduction, such screenings sometimes replace the dances with which family ceremonies traditionally used to culminate (see Figure 4.6). Given the communal nature of film watching practices, I argue that video nights constitute one form of shared enjoyment (see Schleiter 2014a, 11, 2014b, 187-188).

In South Asia more generally, shared enjoyment serves to reinforce relationships (Hindi: rishta, Birhor, Santali sagai) that are considered intrinsically valuable (see Vatuk 1992; Grover 2009; Hardenberg 2009). Such relationships are generally expressed via specific forms of address and the behavioural codes of family

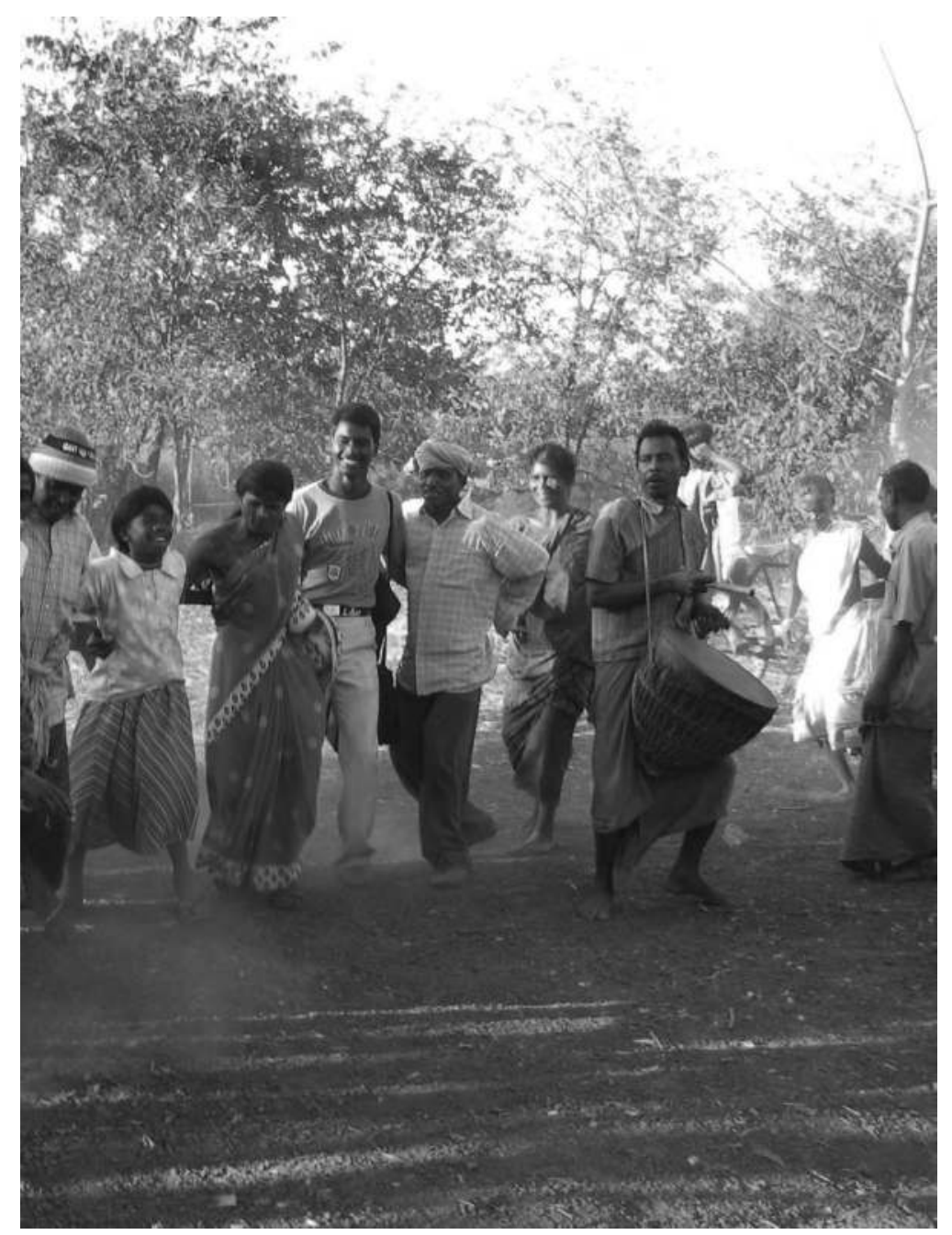

Figure 4.6 Birhor and Santal people dancing together at a village dance in Durdura, 2007 Source: Photograph by Markus Schleiter 
relationships, kinship relationships, or relationships through marriage. For example, a man addresses his elder brother's wife as hilli (Birhor, Santali) and is allowed to make rude jokes with her. This relationship is based upon kin terms, but relationships need not always be based on actual kin ties: people who know each other well can also choose to develop a kin relationship. Relationships can be said to be equally significant in Birhor and Santal society, and people attach great importance to building new relationships with people they are close to. Some kin relationships in Birhor or Santal society are accompanied by practices that differ from their counterparts in other South Asian communities. For example, it is customary for a man and his younger brother's wife to avoid one other, such as by not sitting on the same bench (see Roy 1978 [1925]; Rao 2005; Schleiter 2008).

Thus, one virtue of watching films together at a video night is the creation of an occasion for shared enjoyment with persons related to oneself, thereby reconfirming the bonds of those relationships. For the younger members of the audience, relationships with peers are the most important, hence they sit together. But kin of the same generation and parents with young children also spend such nights together. Furthermore, the emotions that a film's narrative evokes can intensify the pleasure derived from simply enjoying spending time together, while at the same time the pleasure of being together adds value to the film itself. Given the emotional importance of relationships and of spending time with relatives, watching films at a video night gains cultural significance and can offer enjoyment far beyond that which is intrinsic to watching a film (see Schleiter 2014a, 11; 2014b, 187-188).

\section{Organising a video show}

The fact that films are watched through the night is a crucial feature. Watching spectacles at night is a practice associated with the village theatre and drama shows popular in the area, which the audience - who may come from faraway villages manage to reach before sunset on foot and cannot then leave before the light of dawn. This similarity lends video nights an event-like atmosphere, provided that a substantial audience gathers, in which case the status of the subvillage where they take place is validated.

A video night, as an event, draws attention to those who put it on. Usually, about ten young men from the subvillage are the driving force behind the organisation, with some - like Raja in the earlier description - taking particularly prominent roles. Their engagement enables the young men to showcase their abilities as successful organisers, as well as to demonstrate their commitment to the village and society at large. Many people are involved in the various organisational tasks such as collecting donations for hiring the TV, arranging a date with the TV lender, obtaining consensus within the subvillage, and attracting a wider audience. Furthermore, should any difficulties arise during the course of this organisation, more people may need to be found to support the show; for example, somebody who knows the TV lender and can therefore ensure that the TV set actually arrives. As a consequence, arranging an event is also a chance for a young person to prove 
(and show others) that they can rely on an extended network of relationships to persons of importance, thereby increasing their own status. Furthermore, arranging video nights puts a person in a position to invite people to the event, which is a way to reciprocate help received in the past or future.

\section{Romance}

But there is far more to a video night than simply the showcasing of status or the reiteration of kinship bonds. In Santal and Birhor society, young men and women 'traditionally' attend village dances in order to get to know each other and to flirt. Video nights, held at the same locations and time of day as dance nights, implicitly offer the unspoken attraction of a chance for romance. As well as a space for real dating, moreover, films and video nights bring their own atmosphere of the illicit with the love stories displayed on screen (see Schleiter 2014a, 10-11, 2014b, 187-188).

Dating is relatively common among unmarried young people in Birhor or Santal society, and many premarital relationships are conducted discreetly. Nonetheless, as in South Asia at large, in Santal and Birhor society 'love' partnerships are regarded as illicit, and marriages arranged by parents are considered preferable to love marriages (see Dwyer 2000; Brosius 2005; Orsini 2006; Mody 2008). Nonetheless, a large number of cultural practices specific to Birhor and Santal culture facilitate romance and flirting, including the aforementioned 'traditional' dances and contemporary video nights. A further example is that in Birhor and Santal society, young people who are getting to know each other often strategically invoke a sangart relationship (see Skoda 2009). A sangart is a sibling of one's sibling's spouse, with whom one may joke and talk very openly. It is an open secret that a pre-marital love partnership can easily develop from such a relationship. Finally, Santals and Birhors recognise various alternative marriage forms such as angir bapla ("marriage by elopement"), which allow a couple who love each other to demand that their parents and society consent to their marriage (see Gautam 1977, 121-123; Mody 2008).

One rather clandestine but significant aspect of the organisation of a video night is that the films to be screened are usually requested of the event's organisers by unmarried women in the context of courting. While a man can show his commitment to the woman he admires by arranging for the screening of her chosen film, a young woman who makes such a request also opens up a range of possibilities. Firstly, she can indirectly hint that she is interested in a man, attracting his attention. The suggestive atmosphere is heightened by the illicit tone of love stories; by requesting a particular film she may deliberately transgress what is appropriate behaviour towards a man. Furthermore, she might choose a film that features emotions and romantic topics - such as elopement - ideas she may want to raise indirectly. Although unmarried young men and women generally sit separately during video nights, any courting couples within the audience try not to sit too far from one another, so that they can exchange glances and share the experience of the films, which evoke joint emotions and offer inspiration for later conversations in 
which viewpoints and feelings can be indirectly discussed in relation to the fictional narratives.

\section{Video nights as a "cultural margin" that drives film circulation}

Going against the view that the circulation of media is primarily determined by technological and economic factors, I have been trying to highlight why and how the residents of Durdura village in Odisha engage with Santali films, and how that influences the way that VCDs are screened in the village. The preceding paragraphs have shown that audiences' motivations to attend video nights extend far beyond the simple consumption of films. Thus, as I have outlined, several modes of interaction associated with video nights are significant in their own right. Village residents participate in video nights in order to enjoy spending time with kin and/ or peers. Additionally, the motivations underlying many of the interactions involved in arranging a video night can be quite unrelated to the idea of watching films, for example, when someone helps to organise a video night in order to assert their status within the village or to win the attention of someone they are attracted to. Hence, in order to understand how video nights can facilitate diverse interactions that are important to audiences, it is necessary to examine how such events are embedded within the wider everyday culture. Similarities to established events like village dances and drama shows, for example, imbue video nights with the weight of culturally significant occasions.

Taking these observations into account, I conclude that the screening of any particular film is the result of a combination of the practices outlined above. Consequently, I argue that films are ultimately brought to the village by the cultural practices of village residents, while the interactions involved in the video nights as events constitute cultural practices in themselves (see Bourdieu 1987 [1980]; Mazzarella 2004; Rao 2010; Ram 2011; Larkin 2013).

It is in this sense that I refer to the ways in which everyday cultural interactions influence the circulation of media as the "cultural margin" of a media infrastructure - an aspect which, in my view, has been overlooked by authors who have focused on technological and economic factors in relation to media circulation. I suggest that the concept of a "cultural margin", comprising multiple networks of everyday media practices and significations that bring media to a specific place, is an important aspect of media infrastructures in general.

The content and narratives chosen by makers of Santali films, however, are not irrelevant to my argument. On the contrary, they offer the attractions of imaginative stories, beautiful allegories, and emotional invocations of love and sorrow. The "cultural margin" influences which films and film narratives are selected for screening on a particular occasion. Viewers choose films for a video night according to specific criteria when they seek out, for example, a story that can raise certain issues relating to love affairs in an indirect way. Further, as video nights have become established practice, they have taken on the significance of community-specific events with their own characteristic meanings. Consequently, film 
narratives are perceived by the audience in the context of a video night and become inseparable from the off-screen dramas that take place during the event. The enjoyable context of the video night thus enhances not only village audiences' appreciation of specific films and their narratives, but also their stance towards video itself as a medium.

\section{Representing South Asian cinema audiences in academic literature}

Considered alongside other research on South Asian cinema audiences, my analysis of a video night and the factors that constitute a "cultural margin" takes quite an unusual approach. In many South Asian cinema studies, the most significant trope is not the specific cultural context of the research setting, but rather 'modernity' - either on the screen or as a context within which films are watched. This focus has led to a clear division within academia: in work on 'lower class' audiences, film viewers are seen to watch films in ordinary places, seeking escape from their ordinary lives via the film's invocation of 'modernity' (Dickey 1993; Pandian 2008). Elite and middle class audiences, by contrast, apparently consume films in places associated with 'modernity', such as extravagant multiplexes (Brosius 2010; Hughes 2010).

The most influential work to highlight 'modernity' as a feature of popular films' visual language is that of Rachel Dwyer and Divia Patel (2002) on 1990s Bollywood films. They identify the films' allusions to a hybrid identity as an important element in the propagation of a pan-national Indianness. For example, a movie might depict a modern, globally successful Indian who remains 'traditional' at heart. In a similar way, but focusing on indigenous film circulation, Daisy Hasan (2010) sees the incorporation of Bollywood stylistic elements in Khasi movies as part of a move to build a 'modern' identity for the indigenous Khasi community in Meghalaya. Also addressing the 'modernity' of cinema audiences, Stephen Hughes has shown that the very first screenings of moving images in South India at the end of the 19th century took place in locations associated with newly introduced European forms of entertainment (Hughes 2010). Furthermore, studies on new forms of film viewing in multiplexes have concluded that such consumption practices allow people to assert themselves as members of a trendy, wealthy section of society (Liechty 2003; Brosius 2010; Donner 2011).

One example of a detailed study on lower class audiences is that by Sara Dickey (1993), in which she identifies that, for the urban poor, cinema offers an escape from real life. In this way, she explains how the elaborate mise-en-scène of 1980s Tamil cinema provides fodder for fantasies of luxuries unattainable in viewers' real lives (Dickey 1995: 147-153). However, Dickey (1993) complicates this focus on aspirations to modernity by drawing attention to cinematic portrayals that set working poor with good values against morally corrupt rich persons. In her view, such content enables film viewers to identify positively with lower class backgrounds. She also confirms, substantiated by audience interviews, that Tamil films relate to viewers' specific worries in connection to kin, family, and peer 
relationships. Consequently, film watchers - like those I questioned in relation to Santali films - identify strongly with film narratives that deal with complex moral obligations arising from family roles or peer relationships. Anand Pandian (2008) adds to the debate on South Asian film audiences with his in-depth research on rural film viewing, based upon a village study conducted in Tamil Nadu. In striking opposition to the media practices that I have observed, his informants emphasised that they lived in an "age of cinema" (Pandian 2008: 125). While Tamil films watched in the village often depict 'traditional' rural life on screen, at the same time they include modern ideas and concepts, such as positive evaluations of love marriages as opposed to 'traditional' arranged ones. According to the villagers' comments as well as Pandian's own observations, the everyday culture of the village had clearly been shaped by an influx of quotes from films. As such, he concludes that films are an influential medium that villagers refer to in debates on morality, which can ultimately spark unforeseeable changes in the social life of a village.

Lakshmi Srinivas' (2002) analysis offers a ground-breaking, detailed description of the cultural practices typically associated with cinema-going in India. These include the physical segregation of cinema audiences according to status, which is clearly signified by the different styles of seating, from rows in the main hall up to the luxury places in the balcony. Another feature is the constant shouting, talking, and gossiping of audiences during screenings. Also common among cinemagoers in India is the practice of 'repeat viewing', whereby people watch a single movie several times. The obligatory intermission in the middle of a movie provides an extra break for socialising during a cinema visit. In line with my observations in Durdura, Srinivas argues that audiences' main motivation for attending cinema screenings is to enjoy a group experience in the form of a family or peer group outing (Srinivas 2002, 160). Stressing the importance of the social experience, she explicitly counters the persisting presumption that ordinary people primarily go to the cinema in order to enter a fantasy world and forget about everyday miseries. Her emphasis on the social aspects of cinema, together with her critique of the generalisations often made about why lower class audiences watch films, has been an inspiration for my own study. One significant difference, however, remains. Srinivas sees cinema as a specific social experience that takes place in a more or less uniform way across India. I hope to make clear, by contrast, that the practice of watching films occurs within specific settings in which distinctive cultural contexts strongly influence viewers' media preferences and their particular practices of film consumption. Nonetheless, some of the practices I have described do relate to concepts that apply across a wider range of South Asian contexts; for example, the importance of social networks and kin relationships. In her analysis, Srinivas does not relate her observations regarding practices of film watching to specific aspects of everyday culture in South Asia.

As this brief summary of research on South Asian cinema audiences has shown, identifying audiences' aspirations to 'modernity' has been central to many analyses of why people watch films. This upholds academic endeavours to counter the notion that 'pre-modern' cultures persist in South Asia: an idea that influenced 
much research from colonial times onwards and underlies the archetypal image of unchanging 'traditional' Indian village life (see Fuller 1989; Das 1993). In my view, however, the way certain writers portray rural and/or lower class audiences' engagement with films in relation to 'modernity' brings its own pitfalls. By identifying an opposition between 'modern' film worlds and their supposedly nonmodern viewers, researchers often imply that trendy films cater to the fantasies of lower class urban and rural audiences who otherwise inhabit a "miserable", "moral", and/or declining "traditional" reality. I see such representations of film audiences as yet another way of reinforcing the perception that the 'natural' sphere of the urban poor and residents of villages lies somewhere beyond the realm of 'modernity' - thereby perpetuating an opposition that continues to exclude underprivileged urban and rural Others.

Instead, by focusing on the "cultural margin" as a force that influences media circulation, I have shown that in Durdura it is not aspirations to 'modernity' but rather commitment to their own cultural practices and values that motivate people to watch films. My assertion that culturally specific ideas are extremely important to audiences could be criticised for implying a representation and generalisation of certain audiences as culturally distinct communities. But, by shifting the focus away from film viewers' modernity - or non-modernity - I believe that my approach makes it possible to represent village audiences without relegating them to a sphere that appears anachronistic to 'modernity' and present-day media circulation. By examining the "cultural margin" of video nights, I have shown that residents of villages and non-metropolitan localities are not merely passive in their media consumption, but rather actively testify to the long-standing, ongoing entanglement of rural life with entertainment media such as VCDs, and that individual people with their specific everyday practices are ultimately what enable media infrastructures to evolve and flourish.

\section{Outlook}

All that remains is to relate the earlier deliberations on VCD infrastructures and the representation of rural film audiences one more time to the specific setting of the village Durdura. Let me again reiterate that just because films have been coming to the village for almost a decade - while other forms of entertainment such as drinking mahua or 'traditional' dancing have continued to be enjoyed - does not mean that 'timeless' village culture has been corrupted by the arrival of cinematic 'modernity'. Rather, a "cultural margin" located in the midst of everyday life and appearing in the form of a multiplicity of practices is what has brought a TV set and VCDs to the village time after time. Thus, in opposition to claims that the intrusion of films is altering village life in South Asia, and that 'modern' cinematic worlds serve primarily as an escape from (or even loss of) everyday realities, this chapter has offered two main significant insights: firstly, the question of whether video is a 'modern' medium does not appear to be of interest to the film watchers concerned, nor does 'modernity' emerge as a relevant category in representing what characterises Birhor people as a film audience. Secondly, in the settlement of 
Durdura, watching films in the form of a video night has simply become one more way for the audience to enjoy Birhor and/or Santal everyday culture at an event that can serve to strengthen social relationships, uphold the tradition of dance nights as communal enjoyment, or offer opportunities for courting.

\section{Notes}

1 This research was initiated thanks to the inspiring suggestions of Lotte Hoek, Karl-Heinz Kohl, and Willem van Schendel, as well as the generous help of Shyamranjen Hembram, Chandrama Murmu, Gobora Murmu, Lugu Murmu, Soben Murmu, Sundarmani Murmu, and Sukurmuni Murmu in the village of Durdura. I express my gratitude for the valuable advice I have received from Kishore K. Basa, Chandan Baskey, Deepak Beshra, Birbaha Hansdah, Pip Hare, Holger Jebens, Anne Koth, Erik de Maaker, Anika Meier, Francesca Merlan, Prasanna Kumar Nayak, Manon Osseweijer, and Pratima Soren. Draft versions of this chapter have been presented at De Nieuwe Oogst in Rotterdam, the Institutes of Ethnology at Heidelberg and Munich universities, the Institute de Sciences Sociales and Humaines in Paris, and the Jawaharlal Nehru University at Delhi, and I am grateful for the invitations and the very inspiring discussions with Lotte Hoek, Annette Hornbacher, Frank Heidemann, Raphaël Rousseleau, and Madhuja Mukherjee. I wish to express my gratitude to the DFG (German Research Foundation) for generously funding the research from 2011 to 2014, and to the Frobenius-Institute at the Goethe University, Frankfurt am Main, for hosting the project and providing support.

2 Birhor/Santali term meaning a subsection of a village.

3 See Schleiter $(2014 b, 187)$ for a further and more comprehensive description of the interview.

4 These groups are administratively classified as "Scheduled Tribes". This official term, however, has (since colonial times) contributed to such communities' stigmatisation by implying a position of marginality within the state. By contrast, the terms "Adivasi" (Hindi: first people) or "indigenous people" are seen to assert a positive self-identification. Nonetheless, the latter terms may still serve to evoke ambivalent connotations regarding the people referred to and do not necessarily reflect a factual "firstness" of such groups in a particular area (see Rousseleau 2009; Shah 2010; Schleiter and de Maaker 2010; van Schendel 2011; Kohl 2012; de Maaker 2013; Heidemann and Wolf 2014).

\section{References}

Adhikary, Ashim Kumar. 1984. Society and World View of the Birhor: A Nomadic Hunting and Gathering Community of Orissa. Calcutta: Anthropological Survey of India.

Ang, Ien. 1985 [1982]. Watching Dallas: Soap Opera and the Melodramatic Imagination. London: Methuen.

Appadurai, Arjun. 1996. Modernity at Large: Cultural Dimensions of Globalization. Minneapolis: University of Minnesota Press.

Archer, William George. 1974. The Hill of Flutes: Life, Love and Poetry in Tribal India: A Portrait of the Santals. London: Allen and Unwin.

Basu, Helene. 2011. "Darstellungen der Psychatrie in indischen Filmen." Zeitschrift für Ethnologie 136 (1): 69-92.

Bourdieu, Pierre. 1987 [1980]. Sozialer Sinn: Kritik der theoretischen Vernunft. Frankfurt am Main: Suhrkamp.

Bräuchler, Birgit, and John Postill. 2010. Theorising Media and Practice. Oxford: Berghahn Books. 
Brosius, Christiane. 2005. "The Scattered Homelands of the Migrant: Bollyworld through the Diasporic Lens.” In Bollyworld: Popular Indian Cinema through a Transnational Lens. edited by Raminder Kaur and Ajay J. Sinha, 207-238. New Delhi: Sage.

Brosius, Christiane. 2010. India's Middle Class: New Forms of Urban Leisure, Consumption and Prosperity. London: Routledge.

Carrin, Marine. 2008. "Santal Autonomy as a Social Ecology." In People of the Jangal: Reformulating Identities and Adaptations in Crisis. edited by Marin Carrin and Harald Tambs-Lyche, 143-172. New Delhi: Manohar.

Carrin, Marine. 2014. "The Santal as an Intellectual." In The Politics of Ethnicity in India, Nepal and China. edited by Marine Carrin, Pralay Kanungo and Gérard Toffin, 77-100. Primus Books: Delhi.

Choksi, Nishaant. 2014. "Scripting Autonomy: Script, Code, and Performance among Santali Speakers in Eastern India." PhD Thesis, University of Michigan. https://deepblue.lib. umich.edu/handle/2027.42/110402. Accessed on 5 March 2016.

Dalton, Edward Tuite. 1872. Descriptive Ethnology of Bengal. Calcutta: Office of the Superintendent of Government Printing.

Das, Veena. 1993. "Der anthropologische Diskurs über Indien: Die Vernunft und ihr Anderes." In Kultur, soziale Praxis und Text: Die Krise der ethnographischen Repräsentation, edited by Eberhard Berg and Martin Fuchs, 402-425. Frankfurt am Main: Suhrkamp.

de Maaker, Erik. 2013. "Performing the Garo Nation? Garo Wangala Dancing between Faith and Folklore." Asian Ethnology 72 (2): 221-239.

Dickey, Sara. 1993. Cinema and the Urban Poor in South India. Cambridge: Cambridge University Press.

Dickey, Sara. 1995. "Consuming Utopia: Film Watching in Tamil Nadu.” In Consuming Modernity: Public Culture in a South Asian World, edited by Carol Breckenridge and Arjun Appadurai, 131-156. Minneapolis: University of Minnesota Press.

Donner, Henrike. 2011. "Gendered Bodies, Domestic Work and Perfect Families: New Regimes of Gender and Food in Bengali Middle-Class Lifestyles." In Being MiddleClass in India: A Way of Life, edited by Henrike Donner, 47-72. London and New York: Routledge.

Dwyer, Rachel. 2000. All You Want Is Money, All You Need Is Love: Sexuality and Romance in Modern India. London: Cassell.

Dwyer, Rachel, and Divia Patel. 2002. Cinema India: The Visual Culture of Hindi Film. London: Reaktion Books.

Dwyer, Rachel, and Jerry Pinto. 2011. Beyond the Boundaries of Bollywood: The Many Forms of Hindi Cinema. New Delhi: Oxford University Press.

Fortier, Jana. 2009. "The Ethnography of South Asian Foragers." Annual Reviews in Anthropology 38: 99-114.

Fuller, Chris. 1989. "Misconceiving the Grain Heap: A Critique of the Concept of the Indian Jajmani System." In Money and the Morality of Exchange, edited by Jonathan Parry and Maurice Bloch, 33-63. Cambridge: Cambridge University Press.

Ganti, Tejaswini. 2002. “'And Yet My Heart Is still Indian': The Bombay Film Industry and the (H)Indianization of Hollywood." In Media Worlds: Anthropology on New Terrain, edited by Faye D. Ginsburg, Lila Abu-Lughod and Brian Larkin, 281-300. Berkeley: University of California Press.

Ganti, Tejaswini. 2012. Producing Bollywood: Inside the Contemporary Hindi film Industry. Durham: Duke University Press.

Gautam, Mohan K. 1977. In Search of Identity: A Case of the Santal of Northern India. Leiden: Rijksmuseum voor Volkenkunde. 
Ginsburg, Faye D., Lila Abu-Lughod, and Brian Larkin. 2002. Media Worlds: Anthropology on New Terrain. Berkeley: University of California Press.

Gopalan, Lalitha. 2002. Cinema of Interruptions: Action Genres in Contemporary Indian Cinema. London: British Film Institute.

Grover, Shalini. 2009. "Lived Experiences: Marriage, Notions of Love, and Kinship Support amongst Poor Women in Delhi." Contributions to Indian Sociology 43 (1): 1-33.

Hardenberg, Roland. 2009. "Categories of Relatedness: Rituals as a Form of Classification in a Central Indian Society." Contributions to Indian Sociology 43 (1): 61-87.

Hasan, Daisy. 2010. "Talking Back to 'Bollywood': Hindi Commercial Cinema in NorthEast India." In South Asian Media Cultures: Audiences, Representations, Contexts, edited by Shakuntala Banaji, 29-50. London: Anthem Press.

Heidemann, Frank, and Richard K. Wolf. 2014. "Guest Editors' Introduction: Indigeneity, Performance and the State in South Asia and Beyond." Asian Ethnology 73 (1-2): 1-18.

Hoek, Lotte. 2013. Cut-Pieces: Celluloid Obscenity and Popular Cinema in Bangladesh. New York: Columbia University Press.

Horkheimer, Max, and Theodor W. Adorno. 2000 [1947]. "Kulturindustrie: Aufklärung als Massenbetrug." In Dialektik der Aufklärung: Philosophische Fragmente, edited by Max Horkheimer and Theodor W. Adorno, 146-204. Frankfurt am Main: Fischer.

Hornbacher, Annette. 2014. "Machtvolle Zeichen: Schrift als medium esoterischer Spekulation, ritueller Wirkung und religiöser Kanonisierung." In Erscheinungsformen und Handhabungen heiliger Schriften, edited by Joachin F. Quack and Daniela Luft, 311-336. Berlin: De Gruyter.

Hu, Kelly. 2005. “Techno-Orientalization: The Asian VCD Experience.” In Asian Media Studies: Politics of Subjectivities, edited by John Nguyet Erni and Siew Keng Chua, 55-73. Malden: Blackwell.

Hughes, Stephen Putnam. 2010. "When Film Came to Madras." Bioscope South Asian Screen Studies 1 (2): 147-168.

Jeffrey, Robin. 2000. India's Newspaper Revolution: Capitalism, Politics and the IndianLanguage Press, 1977-99. London: Hurst.

Kohl, Karl-Heinz. 2006. "Coming Back to One's Own: What Happens to Tradition in NeoTraditional Movements?.” In The Making and Unmaking of Differences: Anthropological, Sociological and Philosophical Perspectives, edited by Richard Rottenburg, Burkhard Schnepel and Shingo Shimada, 97-106. Bielefeld: Transcript.

Kohl, Karl-Heinz. 2012. "Die Rechte der Indigenen: Seltsames in der Deklaration der Vereinten Nationen.” Merkur 758 (7): 581-591.

Krings, Matthias. 2005. "Bollywood/Kallywood: Mediale Transfers und populäre Videos in Nigeria." In Popularisierung und Popularität, edited by Gereon Blaseio, 303-317. Cologne: DuMont Literatur und Kunst Verlag.

Larkin, Brian. 1997. "Indian Films and Nigerian Lovers: Media and the Creation of Parallel Modernities." Africa Journal of the International African Institute 67 (3): 406-440.

Larkin, Brian. 2013. "The Politics and Poetics of Infrastructure." Annual Review of Anthropology 42: 327-343.

Liechty, Mark. 2003. Suitably Modern: Making Middle-Class Culture in a New Consumer Society. Princeton: Princeton University Press.

Mahadevan, Sudhir, and Anuja Jain. 2017. "The Poetics of Indian Cinema: Introduction." Screen 58 (1): 59-63.

Mankekar, Purmina. 1999. Screening Culture, Viewing Politics: An Ethnography of Television, Womanhood, and Nation in Postcolonial India. Durham and London: Duke University Press. 
Mankekar, Purmina. 2015. Unsettling India: Affect, Temporality, Transnationality. Durham: Duke University Press.

Manuel, Peter L. 1993. Cassette Culture: Popular Music and Technology in North India. Chicago: University of Chicago Press.

Manuel, Peter L. 2012. "Popular Music as Popular Expression in North India and the Bhojpuri Region, from Cassette Culture to VCD Culture." South Asian Popular Culture 10 (3): 223-236.

Mazzarella, William. 2004. "Culture, Globalization, Mediation.” Annual Review of Anthropology 33: 345-367.

McLuhan, Marshall. 1987. Understanding Media: The Extensions of Man. London: Routledge and Kegan.

Mehta, Nalin. 2008. Television in India: Satellites, Politics and Cultural Change. New York: Routledge.

Mody, Perveez. 2008. The Intimate State: Love-Marriage and the Law in Delhi. London: Routledge.

Morcom, Anna. 2011. "Film Songs and the Cultural Synergies of Bollywood in and Beyond South Asia." In Beyond the Boundaries of Bollywood: The Many Forms of Hindi Cinema, edited by Rachel Dwyer and Jerry Pinto, page numbers. New Delhi: Oxford University Press.

Mukherjee, Madhuja. 2011. "Cinemas Outside Texts: The Mise-En-Scene in Publicity Images and Theaters of Spectacle." South Asian Popular Culture 9 (3): 327-334.

Nadal, Deborah. 2015. "Housing Ancestors: The Reorganization of Living Spaces among the Birhor of Jharkhand and Odisha." Internationales Asienforum 46 (1/2): 39-58.

Orsini, Francesca. 2006. Love in South Asia: A Cultural History. Cambridge: Cambridge University Press.

Pandian, Anand. 2008. "Cinema in the Countryside: Popular Tamil Film and the Remaking of Rural Life." In Tamil Cinema: The Cultural Politics of India's Other Film Industry, edited by Selvaraj Velayutham, 124-138. Abingdon: Routledge.

Pandian, Anand. 2015. Reel World: An Anthropology of Creation. Durham: Duke University Press.

Parkin, Robert. 2000. “Proving 'Indigeneity', Exploiting Modernity: Modalities of Identity Construction in Middle India." Anthropos 95: 49-63.

Rajadhyaksha, Ashish. 2003. "The 'Bollywoodization' of Indian Cinema: Cultural Nationalism in a Global Arena." Inter-Asia Cultural Studies 4 (1): 25-39.

Ram, Kalpana. 2011. "Being 'Rasikas': The Affective Pleasures of Music and Dance Spectatorship and Nationhood in Indian Middle-Class Modernity." Journal of the Royal Anthropological Institute 17: 159-175.

Rao, Nitya. 2005. "Kinship Matters: Women's Land Claims in the Santal Parganas, Jharkhand." Journal of the Royal Anthropological Institute (N.S.) 11: 725-746.

Rao, Ursula. 2010. News as Culture: Journalistic Practices and the Remaking of Indian Leadership Traditions. New York: Berghahn Books.

Röschenthaler, Ute, and Dorothea Schulz (eds.). 2016. Cultural Entrepreneurship in Africa. New York: Routledge.

Rousseleau, Raphael. 2009. "The King's Elder Brother: Forest King and 'Political Imagination' in Southern Orissa." Rivista Di Studi Sudasiatici 4: 39-62.

Roy, Sarat Chandra. 1978 [1925]. The Birhors: A Little-known Jungle Tribe of Chota Nagpur. Ranchi: Man in India Office.

Rycroft, Daniel J. 2006. "Santalism: Reconfiguring 'the Santal' in Indian Art and Politics." The Indian Historical Review 33 (1): 150-174. 
Schleiter, Markus. 2005. "Enduring Endangerments: Constructing the Birhor 'Tribe', Development Officers and Anthropologists from Early Twentieth-Century Colonial India to the Present." In Perspectives on Endangerment, edited by Graham Huggan and Stephan Klasen, 71-82. Leipzig: Olms.

Schleiter, Markus. 2008. Die Birhor: Ethnographie und die Folgen: Ein indischer "Stamm" im Spiegel kolonialer und postkolonialer Beschreibungen. Heidelberg: Draupadi.

Schleiter, Markus. 2014a. "India's Indigenous Cinemas: A Village Video Night and the Future of Santal 'Traditional' Dances.” IIAS Newsletter 67: 10-11.

Schleiter, Markus. 2014b. "VideoCD Crossovers: Cultural Practice, Ideas of Belonging and Santali Popular Films.” Asian Ethnology 73 (1-2): 181-200.

Schleiter, Markus. 2017. "Der Pop-Hit Injurious to Health: Musikschaffende, indigene Traditionen und kulturelle Praktiken des Flirtens am Beispiel eines Santali-Videosongs aus Indien.” In Soziale Ästhetik, Atmosphäre, Medialität: Beiträge aus der Ethnologie, edited by Philipp Zehmisch, Ursula Münster, Jens Zickgraf and Claudia Lang, 161-174. Münster: LIT.

Schleiter, Markus, and Erik de Maaker. 2010. "Indigeneity as a Cultural Practice: 'Tribe' and the State in India." IIAS Newsletter 53: 16-17.

Schulte-Droesch, Lea. 2014. "Fertility or Indigeneity? Two Versions of Santal Flower Festival." Asian Ethnology 73 (1-2): 181-200.

Schulte-Droesch, Lea. 2018. Making Place Through Ritual: Land, Environment and Region among the Santal of Central India. Berlin: De Gruyter.

Shah, Alpa. 2010. In the Shadows of the State: Indigenous Politics, Environmentalism, and Insurgency in Jharkhand, India. Durham, NC: Duke University Press.

Sherwill, Walter S. 1851. "Notes upon a Tour through the Rajmahal Hills." Journal of the Asiatic Society of Bengal 20: 544-606.

Skoda, Uwe. 2009. "Delayed Sister Exchange in Middle India: A Preliminary Sketch of Co-Sister-in-Law and Granddaughter Marriage among the Aghriaa and Neighbouring Communities." In Contemporary Society: Tribal Studies: Structure and Exchange in Tribal India and Beyond, edited by Georg Pfeffer and Deepak Kumar Behera, 83-118. New Delhi: Concept Publishing Company.

Sprenger, Guido. 2006. "The End of Rituals: A Dialogue between Theory and Ethnography in Laos." Paideuma 52: 51-72.

Srinivas, Lakshmi. 2002. "The Active Audience: Spectatorship, Social Relations and the Experience of Cinema in India." Media Culture Society 24 (2): 155-173.

Thomas, Rosie. 1985. "Indian Cinema: Pleasures and Popularity." Screen 26 (3-4): 116-130.

Tripathy, Ratnakar. 2012. "Music Mania in Small-Town Bihar: Emergence of Vernacular Identities." Economic \& Political Weekly 47 (22): 58-66.

van Schendel, Willem. 2011. "The Danger of Belonging: Tribes, Indigenous Peoples and Homelands in South Asia." In The Politics of Belonging: Becoming Adivasi, edited by Daniel J. Rycroft and Sangeeta Dasgupta, 19-43. London: Routledge.

Vatuk, Sylvia. 1992. "Forms of Address in North India: The Family Domain." In Concepts of Person, edited by Akos Ostor, Lina Fruzetti and Steve Barnett, 56-98. New Delhi: Oxford University Press.

Udupa, Sahana. 2017. "Gaali Cultures: The Politics of Abusive Exchange on Social Media." New Media \& Society 20 (4): 1506-1522.

Wagner, Anja. 2013. The Gaddi Beyond Pastoralism: Making Place in the Indian Himalayas. New York: Berghahn Books. 


\section{Filmography}

Achchha Thik Geya. 2008. dir. Sonaram Soren; writ. Sonaram Soren; with Birbaha Hansda, Prem Mardi. Kolkata: Gold Disc.

Chando Likhon. 2003. dir. Dasrath Hansda; writ. Sonot Sano Murmu, Dasrath Hansda; with Fulmani Besra, Prem Mardi. Kolkata: Choice.

Chorok Chikan. 2005. dir. Somra Soren, Chandra Mohan Hembram; writ. Somra Soren, Chandra Mohan Hembram; with Pinky Hansda, Ravi Hansda. Kolkata: Gold Disc.

Mirza \& Juuliet. 2017. dir. Rajesh Ram Singh, writ. Shanti Bhushan; with Pia Bajbai, Darshan Kumar. Mumbai: Shemaroo Entertainment.

Singham. 2011. dir. Rohit Shetty, writ. Sajid Samji, Farhad Samji; with Ajay Devgan, Kajal Aggarwal. Mumbai: Reliance Entertainment. 


\title{
5 The diffused substance of Bhojpuri indigeneity
}

\author{
Akshaya Kumar
}

One after another, the people I talked to all across the Bhojpuri-speaking region told me that Bhojpuri cinema was a product of "vikshipt mansikta" ("a rotten mentality"). They also assured me that Bhojpuri is "the sweetest language in the world" and Bhojpuri culture is a repository of moral values, politeness and respect for others. There was no space in this refined Bhojpuri culture to accommodate the sort of cinema that was being sold in its name. The implication, therefore, was that the essence of Bhojpuri culture and that of its contemporary cinema were irreconcilable. Indeed, all those who responded thus belonged to the educated middle classes, and their suspicion of the working classes who indulged in Bhojpuri cinema was not limited to the realm of cinema. All the musicians, singers or actors I spoke to tried to distance themselves from the bulk of Bhojpuri popular media. What might appropriately represent the Bhojpuri 'essence' is thus deeply contested. This chapter tries to show that it is the apparatus of distribution, by which media commodities are made available to a vast community, which often ends up triumphing over other logics of claiming the 'true' essence of Bhojpuri indigeneity.

This chapter builds upon fieldwork conducted intermittently over four years in Delhi, Mumbai and the Bhojpuri-speaking western districts of Bihar. Following Peter Manuel (1993, 2012), who has shown in great detail the cultural impact of the arrival of the audio cassette and later video compact discs (VCDs), this chapter addresses the subject not merely of what the Bhojpuri media represent, but also of why they do so. Manuel highlighted the extraordinary impact of 'cassette culture', which led the centralised film music economy to gradually surrender a vast territory to decentralised vernacular music production. As well as extending the understanding offered by Manuel, I also wish to point out ways in which Bhojpuri media production, distribution and exhibition may be somewhat distinct from the films and music videos produced in its neighbouring language industries. At the same time, I must also ask, what are the defining features of Bhojpuri media? Does the emergence of large-scale Bhojpuri media production mean an expansion of the media production space, or does it entail a triumph of vernacular media over the 'national' media within the Bhojpuri-speaking region?

The centrality of distribution is predicated upon the fact that the mainstream film industries across India have long been firmly in the grip of the distributors. The 
emergence of alternative claims to indigeneity via vernacular media industries have then appeared from outside this established distribution infrastructure. Technology has played a key role in leading this shift. Audio cassettes and VCDs, as well as cable and satellite television, have altered the Indian media landscape beyond recognition (see Manuel 2014; see also Athique 2012). The history of indigenous cultural production, however, begins with audio cassettes becoming a prized domestic or community possession. Piracy, too, by radically challenging the means of distribution, is driving a commercial reconfiguration of the media industries, and has now made the internet a key distribution site (Manuel 2014). On which side of these axes of configuration does the Bhojpuri media industry locate itself and why? If distribution has been revolutionised by technology, and consumption by existing fault lines within social hierarchies, what impels Bhojpuri media production?

At the heart of my analysis are the competing claims to the substance of Bhojpuri indigeneity. To begin with, however, let me position myself with respect to the debate on the term 'indigeneity'. Karlsson (2003), commenting on critiques associated with the term's historical trajectory, argues that persisting to use it does not mean straightforwardly reiterating its historico-political orientation. Wolf (2014: 61) stresses that

the question of what constitutes indigeneity in any part of the world is entangled with issues of who has the right to define and apply the term. To anthropologists, indigeneity is entangled with a technical notion of tribe and a concomitant set of social, political, and cultural structures. To those outside the academy, indigeneity conjures up a range of images associated with a community's long-standing habitation in a place. To the state, indigenous groups are potent symbols of history and place that resonate internationally. Communities themselves vie for recognition as indigenes in the larger political sphere, as well as in small-scale local interactions.

In agreement with both Karlsson and Wolf, the vantage point from which I investigate claims to indigeneity is also a contingent one. Even though Bhojpuri media audiences cannot be termed 'tribal' or adivasi, I explore the roles of audiovisual media and performance in shaping ideas of indigeneity, as mobilised by Bhojpuri media. I deploy a very broad definition of indigeneity congruous with the idea that "the indigenous peoples are non-dominant people with a culture different from that of the majority" (Karlsson and Subba 2006, 6). The claim to indigeneity made by emphasising Bhojpuriness in media-based narratives has only appeared since the advent of heavy migration to other parts of India where Bhojpuri speakers are in the minority. Most usefully for our purpose, Berger $(2014,19)$ distinguishes between "three types of indigeneity: (1) local practices asserting and reproducing an indigenous status, indigenous indigeneity; (2) the ascription of an indigenous status, ascribed indigeneity; and (3) the political claim of an indigenous status, claimed indigeneity".

If we were to use these types as a grid to aid understanding, the case of Bhojpuri indigeneity resonates best with claimed indigeneity, making its political claims 
through the figure of the male star. Except that this Bhojpuri indigeneity does not seek approval from any bureaucratic authority. Instead, it seeks approval from the Bhojpuri-speaking erstwhile audience of Hindi cinema, to rehabilitate its own essence within a displaced sub-region. In other words, Bhojpuri cinema's claim to indigeneity aspires to locate, in aural, visual and performative idioms, the unstable territoriality of the Bhojpuri essence, scattered as it is across the map of labour migration and the subaltern fringes of metropolises.

While I prefer the term 'vernacular', as I have discussed in elaborate detail elsewhere (Kumar 2015, 28-29), this volume maps an indigenous moment that the emergence of Bhojpuri media partially resonates with. As I have pointed out above, the case for indigeneity in Bhojpuri cinema is deeply contested. And I leave it to other scholars in this volume to argue the case for indigeneity created by other media industries representing other indigenous people of India. The shared ground for us, then, is the moment around the mid-2000s when music videos and narrative cinema in various vernacular languages and dialects began to emerge across northern India. While films have been made in Bhojpuri since 1963, the reason why substantial film production has been sustained since 2004, alongside the massive production of music videos, is the technological infrastructure via which the indigenous media content emerged. Therefore, while I do not claim that Bhojpuri media represents an indigenous culture, I acknowledge that it has much in common with other media industries representing indigenous communities.

At the same time, we must situate the Bhojpuri media industry within the complex landscape of South Asian media enterprises, as this volume tries to do. While the Bhojpuri media industry, like any other, facilitates the accumulation of capital, it simultaneously facilitates a process by which accumulated economic capital can be used to generate and reinforce other varieties of surplus. I will discuss this process in detail later, in relation to my fieldwork. The crucial task here is to broaden our understanding of capital itself. When we take into account not only economic capital, but also various hues of what could be called social capital, in the media industries we may have an instrument of not so much capital generation as the conversion of one form of capital into another. On the one hand, this aspiration to translate authority within the social order into an authoritative presence on the media screen drives the indigenous media industries further; on the other hand, the banality of such screen appearances shapes the hyper-energetic cultural universe. It is on this plane of media activity that perceptions of and claims to indigeneity are contested and reconfigured.

\section{Historicising the contemporary}

The indigenous media industries, located as they are within the history of media enterprise, are constitutive of a broadly contiguous geography of low-budget media production. When vernacular music erupted across North India with the spread of audio cassettes - a phenomenon that Peter Manuel (1993) called "cassette culture"- Bhojpuri inhabited a shared terrain with Khari Boli, Awadhi, Maithili, Braj, Haryanvi and other vernacular languages. Various 'folk' musical 
forms - such as qawwali, ghazal, birha, rasiya, kajri and chaiti - flourished in a market saturated with such media content. The production centre for much of this new musical output was Delhi. Gradually, however, the music industry was also decentralised. Bhojpuri, officially the mother tongue of the highest percentage of Hindi speakers, clearly held a numerical advantage over other smaller industries that could not scale up to the same extent. Bhojpuri music videos grew immensely popular in this period, and instead of remaining restricted to the 'folk' genre, found a new vitality with the emergence of song-and-dance routines. In such videos, the male star would lead a bunch of young men as they danced together to woo the female lead. While I have discussed this shift and its consequences in great detail elsewhere (Kumar 2016a), one landmark instance of the new kind of Bhojpuri music video was Manoj Tiwari's enormously popular Bagalwali jaan mareli ("The girl in my neighbourhood bowls me over").

Also, due to a very significant Bhojpuri-speaking working class population already migrating to metropolitan centres, it was the language itself that distinctly encouraged the narratives of cultural indigeneity and a desirable, if often antagonistic, modernity. Here, 'modern' is not a reference to historical modernity; instead it refers to the markers of a performative modernity, with immense local significance. The dialectics of rural and urban, subaltern and elite, native and foreign anchor the narrative trajectory of Bhojpuri media. On a sustained basis, the masculine is encoded as rural, subaltern and indigenous to the culture, while the feminine is configured as urban and foreign. There is thus a distinctly gendered vocabulary in this media content. Such tendencies became increasingly pronounced as VCDs appeared and the moving images increased the materiality - or literally, visibility - of Bhojpuri narrative content. If audio cassettes had opened up the field of self-projection through voice, the VCDs enabled the projection of singer-performers in an audiovisual format. As the music video developed into narrative forms, particularly of a romantic orientation, it enabled singer-performers to present themselves as stars in the making. The shift from audio to audiovisual music production gradually sidelined singers who could not feature in their videos themselves. The dominance of song-and-dance routines in the music videos and the rise of aspirations to stardom expressed in such music videos were synchronous. The music videos allowed male singers to style themselves as desirable commodities among an existing fan base already dancing to their tunes. Romancing a desirable female figure while leading one's fan base became the prototypical music video form, which hinged crucially on codes of performative stardom (see Rawlley 2007 for more on Bhojpuri music economy; see also Tripathy 2012).

At the level of technology, VCDs provided cheaper access to video just as MP3s had for audio content, though the discs have lately been superseded by Chinese and other cheap mobile phones with a huge storage capacity. Manuel $(2012,226)$ distinguishes the VCD format thus:

a particularly distinctive feature of VCDs is that despite being a modern digital technology, they are common primarily in the developing world, and especially in association with lower-class genres within those countries. 
(Due to the ease with which VCDs can be copied, their adoption in the developed West and Japan was actively suppressed by entertainment corporations in the 1990s, during which period the DVD format became more firmly entrenched.)

While the music video format per se may not be new, VCD technology has served to stimulate music video production among genres that were never previously marketed in such fashion, including Nigerian jùjú, Andean chicha, Thai-Malay shadow puppetry, and Cuban timba.

A music video production company, as Manuel notes, "might consist of no more than a producer with a mobile phone, who contracts performers, rents studios, and orders mass duplication of discs, colourful paper labels, and the like" (ibid., 227). While that may be somewhat rare, with decent investment in a performance space, offices, and filming and editing equipment, production companies operate in strong networks often exchanging and outsourcing personnel and expertise. Indeed, I visited one floor of a busy media market in Patna, which hosted at least two production companies. In the studio, I found just two young men playing carrom, who showed me the rooms where recording takes place. They explained that they also shoot outdoors when needed and send the edited videos to Delhi, where the discs are cut and then sent for censor clearance and distribution. But, of course, music videos are not all that they record. Video production has indeed become a very significant enterprise, on the strength of which a range of commodities have arrived on the media market. For example, wedding videos - a videographed and stylishly edited compilation of the various rituals, events and participants at a wedding, often packaged with some pre- and post-wedding events - are particularly exciting mutations of music videos and home videos, lavishly animated to blend the rituals with the more aspirational components. The recording studio is a space where such practices and skills come together and enrich one another. The music video and narrative cinema economies feed off, and feed into, such practices of blending the experimental and quirky with the wider world of television and the advertisement-centric media universe.

As a narrative extension of the flourishing music video economy, the film industry has gradually realised its potential. During the late 1990s and early 2000s, the recently launched music channels (MTV and V) showcased a variety of IndiPop music - a hybrid of Western pop and Hindi film music, featuring Hindi lyrics interspersed with English phrases, and a rather unsubtle mimicry of Western fashion. A significant percentage of the music videos were not merely song-and-dance routines, but were also narratively driven. It can be argued that most of them were also hybrids of Bollywood romances and youth-specific fashion, designed for portable technology. While the videos provided a capsule experience of romantic Hindi films, the Bhojpuri media industry, like many others, simultaneously charted an opposing trajectory. The music video had been a thriving form in Bhojpuri media; from 2004 onwards, there was a big boom in films that extended the music videos narratively, drawing upon the older Hindi film form of epic melodramas driven by the centrality of family and honour and the tropes of memory, sacrifice 
and justice. Gentrification of both the content and the sites of showings played a vital role in the emergence of the new film form. Hindi cinema strategically moved away from wider geographies and began to focus entirely on metropolitan Indians and the diaspora. Several scholars, particularly Athique and Hill (2010) and Ganti (2012), have detailed this process of gentrification. Schleiter (2014), studying Santali films, also highlights the narrative and corporeal identification that low-budget indigenous films offer, as opposed to the gentrified Bollywood fare. I have also discussed elsewhere how these shifts led first to the emergence of Bhojpuri cinema in rundown single-screen cinemas (Kumar 2016a), and later to the emergence of 'small-town' multiplex films in Hindi (Kumar 2013). The resultant antagonism between the Hindi and Bhojpuri film industries, therefore, has led to assessments such as that by Ghosh (2005, see also 2010) who described Bhojpuri cinema as the revenge of the mofussil. ${ }^{1}$

In order to understand this better, closer attention must be paid to the exhibition circuit. For highly populated regions of eastern Uttar Pradesh and western Bihar where Bhojpuri is the native language - the screen density is rather poor. On top of that, they generally suffer from the absence of a female audience because most cinemas are seen as indecent places for women to visit. This has, on one hand, kept ticket prices extremely low, and on the other, left the cinemas neglected in terms of infrastructure. Broken seats, power cuts, extremely poor projection, out-of-order ventilation in terrible heat, blocked or non-functioning toilets and spit-stained walls and floors - put together, these factors do not call to mind a middle class evening out, and cinemas can barely compete with home video equipment: large television screens and cheap DVD players. Indeed, a few young women I spoke to in Patna and Siwan confessed to never having visited a cinema before the arrival of a multiplex in Patna. While Hindi films still meant a lot to them, Bhojpuri ones did not. This was particularly interesting in the case of a Siwan-based family in which the father was not only a stage actor but had also acted in a few Bhojpuri films, yet never took his family out to the cinema in town.

In this above-mentioned ecology of the exhibition sector, cinemas were already marked as dubious sites, an exclusively male sphere. When Bhojpuri films started playing in towns across the region, they often took over from new Hindi releases that would have otherwise played there. Also, it is because the cinemas and the incoming films were both marked as indecent that the fit between the two worked out to their advantage. Women very rarely visit such cinemas, and if they do, always prefer a balcony seat. Hindi films, on the other hand, continue to be seen as superior - having an altogether different "standard", as one respondent after another told me. In fact, Bhojpuri films and their entire ecology - the people who watch them, the cinemas where they are screened, the markets where Bhojpuri media is bought and sold, and the language itself - remain an object of embarrassment for the middle classes. A very high percentage of middle class people I spoke to not only across Bihar, but also in Delhi and Mumbai, spoke of Bhojpuri media in derogatory terms. In other words, it was always the other classes who seemed to have an affinity for them, be they the poor, the villagers, the Biharis, the illiterates, the rickshaw-wallahs, the labourers, or whoever. The popularity of the 
Bhojpuri media was always something of a mystery to the middle classes, which could only be due to its otherness. Explanations might be based on viewers' physical exhaustion after daily wage labour, or addiction, or illiteracy, but would always conclude with a speculative assessment of "those who have little to do with us".

\section{Prescriptive vulgarity}

"For years, we have shown them films like $A r t h{ }^{2}$ and they suffered sitting on the front benches. Now they are showing us these films", a friend's brother from Bhagalpur in Bihar said to me in a telephone conversation. Us and them were neatly laid out categories in this perspective, which not only arranged them in a revenge narrative, but also essentialised preferences towards class identities (see Kumar 2014). There is little basis to support such a viewpoint, even if it continues to retain a lot of traction. Like much of Indian society, the Bhojpuri-speaking region is deeply stratified, and large numbers of people do not feel tied down by the burden of Bhojpuri media's representativity. They buy the VCDs and DVDs, visit cinemas and turn out in huge numbers when one of the Bhojpuri singers turns up in their town or city. The working class population, engaged in daily wage labour, constitutes a different audience from the middle classes, who negotiate public space far more cautiously. Indeed, it can be surmised that the two are identifiable in terms of caste as well (based on my modest observations instead of any specific set of data): the migrant working classes that flock to Bhojpuri cinemas appear to be predominately lower caste.

However, Bhojpuri cinema audiences are gradually decreasing in size, as most of my respondents told me, and as I also witnessed through my participant observation. Yet those who consume Bhojpuri films and music on portable media formats have become more numerous; in fact, the popularity of such products has spread to exceed the traditional Bhojpuri-speaking region by far. Stage shows often draw a turnout of several thousand people in remote villages, small towns or cities across Bihar and eastern Uttar Pradesh (UP), or in Delhi and Mumbai. Due to the emergence of digital distribution and other changes, distributors have lately favoured Hindi releases over Bhojpuri films. Also, the release structure of Bhojpuri films has been erratic; new films are released in a very small number of cinemas, depending on which distributor agrees to screen them. It is only the success of the first showing that makes a case for the next one. This means that anticipation, which remains key to film economies across the world, is diffused, and people may be more likely to watch the films on portable media.

The persistent identifier of Bhojpuri cinema, however, remains vulgarity. A journalist and cinema activist from Patna told me, "Cinema mein BF dikhaate hain" ("They show BFs in the cinema": $\mathrm{BF}=$ Blue Films, which is a reference to pornography). Another local film analyst and documentary filmmaker gestured with his hands to speak of low camera angles as representative of the voyeuristic tendencies of Bhojpuri cinema, "Yahan camera lagate ho, yahan nahin laga sakte? Camera placement mein bhi budget ka constraint hai?" ("Why do you place the camera there? Why not here? Does the budget constrain your camera placements too?") 
Almost everyone identified the absence of families as marking the limits of Bhojpuri media viewership. The fact that you cannot possibly watch such music albums or films with your family meant that they had no place in the conventional domestic set-up. Even those who had released their own albums, acted in minor roles in Bhojpuri films, and were still struggling to make it big, claimed that Bhojpuri media was too indecent (ashleel) for their families. Actor Chhavvi Pandey, who appeared in the Bhojpuri film Bidesia, said

A Bhojpuri film is never seen by people of a good class. Those who see it are either auto rickshaw drivers or vegetable and fruit sellers ...Ab ek bold scene Bollywood mein hota hai, aur ek Bhojpuri movies mein, inn dono mein zameen aasman ka nahi, antariksh ka farak hai [There are bold scenes in both Bollywood and Bhojpuri films, but the two are galaxies apart]. If you see the posters of Bhojpuri films, you'll see a girl exposing herself ajeeb tareekey se [in a strange way].

(as cited in Wadhwa 2013)

The alleged strangeness of the Bhojpuri "bold scenes" works in close association with the strangeness of the Bhojpuri masses - the auto rickshaw drivers and vegetable/fruit sellers, who are not of a "good class". At the same time, it is also about the raw performativity of the sexualised approach of the Bhojpuri film, opposed to which a fast-cut Bollywood song item - the average shot length of which is often less than one second - comes across as more sophisticated. This point needs a little substantiation. In various Bhojpuri films, the voyeuristic presentation of the female body is in contradiction with the moral purity, and inviolable honour, of the family. The ambivalent representation repeatedly switches between a melodramatic construction of familial honour and the bodily allure of public performers (mujra, nautanki). The soundtrack often guides attention towards the sexualised female body, isolated in the diegetic universe it inhabits. Thus, the mode of address deployed by the film prescribes the voyeuristic pleasure that the audience is to relish. The standards of urban fashion that appear normative and unremarkable in contemporary Bollywood, when imitated in a Bhojpuri film, appear extraordinary. For instance, a female protagonist working out in gym-wear, whose attire may appear banal in a Mumbai or New York residence featured in Hindi films, becomes tantalising in the provincial setting of Bhojpuri cinema. The desire to provincialise the female body, as represented in contemporary Bollywood, is not realised without translating representation into voyeurism. This significantly contributes to the way female sexuality in Bhojpuri films comes across as vulgar. The crisis, however, remains in not being able to produce a diegetic ecology in which the same content of female sexuality could be presented as if it were a mundane occurrence.

\section{Capitalisation versus monetisation}

While the industry registered rapid growth in its first few years, the crisis of overproduction - of music albums as well as films - reversed the advantage that cheap 
production initially enjoyed. At first the companies had to search for new artists, but by 2008 the balance was beginning to shift. The aspiring singers became so numerous that even though small recording companies kept coming up, the market was too small to provide for them all. Also, rampant piracy meant that very little money could be made with the albums. The endless queue of singers who wished to cut an album were driven by an aspiration to become not only singing stars, but also film stars. The film economy, too, suffered from a similar overgrowth that wrested control back to the exhibitors, who were spoilt for choice and could bargain to their advantage. This has meant that singer-performers, film producers and directors have all continued to register losses. Nearly all the Bhojpuri films fail at the box office now, which explains why, except for a handful of regulars, the entire industry runs on first-time producers who never recover the losses incurred. The recording companies are also reluctant to record new artists, as the extent of piracy prevents them from making any profits. This results in their asking the artists to put up their own money in return for distribution contracts. Yet, despite all these difficulties, the number of new films and albums continues to soar. What can explain this counterintuitive phenomenon?

My fieldwork corroborated Ratnakar Tripathy's findings (2012) in establishing that the Bhojpuri media industry is sustained by a large number of people investing in it to launch themselves or their offspring as a star. I interviewed a number of young boys training to achieve stardom, some already with a few albums, or a film contract, to their name. In most cases, fixed assets such as land are sold to raise capital for investment. One wonders why so many people in a 'backward' region such as Bihar invest so heavily in a high-risk business, often with poor talent. Why do young men and women from villages and small towns take crash courses in music and dance, perform in stage shows for free or invest their own money to release albums that make no money, and then continue to invest with high hopes? To answer these questions, one needs to take two key factors into account. The Bhojpuri-speaking region is not only marred by a lack of prospects for economic growth; economic capital itself also remains insufficient to claim any social status. This is not to claim that economic capital is insignificant, or that cinema is the only opportunity to monetise investible surplus. But the Bhojpuri film industry does provide one avenue by which to generate not only wealth, but also, even more importantly, to reinforce one's social status.

Shaibal Gupta calls Bihar a "competitive exam-driven state" (2013), while several others have told me, "there is nothing here except politics". Electoral politics, as well as the various competitive entrance exams, open up ways by which one form of capital can be converted into another: caste privileges can be turned into identity politics or casteless global citizenship (see Deshpande 2013). The Bhojpuri media industry also opens up a way to rid oneself of one's local identity and enter the channel of wider celebrity. After all, the media continue to be seen as a destination without territory; belonging everywhere and nowhere, and therefore able to liberate its faces from their localised identities. To that extent, the media remain a key avenue of social mobility. One might come across a middle-aged villager proudly declaring, "Bachuwa hero hai!" ("My son is a hero!") The fact of 
his having appeared as the protagonist of a Bhojpuri film holds extraordinary social value. An emerging singer-performer whose house I visited in Sasaram had his music album covers on display all around the room in which we sat. The media industry, regardless of wealth generation, opens up an avenue for capitalisation, which, crucially, must not be reduced to its economic footprint.

\section{Staging coalitional indigeneity}

Finally, I must discuss the role played by the most resilient site of the Bhojpuri media industry: the stage show. It may seem counterintuitive to posit an 'unmediated' address as a key site for the media industry, but it is in the stage show that the industry finds true assurance of its strength. Given the unorganised nature of Bhojpuri media distribution and rampant piracy, there is no reliable data to verify the often lofty claims regularly made by trade magazines and artists themselves. The stage show, on the other hand, enables a direct encounter between the performers and their audiences. In doing so, it aggregates the audiences, whom the performer addresses as one. Due to rampant piracy, hardly any significant numbers of VCDs/DVDs are sold. The music industry therefore remains highly uneven; its artists often bear the entire burden of financing, orchestrating and publicising their albums within small clusters via direct transactions. In fact, there is very little that could be understood as the music industry, particularly since the recording companies based out of small towns in Bihar took over from those in Delhi. The stage shows organise, advertise and lavishly stage the musical performances while also drawing significant earnings for the performers.

To grasp the essence of a stage show one must consider the variety of transactions that it mediates. The show is often publicised under the name of one popular artist, but an entire range of semi-popular, local and rookie singers are also introduced; the dancing girls to accompany the raunchy songs are mandatory attractions; the performers are known from their films and albums; the shows are overwhelmingly driven by popular feedback and demand, and are also used as publicity for upcoming films and albums; local businesses often use the shows to make token contributions in the name of their trade, and the shows nearly always involve a political coalition between the organisers and local politicians. In Delhi or Mumbai, where the migrant working classes live with a high risk of violence and displacement, the stage shows help unite the Bhojpuri or northern Indian public, and give them a political voice - as a vote bank and as an interest group.

At the same time, the stage is also used to improvise strategic coalitions. In Mumbai, a Lavani - an erotic dance performance from the Marathi Tamasha - may be thrown into a Bhojpuri live show to accommodate the neighbouring Marathi constituency. Chhath Pooja celebrations - one of the most significant religious festivals for the people of eastern UP and Bihar - during which several night-long stage shows take place, have found increasing political patronage on account of the massive northern Indian vote bank. The stage show, therefore, does not merely provide a direct, unmediated encounter between performers and their audiences; it simultaneously becomes a platform, a key site to make those audiences 
accessible for various political and business interests. The Bhojpuri media, then, only provide the shared ground upon which other coalitions can be built. The stage show is a key facilitator of such results, and therein lies its crucial significance for all the participants.

What, then, happens to claims to indigeneity? Even in the midst of these strategic coalitions, the audiences are addressed as Bhojpuri brothers, northern Indians, or people from UP and Bihar. The consolidations thus invoked draw boundaries of convenience, loosely based on demographic distribution. In the small towns and villages of Bihar and UP, more local identities are taken into account, such as the Benarasis, the Chhaprahiyas and others. The substance intrinsic to the community of addressees remains the same, even if it comes in various guises. Bhojpuri or northern Indian (etc.) indigeneity is projected as tolerant and hard working people belonging to a great culture that values tradition and family. This substance is rhetorically pitched against others, who allegedly cannot afford such high standards. What matters, then, is the rhetoric of difference by which narrative consistency is achieved in the address. What is claimed to be intrinsic to Bhojpuri, integral to its variant of indigeneity, is only a narrative signification that can later be extended to audiences speaking neighbouring languages such as Magahi, Maithili or even Awadhi. The Bhojpuri media industry thus forms an overarching claim to indigeneity which is deliberately kept porous - to Bhojpuri's hegemonic advantage.

\section{Conclusion}

Aspirations to celebrity and social capital, as I have argued, have been vital to the growth of the Bhojpuri media industry (for an elaborate discussion on stardom in Bhojpuri cinema, see Kumar 2016b). The primacy of the stage shows creates a platform for promoting a variety of political and commercial interests arbitrated by the media industry. The decrepit infrastructure of the Hindi film industry after the arrival of multiplexes was also instrumental in the rise of Bhojpuri cinema, especially in the neighbourhoods accessible to working class Bhojpuri-speaking migrants. Several such factors, therefore, have fuelled the rise of Bhojpuri media. The expressions of indigenous cultural essence in Bhojpuri films and music videos were only deployed to consolidate Bhojpuri audiences in spite of their differences. The Bhojpuri indigeneity claimed is thus a mere placeholder. The absence of any existing polity in the name of Bhojpuri, unlike other state-supported languages, means that the Bhojpuri media had to imagine its indigeneity prior to claiming it.

It must, however, be explained that this imagined identity, in the case of the Bhojpuri media, is never insular or inward looking. Unlike several other indigenous media industries discussed in this volume, the Bhojpuri media harboured, and continue to harbour, a deep affinity towards Hindi cinema. To that extent, the Bhojpuri media projects an ambivalent desire: (i) to move away from Hindi cinema to claim its autonomy and indigeneity against the mainstream, but also (ii) to assert a continuity with Hindi cinema's epic melodramas, which gradually disappeared 
after the late 1990s as the multiplexes took over and genre-based narratives began to flood the Hindi film market (see Prasad 2011). The effect produced as a result is that of a compromised claim to Bhojpuriness. Primarily because the educated middle classes of the Bhojpuri-speaking region do not patronise the Bhojpuri language, the Bhojpuri media cannot afford to build their commercial enterprise entirely upon its claimed indigeneity. Of course, the supersedence of Bhojpuri by Hindi in the school education system is only relevant for those who manage to access that system. This created uneven stakes in the Bhojpuri language even prior to the emergence of the Bhojpuri media. Far more significant for the Bhojpuri media, then, are the working class migrants from neighbouring regions (speakers of Awadhi, Magahi, Maithili, etc.) in urban centres across India seeking a substantive solidarity with the Bhojpuri speakers.

The factors discussed above diffuse the claims to Bhojpuri indigeneity; indeed, they cultivate a wider solidarity and distributive consolidation to include extraindigenous resonances based on labour, capital, migration and gender. These are nonetheless articulated in the form of cultural values. The discourse on indigenous values, as if persisting across centuries, anchors this far more ambivalent, complex and contingent phase of media enterprise. Curiously enough, this discourse on values is also deployed to accuse Bhojpuri media of compromising cultural honour. Exactly when digital technologies have breathed a new life into the spheres of Bhojpuri values, digital literacy has brought to the fore not only alternative lifeworlds, but perhaps also an alternative distribution of values. ${ }^{3}$ Evidently, it has also split claims of indigeneity across different orbits.

Creators of Bhojpuri films, music videos and stage shows are often compelled to make the text more porous - e.g., addressing 'us northern Indians' - while also simultaneously providing an intimate identification for Bhojpuri speakers based on mise-en-scène and performativity - best illustrated by the sustained featuring of gamchha. ${ }^{4}$ The Bhojpuri media cannot claim absolute indigeneity because a substantial percentage of their audience, across the migrant labour distribution circuits of India, have only limited knowledge of the Bhojpuri language. The subregional constellation of the Bhojpuri media draws too little on its 'folk' repertoire, and leans too heavily on Hindi cinema idioms, to sit easily among other indigenous media industries. But its hybridity, intertextuality and ambiguous commercial profile anticipate a market able to meet its industrial ambitions. ${ }^{5}$ With various strategic coalitions, as discussed in this chapter, the Bhojpuri media thus push us into a complex, and as yet unsettled, public sphere of claimed indigeneity.

\section{Notes}

1 The mofussil is a reference to the geographies ignored by the mainstream - small towns and villages away from the big cities where the infrastructural access to services guaranteed elsewhere may not be available.

2 Arth (1982) is a film about the male protagonist's extra-marital affair with an actress, after which he decides to leave his wife. The film is a meditation on a wounded woman's search for her identity. As one of the many films of the 1980s termed 'parallel cinema', Arth was situated outside the epic melodramas of the Hindi film industry. 
3 Several of my respondents across Bihar, in particular, argued in Bhojpuri's defence, "Bhojpuri sanskaar ki bhasha hai" ("Bhojpuri is the language of values!") As we have observed through many historical points of inflection, languages come to bear the burden of an ideological force when they lead the threat to reconfigure a contested lifeworld (see Dalmia 1997; Mir 2010; Orsini 2002; Ramaswamy 1997; Rai 2002).

4 Gamchha is a thin, coarse, traditional cotton sweat-towel used widely across the Bhojpuri speaking region, but also in eastern India more generally. In Bhojpuri films, it becomes a handy prop. The male protagonist can tie it around his head or waist, or wear it around his neck.

5 Bhojpuri film stars may not be as swashbuckling as their Hindi counterparts, but their rising remunerations are encouraging Bhojpuri media enterprises to address a much wider market than their indigenous counterparts.

\section{References}

Athique, Adrian. 2012. Indian Media: Global Approaches. Cambridge: Polity Press.

Athique, Adrian, and Douglas Hill. 2010. The Multiplex in India: Cultural Economy of Urban Leisure. London and New York: Routledge.

Berger, Peter. 2014. "Dimensions of Indigeneity in Highland Odisha, India." Asian Ethnology 73 (1/2), Special Issue: The Bison and the Horn: Indigeneity, Performance, and the Sate of India: 19-37.

Dalmia, Vasudha. 1997. The Nationalization of Hindu Traditions: Bharatendu Harischandra and Nineteenth-Century Banaras. New Delhi: Oxford University Press.

Deshpande, Satish. 2013. "Caste and Castelessness: Towards a Biography of the 'General Category'." Economic and Political Weekly 48 (15): 32-39.

Ganti, Tejaswini. 2012. Producing Bollywood. Durham, NC: Duke University Press.

Ghosh, Avijit. 2005. "The Mofussil's Revenge." The Times of India, Nov 1. http://articles. timesofindia.indiatimes.com/2005-11-01/edit-page/27857786_1_bhojpuri-sasurabada-paisewala-regional-genre.

Ghosh, Avijit. 2010. Cinema Bhojpuri. New Delhi: Penguin.

Gupta, Shaibal. 2013. Idea of Bihar: A Lecture. Patna: Asian Development Research Institute.

Karlsson, Bengt G. 2003. "Anthropology and the 'Indigenous Slot': Claims to and Debates about Indigenous Peoples' Status in India.” Critique of Anthropology 23 (4): 403-423.

Karlsson, Bengt G., and Tanka B. Subba. 2006. "Introduction." In Indigeneity in India, edited by Bengt G. Karlsson and T.B. Subba, 1-17. London and New York: Kegan Paul.

Kumar, Akshaya. 2013. "Provincialising Bollywood? Cultural Economy of North-Indian Small-Town Nostalgia in the Indian Multiplex." South Asian Popular Culture 11 (1): 61-74.

Kumar, Akshaya. 2014. "The Aesthetics of Pirate Modernities: Bhojpuri Cinema and the Underclasses." In Arts and Aesthetics in a Globalising World, edited by Raminder Kaur and Parul Dave Mukherji, 185-203. Oxford: Berg.

Kumar, Akshaya. 2015. "Provincialising Bollywood: Bhojpuri Cinema and the Vernacularisation of North Indian Media." Glasgow: PhD diss., University of Glasgow.

Kumar, Akshaya. 2016a. "Bhojpuri Cinema and the 'Rearguard': Gendered Leisure, Gendered Promises." Quarterly Review of Film and Video 33 (2): 151-175.

Kumar, Akshaya. 2016b. "Bhojpuri Consolidations in the Hindi Territory: Infrastructure, Aesthetics and Competing Masculinities in North India." BioScope: South Asian Screen Studies 7 (2): 189-206.

Manuel, Peter. 1993. Cassette Culture: Popular Music and Technology in North India. Chicago: University of Chicago Press. 
Manuel, Peter. 2012. "Popular Music as Popular Expression in North India and the Bhojpuri Region, from Cassette Culture to VCD Culture." South Asian Popular Culture 10 (3): 223-236.

Manuel, Peter. 2014. "The Regional North Indian Popular Music Industry in 2014: From Cassette Culture to Cyberculture." Popular Music 33 (3): 389-412.

Mir, Farina. 2010. The Social Space of Language: Vernacular Culture in British Colonial Punjab. Berkeley and Los Angeles: University of California Press.

Orsini, Francesca. 2002. The Hindi Public Sphere, 1920-1940: Language and Literature in the Age of Nationalism. New York: Oxford University Press.

Prasad, M. Madhava. 2011. "Genre Mixing as Creative Fabrication." BioScope: South Asian Screen Studies 2 (1): 69-81.

Rai, Alok. 2002. Hindi Nationalism. New Delhi: Orient Longman.

Ramaswamy, Sumathi. 1997. Passions of the Tongue: Language Devotion in Tamil India, 1891-1970. Berkeley: University of California Press.

Rawlley, Vishal. 2007. "Miss Use: A Survey of Raunchy Bhojpuri Music Album Covers." Tasweer Ghar: A Digital Archive of South Asian Popular Visual Culture. www. tasweerghar.net/2007/vishal/index.html.

Schleiter, Markus. 2014. "VideoCD Crossovers: Cultural Practice, Ideas of Belonging and Santali Popular Films." Asian Ethnology 73 (1/2), Special Issue: The Bison and the Horn: Indigeneity, Performance, and the Sate of India: 181-200.

Tripathy, Ratnakar. 2012. "Music Mania in Small-Town Bihar: Emergence of Vernacular Identities." Economic and Political Weekly 47 (22): 58-66.

Wadhwa, Akash. 2013. "Bhojpuri Cinema Is Sustaining on Vulgarity: Chhavvi Pandey." The Times of India, September 1. http://articles.timesofindia.indiatimes.com/2013-0901/news-interviews/41662417_1_bhojpuri-cinema-bhojpuri-film-bidesia.

Wolf, Richard K. 2014. "Tribal and Modern Voices in South Indian Kota Society." Asian Ethnology 73 (1/2), Special Issue: The Bison and the Horn: Indigeneity, Performance, and the Sate of India: 61-89. 
$\because$ Taylor \& Francis Taylor \& Francis Group http://taylorandfrancis.com 


\section{Part II}

\section{Politicising indigeneity}

Video clips and movies 
$\because$ Taylor \& Francis Taylor \& Francis Group http://taylorandfrancis.com 


\title{
6 Primitive accumulation and "primitive" subjects in postcolonial India
}

\author{
Tracing the myriad real and virtual \\ lives of mediatised indigeneity activism
}

\section{Uday Chandra}

\section{Introduction $^{1}$}

In late 2008, a five-minute video clip titled Gaon Chodab Nahin (literally, "We Shall Not Leave Our Village") came into circulation among activists and grassroots NGOs in the forest highlands of eastern India. The musical score that runs through the clip, it claimed, was "inspired" by Bhagwan Maaji, a key leader of the struggle against bauxite mining in Kashipur, Odisha. The images did not belong to any particular place but formed a bricolage that sought to tell a common tale of oppression and exploitation under today's neoliberal economic regime. The film was directed by K.P. Sasi, an activist and documentary filmmaker from Kerala, and funded by ActionAid, a global anti-poverty NGO with its headquarters in South Africa. To those who watched and circulated the video clip throughout the eastern Indian states of Jharkhand, West Bengal and Odisha, Gaon Chodab Nahin (henceforth, GCN) summed up the plight of adivasi/tribal/indigenous populations in the region as they battled an emerging state-corporate nexus whose plans for rapid industrialisation in India relied on access to forest and mineral resources (Padel 2009; Padel and Das 2010; Whitehead 2010; Varma 2013).

This new wave of "primitive accumulation," as the Marxist geographer David Harvey (2003) explains, lies at the heart of contemporary capitalist expansion in regions hitherto deemed marginal or peripheral. What Harvey terms "accumulation by dispossession" is the dominant mode of appropriation today outside the core of the capitalist world economy (Glassman 2006). Such accumulation is "primitive" or originary in the sense that it is foundational to the workings of capitalism, whether in its classical or contemporary avatars (Perelman 2000). As Karl Marx (1967, 714-715) wrote in Part VIII of Das Kapital (Volume 1),

the so-called primitive accumulation . . . is nothing else than the historical process of divorcing the producer from the means of production. It appears as primitive, because it forms the prehistoric stage of capital and of the mode of production corresponding with it.

Marx refers here to enclosures in England or the conquest of the Americas as precursors to the rise of industrial capitalism and its more familiar, everyday forms 
of accumulation. But it is useful to heed the political economist Kalyan Sanyal's (2007) warning that primitive accumulation is not necessarily prior to capitalism proper. It is better understood as an ongoing process in the frontiers of the capitalist economy. Equally, as Sanyal argues, primitive accumulation does not inevitably turn communities of peasants into exploitable wage labour in the manner suggested by an older Marxist teleology. These processes of accumulation, especially in the ex-colonial world, curiously reproduce what Sanyal calls "non-capital" or social relations of capital that either predate wage labour or are distinct from it. Non-capital encompasses various forms of kinship, ethnic and gender relations that are reinforced rather than extinguished by the expansion of colonial and postcolonial capitalism. In Sanyal's $(2007,61)$ terms, in the postcolonial world, capitalism's "arising is never complete, its universality never fully established, its being forever postponed." This perpetual postponement of the apparently universal logic of capitalism may be attributed, on the one hand, to colonial policies that sought to preserve "traditional" hierarchies (Mamdani 1996; Mantena 2010), and on the other hand, to the postcolonial workings of electoral democracy and popular welfarism (Chatterjee 2008). As capital expands, therefore, so too does the space for non-capital.

In this chapter, I focus on a particular form of non-capital, namely, subjects deemed to be "primitive" by postcolonial states, non-governmental agencies and transnational activist networks. "Primitive" in this anthropological sense is, it must be clarified, a priori unrelated to socioeconomic processes of primitive accumulation. I refer here to postcolonial subjects, who are labelled as "tribes" by the Indian government and as adivasis (literally, "ancient inhabitants") by activists sympathetic to their plight, are represented simultaneously as hapless victims as well as fierce warriors in defence of Nature and Freedom (Varma 2002; Bates and Shah 2014). What appears as a discursive contradiction here actually reflects a central tension in colonial and postcolonial policies towards adivasis in modern India, or what may be termed "primitivism" (Chandra 2013a). This tension is reproduced in the languages and logics of resistance when adivasis and their benefactors negotiate the modern state from below (Chandra 2013b). Such resistance is, as I shall explain in this chapter, necessarily reliant on "strategic essentialisms" (Spivak 1988 ) that invoke the figure of the "primitive" talking back to the state and statelike actors in its own languages, domestically and globally (Chakrabarty 2006; Jung 2006; Li 2010; Hodgson 2011). Although this is a risky venture on many counts (Béteille 1998; Kuper 2003; Banerjee 2006; Shah 2010; Mamdani 2013; Sylvain 2014), it is in this sense that the GCN clip came to be presented in rural eastern India and beyond as a key symbol of resistance by postcolonial adivasi subjects to emerging forms of primitive accumulation. "Primitive" subjects and processes of primitive accumulation, therefore, became conjoined in peculiar historical circumstances in contemporary India.

This chapter critically interrogates the myriad lives of this video clip through a close study of the real and virtual arenas in which it came to be viewed and engaged with by different audiences. In doing so, I follow recent trends in the anthropology of media that emphasise studying practices of production, consumption and 
circulation (Bräuchler and Postill 2010) in the making of new "media worlds" (Ginsburg, Abu-Lughod and Larkin 2002). I also draw on long-term ethnographic fieldwork in the forests of Jharkhand in eastern India to examine how developmental NGOs, indigeneity activists and adivasi villagers came to view and interpret this video differently. These different interpretations, I show, simultaneously perpetuate and destabilise long-established ideas of "primitivism" in postcolonial India, especially when some adivasi subjects question the wisdom of their wellmeaning patrons and then proceed to critique representations of themselves as "primitives". Beyond my fieldsites in rural Jharkhand, I examine the virtual audiences of GCN on YouTube, Facebook and other online peer-to-peer video-sharing portals. These audiences, albeit different from those offline, connect local adivasi struggles to a wider canvas of global activism in the name of the "indigenous" (cf. Ginsburg 1995; Wilson and Stewart 2008). By doing so, they seek to transcend "militant particularisms" (Harvey and Williams 1995) even as the specificities of particular lives and places are progressively stripped away. These articulations of "indigeneity" keep alive the all-too-modern figure of the "primitive" as a symbol of ineradicable difference and as an object of our neo-romantic longings for a past that arguably never existed. In doing so, the reproduction of "primitive" subjects in contemporary India ought to be understood not in opposition to the logic of primitive accumulation, but, in fact, within it.

\section{Gaon Chodab Nahin as a cultural text}

GCN opens poignantly with a scene that is apparently meant to depict an eternal sense of adivasi existence. A melancholy flute plays in the background on a dark night in the forest, where villagers congregate around a flickering fire, singing self-absorbedly in communion with each other. The next scene zooms in on butterflies fluttering by day around some creepers in the forest, and a livelier tune takes over to accompany the vivacity of life on display. At the very outset, we thus encounter two contrasting scenes of adivasi life in the night and day. Both scenes, however, complement each other insofar as they delineate together a life of nature, freedom, joy and community, away from the sights and sounds of big cities, modern technology and the insignia of the state. This complementarity is emphatically brought together in the next scene, which is a computer-generated white-on-brown image of a Warli-style painting that shows an idealised adivasi village nestled amidst trees, clouds and mountains. Women perform household chores under a smiling sun. The beat of the nagāda drum, played at the centre of the painting, binds their labours together within a village community. In roughly half a minute, an undisturbed rural idyll is conjured before our modern eyes, an object of longing and loss simultaneously.

It is this "primitive" idyll, we are asked to contemplate, that is under threat from the primitive accumulation of capital in India today. The lyrics of the song, written by the Ranchi-based activist-filmmaker Meghnath Bhattacharya, then erupt in a male baritone: "We shall not leave our villages/ We shall not leave our forests/ We shall not leave our motherland/ We shall not give up our fight." Scenes of an 
adivasi woman drawing water from a well and several others sowing paddy in the fields accompany the lines that mention the "village" (gaon) and "motherland" (maar maati), whereas forest-covered hills and a protest march of adivasi women depict "forests" (jangal) and "fight" (larai) respectively. There is an undeniable eco-feminist undertone to these depictions that suggests the centrality of women to rural adivasi communities. Women labour and protest as well as tending to home and hearth. Men play drums, by contrast. Behind this celebration of the adivasi feminine that undergirds the village community lies, however, an ambiguity, whereby women's voices are seemingly silent or at least drowned by male drums and song in the video clip.

Nonetheless, the male singer accuses a mysterious "It" of wreaking havoc within these feminine-centred communities. "It" builds dams, submerges entire villages, builds factories and mines, destroys forests and creates sanctuaries. A chorus of adivasi women follows the male lead and repeats the accusation against "It." Images of trucks carrying coal from mines and dynamite blasting through the surface of the Earth reinforce these accusations. "Where," the male lead, asks the God of Development (vikās ke bhagwān), "can we go if we leave the land and forests (jangal-jameen)?" "It" then turns out to be the God of Development invoked here. It is a mysterious amoral force acting in various guises to displace and dispossess adivasis throughout India. As if to underscore what is at stake in the current wave of primitive accumulation, the "primitive" idyll of community life re-appears as another Warli painting. Women labour and play music in and outside their homes, some with children. This scene, the clip suggests, may end up merely as a painting for posterity, not as lived reality.

The next sequence of images (and the next stanza of the song) identify and address an audience. It tells this audience of viewers in metropolitan centres of privilege in urban India and beyond that, as a result of their apparently innocent everyday acts of consumption, the Yamuna, Narmada, and Subarnarekha rivers are drying up, the Ganges is now a filthy drain and the Krishna simply a black line. Images of dry river beds and clogged streams reinforce the lyrics of the song. Additionally, this segment of GCN accuses its audience directly ("you" or tum) of drinking Pepsi and bottled mineral water ("Bisleri") even as adivasi villagers are increasingly forced to drink contaminated water (kachrā pāni) from wastewaterlike streams and rivers. Primitive accumulation of capital then, ultimately, affects everyone through its impact on local, regional and national ecologies. The audience of GCN must take the blame for the current circumstances adivasis find themselves in even as it ponders dire ecological consequences for itself in future. This is a political argument that hitches the adivasi cause firmly to the environmental one in India today. It averts the possibility of adivasi resistance being dismissed as merely another species of identity or sectarian politics in the Global South. The upshot is that the audience ought to be interested in, if not part of, the "fight" (larai) against the amoral forces of "Development" (vikās) just as adivasis are.

Insofar as the audience and the subject of GCN are united by the middle of the video clip, this is achieved by a clever sleight of hand. None of the makers of GCN are adivasis, though a number of them have had lengthy careers in social activism 
on behalf of adivasis and the environment. GCN's appeal to the predominantly urban middle-class audience in India and abroad is borne out of a familiarity with the milieus that this audience inhabits. Yet the makers of GCN, assuming the mantle of the indigeneity activist, endeavour to speak for adivasis to non-adivasis. Hence, the non-adivasi viewer of GCN is addressed as "you" (tum), and the subject of the clip is "we," the adivasis and the filmmakers (hum). The sleight of hand lies in the middle-class indigeneity activist speaking to his own kind based on a prior familiarity, albeit with a you/we distinction. A conversation within bourgeois society about adivasis thus seeks popular legitimacy by speaking in complete identification with the modern tribal subject. An aspiration to fictive kinship is posited between the filmmakers and adivasis all over India, though as we shall see in the next section, this aspiration runs into some real-world difficulties. It is this sleight of hand based on an aspirational "we" that, of course, makes the video so powerfully evocative.

GCN moves swiftly from "you" to "we" as if to sharpen the contrast. The next scene takes us back to the rural adivasi idyll in the darkness of night, illuminated only by a community fire. We then see an ojha or witch-doctor warding off malevolent spirits with a broom in the darkness of a thatched hut. A pahan or village priest worships by day, invoking ancestral spirits in a sacred grove with sal (Shorea robusta) leaves and a ritual pot of water. The male lead sings, "Were our ancestors fools (moorakh) that they protected the forests, kept the earth green, and the rivers flowing with honey?" There is a tone of defiance here. The arrogance of the urban middle-class beneficiaries of Development is being confronted here. The singer goes on to accuse these votaries of Development of setting fire to the Earth and denuding it of vegetation, killing fish and driving away birds in unknown directions. The time-honoured wisdom of adivasis is explicitly contrasted here by the makers of GCN to the modern-day gospel of industrial progress in India and elsewhere. "We" are putting "you" in their place, so to speak. And yet, "we" are also vulnerable thanks to "you," as we see the computer-generated Warli paintings with moving figures portraying fragile but heroic communities under threat today.

"Development" in the scheduled or "tribal" areas of contemporary India is, GCN then reminds us, directly related to the primitive accumulation of capital there. "Companies" interested in acquiring land occupied at present by adivasi villages are represented by a computer-generated image of a white businessman with an American flag on his hat and necktie. The American businessman holds in his clutches a greedy-looking Indian politician (mantri) in his grey safari suit and Nehru cap: his dalāl or broker in GCN's words. This politician, in turn, holds up a policeman in khaki uniform to "seize lands" occupied by adivasis. The policeman holds an old-fashioned wooden rifle in his hand. The trio move steadily towards the Warli depictions of rural adivasi idylls as the background score speaks of "platoons" (paltan) accompanying them. Visuals of police atrocities against villagers in Singur and Nandigram, West Bengal, follow to give a graphic sense of how brutally the state attacks its own citizens in order to acquire land for private companies. "The officer becomes a king (rāja) $)$," goes the GCN song, "and the contractor becomes wealthy (dhani). Our village becomes their colony." This, 


\section{Uday Chandra}

then, is a critique of the primitive accumulation of capital in the name of "primitive" subjects in the margins of the world capitalist economy. In the postcolonial context, adivasis are, GCN alleges, doubly victimised in the form of primitive accumulation at a global scale and in the form of internal colonialism within the nation-state framework.

In response to these nested regimes of victimisation and exploitation, GCN asserts, there is no alternative but to fight (laräi). The precise nature of this fight is ambiguous, perhaps unintentionally, albeit in a productive sense. It is not clear whether violence is to be abjured or adopted, and as we shall see in the next section, this ambiguity propels GCN's popularity in rural Jharkhand today. The final stanza of the GCN song invokes Birsa Munda, the legendary leader of a late 19thcentury rebellion in what is now Jharkhand (Chandra 2016; Singh 1966), to call for unity among disparate adivasi/tribal/indigenous groups as well as Dalits (exuntouchable castes) and fisherfolk (machchuāre). According to the video clip, this kind of unprecedented subaltern unity will "break this silence," which is believed to be characteristic of everyday adivasi, indeed, subaltern life in India. Images from different parts of India conjure up a vision of subaltern unity. The call to arms, metaphorical or literal, follows: "Sound the battle drums (nagāra $)$ from the fields and mines. There is no recourse but to fight, fellow countrymen (deshvāsi)."

\section{Multiple audiences, multiple meanings}

In late 2008, I was introduced to GCN in Khunti district of central Jharkhand by those working in a non-governmental organisation committed to rural development that I shall name "Utthaan" here. Utthaan's officials were young middle-class urban professionals from small towns and cities across the eastern Indian states of Bihar, West Bengal, Assam and Odisha. Knowing my interest in adivasi involvement in social movements, especially the Indian Maoist movement, Sushil greeted me enthusiastically and hastened to show me GCN as I entered Utthaan's Khunti office on a warm afternoon. He told me in Hindi, "You have to watch this video. It is all about indigenous peoples' rights in India." After watching the video, I asked Sushil if he felt uncomfortable with the references to "Development." That was, after all, what he and his colleagues were engaged in. My question took him by surprise. He said,

No, not at all, [my name]. We are here for capacity building. This will help adivasis become more self-sufficient in terms of food security and household finances, and then, they can define their own future without anybody's help. This "Development" that you see in this video is what the state and private companies do to adivasis. Ours is the true development. You know Amartya Sen has said the true meaning of development is freedom. We follow that.

His colleague Vinod had overheard us and joined the conversation. He had seen GCN too. I asked Vinod what he took to be the main takeaway point of the video. He responded in English, "It is a manifesto for adivasi liberation. This can only 
happen through a mix of rights-based activism and developing sustainable livelihoods options." But if adivasis liberated themselves, what would organisations such as Utthaan do? Vinod smiled and responded, "Good question. We will be here as long as adivasis cannot stand on their own two feet. We are like coaches; they are the players. They must play and win. We can only coach and then watch from the sidelines."

A month or so later, we drove in a jeep to a forest village named Longa on the western edge of Khunti district. For that evening, Utthaan had combined forces with Meghnath, the lyricist for GCN, to screen the video for adivasi villagers in Longa. There was a technical challenge, of course: Longa had no electricity. Utthaan's solution was to take along in the jeep a portable generator along with a CD player, a CD with the GCN video, a white screen, and projector. On the way to Longa, Meghnath told us how much he loved coming to adivasi villages, but his poor heart condition meant he could not travel much from his home in the outskirts of Ranchi, the capital of the state of Jharkhand. I asked him about the making of GCN and what it sought to achieve. He said, "Adivasis are the original inhabitants of India, and still, you see how we are treating them." "We must learn from them," he added, "they know more than any university can teach." Did he, I asked, feel that GCN presented an overly romantic portrait of adivasi village life? After all, the village we were visiting, Longa, was hardly the image of harmony that GCN presented to its audiences. It was, like many other villages in rural Jharkhand, torn apart by intergenerational conflicts that lay at the heart of the Maoist movement in the region (Chandra 2013b). Meghnath listened carefully to my question, pondered over it and paused before replying, "These days, young people are the same everywhere. They want money, mobiles, guns. They don't respect their own traditions. That is a major cause of the problems adivasis are facing today." But why did he not ask the filmmaker to include this internal challenge to the adivasi village community in GCN? "How could we put it? All our middleclass friends in Delhi and Bombay will say these communities are backward and the problem lies within them."

In Longa that evening, villagers had assembled to watch the film screening. Usually, when film screening equipment arrived, it was a night of revelry in the village. GCN would last only five minutes, but then Meghnath would participate in a free-ranging discussion of the video. What most villagers were looking forward to, however, was the screening of the Bollywood film Dabangg, starring the muscular youth icon Salman Khan. ${ }^{2}$ Glasses of home-brewed rice beer (hanriā) and dancing would extend well into the small hours of the morning. At the film screening, I sat next to a couple of friends of mine in the village: Johan and Barnabus. ${ }^{3}$ Everyone watched GCN with their eyes glued to the screen. Then, they twice requested a re-run of the video. Johan, who teaches at the village school, turned to me afterwards and muttered in the local Mundari language: "Maybe if we did less fighting (larāi), this village would have electricity. We have to go three kilometres to charge our mobile phones now." Barnabus, who works as a village-level representative of one of Utthaan's rival NGOs nearby, chimed in: "Whenever city people make these films, I feel proud to be an adivasi. But I also know the reality here. 


\section{Uday Chandra}

There is so much hardship. No one wants to farm. Everyone wants to go and work in big cities." None of this, of course, implied that they endorsed the displacement and dispossession of adivasis by private corporations backed by the Indian state. Primitive accumulation was real enough as a phenomenon for them, but the solution for Johan and Barnabus lay in fighting for a share of the revenues from mining. "When they need land for building factories and mines," explained Barnabus, "companies should be made to pay a lump sum amount plus a share in their future profits for a certain number of years. Even if we go and work in Delhi, the money will be in our bank accounts." Johan added, "Whenever companies ask us for land, villages are divided on what to do. Can anyone get 12 months of food from their land today? Every household has at least one or two members who migrate to big cities in search of work and that is what keeps our households running." Were films such as GCN not helpful then, I asked? "No, they help in telling city people about how we live here," replied Barnabus, "but it cannot help us. We know the truth of the whole thing."

Four months later, I was back in Longa for another screening of the film. This was part of a Maoist night meeting, in which the local leadership would communicate their ideas to ordinary villagers after the film. Shailendra, as I shall call him, was a local Maoist party leader from south Bihar known to me from my fieldwork in Khunti district. I attended as his guest. Johan and Barnabus were again present at the screening, but we did little more than exchange quick glances that evening. After the film, Shailendra gave a long, passionate speech in Hindi. He exclaimed:

This video shows how the government is looting and killing (loot-mār) adivasis and seizing their lands for companies to make profits from . . . During the British Raj, Birsa Munda, Sidhu-Kanu, Baba Tilka Manjhi and others laid down their lives for the sake of freedom. We must follow in their footsteps now.

He proceeded later to discuss the naturally revolutionary character of adivasis:

Today, the whole world is learning how adivasis conserve forests and farm sustainably. We have come to learn from you. But we also want to teach you how to fight against the state (sarkār) and its brokers/pimps (dalāls). Your fight is the fight of oppressed people all over India and the world. We are with you.

The audience agreed solemnly. They could, of course, do little but agree. The village headman (mundā), an ageing patriarch, met me after the Maoist meeting. Karia Munda said he supported the adivasi fight against the state and corporations, but he did not know whether the Maoists were their best allies. "They say they will arm us. But what will happen when the CRPF [state paramilitaries] come to question and torture us? Will they save us then? Will the youth who join the Maoists come back to us?" These are genuine concerns harboured by adivasi elders in Longa and its neighbouring villages. Shailendra himself did not know the answers when I put the same questions to him. He told me, "These headmen have always sided with the state. Even during the Birsa rebellion (ulgulān). The youth will 
always support us. They have no future without us, you see?" I asked Shailendra what he thought of the video. He said it was an excellent addition to their existing propaganda materials: short, hard-hitting, and with memorable lyrics and music. "It brings out the need for Maoism (Maovād) clearly for all to see."

Across these multiple audiences ${ }^{4}$ and strands of meaning, what stands out is how our distinctive interests shape our appreciation of GCN. For Sushil and Vinod at Utthaan, the video is about "true" development, in which adivasis can liberate themselves through a fight against poverty and deprivation. For Meghnath, it is about learning from the subaltern and supporting her fight for survival and dignity in a hostile modern world. For Johan and Barnabus, it is about raising awareness among urban middle-class viewers about the plight of adivasis in India today, though the real issues faced by adivasis are, in their view, an altogether different matter. For Shailendra and the Maoists, it is about raising revolutionary consciousness among adivasis. Arguably, my own reading of the film may be linked to my own positionality as a researcher who is not himself an adivasi. The bricolage of images in GCN thus mirrors the myriad audiences and interests that encounter it to produce disparate meanings of indigeneity and its discontents.

Equally important is an emerging set of contestations in the public sphere in rural Jharkhand over indigeneity, or more precisely, adivasi-ness. For the makers of GCN as for Meghnath, adivasi-ness is a given and needs to be salvaged by rural adivasi communities with the aid of sympathetic outsiders. For Utthaan and the Maoists, a modernist vision of progressive social change is quite compatible with assertions of adivasi identity. Yet, the adivasi voices in this chapter are, surprisingly, sceptical about how they are represented in the video. Whereas they see the wisdom in educating non-adivasis about adivasi lives, they attack frontally the basic premise of GCN, which is that the neoliberal developmental regime is antithetical to the existence of the modern adivasi subject. Effectively, they say, the "primitive" emerges alongside processes of "primitive accumulation," but an inclusive modernism is not beyond the realm of negotiable possibilities for adivasis in contemporary India.

These contestations become even more visible in virtual public spheres, especially on social media portals such as YouTube and Facebook. ${ }^{5}$ On YouTube, where the earliest video of GCN was posted in March 2009, non-adivasis are most prominent in voicing their appreciation. Alok Kumar Mishra, a commenter on YouTube, wished to "dedicate $[\mathrm{GCN}]$ to all those who migrated to cities . . . because for their survival, they have to fulfil the greedy needs of corporates and corrupts." Prem Anand says,

What a State we have reached ... in the name of development we have become greedy[;] success is measured in money value and not in terms of making positive impact on people ... basic human rights and inclusive growth is lost . . . PAIN PAIN every where.

Another commenter, named Puru Ekta, writes, "This song is a grim reminder of our shameful apathy while the tribals were being uprooted from their homes. We 


\section{Uday Chandra}

pay for our sins in the form of Naxalism [Maoism] now." A further viewer adds, "the video really shows the true side of the Maoist struggle in India." The person who had posted the video, a Bengali man named Kaustav De, responds angrily to these comments that link adivasi struggles to the Maoist movement:

where did Maoists come into this? This is a plane [sic] and simple song about the exploitation of the adivasis and their way of living by the Indian state and big capital, and adivasis are protesting all around. It is only some people who find the Maoist way of protesting a thing to be hyped and mentioned. That is why millions of adivasis protesting non-violently are neglected or silently butchered, while violent resistance enjoys all the limelight and attention of the State, and the media.

Others such as "Shashwat DC" take a more explicitly nationalistic line:

150 years ago we Indians fought against the exploitative Company Raj (East India Company), I guess the time has come again to fight against the new 'Company' raj of the high and mighty in the hinterlands of India . . . Need a rallying cry like Vande Mataram!!!

Another writes, "my national anthem this week." A third laments, "I'm sad to know all the thing happen in my country, we have to come forvard and appose these tings [sic]." Finally, there are those that express scepticism about the core message of GCN. Abhilash Nambiar notes, "Bhagavan maaji can hedge his bets if he copyrights this song. If his song inspires enough people to save the forests, he can live there. If not he can live off the royalty payments from this song." Another sceptic, Ganapati Bhat, writes,

However the noble their idealism may be, even people in village want development. We can not live without electricity. Can we? from where we get it? No hydro power, No coal, No nuclear. What is the remedy? I am sympathetic to their feelings. Living in a village, I can understand their feelings much better. But don't they also want education, health care and progress?

In sum, there are those who react in a positive manner to GCN spontaneously because it matches their own thoughts on the ills wrought by developmentalism, especially environmental degradation and the suppression of adivasis' rights; there are those who hitch the adivasi cause to the national one, the former constituting a part of the latter's wholeness; lastly, there are those who appreciate GCN in some ways but question the naiveté of its political idealism. If this is the intended audience for GCN, it is clear enough that some awareness of adivasis' circumstances is being generated. But insofar as YouTube commenters absorb GCN's message into their own pre-existing ideological schemas, those who are likely to be sympathetic to GCN are those who choose to view the video and comment on it. Those who do not care continue not to, of course. 
Besides the fundamental axis of sympathy/apathy among viewers of GCN, there is also the not-so-small matter of representing adivasis in contemporary India. In a discussion on Facebook related to GCN, Subuddhi, a Ho friend from Chaibasa in southern Jharkhand, posted an article by the anthropologist B.K. Roy Burman (2009), who argued that "[i]t will perhaps be always better to avoid using the . . nomenclature 'Adivasi' in the tenors of serious academic discourse when dealing with the notion of indigenous groups in the Indian context." A young adivasi man who goes by "Roi Raj" on Facebook commented in response:

All indian groups are based on linguistic identity no matter how minor that group is in no of population - each language should be honored in referencing $\mathrm{n}$ identifying a race - Hi I am a Munda sounds much better and respectful than hi i am a tribal adivasi $i$ live in the wilderness with no clothes $i$ have no internet.

When asked about his views, Subuddhi explained himself:

[my name] well as i know there is no such term Adiwasi or Tribe in our dictionary, these terms are given by some outsiders of our society and we are feeling proud without knowing whats its real meaning.

Ya i am agree what Roi Raj is saying we should call ourselves as I am a Ho - I am a Munda.

... They have termed us as tribes. We have accepted this without questioning and without shame. The term tribal or tribe is humiliating and insulting. We are not challenging social theories evolved by others. This is nothing but social construction. It seems to be sometimes we so called educated people are merely literate. It is a clear manifestation of mental slavery on our part. How long will it take for us. Or i must assume that we do not want to come out from this psychological slavery.

Note that these challenges to the notion of "tribe" and its cognates (adivasi, janjati, indigenous, etc.) come from aspirational adivasi youth. To dismiss them as somehow exceptional would not only neglect a longer historical relationship between adivasi communities and a range of print and electronic media (Choksi 2017; Schleiter 2014), but also reinforce the colonial and postcolonial logics of primitivism in which they are entrapped. Just as in offline exchanges discussed earlier, online interactions, too, generate a distinctive critique of the "savage slot" (Trouillot 2003). The politics of "primitivism" is thus called into question in both real and virtual forums, albeit in different ways, even as its usefulness in producing tropes that popularise the adivasi cause may be grudgingly acknowledged. Youthful critiques of primitivism and, indeed, of the notion of indigeneity itself are a mirror image of non-adivasi representations of adivasis such as GCN, and they destabilise tropes of backwardness and savagery associated with the "primitive" even as they popularise new imagery of an "eco-savage" (Shah 2010: 107; cf. Whelan 1999) for our times. These competing articulations of indigeneity, paradoxically, nourish the figure of the "primitive" under conditions of primitive accumulation in 


\section{8}

contemporary India. The modern adivasi subject thus continues to be regarded as an oxymoron in activist and popular discourses.

\section{Conclusion}

This chapter has attempted an analysis of one particular instance of mediatised indigeneity activism in contemporary South Asia. GCN, as I have shown, is a complex bricolage of words, images and music that seeks to claim the "indigenous slot" (Karlsson 2003) for those who were cast previously in the "savage slot" (Trouillot 2003) as primitives and who now face the full onslaught of primitive accumulation in India. But the audiences that view GCN are an equally complex bricolage of interests, ideologies and agendas. The mere fact that the bulk of India's mining resources are located in the scheduled areas does not necessarily imply that all adivasis are equally affected by extractive industries or land acquisition bids. Munda adivasis in Khunti do not identify with the politics of GCN in any straightforward way. They appreciate the good intentions of their urban middle-class patrons but do not, in fact, claim the indigenous or savage slots for themselves.

No one denies that mediatised activism in the form of music videos such as GCN spread awareness of the problems faced by adivasis in India today. Such activism certainly transcends the militant particularisms of specific local circumstances, but it is also accurate to say that it homogenises disparate adivasi experiences into a neat, coherent "activist simplification" (Chandra 2013c). At the heart of this activist simplification is the figure of the "primitive" fighting against primitive accumulation, a struggle that is both ours as the audience and not ours. As different audiences offline and online interpret GCN, the activist simplification refracts once more according to our different interests as viewers. Indians relate to the "primitive" in different ways, and the threat to this bulwark posed by subcontinental modernity (Ghosh 2006) brings out their deepest fears and anxieties over their own future as a nation, civilisation, and indeed, humanity at large. It is useful to remember, however, that these fears and anxieties are not the same as those of adivasis in Khunti or Kashipur. Despite the "primitive" or "indigenous" being a key symbol of ineradicable difference in our postmodern times, it is also an object of our neo-romantic longing for cultural authenticity that arguably never existed at all. The political-economic and sociocultural logics that make and remake "primitive" subjects in modern India cannot be counterposed to the logics of primitive accumulation because, in fact, they coincide.

\section{Acknowledgments}

I would like to thank Erik de Maaker and Markus Schleiter for inviting me to contribute an early draft of this chapter to the workshop on "Tribes on Screen: Mediatizing South Asian Indigeneity" in the Völkerkundemuseum of the University of Zurich on 22 June 2014. Comments and suggestions from fellow participants, along with those of the anonymous reviewers for the journal Interventions, were immensely helpful in improving and revising this chapter. 


\section{Notes}

1 This chapter was originally published in the journal Interventions as Uday Chandra, "Primitive Accumulation and 'Primitive' Subjects in Postcolonial India: Tracing the Myriad Real and Virtual Lives of Mediatized Indigeneity Activism," Interventions, vol. 19, no. 3 (2017), pp. 322-337, DOI: 10.1080/1369801X.2016.1231583 and is reproduced here with kind permission of the publisher.

2 Interest in watching a Bollywood film here should not be taken to imply a lack of interest in GCN. It was, after all, watched with keen interest not once but twice by the audience in Longa. There is arguably space for both here, though they certainly do elicit different affective responses.

3 It would be a mistake to see the likes of Johan and Barnabus as "elite" in an unqualified sense. While they do hold college degrees, they were not the only graduates in the audience at Longa, and their families, in fact, counted among the land-poor locally. Education is certainly a resource in contemporary rural India, but it ought to be seen alongside other resources that individuals and households possess or lack. It is important here to appreciate that the village headman in Longa actually lacked any substantial education or wealth but exercised certain inherited privileges associated with his office.

4 These audiences and interests are, I suggest, best understood in terms of social interfaces between the adivasi village community and other lifeworlds that intersect with it. I resist the temptation here to distinguish between "elite" and "non-elite" because, theoretically as well as empirically, the quest for finding the authentic subaltern subject may ultimately prove to be a futile one. Tensions between younger and older villagers over what it means to be adivasi were, I found during my fieldwork, reproduced throughout the village community.

5 I am not suggesting that these virtual voices can be unproblematically treated as coeval with those voices that we encounter during fieldwork. But I am also not arguing for a sharp divide between political realities online and offline. To the extent that my argument contributes to a vast, growing body of scholarship on mediatised political environments in contemporary India, I urge readers to reflect on how different forms of media and society are enmeshed with each other as they consider the evidence offered in this chapter.

\section{References}

Banerjee, Prathama. 2006. "Culture/Politics: The Irresoluble Double-Bind of the Indian Adivasi." Indian Historical Review 33 (1): 99-126. doi: 10.1177/037698360603300106.

Bates, Crispin, and Alpa Shah (eds.). 2014. Savage Attack: Adivasis and Insurgency in India. New Delhi: Social Science Press.

Béteille, Andre. 1998. “The Idea of Indigenous People.” Current Anthropology 39 (2): 187-192. doi: 10.1086/204717.

Bräuchler, Birgit, and John Postill (eds.). 2010. Theorizing Media and Practice. New York: Berghahn Books.

Chakrabarty, Dipesh. 2006. "Politics Unlimited: The Global Adivasi and Debates about the Political." In The Politics of Indigeneity in India, edited by Bengt A. Karlsson and Tanka B. Subba, 235-246. New Delhi: Routledge.

Chandra, Uday. 2016. "Flaming Fields and Forest Fires: Agrarian Transformations and the Making of Birsa Munda's Rebellion." The Indian Economic and Social History Review 52 (1): 69-98. doi: 10.1177/0019464615619540.

Chandra, Uday. 2013a. "Liberalism and Its Other: The Politics of Primitivism in Colonial and Postcolonial Indian Law." Law \& Society Review 47 (1): 135-168. doi: 10.1111/ lasr.12004. 
Chandra, Uday. 2013b. "Beyond Subalternity: Land, Community, and the State in Contemporary Jharkhand." Contemporary South Asia 21 (1): 52-61. doi: 10.1080/09584935. 2012.757579 .

Chandra, Uday. 2013c. "Going Primitive: The Ethics of Indigenous Rights Activism in Contemporary Jharkhand.” South Asia Multidisciplinary Academic Journal 7. doi: 10.4000/ samaj.3600.

Chatterjee, Partha. 2008. "Democracy and Economic Transformation in India." Economic \& Political Weekly 43 (16): 53-62.

Choksi, Nishaant. 2017. "From Language to Script: Graphic Practice and the Politics of Authority in Santali-Language Print Media, Eastern India.” Modern Asian Studies 51 (5): 1519-1560.

Ghosh, Kaushik. 2006. "The Modernity of Primitive India: Adivasi Ethnicity in Jharkhand and the Formation of a National Modern." PhD diss., Princeton University.

Ginsburg, Faye D. 1995. "The Parallax Effect: The Impact of Aboriginal Media on Ethnographic Film.” Visual Anthropology Review 11 (2): 64-76. doi: 10.1525/var.1995.11.2.64.

Ginsburg, Faye D., Lila Abu-Lughod, and Brian Larkin (eds.). 2002. Media Worlds: Anthropology on New Terrain. Berkeley: University of California Press.

Glassman, Jim. 2006. "Primitive Accumulation, Accumulation by Dispossession, Accumulation by 'Extra-Economic' Means.” Progress in Human Geography 30 (5): 608-625. doi: 10.1177/0309132506070172.

Harvey, David. 1995. "Militant Particularism and Global Ambition: The Conceptual Politics of Place, Space, and Environment in the Work of Raymond Williams." Social Text 42 (Spring): 69-98. doi: 10.2307/466665.

Harvey, David. 2003. The New Imperialism. New York: Oxford University Press.

Hodgson, Dorothy. 2011. Being Maasai, Becoming Indigenous: Postcolonial Politics in a Neoliberal World. Bloomington: Indiana University Press.

Jung, Courtney. 2006. The Moral Force of Indigenous Politics: Critical Liberalism and the Zapatistas. New York: Cambridge University Press.

Karlsson, Bengt G. 2003. "Anthropology and the 'Indigenous Slot': Claims to and Debates about Indigenous Peoples' Status in India.” Critique of Anthropology 23 (4): 403-423. doi: 10.1177/0308275X03234003.

Kuper, Adam. 2003. "The Return of the Native." Current Anthropology 44 (3): 389-402. doi: $10.1086 / 368120$.

Li, Tania M. 2010. "Indigeneity, Capitalism, and the Management of Dispossession." Current Anthropology 51 (3): 385-414. doi: 10.1086/651942.

Mamdani, Mahmood. 1996. Citizen and Subject: Contemporary Africa and the Legacy of Late Colonialism. Princeton, NJ: Princeton University Press.

Mamdani, Mahmood. 2013. "What Is a Tribe?" London Review of Books 34 (17): 20-22.

Mantena, Karuna. 2010. Alibis of Empire: Henry Maine and the Ends of Liberal Imperialism. Princeton, NJ: Princeton University Press.

Marx, Karl. 1967. Capital: A Critique of Political Economy, Volume 1. New York: International Publishers.

Padel, Felix. 2009. Sacrificing People: Invasions of a Tribal Landscape. New Delhi: Orient Blackswan.

Padel, Felix, and Samarendra Das. 2010. Out of This Earth: East India Adivasis and the Aluminium Cartel. New Delhi: Orient Blackswan.

Perelman, Michael. 2000. The Invention of Capitalism: Classical Political Economy and the Secret History of Primitive Accumulation. Durham, NC: Duke University Press. 
Roy Burman, B. K. 2009. “'Adivasi'-A Contentious Term to Denote Tribes as Indigenous Peoples of India": South Asia Citizens Web (27 July). www.sacw.net/article1066.html. Accessed on 24 May 2019.

Sanyal, Kalyan. 2007. Rethinking Capitalist Development: Primitive Accumulation, Governmentality and Post-Colonial Capitalism. New Delhi: Routledge.

Sasi, Karivannoor, P. 2008. Gaon Chodab Nahin ("We Shall Not Leave Our Village") India: $5 \mathrm{~min}$. www.youtube.com/watch?v=8M5aeMpzOLU. Accessed on 9 December 2018.

Schleiter, Markus. 2014. "VideoCD Crossovers: Cultural Practice, Ideas of Belonging and Santali Popular Films." Asian Ethnology 73 (1-2): 181-200.

Shah, Alpa. 2010. In the Shadows of the State: Indigenous Politics, Environmentalism, and Insurgency in Jharkhand, India. Durham, NC: Duke University Press.

Singh, Kumar Suresh. 1966. The Dust-Storm and the Hanging Mist: A Study of Birsa Munda and His Movement in Chotanagpur, 1874-1901. Calcutta: Firma K.L. Mukhopadhyay.

Spivak, Gayatri C. 1988. "Subaltern Studies: Deconstructing Historiography." In Selected Subaltern Studies, edited by Ranajit Guha and Gayatri Chakravorty Spivak, 3-32. New Delhi: Oxford University Press.

Sylvain, Renée. 2014. "Essentialism and the Indigenous Politics of Recognition in Southern Africa." American Anthropologist 116 (2): 1-14. doi: 10.1111/aman.12087.

Trouillot, Michel-Rolph. 2003. "Anthropology and the Savage Slot: The Poetics and Politics of Otherness." Chapter 1 in Global Transformations: Anthropology and the Modern World. New York: Palgrave Macmillan.

Varma, Rashmi. 2002. "Developing Fictions: The 'Tribal' in the New Indian Writing in English.” In World Bank Literature, edited by Amitava Kumar, 216-233. Minneapolis: University of Minnesota Press.

Varma, Rashmi. 2013. "Primitive Accumulation: The Political Economy of Indigenous Art in Postcolonial India." Third Text 27 (6): 748-761. doi: 10.1080/09528822.2013.857902.

Whelan, Robert. 1999. Wild in Woods: The Myth of the Noble Eco-Savage. London: IEA Environment Unit.

Whitehead, Judith. 2010. Development and Dispossession in the Narmada Valley. New York and New Delhi: Pearson International.

Wilson, Pamela, and Michelle Stewart (eds.). 2008. Global Indigenous Media: Cultures, Poetics, and Politics. Durham, NC: Duke University Press. 


\title{
7 Giving voice? Experiences of collaboration on indigenous video-making projects
}

\author{
Radhika Borde
}

\section{Introduction}

A volume that explores the visualisation of indigenous cultures invites an examination of issues pertaining to the representation (including the self-representation) of the marginalised Other. The United Nations considers indigenous peoples to constitute non-dominant sections of society (Cobo 1986), i.e., people who have been suppressed by other groups. The International Labour Organization regards indigenous people as socio-economically and culturally distinct from the majority groups alongside which they co-exist in the various nation-states in which they can be found (ILO 1989: Art. 1.1). In short, international organisations' definitions of indigenous peoples focus on their marginalisation and cultural otherness. As such, indigenous people can be seen as subalterns in the sense described by the postcolonial scholar Gayatri Spivak, i.e., as people who are marginalised, culturally other, and spoken for and about (Spivak 1988).

There has been much discussion surrounding the issue of giving voice to the subaltern, of whether and how the subaltern can be heard (Maggio 2007; Alcoff 1991; Spivak 1988). Scholars such as Sivaramakrishnan argue that subalterns are embedded in an epistemological framework that is at odds with that of mainstream society (Sivaramakrishnan 1995). It has also been argued that subalterns can occupy a place of aporia between subject and object status - the term aporia denoting a logical contradiction (Morton 2011). In other words, subalterns may not be able to speak as subjects, despite their attempts to overcome their position as the object of the speech of others. How subalterns can or cannot 'speak', i.e., have their speech acknowledged, is a problem that has been addressed in academic debates for some time. However, I would like to reformulate the question, and ask whether the subaltern actually wants to speak and wants to be heard. I will examine this question with reference to my own experiences of working with an indigenous documentary filmmaker in the Indian state of Jharkhand on a project that involved the production of activist videos to raise awareness about anti-mining movements.

Indigeneity is a contested category in India, which does not receive official recognition from the Indian government (Karlsson 2003). Nevertheless, groups that have historically experienced marginalisation and isolation do claim 
indigenous identities and are given special rights and privileges by the Indian government to combat their marginalisation and isolation from the Indian mainstream (Rycroft 2014). In much of central India, these groups choose to refer to themselves as Adivasis, which is a term that is derived from Sanskrit and means 'original dwellers'. It has been used since the 1930s for the purpose of political self-assertion (Kela 2006). Officially, the Indian government refers to Adivasis as 'Scheduled Tribes'. Along with Scheduled Castes (groups that are at the bottom of the Hindu caste hierarchy), members of Scheduled Tribes benefit from statesponsored affirmative action programmes. However, it has been argued that the primary beneficiaries of such measures tend to be the elite members of the respective communities (Corbridge 2000). Some NGOs have been working together with Adivasis to aid them in furthering their socio-economic development as well as in ensuring that their land rights are not violated. However, there are also a few NGOs that stand accused of working as agents of the state and of multinational corporations (Kapoor 2013). Nonetheless, particularly in East Central India, some NGOs such as BIRSA and PUCL have focused on defending Adivasi land rights and preventing the acquisition of Adivasi land for mining projects. In this chapter, I will present an auto-ethnographic case study (cf. Anderson 2006), which describes my work with one such NGO and discusses how the issue of giving voice to Adivasis came up in relation to my work.

\section{Case study}

The case study that I present in this chapter is based upon my own experiences of working at an NGO (which I shall not name) in Ranchi, the capital of Jharkhand. The NGO's work focused on the protection of Adivasi land from mining. The NGO had a policy of employing Adivasis - many of whom came from areas that had been affected by mining and some of whom had family members who had personally experienced the loss of their land. I wasn't an Adivasi myself, and although I had grown up in the state of Jharkhand, which is rich in minerals and where land is always being prospected for mineral extraction, my family hadn't lost any of their land. Though my family is not Adivasi, it also cannot claim to belong to the caste Hindu population. The reason that I was hired was unclear to me, but it seemed to me that the de facto director of the NGO, who wasn't an Adivasi himself, believed that since I was already doing work to support Adivasis (as a social entrepreneur to revive an Adivasi craft), it would be good to grant me the opportunity to work with the Adivasis in the NGO he was leading.

I was assigned the role of coordinator of the NGO's media cell, and was allotted the task of managing the production of YouTube videos that would present the plight of the Adivasis in Jharkhand and neighbouring parts of Odisha who were trying to resist the acquisition of their land for mining. The NGO I was working for had created a non-party political organisation that was coordinating the struggle against approximately 100 mining projects in Jharkhand and Odisha. Although the NGO focused on championing Adivasi issues, it also supported the struggle of Dalit villagers ${ }^{1}$ who were resisting the acquisition of their land for coal mining by 


\section{Radhika Borde}

the National Thermal Power Corporation. The most powerful memories I have from my time at the NGO relate to my experiences of interacting with the grassroots activists who came to the office of the NGO in Ranchi from their various villages in Jharkhand and Odisha, and of my interactions with my Adivasi filmmaker colleague, whom I was supposed to 'manage'.

As the coordinator of the media cell of the NGO, I was in charge of the media cell's output, which was to be the activist YouTube videos mentioned above. My colleague, whom I shall call Mangal, was a Ho Adivasi man in his early thirties from a village near the town of Chaibasa in Jharkhand. He had received training in filmmaking and videography in New Delhi, sponsored by the NGO. A quiet and extremely reflective character, Mangal was a man of great intellectual depth, as I came to learn in the course of our interaction. The head of the NGO had described how Mangal had reacted to the presentation of a new piece of software that the NGO was planning to use. He had asked, after listening to an extremely complex and intimidating account of the functionalities of the software, "But, how it is going to be helpful?" According to the head of the NGO, this was evidence of Mangal's deep and pragmatic intelligence. And, over the course of our interaction, I have to say that I came to agree with this assessment of Mangal. Mangal tried to teach me many amazing things in regard to the way he believed life should be lived (which I don't think I learned). For my part, I tried to explain to him how things were generally done.

Mangal and I were to produce the YouTube videos together. This had not been done by the NGO before, although the NGO had worked on several documentary filmmaking projects. The previous manager of the media cell had been a documentary filmmaker. I felt that I was technically underqualified for the task I had been assigned, but I was reassured that Mangal would make the YouTube videos and I was to be a creative director and manager of sorts. Since I had not joined the NGO in order to work on media projects, but to learn more about Adivasis and the issues they were facing, it is unsurprising that my communication with Mangal did not fall into the standard pattern prescribed by management textbooks. To begin with, Mangal was about eight years senior to me and had never been supervised by a woman before. Furthermore, just prior to my joining the NGO, Mangal had been involved in a car accident that had resulted in traumatic injury to his head. It had not impaired him in any way, but the experience had left him emotionally vulnerable. It is easy to imagine that I often asked myself why I had been assigned the task of managing him. Maybe our boss was just curious to see what would happen?

In the beginning, Mangal and I approached our assigned task by working on the production of the videos together. Mangal liked the idea of teaching me the ropes, and his technical skills were so far superior to mine that I thought this was probably the best way to start. I knew nothing about video production or how pieces of footage are strung together and edited. So Mangal was my guide in this terrain. After working with him for a while, I realised that despite his technical skills, Mangal had never made a video before. Part of the reason for this was that he had never been given the chance. And another part of the reason was that he was not very keen to do so. The previous manager of the NGO's media cell had been a 
filmmaker with several acclaimed documentaries under his belt. Mangal used to shoot footage under his direction and, by watching him edit the video and sound, had learnt about the process. He knew everything that making a video involved. However, as he confessed to me, he found the process of working on and making activist videos traumatising. Watching footage of Adivasis being harassed, intimidated, and even shot at made him very angry. He would much rather shoot footage of Adivasi culture before it disappeared, he told me. That was his main interest. But it was not the NGO's mandate.

I was very keen for Mangal to express himself, and was determined to avoid speaking for him. Therefore, I proposed that our collaborative work should aim to allow Mangal to express through video what he had told me he wanted to show the world. We would find a way to make the sorts of videos that Mangal wanted to make. I remember him expressing an interest in mundane visual details. We were once assigned to record footage of an activist rally and meeting concerned with the Chotanagpur Tenancy Act, a piece of legislation that protected Adivasi land. Next to the rally ground, a few vendors were selling handia, the traditional rice beer that Adivasis in Jharkhand drink. We watched a man in a dhoti sit down on his haunches and accept a leaf-cup of handia. "That is the sort of thing I want to capture," said Mangal. "The way he sits down, adjusts his dhoti and takes the handia. It is very typical. I want to show how Adivasi villagers do these ordinary things that mean so much to them. This is what I mean by capturing Adivasi culture." He did not shoot those specific moments but he did record others like them, and went on to include such footage in one of the videos he made later. It showed a group of Adivasi women dancing at a wedding. The dance was the traditional rhythmic and communal Adivasi dance that is performed by women with their arms linked together. The dance that Mangal filmed was not a performance for an audience - the women were dancing for themselves and indeed they looked as if they had had quite a bit of handia and were in a trance of sorts. Mangal told me he wanted to show how well coordinated and in time with one another the women were. How they almost lost themselves in the dance. It seemed as if the dance allowed them to express their collectivity.

Mangal was very clear about the message he wanted to convey, and that his message should be a positive one. He insisted that it had not been good for him to work on activist documentary films and to make videos that focused on the suffering of Adivasis and their oppression by the police and the state. He wanted to capture the beautiful, mundane details of Adivasi life. Mangal was also emphatic that Adivasi life was village life. When Adivasis became urbanised they stopped being Adivasi. "I am no longer Adivasi," he told me. "An Adivasi is someone who lives in the village and relates to his environment as Adivasis have always done. I have left that behind and now I am trying to capture it."

However, these videographic expressions of Mangal's love for Adivasi village culture were few and far between. Mangal wanted to express himself, but felt that he was unable to - and that in fact it was safer for him not to do so. After a while, it became clear to me that Mangal wasn't just nostalgic for his Adivasi life in the village. He was quite suspicious of the NGO we were working for and of our 
colleagues. He would often tell me that the strategy he had followed before my arrival had been to lie low and avoid attracting attention. According to him, if he attracted attention people would be jealous of him and make life difficult for him. He was worried that by encouraging him to express himself, I was going to put him at risk of experiencing the jealousy of his colleagues. I remember several discussions during which I told him I wanted to help him to excel at his work and express himself in the way that he had always wanted to. He told me two stories in response, which I have not forgotten. They were almost parables.

The first story that Mangal told me was about how the search for 'more' (and this included demanding more from oneself) resulted in people feeling lost. "Let me tell you a story," he said one day.

It is a story of the time before aeroplanes and before there were big buildings. But at that time, before all this, there were people and those people lived in the forest and had cows. The cows would keep getting lost in the forest, so the people put bells around the necks of the cows so that when the cows got lost they would be able to find them by listening for the bells. Now, we have aeroplanes and big buildings. And there are still people. And these people have mobile phones around their necks that keep ringing, and they keep ringing because the people are lost. That's what all our human activity and excellence has brought us to.

The second story that Mangal told me was about how he had lost his sense of community feeling after coming to work in the NGO in the city. "When I first came here," Mangal said,

I thought that I would cook and other people would cook, and we would all cook a little bit and we would all eat together. But then I saw that this didn't happen. So I decided that $I$ would cook and $I$ would eat. Everything just had to be for me.

After listening to all his stories it became clear to me that Mangal didn't really want to represent Adivasi village life through the lens of a camera. He wanted to go back to living it. And it was there for him to live and to enjoy. It was just that he had been taken from his village, as he described it, by the people who were working with the NGO. He had been taken away because he had shown himself to be an Adivasi youth leader of some capability, and now here he was in an NGO in a city he wanted to escape from, faced with the task of making videos about how Adivasis were suffering.

Mangal and I made several videos together. Some of them contained footage supplied by activists in the field, and many of them contained powerful and disturbing images of violent clashes between Adivasi protesters and the police in Jharkhand. We did this because it was our job, and I at least imagined that the circulation of these sorts of videos would draw attention to the police oppression that was being experienced by Adivasis who were resisting the acquisition of their 
land for mining. One of the videos we made showed how police in the district of Dumka in Jharkhand fired upon Adivasi protesters in 2008. The video has received 25,486 views to date. ${ }^{2}$ But now, many years later, I am still not sure whether the circulation of this video and others like it has done anything to make the police reconsider the ways that they react to Adivasi protests. The blaming and shaming of the government by activist media does not appear to have had a great impact. Over a year ago, a similar incident occurred in the village of Badkagaon in Jharkhand. The police fired upon, killed, and injured Adivasi protesters. The ineffectiveness of activist video-making had disillusioned Mangal. He had seen the making of many documentary films that presented hard-hitting evidence of the manner in which the government was trampling upon the rights and lives of Adivasi citizens. But little had resulted from the production and circulation of such videos.

Mangal's interest in capturing the ordinary, mundane details of Adivasi village life was a reaction to the ineffectiveness of these political videos. It was also a reaction to the sort of Bollywood-inspired video-making that had become popular amongst Adivasis. Mangal always maintained that he wanted to record the things people didn't really pay attention to, that weren't fashionable. It wasn't that he was romanticising Adivasi culture, although he was certainly nostalgic for something he had left behind. That's why he was convinced that certain small, culturally specific details were so important.

Mangal and I had around six months to explore video-making together and to discuss his insecurities and meditative reflections on life. I ended up leaving the NGO because I was afraid that one of the videos that our boss insisted we should make would put an Adivasi activist in danger. It was an interview conducted by the head of the NGO with a grassroots-level activist on the subject of how goons who were understood to have been paid by a large company had threatened him at gunpoint. We had never filmed an interview of this sort before and I did not feel that I had control over the process, which did not include any provisions for protecting the interviewee's identity. A few days after the interview was filmed, the interviewee was arrested, although he was later released.

Mangal also ended up leaving the NGO and returning to his village, where he now seems to be enjoying a good life. While I was still working at the NGO, our colleagues had told me that he was a rich man. His wealth, however, was in the form of land. His family owned ten acres of farmland in a village near Chaibasa in Jharkhand. All his siblings had government jobs and none were interested in working the family's land. His mother had fallen ill and Mangal often told me that it was ironic that she had given birth to so many sons and yet none of them were ultimately interested in caring for her. Several months after I left the NGO, Mangal came to visit me at my home. Very quietly, in his characteristic manner, he told me that he had planted trees $-6,000$ trees. "Six thousand trees?" I asked. "Yes," said Mangal. "I get a salary of 6,000 rupees from the NGO and you can buy a tree sapling for a rupee. So I bought 6,000 fruit trees and I have planted them on part of our land. It was very hard work." Mangal told me that he was going back to live off his land. I was happy for him. Filmmaking had never really been his primary 


\section{8}

interest. He had told me that it had been his dream to make small improvements to the way agriculture was done in his village. He liked tinkering with machines and getting them to work better. He had enjoyed fixing broken radios in his spare time at the NGO's office. In a recent telephone conversation, Mangal seemed to be happy - he agreed that his time at the NGO had been very challenging.

\section{Ventriloquy}

After working with Mangal and witnessing how he struggled through his various insecurities, what life in his village meant to him and how he returned to it, I can't help but find myself reflecting upon the representation of those who are considered marginalised. Adivasis constitute a group that well-meaning activists often want to champion and in many cases this results in activists imposing what they believe is best upon Adivasis' self-understanding and self-representation. I think it was important that I interacted with Mangal from a position that demonstrated that I was 'angled towards' him, to use the language with which postcolonial scholar Gayatri Spivak prescribes an ethical or responsible relationship with the Other (as cited in Chakravorty, Milevska and Barlow 2006). It allowed Mangal to open up and discuss the things that were troubling him. I also shared and discussed the things that were troubling me - including my reservations regarding the work that we were doing. Of course, in re-presenting Mangal in this chapter I cannot help but portray him inaccurately - it is inevitable that my own consciousness colours what I remember of his behaviour. I am also representing him, i.e., speaking on his behalf and that of others like him who are put into a position of speaking for their community when they would rather avoid such a role. But I hope that my conscious understanding of these dynamics à la Spivak (Kapoor 2004) ameliorates whatever damage my representation and re-presentation risks. ${ }^{3}$

Ventriloquism is an important dynamic to consider in the context of activism, especially when grassroots-level activists are brought into the world of professional activism. In the NGO, Mangal was asked to make the sort of videos and films that the NGO thought would further its cause. It could have hired professional filmmakers to make these videos, but felt that employing Adivasis from villages and training them to do the work would demonstrate a greater commitment to the NGO's espoused mandate of working for the empowerment of Adivasis. Mangal liked technology, but his sensitivity to the recording and screening of his people's suffering made it hard for him to enjoy his job. He told me that the sorts of feelings he experienced were never discussed within the NGO, and that it was perhaps necessary for a space to be created where such feelings could be discussed.

The NGO was representing Adivasis, i.e., speaking on their behalf and representing them via the production of videos, films, images, posters, and reports. The fact that the NGO had predominantly hired Adivasis to do such work did not mean that the Adivasis were representing themselves. Rather, I would like to argue that this resulted in a situation in which Adivasis were representing other Adivasis, but in ways that they were perhaps not entirely comfortable with. It can be argued that Adivasis such as Mangal became like ventriloquists' puppets, hired to speak 
about the issues facing Adivasis in Jharkhand - in accordance with the NGO leadership's understanding of the issues. Clearly, a critical examination of issues of representation is called for.

\section{Controversies surrounding representation}

The controversial question of the representation of Adivasis by non-Adivasi activists came to the fore in Jharkhand in 2011, when two non-Adivasi activists who had spent several years supporting Adivasi causes in India were awarded the Gandhi Foundation International Peace Award by the London-based Gandhi Foundation. It was announced on the Foundation's website that the awardees would accept the award on behalf of the Adivasis of India. The phrasing of this announcement provoked protests from Adivasi activists, who took issue with the notion that the award would be accepted 'on behalf of' the Adivasis of India - by two non-Adivasis. I mention this controversy as a further example in which Adivasis have clearly expressed their resentment towards being represented by others. Furthermore, the fact that some Adivasis can and want to represent themselves, write about themselves, and make videos about themselves is well accepted. As scholars working on these themes have advised, however, it is important to avoid an uncritical celebration of acts of self-representation by Adivasis (Radcliffe 2014). A great deal of what is expressed by Adivasis working in the field of media is created in accordance with expectations as to how media productions will be received by wider society. As Gayatri Spivak has pointed out, speech-acts are constituted of both speaking and hearing (Spivak 1988). Hence, subalterns who wish to speak their way out of their subalternity need to speak in a way that makes others listen. But are they then still speaking authentically? Are they then really able to voice themselves? And if they are not able to voice themselves authentically, does it really matter who does the voicing?

\section{Conclusion}

Mangal's case is reminiscent of a similar, perhaps even more serious situation that emerged in relation to the Niyamgiri Movement in the state of Odisha. The Niyamgiri Movement's objective was to resist the acquisition of the Niyamgiri mountain for mining by the multinational mining company Vedanta Resources, on the grounds that the mountain was sacred. The volte-face of Jitu Jakesika during the process provides another interesting example of how the pressure to self-represent as encouraged by activists can have serious consequences for the person concerned and for the movement for which the person may have become a representative. A young, educated Adivasi man, Jitu had at one time been the main face and voice of the Adivasis in the Niyamgiri Movement. He appeared in a very successful documentary film that Survival International had made about the movement. The voiceover in the documentary was narrated by the British actress Joanna Lumley, and its YouTube version has received 708,329 views to date. But when the Niyamgiri movement was at its height, Jitu chose to abandon it, accepting instead a 
fellowship from Vedanta Resources to embark upon an undergraduate programme in business management. By accepting this scholarship, Jitu Jakesika did in fact switch sides in the Niyamgiri Movement. In a study of Jitu's change of direction, his description of his confusion and exhaustion as an activist in the Niyamgiri Movement is cited: "Sometimes I was utterly tired that time, means I had no peace that time. . . . Like I was mentally . . broken. So I couldn't study because of these guys [activists], I [also] couldn't go to my family" (in Kraemer, Whiteman and Banerjee 2013).

As the example of Jitu's defection from the Niyamgiri Movement demonstrates, a subaltern who finds himself/herself the object of vociferous representations/ re-presentations, as well as pressured into being the subject of his/her selfrepresentation, may find it hard to find his/her own voice. It is also an example of how Adivasis might find themselves occupying a place of aporia, where they shuttle between being spoken for and speaking for themselves - a place that does not really give voice. With the increasing dissemination of video-making technology amongst Adivasis, it is unlikely that this problem will be resolved, and it may perhaps only be compounded, if there is not an accompanying attempt to help Adivasis find a way out of subalternity, so that they are not pressured to become the puppets of hegemonic ventriloquists or of counter-hegemonic voices that they may not necessarily identify with.

\section{Notes}

1 Communities that have faced marginalisation due to their perceived position at the bottom of the Indian caste hierarchy.

2 JMACC Ranchi. 2009. Jharkhand - Police Firing Dumka 1. www.youtube.com/ watch?v=7DCdVVcMG_8\&t=16s [accessed on 17.6.2018].

3 For a discussion on the different nuances of representation and re-presentation, see Spivak (1988).

4 Survival International. 2009. The Real Avatar: Mine - Story of a Sacred Mountain. www. youtube.com/watch? $\mathrm{v}=\mathrm{R} 4 \mathrm{tuTFZ3} \mathrm{wXQ} \& \mathrm{t}=174 \mathrm{~s}$ [accessed on 17.6.2018].

\section{References}

Alcoff, Linda. 1991. "The Problem of Speaking for Others." Cultural Critique 20: 5-32.

Anderson, Leon. 2006. "Analytic Autoethnography." Journal of Contemporary Ethnography 35: 373-395.

Chakravorty, Swapan., Milevska, Suzana. and Tani E. Barlow. 2006. Conversations with Gayatri Chakravorty Spivak. Calcutta and New York: Seagull Books.

Cobo, José. M. 1986. "Study of the Problem of Discrimination against Indigenous Populations." Sub-Commission on Prevention of Discrimination and Protection of Minorities. (E/CN.4/Sub.2/L. 566. Paragraph 34).

Corbridge, Stuart. 2000. "Competing Inequalities: The Scheduled Tribes and the Reservations System in India's Jharkhand." The Journal of Asian Studies 59 (1): 62-85.

International Labour Organization. 1989. C169: Indigenous and Tribal Peoples Convention, 1989 (No. 169). www.ilo.org/dyn/normlex/en/f?p=NORMLEXPUB:12100:0::NO: :P12100_ILO_CODE:C169. Accessed on 22 September 2016. 
Kapoor, Dip. 2013. "Trans-Local Rural Solidarity and an Anticolonial Politics of Place: Contesting Colonial Capital and the Neoliberal State in India." Interface: A Journal for and about Social Movements 5 (1): 14-39.

Kapoor, Ilan. 2004. "Hyper-Self-Reflexive Development? Spivak on Representing the Third World 'Other'." Third World Quarterly 25 (4): 627-647.

Karlsson, Bengt G. 2003. "Anthropology and the 'Indigenous Slot': Claims to and Debates about Indigenous Peoples' Status in India.” Critique of Anthropology 23 (4): 403-423.

Kela, Shashank. 2006. "Adivasi and Peasant: Reflections on Indian Social History." The Journal of Peasant Studies 33 (3): 502-525.

Kraemer, Romy., Whiteman, Gail, and Banerjee, Bobby. 2013. "Conflict and Astroturfing in Niyamgiri: The Importance of National Advocacy Networks in Anti-Corporate Social Movements." Organization Studies 34 (5-6): 823-852.

Maggio, Jay. 2007. “'Can the Subaltern Be Heard?': Political Theory, Translation, Representation and Gayatri Chakravorty Spivak." Alternatives 32: 419-443.

Morton, Stephen. 2011. "Subalternity and Aesthetic Education in the Thought of Gayatri Chakravorty Spivak." Parallax 17 (3): 70-83.

Radcliffe, Sarah. A. 2014. "Plural Knowledges and Modernity: Social Difference and Geographical Explanations." In Traditional Wisdom and Modern Knowledge for the Earth's Future: Lectures Given at the Plenary Sessions of the International Geographical Union Kyoto Regional Conference, 2013, edited by K. Okamoto and Y. Ishikawa, 79-102. Tokyo: Springer.

Rycroft, Daniel. J. 2014. "Looking Beyond the Present: The Historical Dynamics of Adivasi (Indigenous and Tribal) Assertions in India." Journal of Adivasi and Indigenous Studies 1 (1): 1-17.

Sivaramakrishnan, Kalyanakrishnan. 1995. "Situating the Subaltern: History and Anthropology in the Subaltern Studies Project." Journal of Historical Sociology 8 (4): 395-429.

Spivak, Gayatri. C. 1988. “Can the Subaltern Speak?” In Marxism and the Interpretation of Culture, edited by C. Nelson and L. Grossberg, 271-313. London: Macmillan Education Ltd.

\section{Videos}

Jharkhand: Police Firing Dumka 1. Uploaded on 27.1.2009. www.youtube.com/ watch? $=7$ DCdVVcMG_8\&t=16s. Accessed on 17 June 2018.

The Real Avatar: Mine - Story of a Sacred Mountain. Uploaded on 31.3.2009. www. youtube.com/watch?v=R4tuTFZ3wXQ. Accessed on 17 June 2018. 


\title{
8 From clanships to cyber communities
}

\author{
India's Northeast in the digital age
}

\author{
Daisy Hasan
}

\section{Introduction}

As I was completing this essay, a controversy, which throws into sharp relief some of the key concerns of this chapter, was raging in the Indian media. On Sunday 25 June 2017, Tailin Lyngdoh (a Khasi governess from Meghalaya, one of the eight states of Northeast India) accompanied her employer to the Delhi Golf Club for lunch dressed in the indigenous attire of her region. She was denied entry to the club on the grounds that she looked like "a maid". This incident hurt the sentiments of indigenous people from Northeast India. These people have a fraught relationship with the Indian mainstream, as I will elucidate in the following case studies that showcase the ways in which race is imagined, negotiated, and mediated. I want to ask whether the ways in which race and indigenous identity are articulated and narrated in public media forums are exclusionary or facilitate cultural and political democracy. New and digital media enable marginalised communities to mobilise supporters easily and quickly. Today there are new networks that are sustained by intense affective affiliation or common identity projects (Dean 2016; Kavada 2015). The emerging public sphere, where such affiliations are expressed, produces both exclusions and a plurality of voices that exist, as Nelly Quemener writes (quoting François, Neveu 1999; Miège 2010), in "a multiplicity of arenas where conflicts in the production of meaning take place". The cases I will examine in this chapter "inhabit micro-public spheres" within which identities are fashioned and counter-hegemonic discourses formulated. As Quemener (ibid.) writes, this "is a privileged site for alternative worldviews and definitions", but it is also, as I will argue, a highly contested space.

Northeast India is a borderland comprising eight ethnically diverse federal states of India. ${ }^{1} \mathrm{~A}$ fraught relationship has historically existed between the post-colonial Indian state and indigenous communities of Northeast India, despite the Indian government's 'nation building' efforts. There are several reasons for this, the most prominent being demands for independence from the Indian state, which are rooted in cultural, political, and religious differences to 'mainland' India. The Indian state has tried to use military force to quell such 'insurgencies' in states like Nagaland, Assam, Mizoram, and Meghalaya, while also using cultural 'soft power' in attempts to integrate Northeast India's indigenous peoples. These exercises have 
largely been hegemonic projects designed to subsume regional differences and incite loyalty towards a centrally defined pan-Indian nation rather than devolving more power to the region.

In 1947, when India became independent (after a prolonged struggle for selfrule against the British imperial administration), the ruling Congress party granted special political and economic privileges to certain disadvantaged groups. Historically oppressed castes became beneficiaries of special state privileges as did all the indigenous people of the Northeast who were now included in the government list of "depressed forest tribes". These groups were listed in a special schedule of the constitution as Schedule Castes (SCs) and Schedule Tribes (STs) (Metcalf, Barbara, and Thomas R. Metcalf. 2000, 228). This schedule of the Indian constitution, now famously known as the 'Sixth Schedule', is supposed to ensure a federated political structure by guaranteeing that members of STs and SCs are represented in District Councils and Regional Councils, which have certain legislative and judicial powers in matters of local importance including education, agriculture, health, social security, and culture.

Since independence, the post-colonial Indian state has made a self-conscious effort to create an 'imagined' cultural identity that subsumes regional differences. In accordance with its 'Unity in Diversity' concept, government policies generally aim to advance the state's conceptualisation of a composite Indian culture rather than to reflect local cultural understandings. A good example of this is the Republic Day parade in India's capital, New Delhi, which includes the performance of 'tribal' dances from Northeast India. While ostensibly representing the indigenous cultures of the Northeast and showcasing the diversity of the nation-state, these performances are underpinned by the paternalistic approach that has been adopted by the Indian state to culturally integrate the nation.

Thus, while aiming to bring local cultures to national prominence, promoting them in parades, museums, archives, and the centralised mass media, the state ultimately perpetuates a culture of 'gazing' at indigenous peoples, which reinforces cultural stereotypes. This happens as orientalist perspectives on indigenous tribes are combined with the discourse of the post-colonial state, forging 'imaginings' that suppress local histories and limit indigenous communities' opportunities to shape their own futures (Lutz and Collins 1993, 274). Such a gaze serves to distinguish communities from the Northeast as 'other' than the 'normal', mainstream, modern Indian community. This is a result of defining Northeast cultures as "exotic" and regarding them as out of touch with the contemporary movement of history (ibid.: 276).

In my earlier work, I have critiqued these ways in which the Indian government adopted colonial and orientalist ways of thinking about and governing indigenous communities (Hasan 2008). The story is complicated by the role of indigenous political elites who have often colluded with narratives of 'primitivism' and backwardness for their own political and economic gain. Today, tensions are aggravated by the increasing number of 'insurgent' movements that demand greater autonomy and, in some cases, even secession from the Indian state. These include movements in the states of Nagaland, Manipur, Tripura, Assam, and Meghalaya, the objectives 


\section{Daisy Hasan}

of which range from secessionism to communal and inter-ethnic conflicts. One of the oldest and most persistent conflicts is in Nagaland, where, even before Indian independence, the Nationalist Socialist Council of Nagaland (NSCN; now further factionalised) had already begun calling for the assimilation of all Naga-inhabited contiguous areas under one administrative "umbrella" that would exist independently of India.

The situation is made all the more complex by the geographical location of the Northeast region, which borders other nation-states such as Burma and China. The Indian government fears that the area is especially vulnerable to international territorial conflict. These fears shape the central government's policies regarding the Northeast to this day. Additionally, poor governance and corruption are problems in many states of the region, contributing to economic underdevelopment and political instability. Since 1991, when India shifted into the post-liberalisation economic era, the easy availability of consumer goods has created a culture of consumption that has 'lulled' people into greater acceptance of commercialised mainland culture and also somewhat dulled their desire for conflict. However, Northeast India still remains a volatile place with violent conflicts, religious divisions, and various other "identity projects". ${ }^{2}$ As I have argued elsewhere (Hasan 2008), the region's political and cultural elite commands a large proportion of the cultural resources within respective communities. Because of their privileged positions, these elites are able to articulate their understanding of ethnic identity very effectively in religious and secular civil society and media forums. The interventions of this class are especially potent in a context in which oral traditions, histories, and mythologies are being translated and disseminated via print cultures, the modern mass media, and social media - all of which are controlled to a large extent by this class.

In this chapter, I would like to explore the contemporary moment and sift through three political and cultural events of the recent past that have unfolded via video sharing sites like YouTube and on social media. Dramatized through personalities, practices, and online communities, these events show us how the virtual construction of the 'indigenous' can be politically potent and culturally loaded, yet also exclusionary and contested.

In the following sections, I survey the response (mediated via social media) to three critical events that have been shaped by the online circulation of videos, still images, and an online discourse about tribal identity. I have chosen these case studies as they either have become iconic within Northeast Indian social movements calling for greater respect and equality or mark a culturally significant turning point in the region's recent history. They comprise (1) the 'exodus' in 2012 of Northeast Indian migrants from metropolitan centres in India following the circulation of videos and bulk mobile text messages heralding an unfolding ethnic conflict, (2) the allegedly racist attack against and subsequent death of Nido Taniam, a youth from the Northeastern state of Arunachal Pradesh in India's capital, New Delhi, in 2013, and (3) the phenomenal rise in popularity and political capitalisation of the Shillong Chamber Choir through online videos and social media.

My study homes in on these recent events in order to unpack the ways in which the idea of the indigenous is mobilised. Through this exploration, some of the 
interconnected issues I will examine include indigeneity and cosmopolitanism, rootedness, mobility and migration, and social media practices. My arguments are deduced from a critical evaluation of the articulations and contestations around indigenous identity that take place through social media.

\section{Mapping information and communication technologies in Northeast India}

Historically, societies in Northeast India were represented in the media primarily through the regional channels of the national public service broadcaster, the regional editions of national dailies and magazines, and a small regional press. However, the 1990s saw a boom in cable and satellite broadcasting. This instigated a proliferation of news and entertainment channels and nascent film industries (see Hasan 2004, 2008, 2009, and 2010). Indigenous politicians and civil society groups took advantage of the chance to express themselves more freely via audiovisual media, thereby adding to a public sphere that appeared to intensify the democratic impulse in the region. As internet connections became increasingly available in the early 2000s, this sphere ostensibly expanded, bringing in yet more voices via various online platforms and social media. While no exhaustive study has yet assessed the exact extent of internet penetration and the number of people online, a number of facts can be surmised from extant data.

Indian and global mobile phone companies are flourishing in the Northeast region today, even though digital connectivity is insufficient. The Indian government has introduced schemes such as the setting up of community-oriented information centres through which information and communications technology (ICT) can be used for economic and cultural development. ${ }^{3}$ The goal of such policies is to use ICT for developing agricultural and arts and crafts markets and to improve governance in a region that is poorly connected but rich in resources. The hilly topography of the area makes implementing comprehensive internet access particularly challenging. Yet ambitious plans to bring forth nothing short of an 'IT revolution' in the area have been announced by successive Congress and Bharatiya Janata Party (BJP) governments in order to encourage corporate investment. ${ }^{4}$ Today, a number of publications from the region have online editions, while some media entrepreneurs have started webzines about the Northeast that cater to a global audience, such as The Thumbprint magazine and the alternative political and cultural webzine Raiot. ${ }^{5}$ The region and its culture, politics, news, and personalities have become far more visible than they were in the pre-internet 1990s era and earlier; largely due to the popularity of social media.

While the websites of many government departments are poorly maintained and rural access to the internet remains patchy, India's Northeast is quickly becoming one of the fastest-growing markets for online retailers, with an increasing number of youngsters from urban areas of the region logging on to buy mobiles, accessories, and much more. The use of social media is flourishing among the urban elite and middle class in the region, as well as those who make up the Northeast 
Indian diaspora, which includes a sizeable service class. Yet, as the editor of a leading English daily in Shillong writes,

Social media is good only for those with internet connectivity. In a region with seven [sic] states, in the six states, barring Assam, the rural internet penetration is negligible. ${ }^{6}$ Hence, social media is essentially an urban phenomena connecting PLUs (people like us).

(Mukhim 2014)

However, as Mukhim (ibid.) goes on to point out, the repercussions of an event or discussion that unfolds via social media can be felt far beyond the point of origin, to the benefit or harm of those unconnected to such events in cyberspace. Talking about the indigenous tribes of the region, one of which Mukhim belongs to, she argues,

we are no longer exclusive communities living in a cocoon. If someone in Guwahati, Aizawl or Shillong spreads venom over Facebook or other sites, there are cranks out there who would take revenge on north-easterners living elsewhere. This is a wired world.

(ibid. 2014)

\section{Rootedness, mobility, and migration}

The most stark example of Northeastern communities being thrown into crisis by virtual communication is the 'exodus' of 2012 that was precipitated by rumours spread via social media and other web-based means as well as through mobile phones. ${ }^{7}$ In that year, an ongoing conflict in Assam's Kokrajhar district between the Bodo community and 'illegal' Bangladeshi migrants who were perceived to be encroaching on tribal land and taking away scarce resources escalated into a nationallevel crisis. ${ }^{8}$ A senior journalist with years of experience in reporting on conflicts in the region commented that while such skirmishes had occurred constantly during the late 1990s, they had never previously been reported beyond Assam's regional media. In 2012, however, the mandate for journalists like himself, who had been armed with smart phones by their news organisations, was to be the first to break the news via social media, ensuring that a regional story that would once have only had a narrow reach via regional news channels would now be broadcast to a much larger audience within minutes of its unfolding. This was how the news about a conflict that was, and continues to be, essentially about land rather than religion or ethnic identity came to be rapidly and dangerously misinterpreted by the Indian mainland as a religious conflict, even as the conflict itself mutated into a veritable genocide (Bhattacharjee 2012). While the nature of the conflict and its misinterpretation is not uncommon, the way in which news about the event travelled and the subsequent ramifications for migrant Northeastern communities are noteworthy.

The rate of migration from the Northeast to 'mainland' India is higher today than it has ever been. The migration of people from the Northeast to other Indian 
cities, especially places like Delhi, has recently been documented in detail by Duncan McDuie-Ra, who notes that "while many migrants leave the region to escape conflict, many more leave to find work, to pursue education, and to fulfil changing aspirations" $(2012,14)$.

Harsh Nambiar's (2013) observations on migration support those of McDuieRa. He writes that in the early 1990s, migrants from the Northeast region were "the second distinctly directionally identified internal migrants of India after south Indians of the '60s and '70s." Their movement was initially stimulated by the economic liberal reforms that encouraged English-educated youth to move to Indian cities like Delhi, Pune, Bangalore, Chennai and so on for better-paid jobs in the public and private sectors. Hence, as Nambiar (ibid.) writes, "Northeast Indians came into the Indian mainstream in significant numbers mostly as well-schooled, collegiate, with less troublesome English accents and a favourably disposed skin colour." They thus joined other Indian middle class young professionals, investing their hopes in an "uncertain modernity" unleashed by the forces of technology, knowledge, and economic plenty (Nisbett 2009: 2, see also McDuie-Ra 2012).

This wave of migration brought with it a sort of clash of cultures, for when compared to North Indian communities, for example, people from the Northeast region (though by no means culturally homogeneous) can be said to hold cultural values that are more liberal and egalitarian in general and in terms of gender. Given these differences in values, migrants tend to keep to themselves and are sometimes stigmatised for their cultural habits and their ethnically 'different' features: "They struggle first against racist stereotypes which brand them as non-Indian (usually Chinese), who speak in strange unknown languages, who eat 'smelly' food; and against sexist ideas about them being fashion-obsessed, intellectually impoverished, sexually lax and possessing excessive freedom" (Lamare 2014a). In 2007, the Delhi police issued a controversial pamphlet to Northeast migrants, which advised them of what constitutes acceptable and unacceptable behaviour. Although the Ministry of Home Affairs declared in 2011 that the use of derogatory phrases like "chinki" for Northeasterners was a punishable offence, such laws, as Bhowmick (2014) argues, are difficult to enforce in practice.

It should be noted that at an institutional and policy level, members of Scheduled Tribes enjoy measures for preferential discrimination according to special constitutional guarantees like the 'Sixth Schedule' mentioned above. This Schedule ensures a reasonably federated political structure in the Northeast, devolves power to traditional institutions for governance, and ensures that a certain percentage of jobs in educational and public sector institutions both regionally and nationally are reserved for 'tribals'. However, in contrast to these progressive policies, people from Northeast India are often seen as 'backward' in mainland India. As I have argued elsewhere, following Taylor (2002), the mainland's perception of Northeastern societies as 'tribal' characterises them not only as "close to nature, isolated from the enervations of modernity [. . . carrying in local artistic traditions a non-reflective but powerful creativity that expresses some essential, primitive, timeless humanity" but also as "'backward', 'violent', 'underdeveloped', 'tribal' in the worst sense" (ibid.). These contradictory 'ways of seeing' tribal people from 
the Northeast make those that migrate to mainland India the object of racism, harassment, and differential treatment. For instance, The Northeast Today (TNT) magazine and The Telegraph newspaper in India reported that two students arrested from Jawaharlal Nehru University in Delhi on charges of sedition in March 2016 were shocked to hear the Delhi police address their colleagues from the Nagaland Police Guards as "chinki" in front of the arrested students. Further, it was reported by the TNT that "the Delhi Police officer told Umar [one of the arrested students] not to move without permission because the 'chinkis' did not understand Hindi and they ate humans!"

To return to the case of the exodus, in Mumbai on 11 August 2012, protestors organised a march in solidarity with their "Muslim brethren" (i.e., the so-called illegal Bangladeshi migrants) who were being attacked in the ongoing conflict with the Bodo community in Assam's Kokrajhar district. This protest led to violence towards Northeast migrants. There were further incidents in Mysore and Pune, and, according to a report in The New York Times (see Bajaj 2012), several Northeast migrants were beaten up. Fearing further attacks, Northeastern migrants living in other parts of India (particularly in Bangalore, the capital of the South Indian state of Karnataka) started returning home en masse. Among them were people from different walks of life belonging primarily to the service and middle classes. They included daily wage earners in service and hospitality industries, security guards, hairdressers and students; "those whose sense of insecurity in mainland India is compounded by their precarious economic situation” (Hasan 2012).

Digital and social media played an important role here. As Bhattacharjee (2012) writes,

This is also the first such violence where civil society has been empowered by social media. The jury was out even before the dead were counted, driving a wedge and bringing back the black mood of the 1970s to raise the pitch against illegal migration from Bangladesh.

Social media and text messaging facilitated the spread of unconfirmed reports and images of the incidents that were disseminated with immense speed to large numbers of people across the country, creating panic and inciting what would come to be termed as a 'mass exodus'. The visual imagery shared primarily via social media but also by Multimedia Messaging Service (MMS) and Short Message Service (SMS) arguably shaped the event as much as reflected it. Images of Muslims marching in solidarity with their victimised brethren were circulated widely as video clips and stills. According to Pandalai (2012), social media combined with TV coverage "gave the movement an unprecedented momentum" which surprised the unprepared government. She goes on to detail the 250 websites that were banned by the government for having escalated what they perceived to be an incitement to communal hatred. The Northeast Today magazine reported that modified images (including, bizarrely, morphed images of Chinese earthquake victims) were misconstrued to be photos of Northeastern people being victimised by Muslims in Assam and Myanmar (see also Deburman 2014). In turn, the Indian government 
alleged that it had evidence that an extremist organisation based in Pakistan had been involved in doctoring images and spreading them via social media including Facebook, Twitter, YouTube, and other such websites in order to create social unrest. ${ }^{9}$ It went on to announce a 15-day ban on bulk MMS and SMS messaging services in order to contain rumours of retaliatory attacks by Muslims.

One thing became increasingly clear in this war of images and (mis)information. This was that a formerly information-deprived and often deemed voiceless 'mass' of people living in a region that is economically, politically, and culturally marginal to the rest of India had evidently been empowered by the new information regime. They were a part of the rapidly growing population who are armed with mobile phones that can rapidly transmit digital images and texts to feed social media sites as well as to provide major news channels with the now sought-after 'citizen journalists" perspective (Sundaram 2015). They were therefore in a position to produce events even as they became the topic of news.

Faced with this virtual explosion of communication via the then new digital media platforms, in which, as a senior journalist ${ }^{10}$ put it to me, "for every five facts there were fifty unsubstantiated stories", as well as allegedly doctored images, the government cracked down hard. As edited news coverage jostled for space among a mass of unfiltered content and images, a conflict was set up between the state's and traditional media's familiar discourse of national integration and a contested discourse of persecution and ethnic self-assertion generated from 'below' and made visible and audible by the new media environment.

\section{Cosmopolitanism and indigeneity}

The intervention of a blogger from Mizoram usefully illustrates how effective such a discourse of persecution and ethnic assertion generated from 'below' and enabled by the new media environment could become within such social media chaos of allegations and counter allegations. In Mumbai, a man named Kima, a game developer from Mizoram, who was insulted by being called a 'Kancha' (a term not in itself abusive but often used derogatorily for working class people of Nepali origin), announced that he would like to educate the city's police force in the different ethnicities of the region. His invitation resulted in an apology for the ostensibly derogatory use of 'Kancha' by senior members of the police force. His post was widely disseminated across the web. Nambiar (2013) remarks that what made Kima valuable was his assertion that history is memory's fight against forgetfulness.

While in the earlier sections of this chapter I have dwelt on the imposition of stereotypical and narrow imaginations of identities from the centre, following on from the example above it will now be useful to analyse how the social media space can be a site of contesting voices about identity, nationality, and belonging. I choose, as a further case study, the response to a reflective article by the Indian writer Anjum Hasan about the violence then unfolding in Assam, which was posted on the BBC's website in September 2012. The article tried to historicise the conflict and raised the question of how "illegal immigrants" (against whom the Bodo community was committing violence in Assam) could be distinguished from "a 
Bengali Muslim resident of Assam" (Hasan 2012). As the conflict had manifested itself largely in terms of "Muslims versus north-easterners (rather than, for instance, Assamese versus Bangladeshis), where", Hasan asked, "does it leave Assam's approximately 9 million Muslims? And how does it feel to be both northeastern and Muslim?" The article went on to detail the many identities and affiliations of one Mr. Ahmed, a middle class Assamese Muslim man living in the Northeastern city of Shillong. "Mr. Ahmed", Hasan wrote, is many things at onceManipuri, Assamese, Shillongite, Muslim, north-eastern, Indian . . In negotiating these multiple identities with ease, he gives lie to the dichotomous way in which the Assam conflict has been portrayed".

The article provoked the following discussion on Facebook. I reproduce it at some length here in order to highlight the complexity of the debates surrounding tribal identity and citizenship.

\section{$A B^{11}$}

This article is not very clear on whether you are ironising or supporting the political framework of a nation state like India that would accept only somebody like Mr. Ahmed into its workings. Valourising the multiple identities rationale will not help gain any insights into the identity politics of the NE.

September 5, 2012 at 1:20pm $\cdot$ Like $\cdot 1$

Anjum Hasan

Dear $A B$,

I think a lot of political issues in this country are killed off by the vocabulary in which we talk about them. What is nationalism? What is "identity politics"? Who is a neoliberal? Is drawing attention to something the same thing as "valourising" it? We use these terms as if it's obvious what they mean when we should in fact be subjecting them to rigorous scrutiny. My portrait of Mr Ahmed is the picture of one individual who believes he has a stake in what is happening in Assam. Is he justified in thinking so? Does he have anything in common with the people killed in Assam and the poor people killing them? Is Shillong an "insular, neoliberal island" or a city like many other Indian cities - home to people from all over the country who have not found the perfect way to live together but do still live together in umpteen imperfect ways? I leave you to decide.

\section{$A B$}

We are different writers and use the same language differently. But that doesn't mean one can take a moral high ground based on how one reduces it to the least common denominator. Blame it on my temperament but I don't romanticise the 'umpteen imperfect ways' in which people live (together?) in any city. 
The above exchange, which continued at some length and included interventions by others, illustrates how, as Sanjoy Hazarika (quoted in Bhattacharjee 2014) also highlights, "the social media space" becomes a contested one, with people “misunderstanding each other". Hasan's position is arguably more progressive and nuanced than the government's simplistic 'Unity in Diversity' approach described above, by which the centre's policies generally seek to impose a top-down understanding of a composite Indian culture. While my intention is not to undermine the critique AB expresses in response to Hasan's piece, the above discussion and AB's interventions are, I believe, emblematic of similar debates unfolding online even as I write this, which dramatize the extreme sensitivity and even antagonism evoked by any liberal voice (other than that of the oppressed 'indigenous' subject) that tries to articulate a complex and cosmopolitan approach to conflict. I believe that such intolerance is a result of the increasingly identity-based politics in India, which have seen a hardening of positions around essentialist notions of identity.

Though I will show in the succeeding section how this position is slowly being critiqued from within, encouraged by the many voices that the internet facilitates, it is important to problematize such positions, which in effect shut down reasoned debate by primarily invoking a discourse of victimhood and marginalisation.

\section{Visualising race, defining racism}

The discourse of racial marginalisation reached a virtual crescendo with the death (in 2013) of Nido Taniam, ${ }^{12}$ a 19-year-old student from Arunachal Pradesh who was studying in Delhi. The boy was allegedly beaten to death by shopkeepers in south Delhi's market area of Lajpat Nagar - an incident that sparked intense protests by students and young people from the Northeast living in Delhi. The shopkeepers had allegedly ridiculed Nido's appearance before beating him.

Video recordings and photographs circulated online were presented as crucial evidence of different versions of the story, while the widely shared close-up image of Nido Taniam's young face in trendy glasses, with his hair coloured and flicked back, became emblematic of a people's struggle against racism. Joining the protest against the mainstream's treatment of Northeast people as second class citizens, relentless 24/7 news channels repeatedly transmitted images of the protestors and of Nido, and chimed in with the protestors' interpretation that the attack was racially motivated, not just a street brawl that had turned ugly. It may be worth mentioning that, in terms of content, while the mainstream TV channels' coverage of the incident tended to focus on reportage and analysis in panel discussions, social media platforms, particularly Facebook, wove a more intricate archival and interactive narrative as I will show later in my discussion of the "Justice for Nido Tania" pages. Thus, the main difference in content between traditional and social media in terms of reportage of the incident was that while the former focused on heated debates that responded to the immediacy of the unfolding 'drama', the latter allowed space for a more discursive and polyphonic account. 


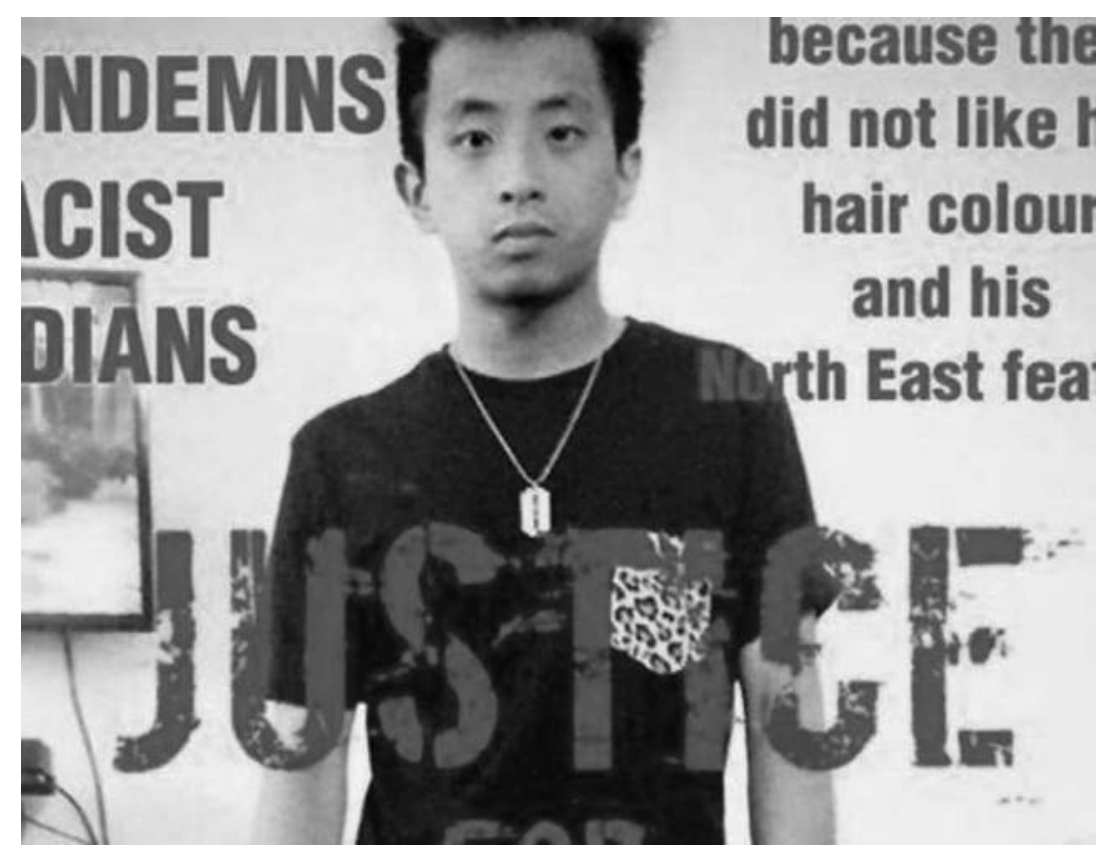

Figure 8.1 An image of Nido Taniam that was used to mobilise a call for justice Source: www.countercurrents.org/kamei020214.htm

Lamare (2014a) writes that "it was only until terrible violence (murder of Nido Tania and rape of a fourteen year old Manipuri girl) was committed that racism was acknowledged as a pressing problem in contemporary India."

Yet even as the death of Nido Taniam "caught the imagination of the mainstream media" (Bhattacharjee 2014), it also marked a turning point in the discourse about racism in India. For the first time ever, some journalists and activists, writing in alternative online forums, challenged the one-directional accusation of racism. Though still in a minority, they asked people in the Northeast to introspect and recognise the racism that 'outsiders' (anyone not considered indigenous) face in the Northeast region. Thus, a Khasi journalist drew attention to the fact that in addition to protesting about racism against themselves, indigenous societies like the Khasis also needed to examine their own racist assumptions with regard to other tribal and non-tribal communities. She emphasised,

while our own experiences of victimhood are important, we also need to introspect and discern the double standards inherent in our own home-state. We need to admit to our roles as agents of racism, not only against other communities but also members of our own tribe. 
Others were even more hard-hitting:

In almost every state there are incidents of anti-outsider campaigns. The most violent xenophobic attacks have been recorded in Northeast India where systematic ethnic cleansing has been practiced. In most of these incidents, people have been killed and maimed. Recently, two non-tribals who were permanent residents of Shillong were murdered with petrol bombs in Meghalaya - only because they "looked different".

(Bhattacharjee 2014)

Such alternative perspectives did not go unnoticed or uncontested by online communities on Twitter, which responded by reiterating the charge of racism against tribals from the Northeast. The incident also saw the formation of several forums against racism such as the North-East India Forum against Racism as well as the creation of two Facebook pages - "Justice for Nido Tania" and "Justice for NIDO TANIA" 13 - which collated posters, photos, and videos, as well as press reports in connection with the killing of Nido and have garnered 37,782 and 65,026 'likes' respectively to date. Central to both pages is the ubiquitous image of Nido striking a number of poses ranging from the defiant to the stylish.

The pages work to create a 'communicative ecology' that seamlessly blends political opinion, assertions of race, photographs, rumour, activism, and embedded videos. The "Justice for Nido Tania"14 page opens with what appears to be a selfie photograph of Nido in a blue T-shirt and a blue beret, which sports a sticker saying "Obey" in reverse. His hair (coloured to look almost blonde) is visible in a side fringe beneath his beret. He is wearing over-sized glasses and a silver chain around his neck. His overall style evokes K-pop cool as Nido's eyes stare out at us in 'faux innocence', evocative of 'Aegyo' mannerisms within K-pop that are highly stylised to look cute. K-pop is extremely popular in Northeast India and easily accessible via the internet. Indo-Korean collaborations for music festivals in the Northeast have stoked the craze for Korean music and also for Korean films, dramas, fashion, and cuisine. Several colour and monochrome photographs of Nido that clearly testify to the influence of K-pop are presented on the two Facebook pages. The following text screams across the cover image:

Don't judge me by my hair. My skin colour. My body size. Or my outer beauty. Because if you do, you might miss who I already am.

While the late Nido's own self-creation through sartorial styles, poses, and photographs forges identifications with a global and hybrid popular aesthetic, there are problematic aspects to the pages set up to commemorate him and seek retribution in his name. I would like to illustrate this point by drawing attention to the particularly unhelpful remarks made about a photograph in which Congress party politician Rahul Gandhi poses with the parents of Nido, who are holding a picture of 


\section{Daisy Hasan}

their dead son. In the following, I reproduce a range of unedited responses to the photograph in order to give a feel for the sentiments expressed:

CJ: My dear Frendss. This Politicians are curpt. . . . They creat diffrnc betwen us. All delhi ppls are not Bad. Yea most of them treat NE ppls badly. It dsnt mean that all of them are bad. My dea NE frends we hve to do Strong Protest against this. We hve to stay unitd against this Racism. . . Me and many ppls like me are there with $u$ until unless $u$ get Justic an Full Respect. God bless $u$ all. RIP Nido.

KP: Why the fuck is Rahul Gandhi smilin . . bludy son of a $b$. . . he is jus useless . . . n we shud nevr Frgt dat aftr all we r 1 . . RIP nido

$H N$ : if NE gets angry . . its very dangerous . . be careful. . . .

JB: Shame to rahul gandhi as he is still smiling in front of the parents of death child Nido tania

SK: $\quad$ Rahul fucka stop smiling like goddamn fagit.

PP: my heart goes wid d Lt,.nido"s parents . . .!!!justice has to done !!!

$M N$ : Is who somelike you dirty indian bring a religious sentiment $n$ spread a venom. . . . so get lost $u$ all thristy sex maniac. . . we dnt need ur support $n$ ur crocodile tear over here. . we among NE are sufficient to fight a justice...

While not all of the responses were as extreme as these, nor were they all from Northeastern people, the majority of sentiments expressed (and the overall composition of the two Facebook pages) work to foreground the 'voice' of a set of people, a narrative which, while it challenges notions of passivity and victimisation associated with the indigenous, also blunts political endeavour, infantilising and offering an exclusionary view of race rather than pushing for more inclusive dialogue. It is, of course, important to highlight that there are also a small but growing number of more 'self-reflexive' reactions from indigenous activists, that, as I have pointed out earlier in this chapter, call for introspection as far as racist attitudes towards non-indigenous communities are concerned. However, my conclusion here is that such voices are all too easily drowned out by the kind of social media 'outrage' described above. Such high-pitched social media reactions, which are by no means unique to Northeastern communities but, as Bartlett et al. (2013) argue, are a wider Indian and indeed global phenomenon, are detrimental to longterm democratic decision-making as they put governments and politicians on the back foot and lead to polarised debates.

\section{Ethnic chic and oral traditions in the digital age}

I would argue that a similar blunting of the political occurs through another kind of cultural endeavour that is hyper-aestheticized in the way in which it foregrounds ethnic identities. I take the case of the talented Shillong Chamber Choir (SCC): a group of Khasi musicians who came together in 2001 to form a "multi-genre" band that has put Shillong on the Indian and international music map. With 
performances all over the world for an elite class including then US President Barack Obama, the SCC has professionalised the region's love for both Western music and its folk traditions of orality. Today the SCC is seen as a "powerful cultural icon" that can be used to mobilise people to call for social justice and to support political campaigns, which is why I have chosen to discuss the band as the final case study in this chapter.

In the 2014 Lok Sabha (House of Commons) elections in India, the Office of the Chief Electoral Officer engaged the SCC to produce a music video entitled "Just One" that would appeal to young urban voters in Meghalaya (see Figure 8.2). The video proved to be a huge success and gained over forty thousand views within a span of four days. The video presents a romantic view of the region and its empowered urban youth who are eager to take charge of their destinies by casting their vote. Yet the video only pays lip service to disabled people, ethnicities other than Khasi people, and to the rural poor. It appears to be utopian in its projection of what people in a democracy look like and how they behave. As Lamare (2014b) points out, the actors in the video

seem to have come out of a fashion magazine. The combination of such images and words seem to generalise what the outcome of voting would be for an individual and a community. It looks like an imagining of some joyous wonderland with song and dance, rolling fields and bright skies. It seems that these tranquil surroundings and emotions are a reward of simply casting one's vote.

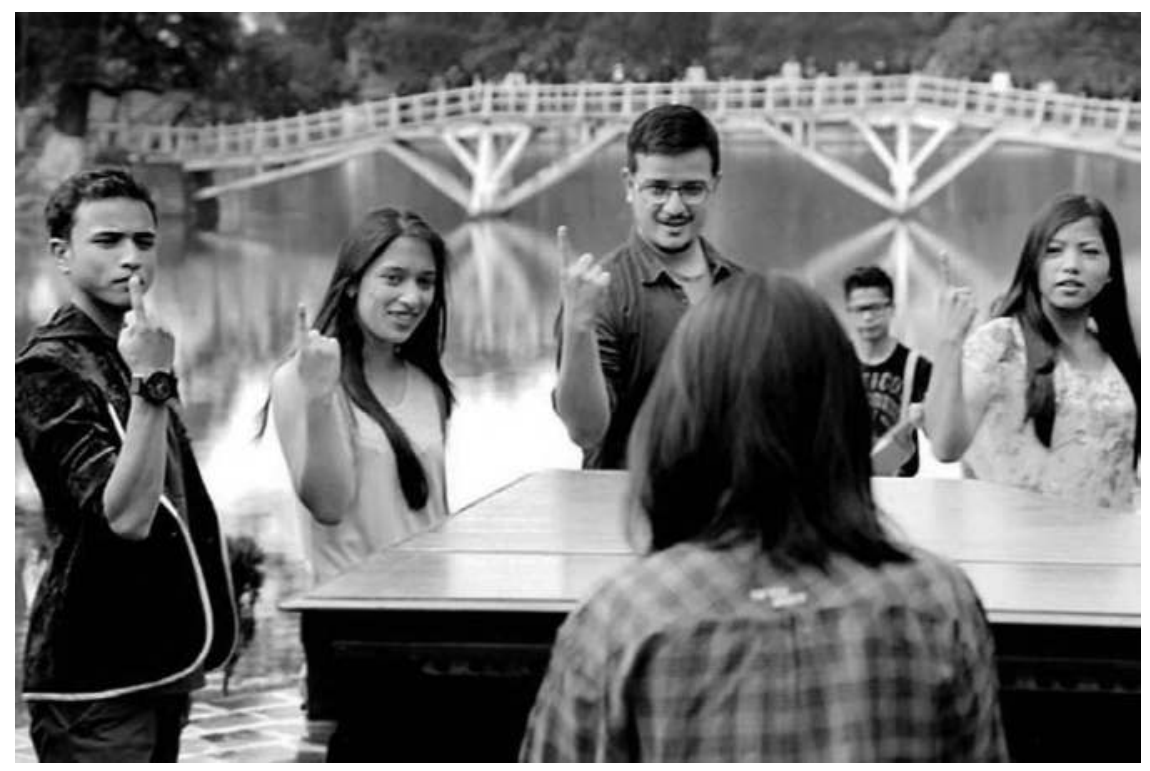

Figure 8.2 A still from the Shillong Chamber Choir's 'Just One' Music Video Source: www.mid-day.com 
The video has what Lutz and Collins $(1993,139)$ (who bring a similar critique to bear upon depictions of the Pacific region in the National Geographic magazine), call a "rose-colored glasses' approach". Its setting is one of stereotypically idyllic natural beauty, which is a common backdrop for films and music videos produced in the region. The edit intercuts images of hip urban youngsters and of hurried city life. Yet the video blurs the distinction between different tribes and ethnicities, and presents young people from various parts of the Northeast region as a homogeneous, happy, purposeful, and trendy group. It thus ultimately lapses into a clichéd representation of Khasi youth as Westernised and presents a highly simplistic depiction of political choice and empowerment. The underlying assumption appears to be that simply casting one's vote is a solution to complex social problems. Lamare's (ibid.) critique of the video elicited an engaged online response, with some people supporting her views but also complicating the debate about democracy, voter participation, and power. My conclusion here is that the lens through which indigenous self-representation is often framed serves to gloss over complex and negotiated histories and identities. While, as I have mentioned before, a more self-reflective critique is also being generated from within, the dominant mode of self-reference and presentation (in online forums, films, journalism, and social media) can arguably be critiqued for blunting nuanced historical and political positions.

\section{Conclusion}

My analysis of online interactions in relation to key events on social media for peoples of Northeast India throws up several critical questions in relation to ethnic identities and forms of affiliation in cyberspace. Calls for political mobilisation, as well as some of the most compelling stories about contemporary indigenous life and identities, circulate via videos shared among online communities and arguably reinforce existing stereotypes, since social media, it appears, encourage the formation of clusters of like-minded people. The anonymity afforded by the internet at times encourages the expression of virulent opinions and the dissemination of exclusionary and extreme notions of identity. Ironically, or perhaps complicating these assertions, at the same time migration produces a pan-Northeastern regional identity, a kind of cosmopolitanism that, as McDuie-Ra (2012: 185) writes, "is a way of reshaping ethnic, tribal [. . .] identity [and] challenging mainstream stereotypes". This kind of pan-regional identity is particularly facilitated by social media platforms through which individuals separated geographically can come together virtually as they relate to different causes and concerns and cultural and subcultural subjects. As people increasingly identify as 'Northeasterners', class affiliations gain significance, especially since access to communication resources (like phones, computers, $3 \mathrm{G}$ or $4 \mathrm{G}$ ) is class-based. ${ }^{15}$ The idea of a shared 'Northeastern' identity is also arguably more pronounced among the 'diasporic' groups living outside the region, whereas affiliations within the region are more localised and fragmented. Yet, as the case studies in this chapter have shown, even the shared 'Northeastern' identity can be imbued with exclusionary undercurrents (as in the 
case of the Nido Taniam and exodus stories) or be excessively idealised (as in the case of the Shillong Chamber Choir video). While I have also drawn attention to some of the voices from within the community (Raiot webzine and the voices it foregrounds, for instance), these are nascent endeavours that are outnumbered by more populist and extreme articulations in the mainstream and social media. The arguments I have made based on the case studies examined can contribute to a critical and culturally specific understanding of how social media interactions influence the creation of indigenous subjectivities and identities and generate affective forms of citizenship.

\section{Notes}

1 The eight states are Assam, Nagaland, Manipur, Mizoram, Tripura, Arunachal Pradesh, Meghalaya and Sikkim. The estimated 48 million people who live in the region comprise about 4 per cent of India's population (Rao 2013).

2 This phrase was coined by Anthony Giddens.

3 Information and communications technology (ICT) is a general term that includes communication devices, applications, and relevant services that are used privately and in various sectors such as education, medicine, administration, and so on.

4 In 2010, the Congress government decided to provide telecom, WiMax (Worldwide Interoperability for Microwave Access) and broadband connectivity in the Northeast region (Manzar 2011).

5 See www.thethumbprintmag.com/ and http://raiot.in/

6 In 2013, India had more than 900 million mobile phone subscribers including a high number in Northeast India. Sinha et al. (2013) mention that the penetration of the internet has been increasing in recent years in the Northeast region as many internet service provider companies have started providing internet services via various kinds of modems, dongles, broadband or dial-up connectivity for computers, and even on mobile phones. Companies like BSNL, Airtel, Aircel, Reliance, Vodafone, and Tata Indicom etc. have also started providing internet services on mobile phones. According to the Internet and Mobile Association of India (IAMAI), the mobile internet user base in India grew to an estimated 213 million in June 2015 (The Economic Times, http://articles. economictimes.indiatimes.com/2015-09-03/news/66178659_1_user-base-iamai-internetand-mobile-association). In the Northeast in 2013, there were estimated to be more than one million mobile users, 0.1 million internet users, and 0.1 million social media users (Rao 2013).

7 As mentioned in endnote 6, mobile phone penetration in India is strong. According to a Business Standard report (Dey 2015), India continues to be a global leader in the annual number of new mobile subscriptions. India added 13 million new connections in the last three months of 2015. Dey (ibid.) writes, "against the global average of 99 per cent, mobile phone penetration in India is pegged at 77 per cent, leaving room for further uptake in numbers in the coming years."

8 This region was part of erstwhile East Bengal and the Bengali Muslims now termed 'illegal migrants' were among the original settlers there. Today, the population includes other ethnicities such as 'Adivasis' who settled there not only as workers on British tea plantations in the 19th century, but also worked on farms, in forests, and for the railways. (I am grateful to Markus Schleiter for drawing these various other occupations of the Santal tribe to my attention). The Bodos, another ethnic group, were once forest tribes who practiced shifting cultivation but have since adopted settled agriculture in the wetlands. Today, there are approximately 500,000 Bodos and approximately 300,000 Assamese Muslims in the region (see Bhattacharjee 2012). 
9 See Pandalai (2012) for a fuller account of the government's response to the crisis and its imposition of internet censorship.

10 Personal telephone interview with Kishalay Bhattacharjee (former editor at New Delhi Television) 21 June 2014.

11 Real names here and in all subsequent quotations of social media exchanges have been anonymized and I have used initials to protect identities.

$12 \mathrm{He}$ is variously referred to as 'Taniam' or 'Tania' in different reports. See Figure 8.1.

13 See www.facebook.com/search/top/?q=justice $\% 20$ for $\% 20$ nido $\% 20$ tania\&em $=1$

14 See www.facebook.com/Justice-for-Nido-Tania-1476936645866865/

15 I am grateful to Erik de Maaker for helping me tease out this point.

\section{References}

Bajaj, Vikas. 2012. "Exodus to India's Northeast Continues for a Third Day." India Blogs, the New York Times. http://india.blogs.nytimes.com/2012/08/17/officials-offer-assurancesin-effort-to-stem-exodus-to-the-northeast $/$ _php $=$ true\&_type $=$ blogs\&_r $=0$. Accessed on 24 June 2017.

Bartlett, Jamie, C. Froio, et al. 2013. "Social Media Is Changing Politics across Europe ..." www.demos.co.uk/files/Beppe_Grillo_and_the_M5S_-_Demos_web_version.pdf? 1360766725. Accessed on 4 April 2017.

Bhattacharjee, Kishalay. 2012. "There We See Only Stumps.” Outlook India. www.outlook india.com/article/There-We-See-Only-The-Stumps/282079. Accessed on 22 June 2017.

Bhattacharjee, Kishalay. 2014. "Reporting on Nido's Death." Newslaundry.com. www. newslaundry.com/2014/02/01/reporting-on-nidos-death/. Accessed on 29 June 2014.

Bhowmick, Nilanjana. 2014. "What the Death of Nido Taniam Tells Us about Racism in India." Time. http://time.com/4876/nido-taniam-india-racism/. Accessed on 30 June 2017.

Dean, Jodi. 2016. Crowds and Party. London and New York: Verso.

Deburman, Pradyot. 2014. "The New Social Media Paradox." In TNT, The Northeast Today, Shillong: TNT.

Dey, Sudipto. 2015. "India Adds $13 \mathrm{mn}$ Mobile Phone Users in July-Sep as Many as China and the US Combined." Business Standard. www.business-standard.com/article/currentaffairs/india-adds-13-mn-mobile-phone-users-in-july-sep-115111701224_1.html. Accessed on 01 April 2017.

François, Bastien, and Neveu, Érik. 1999. "Introduction. Pour une sociologie politique des espaces publics contemporains." In Espaces publics mosaïques: Acteurs, arènes et rhétoriques, des débats publics contemporains, edited by François Bastien and Neveu Érik Rennes, 13-58. PUR.

Hasan, Anjum. 2012. "Why the Violence in Assam Is Not Communal." BBC News India. www.bbc.com/news/world-asia-india-19394976. Accessed on 6 May 2017.

Hasan, Daisy. 2004. "Out of the Box: Televisual Representations of North-East India." Sarai Reader 04 Crisis/Media. New Delhi: Centre for the Study of Developing Societies.

Hasan, Daisy. 2008. Re-Imaging and Reimagining Community in North-East India: A Study of Small Scale Electronic Media and Its Implications for Indian Democracy. New Delhi: Public Service Broadcasting Trust.

Hasan, Daisy. 2009. “'Guns and Guys in the Jungle': News and Terrorism in North-East India." The Culture of Terror: Theme Issue, Studies in South Asian Film and Media 1(2): 265-283.

Hasan, Daisy. 2010. "Talking Back to 'Bollywood': Hindi Commercial Cinema in NorthEast India." In Political Pleasures: The Representations, Audiences and Contexts of 
Contemporary South Asian Media, edited by S. Banaji, 29-50. London and New York: Anthem Press.

Kavada, Anastasia. 2015. "Creating the Collective: Social Media, the Occupy Movement and Its Constitution as a Collective Actor." Information, Communication \& Society 18 (8): 872-886.

Lamare, Gertrude. 2014a. "Confronting Racism." Raiot. http://raiot.net/confronting-racism/. Accessed on 29 June 2017.

Lamare, Gertrude. 2014b. "Not Everyone Can Sing 'Just One'.” Raiot. http://raiot.in/. Accessed on 29 June 2016.

Lutz, Catherine, and Jane L. Collins. 1993. Reading National Geographic. Chicago, USA: University of Chicago Press.

Manzar, Osama. 2011. "Let's Connect India's North East." Live Mint and the Wall Street Journal. www.livemint.com/Opinion/HcPJ3Pr0Ne5LEdLRsTB0MK/Let8217s-connectIndia8217s-NorthEast.html. Accessed on 15 June 2017.

McDuie-Ra, Duncan. 2012. Northeast Migrants in Delhi: Race, Refuge and Retail. Amsterdam: Amsterdam University Press.

Metcalf, Barbara, and Thomas R. Metcalf. 2000. A Concise History of India. Cambridge: Cambridge University Press.

Miège Bernard. 2010. L'espace public contemporain. Grenoble: PUG.

Mukhim, Patricia. 2014. "Social Media Versus Traditional Journalism?” In TNT, the Northeast Today, Shillong: TNT.

Mukhim, Patricia. 2016. "Gender and Folklore in Northeast India: Beliefs and Practices." Keynote address delivered on 30 March 2016 at the Department of Creative Arts, NorthEastern Hill University, Shillong, India.

Nambiar, Harsh. 2013. "North-East Exodus: Time for Mainland India to Embrace Diversities." The Economic Times. http://articles.economictimes.indiatimes.com/20130414/ news/38529193_1_mumbai-police-kima-azad-maidan. Accessed on 5 May 2014.

Nisbett, Nicholas. 2009. Growing Up in the Knowledge Society. India: Routledge.

Pandalai, Shruti. 2012. "Don't Shoot the Messenger: The 'Un-Social' Strategy." Institute of Defence Studies and Analysis (Comment Section). www.idsa.in/idsacomments/Dont ShoottheMessengerTheUnSocialStrategy_spandalai_280812. Accessed on 2 April 2016.

Quemener, Nelly. 2015. "The Circulation and Legitimation of Discourse: Conflicts in the Public Sphere.” Études de communication: Thematic issue (47). https://journals.openedition. org/edc/6349.

Rao, Madanmohan. 2013. "Digital Innovators Seek to Inter-Connect and Transform Northeast India.” Your Story. http://yourstory.com/2013/12/digital-innovators-northeast-india/. Accessed on 31 March 2016.

Sinha, Manoj Kumar, S. Bhattacharjee, et al. 2013. "A Study on ICT Literacy and Internet Use Pattern among College Library Users of Barak Valley, South Assam, North East India." Current Trends in Technology and Science 2 (5), August-September.

Sundaram, Ravi (ed.) 2015. No Limits: Media Studies from India. Delhi: Oxford University Press.

Taylor, B. 2002. "Public Folklore, Nation-Building, and Regional Others: Comparing Appalachian USA and North-East India." In Indian Folklore Research Journal 1: 1-27. 


\title{
9 Projecting and rejecting indigeneity
}

\author{
'From Bangladesh with Love'
}

\author{
Carmen Brandt
}

\section{Introduction}

In the last two decades, one important focus of the debate regarding the rights of ethnic minorities in Bangladesh has been on the terminology used to denote most of those groups (see Khātun and Suman 2014). ${ }^{1}$ While the Bangladeshi state itself has refused to use the term 'indigenous' or its Bengali counterpart ádibāsì (often translated as 'original inhabitant') officially for ethnic minorities since the terms gained prominence in the 1990s, the words have nonetheless been omnipresent in the public sphere as a result of their usage by journalists, scholars, and non-governmental organisations (NGOs). The reaction was accordingly vehement when the Press Information Department (PID) of the Bangladeshi state issued the following release (no. 2704) ${ }^{2}$ on 7 August 2014:

With regard to avoiding the usage of the word $\bar{a} d i b \bar{a} s \bar{\imath}$

Although according to the 15th amendment of the constitution of Bangladesh there is no existence of $\bar{a}$ dibāsis in the country at present, at various times, especially on the International $\bar{a} d i b \bar{a} s \bar{\imath} \mathrm{Day}^{3}$ declared by the United Nations, the word $\bar{a} d i b \bar{a} s \bar{\imath}$ continues to be used repeatedly. To note: in the 15 th amendment, the kșudra nrgoșthīs [minor ethnic sects] dwelling in Bangladesh have been designated as upajāti [tribe] or kșudra nrgoșthi $\overline{.}^{4}$ The request has been made to eschew the use of the term $\bar{a} d i b \bar{a} s \bar{l}$ in various functions, discussions, and talk shows on the occasion of the International ādibāsì Day on the coming 9th of August. The request is already being conveyed beforehand to the other members of civil society, including university teachers, ${ }^{5}$ experts and newspaper editors, participating in all these discussions and talk shows to be alert with regard to the avoidance of the use of the term $\bar{a} d i b \bar{a} s \bar{\imath}$ in the context of Bangladesh. ${ }^{6}$

The vehement rejection of these terms on the part of the state and the insistent demand from "indigenous ${ }^{17}$ activists to be recognised as such illustrate the consequences that transnational discourses can have on a local level. This chapter seeks to explain why the Bangladeshi state so forcibly denies these activists recognition 
as 'indigenous'. Apart from the relatively prosaic question of who is more indigenous to the soil of Bangladesh (at times both Bengalis and ethnic minorities claim that status exclusively for themselves), another important factor seems to be the characteristics ascribed to the two groups from outside and inside. By analysing the film Bideśini - From Bangladesh with Love (Bangladesh 2005), I will show that Bangladesh's identity as a state and the self-ascribed characteristics of many Bengalis in Bangladesh actually evoke very similar attributions to those that in other contexts characterise the non-'indigenous'-'indigenous' dichotomy. This exercise will hopefully help us to understand why the Bangladeshi state does not recognise ethnic minorities as 'indigenous'.

\section{Bideśin̄ - From Bangladesh with Love}

The main reason for selecting the film Bideśin̄ - From Bangladesh with Love for this analysis is that I played the leading female role in it - the bideśini (foreign woman), Lisa, the daughter of US millionaires on the run from her parents - and was thus able not only to discuss the film extensively with its director and other crew members, but also to follow its making at first hand. The motivations for my participation in this film were manifold too. At that time, as a student of South Asian studies, Indology, and mass media, I had actually never harboured any ambitions to act in a film. But when a friend told me during my studies in Dhaka in 2003 that the late Shibly Sadik (see Figure 9.1), a well-known Bangladeshi film director, was searching for a foreign woman with Bengali language skills for his current project, I took the opportunity in order to gain insights into the Bangladeshi film industry. Although local friends warned me against joining the film industry, which at that time had an immensely bad reputation ${ }^{8}$ among the so-called educated middle class in Bangladesh, my curiosity and my trust in Shibly Sadik were strong enough that I ignored my friends' advice.

Actually, there was only one incident in the whole film - one sequence - that made me feel rather uncomfortable during shooting: after having a fancy dinner and a first conversation about Lisa's family and the reasons why she has left her parents, Joy, a Bengali man whom Lisa has only recently met, walks home with her. On their way, Lisa stops at the makeshift shelter of a very poor (according to the film script bhikhārī, a Bengali term usually meaning 'beggar') couple with a baby and starts the following conversation with Joy:

Lisa: Beautiful.

Joy: They are very poor.

Lisa: Is there misery in that?

Joy: They have neither home nor house.

Lisa: They have sleep. They can sleep in peace.

Joy: When they cannot get two square meals a day.

Lisa: Nonetheless, they are happy. And I? We have luxury goods all around, we have plentiful food, we have houses in which we can go to sleep. Still . . . 
still . . . there is no end of our burning pain. Why? Why this distance? Why this difference? Today, hundreds of young men and women of America are taking heroin, are taking marihuana, are committing suicide. Why, why, Mr. Joy? ${ }^{9}$

Joy is not able to answer Lisa's questions, though he hints that he might have the answers, but cannot reveal them right now.

I remember the shooting of this sequence very well: I was making fun of the content and asked Shibly Sadik several times to change it. I told him that, although I was German, I doubted that even the most naïve young woman in the US would say something funny like that. Shibly Sadik, who at all other times remained very patient with me, an amateur actress with no experience at all, lost his patience for the first time and ended the discussion by saying, "This is my film! When you make your own film you can decide everything." In a bad mood, I gave in, but failed to learn the major part of the dialogue by heart. After shooting several takes that wasted valuable $35 \mathrm{~mm}$ film, Shibly Sadik decided that I should turn my back to the camera during the long monologue and only turn again for the last sentences. Since the whole film was shot without sound, I could then dub it later by reading out the lines from the script.

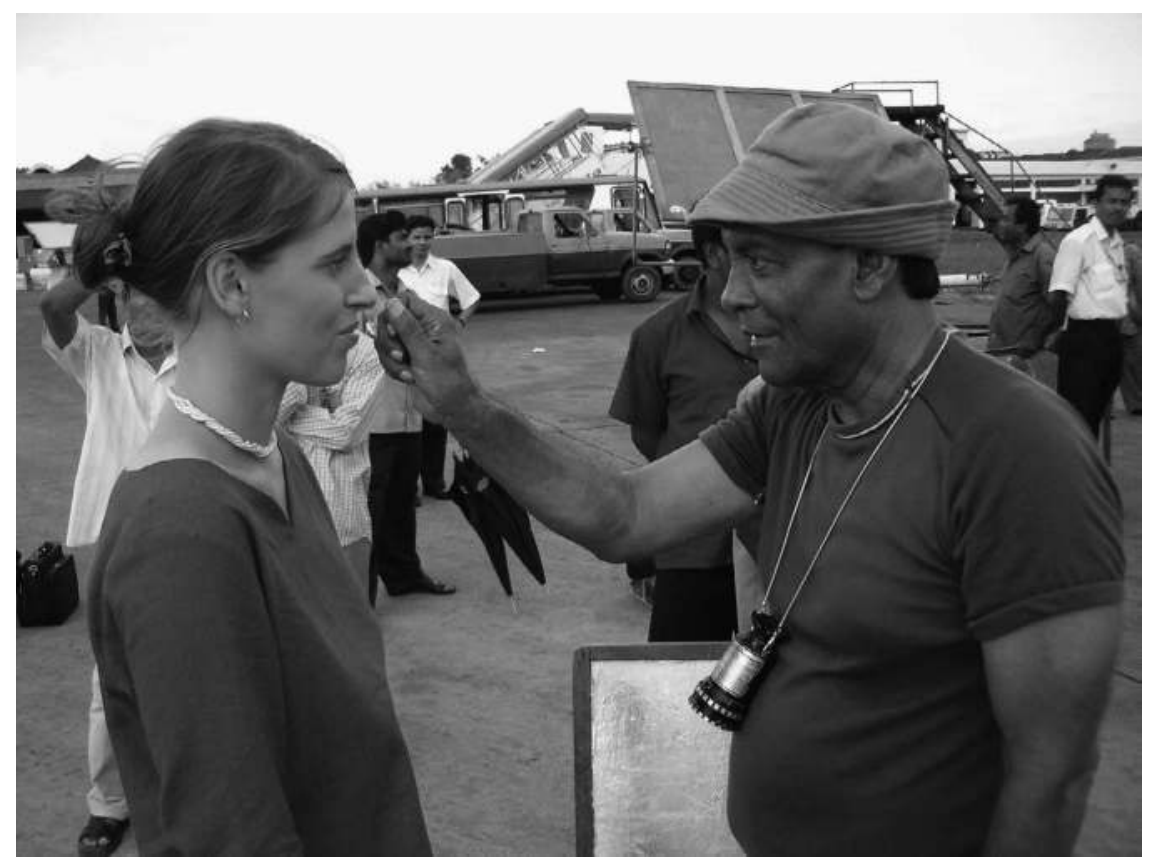

Figure 9.1 Carmen Brandt and Shibly Sadik

Source: Photograph by Khademul Insan 


\section{The task: countering negative perceptions by outsiders}

Only while watching the completed film almost a year later did I fully grasp the importance of this dialogue, which will be discussed later. I came to realise that this was one of the key scenes of the film that was, first and foremost, an attempt to improve the reputation of Bangladesh at home and abroad by showing it positively. For doing so, the film received funds and support from the Bangladeshi government, from the Ministry of Information, the Ministry of Civil Aviation and Tourism, the Ministry of Home Affairs, and the Ministry of Culture, and was intended to be screened at festivals worldwide, partly in order to attract more tourists. While plans to subtitle the film and screen it abroad never came to fruition, the aim of at least contributing to more positive feelings among Bangladeshis towards their country seems to have been achieved - at least that is my impression based upon the reactions of the audiences I have personally encountered, and the fact that the film has been broadcast regularly since 2005 on various TV channels at prime time.

Bangladeshis themselves - from all strata of the society - are often keenly aware of how their country is perceived abroad, especially now that international media reporting has become easily accessible, for instance via Internet. Media coverage of Bangladesh is overwhelmingly negative in the field of economics (e.g., the disasters and poor working conditions in the garment industry, and poverty in general), the environment (e.g., floods, cyclones, and the effects of climate change), and politics (e.g., lack of democracy, human rights violations, the bad situation of ethnic and religious minorities, and the rise of Islamic militancy). In addition, the frequently problem-oriented focus of the countless NGOs and the majority of academic studies in the field of economics and humanities (see Brandt 2010) could also be described cynically as needing a problem-focused approach to Bangladesh and its society in order to justify their existence as problem solvers. Above all, the money that is available in this field to scholars employed by national or international NGOs or highly paid consultants is unlikely to incentivise anything other than negative portrayals in academic writing. Sarah White already noted this phenomenon more than 25 years ago: "Since Independence, Bangladesh has appeared in a package labelled poverty for sale on the international market. Not for nothing did a leading Bangladeshi political scientist jokingly remark: 'Poverty is our main export"” (White 1992, 160).

At the time of the shoot, having already spent six months in 2002 and another six in 2003 in the country, I knew Bangladesh well enough to realise that the way it was perceived abroad, for instance, by people in my home country Germany, certainly did not reflect its complex reality. Hence, I had no problem in becoming an unofficial ambassador promoting a positive Bangladesh in which I had found many new friends and felt at home. However, I was then and still am critical of the attempt to improve Bangladesh's reputation to the detriment of the image of another country, the USA. How this was done will become evident simply by studying the plot. 


\section{Carmen Brandt}

\section{The film plot}

The protagonist Lisa (played by me) is a young woman from the USA travelling in South Asia to flee from her emotionally cold parents - millionaires who care more for their wealth than for their daughter. In search of love, she ends up in Bangladesh, after learning Bengali in Calcutta. While enjoying marihuana and devotional music at a gathering with locals and another American tourist, Monica (played by another German, Silvia Béres), she meets Joy (Helal Khan). ${ }^{10}$ Joy, a journalist in search of a new story, is surprised to see these two foreign young women among local devotees, and coincidentally saves them from two gangsters who were planning to kidnap them. After Monica has moved on, leaving Lisa alone in Dhaka, the story develops around Lisa and Joy, who from then on acts as her local host and guide. In the course of events, Joy and Lisa visit his family for several days in a village, where she gets to know his relatives and the virtues of rural life. Back in Dhaka, the pair decide to travel around the whole of Bangladesh for a month to explore the cultural and natural highlights of the country. During that time Lisa not only falls in love with Bangladesh, but also with Joy, who seems to be attracted to her as well (see Figure 9.1). But in addition to showing Lisa his country, Joy has a mission as a journalist: his editor has given him money for the trip so that he can write an article about a rich

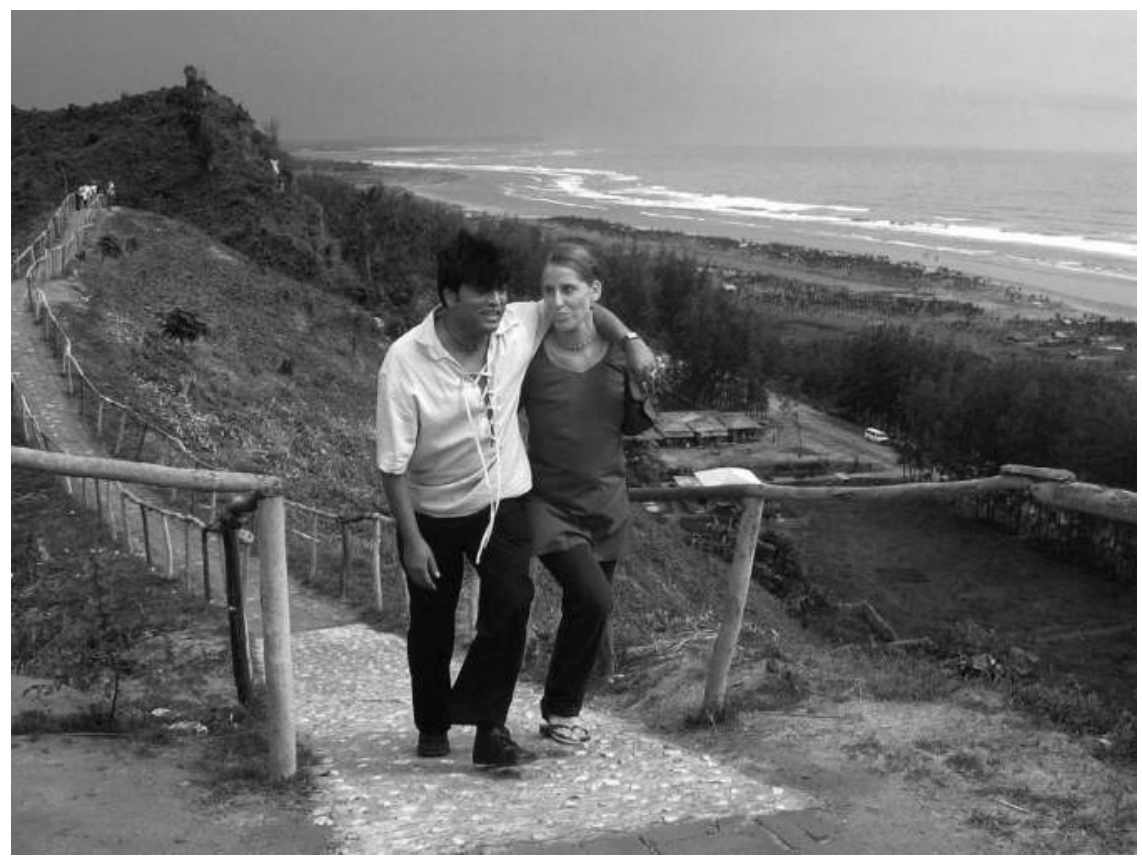

Figure 9.2 Joy and Lisa in Cox's Bazar

Source: Photograph by Khademul Insan 
foreigner's experiences in Bangladesh. Not wanting to influence Lisa's behaviour, he does not reveal his ulterior motive, which leads to several misunderstandings and suspicion, such as when she discovers his secret note-taking. At the end of the journey, Lisa coincidentally meets Monica again, who fuels Lisa's suspicions by suggesting that Joy might only be interested in Lisa's family's money. Overhearing a telephone conversation between Joy and his editor discussing money shortly after, Lisa misinterprets the conversation and decides to leave him. When she subsequently realises that she has misjudged him, she cannot find him for days - neither in Dhaka nor in his village. Once she meets him again, the approaching happy ending is disrupted when the US embassy calls her to say that her father is in Dhaka and intends to take her back home. Astonished that her father knows that she is in Bangladesh, she is told that a local journalist had been paid to track her down. Her suspicions of Joy immediately resurface and she flees from him once again. It is only at the airport that all the misunderstandings are resolved and the happy ending can finally be enjoyed. Lisa stays with Joy, and her father (played by the Dutch expatriate Adrian Becx) departs after proclaiming the film's last words: "God bless you, Bangladesh!"

\section{Portraying a positive Bangladesh}

The portrayal of a positive Bangladesh in this film is achieved by numerous techniques. One tool employed by the director Shibly Sadik is the beautiful images, for which the film crew travelled the country extensively, shooting at locations including Banderban, Chittagong, Comilla, Cox's Bazar, Sylhet, and Teknaf. In addition to these visual impressions, which stand in strong contrast to the pictures of floods, slums, and garment factories that usually dominate outsiders' perceptions of Bangladesh, the film introduces the audience to various positive facets of the country that become emblematic of its unique culture, history, nature, and people. Furthermore, the images relating to its history relate to cornerstones of Bangladesh's identity as a state that will be discussed later. The landscapes captured (among other places, Boga Lake in Banderban, the beach of Cox's Bazar, and the tea gardens of Sylhet) allow the audience to explore the natural beauty of Bangladesh, while the ruins of the Buddhist monastery at Mainamati and Lalbagh Fort in Old Dhaka convey the message that the region has played an important role for a long time. Additionally, music by Rabindranath Tagore, for instance ' $O$ go bideśin $\vec{\imath}$ (' $O$ h you, foreign woman'), the showcasing of a folk theatre play in a village, and the Bengali New Year celebrations (see Figure 9.3) are obviously meant to represent Bangladesh's cultural richness. In our discussions, Shibly Sadik told me that he had been planning the film for years, and it was a matter very close to his heart to show all these positive aspects of his country to a wider audience. Nonetheless, as well as the two gangsters who almost kidnapped Lisa and Monica, the film also gives space to another negative aspect of Bangladesh already mentioned above: poverty. 


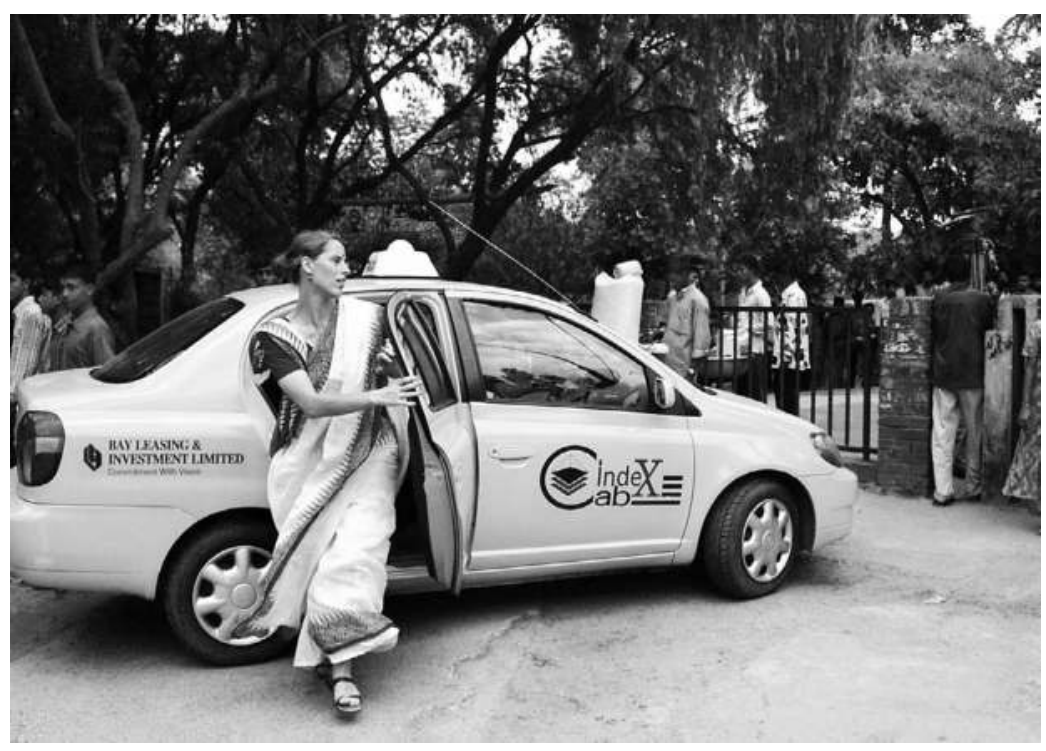

Figure 9.3 Lisa on Bengali New Year's Day dressed in a traditional sari

Source: Photograph by Silvia Béres

\section{The poor but happy people}

The glimpse of poverty - in the form of the dialogue cited above - can be understood as an important way of accommodating an undeniable part of Bangladesh's reality. To completely lack any scene of this kind might have made the film less credible. The dialogue actually goes hand in hand with another one a few sequences later, when Lisa asks Joy to show her his country. Astonished that this rich girl wants to see his poor country, he asks her what Bangladesh can give her. She replies, "Love. It can teach people to love (or: it can teach to love people)." ist idea that 'indigenous' people have a closer relationship to nature, in this case, a virtue is also made out of necessity by constructing the image of the poor but emotionally stable and happy Bangladeshis. This is done by establishing a contrast between Bangladeshis and Americans, with the latter portrayed as well-off economically but generally emotionally cold and unstable, and therefore unhappy. Interestingly, just a few months after the film was released, Bangladesh was ranked first in the World Happiness Survey. The headline of an online news article and its subheading suggest that comparing Bangladesh favourably with the USA, especially, could help boost the national self-esteem of Bangladeshis (bdnews24.com 2006):

Bangladeshis are the happiest! - World Happiness Survey: Bangladesh is the happiest nation in the world, the World Happiness Survey said the United States, on the other hand, is a sad story: it ranks only 46th. 
Lisa, an open-minded and warm-hearted American searching for true happiness in Bangladesh - far away from her rich family - is thus portrayed as something of an exception. The other American character, Monica, is a selfish and calculating person who incites distrust of Bangladeshis in her short appearances. Furthermore, she seems to represent the misinformed outsider whose perception of Bangladesh is mistaken. Even though Monica travels around the country for several weeks like Lisa does, she is apparently unable to shake off her prejudices and discover the true Bangladesh. What is worse, due to her blindness she almost succeeds in destroying Joy and Lisa's growing happiness together.

The contrast between the emotionally stable, poor but happy people of Bangladesh and the emotionally cold but financially rich Americans also reminds us of stereotypes evoking the 'Occident'-'Orient' dichotomy (see Said 2001 and Carrier 2003). In this dichotomy, the 'Orient' (here represented by Bangladesh) is associated with economic backwardness and emotionality, in this case love and emotional stability, while the 'Occident' (represented by the USA) is linked to materialism and rationality that is lacking emotions. Lisa, an exception, seems in her heart to be more Bangladeshi than American. After all, the main reason for Lisa's escape to South Asia was the lack of love expressed by her parents, who seemed more interested in their wealth than in their daughter. According to the film, people's behaviour in Bangladesh is the opposite: when Joy is offered several million dollars by Lisa's father in the last sequence of the film, he rejects the money without hesitation. He replies,

I am sorry, Mr. Reed, your daughter is back to you. That's enough. In our country we don't measure it with money. Through a journalist's pen we help people like Amit ${ }^{12}$ to be cured. That is not a payable deal. Take back your money and donate it for human cause.

Lisa's father is confused: "Unthinkable! Look honey, if I would like to buy a property like Bangladesh, I could. But I could not buy a single Bangladeshi." Taking into consideration the fact that Bangladesh was listed as the world's most corrupt country by Transparency International from 2001 until 2005 (The Daily Star 2014a), this statement at the end of the film must also be understood as a direct critique of the index by constructing the image of the caring, modest, selfless and incorruptible Bangladeshi, in contrast to Lisa's father who, as a typical 'Westerner', measures everything in terms of money.

\section{The true Bangladesh in villages}

Another example that reminds us of the non-'indigenous'-'indigenous' and the 'Occident'-'Orient' dichotomies is found in the section of the film in which a romanticised view of rural Bangladesh and the simple but happy way of life in a joint family are presented. These scenes take up more running time (around 30 minutes) than any other single location. In one sequence, Joy's sisters bathe their grandmother at a manual water pump in the courtyard. Lisa is astonished to 


\section{8}

see this, and at first she assumes that Joy's sisters must resent having to do so. When she learns that they are happy to take care of their grandmother, she comments that she has only met her grandparents once in her life, because they live in an old people's home. Joy's sisters are shocked and express their pity for Lisa. This and other enlightening experiences help Lisa to overcome her emotional instability by learning that happiness is not related to material wealth but to love for and trust in other people. The joy that Lisa discovers in rural Bangladesh is celebrated in the first song and dance scene of the film: while one of Joy's uncles sings the folkloristic song 'Dhẽkite dāo pā́r tom'rà' ('Pedal the [husking] flail [to make it move up and down], you'), cut with beautiful images of happy village life, Lisa, wearing a sari, operates a huge manual flail, similar to a seesaw, to the rhythm of the song.

Her happy stay in the village is only disrupted when one of Joy's distant aunts condemns Lisa for being dressed indecently: wearing a short-sleeved shirt und long skirt. The censorious woman herself is dressed in a black niqab, and seems to represent the growing Wahhabisation ${ }^{13}$ of Islam in Bangladesh. Her rude attack makes Lisa cry, but Joy's mother comforts her and explains, "In the world, people going beyond the limits in the name of religion are found in all places." 14 The fact that Joy's parents themselves are dedicated Muslims is made evident, for instance, in sequences in which they prepare for or perform their evening prayers. The film's message is clear: Islam in (rural) Bangladesh has nothing to do with intolerance. Lisa is treated like a family member despite being neither Bangladeshi nor Muslim. The image of the hospitable, tolerant, and caring villagers is supplemented by the rich culture and traditions they maintain and happily share with Lisa, as when they show her how to clean her teeth with charcoal, take her to a folk theatre performance, and teach her local wisdoms, for instance, that giving one's own handkerchief to another person leads to a quick separation from that person. And when Lisa falls sick and suffers from a fever after bathing with Joy's sisters in the village pond, she is treated with traditional medicine.

The simple rural lifestyle might appear unattractive to an urban audience at first glance, but it is shown to be truly rich in many ways. This topos is also prevalent in Bengali literature and art from the beginning of the 20th century, in which the urban elite search for the "“authentic' voice of the nation" (Mitter 2007, 29) in the villages. From many discussions with people in Dhaka, I gained the impression that the idea of the innocent, modest, and tolerant villager in contrast to the selfish, spoiled, and intolerant city dweller still holds sway. Seemingly, even today, the 'authentic' Bangladesh is to be found in its purest form in rural contexts. And since Bangladeshi villagers have not yet been spoiled by materialism and the hectic daily life of cities, they have also maintained their emotional strength. Ironically, not only poverty in Bangladesh, but also the fact that more than 60 percent of its population still live in rural areas becomes the basis for constructing emotional superiority over the citizens of one of the wealthiest countries in the world, the USA. Apart from these essentialising references to a national culture of the people of the USA, the film also presents important claims to a national Bangladeshi identity. 


\section{Between Bengaliness and Islam: Bangladesh's identity as a state}

The Bangladeshi state has been struggling with the search for its national identity between Bengaliness and Islam since it became independent from Pakistan in 1971. Unlike West Pakistan, an ethnolinguistically heterogeneous region where Islam was seemingly able to unite its population, at least to some extent, the ethnolinguistic homogeneity (around 98 per cent Bengalis today) of what was then East Pakistan became the cornerstone of its independence movement. Sheikh Mujibur Rahman (1920-1975), the founding leader of Bangladesh and today the symbolic figure for Bengali nationalism, is not without reason also called Bangabandhu [bongobond ${ }^{\mathrm{h}} \mathrm{u}$ ( 'friend of Bengal'). Bengaliness has been at the fore since 1971, but Islam has been becoming increasingly important in politics again. This is already reflected in the various amendments to its constitution.

The original constitution (1972) stated that the "citizens of Bangladesh shall be known as Bengalees", obviously emphasising the ethnolinguistic identity of the majority of its citizens. The paragraph was changed in 1979 under Ziaur Rahman (1936-1981), the president at that time, to become "[t]he citizens of Bangladesh shall be known as Bangladeshis". Although this term might appear more inclusive of the other ethnolinguistic groups living in Bangladesh, ${ }^{15}$ the other amendments made at the time suggest that 'Bangladeshi' was added in order to define the citizens of Bangladesh as 'Muslim Bengalis' or 'Bengali Muslims'. For instance, Ziaur Rahman replaced the fundamental principle of "secularism" with the clause "absolute trust and faith in the Almighty Allah" and added the preamble "Bismillah-ar-Rahman-ar-Rahim" in 1977, while the autocratic ruler Hussain Muhammad Ershad made Islam the state religion with his amendment of the constitution in 1988. Defining Bangladesh's citizens as 'Bangladeshis' who are 'Muslim Bengalis' or 'Bengali Muslims' may have seemed a useful way to differentiate them from Bengalis living in the Indian state of West Bengal, who are primarily Hindus. But the last two decades have been marked by the fear among secular forces that the growing Wahhabisation of Islam in Bangladesh constitutes a serious threat to Bengali culture. ${ }^{16}$ Hence, the 15 th amendment of the constitution in 2011 under Sheikh Hasina, the daughter of Sheikh Mujibur Rahman, which restored the principle of "secularism" and an emphasis on the Bengali identity (see Government of Bangladesh 2011a), must be understood as an attempt by the Awami League government to safeguard Bengaliness, while at the same time still giving enough space to Islam by maintaining previous changes, for instance, the preamble 'Bismillahar-Rahman-ar-Rahim' and the declaration of Islam as the state religion.

In the film, several scenes make it clear that Bangladesh is a Muslim majority country, but at the same time underline the tolerant character of Islam in Bangladesh. Other religions are introduced as well, for instance, Buddhism in the past and present. In general, the film defines Bangladesh's national identity as Bengali and secular, although the majority of its citizens are Muslims (currently around 90 per cent). Thus, the film more or less reflects the identity politics of the Awami League (AL), the party of Sheikh Mujibur Rahman and his daughter Sheikh 
Hasina. At the time of shooting, however, the AL's strongest opponent, the Bangladesh Nationalist Party (BNP) - which was founded by Ziaur Rahman, is chaired by his widow Khaleda Zia, and places a stronger emphasis on Islam in general was in power. In addition, since the film received funding from various government institutions, it is not surprising that several scenes refer to Ziaur Rahman, for instance, by dedicating a scene to a visit to the house in Chittagong where he was assassinated in 1981. But apart from that, the film highlights aspects of Bangladesh's (pre)history that make it clear that Bangladeshis are, first and foremost, Bengalis.

\section{Bengali language, Bengali blood, Bengali soil}

One of the most important days for Bangladesh's identity as a state was 21 February 1952. On that day, several people were killed during a demonstration against Urdu being the sole state language in then Pakistan. Today, Ekuśe ("the 21st [of February]') is one of the most important national holidays, on which people lay down flowers at the Śahid Minār ('martyr monument') in Dhaka and other places all over Bangladesh. Furthermore, in 1999, the day was declared the International Mother Language Day by the UN, a fact of which many Bangladeshis are very proud. Lisa joins the commemorations and is extremely impressed:

I have heard of sacrificing one's life for the country, I have heard of sacrificing one's life for religion, but sacrificing one's life for the language in one's mouth, one's mother's language, I heard this first time - saw this first time in Bangladesh. ${ }^{17}$

Joy is happy to see Lisa's appreciation of Bangladesh's history, and together they sing the song that can be heard on Ekuśe all over the country:

\section{āmār bhāiyer rakte rāināno ekuśe phebruȳāri āmi ki bhulite pāri? ${ }^{18}$}

Can I forget the 21 st of February dyed in the blood of my brother?

The song offers a condensed summary of the most important aspect of contemporary Bangladesh's identity as a state: it represents the idea that the state was born out of the Bengali Language Movement (Uddin 2006, 124-133), out of the desire to protect one of the most important features of Bengali culture. The Bengalis' demand in what was then East Pakistan to use their language in every sphere of life, and the fear that they would gradually lose their culture if Urdu was imposed on them, reminds us of the demands and fears of 'indigenous' groups trying to resist cultural hegemony. The Bengalis in East Pakistan evidently had very similar experiences on their way to self-determination. And the people killed on Ekuśe marked only the beginning of the blood shed for Bangladesh's independence. Although the film does not allude to the three million people said to have been killed during the war of independence in 1971, a figure that is otherwise all 
important in present-day Bangladesh, ${ }^{19}$ in the National Museum in Dhaka, Joy shows Lisa photos of the struggle, including images of dead bodies. The message is clear: many people sacrificed their lives for the independence of Bangladesh. While the film does not state explicitly that it was only the blood of Bengalis that soaked the soil of present-day Bangladesh, nothing in the film even hints that there are other ethnolinguistic groups in the country. Despite predominantly referring to the citizens of Bangladesh as 'Bangladeshis' and not 'Bengalis', the identity of Bangladeshis conveyed is constructed solely around Bengaliness. The film repeatedly asserts that it was Bengalis' fear of cultural hegemony, their wish for selfdetermination, and the blood shed by Bengalis that gave birth to Bangladesh. Self-evidently, this narrative leaves no space for the non-Bengali ethnolinguistic groups living in Bangladesh who vehemently refer to themselves today as 'indigenous'.

\section{Who is indigenous in Bangladesh?}

Since the United Nations (UN) began increasingly using the term 'indigenous' in its work to protect and support marginalised ethnic groups, matters seem to have become more complicated rather than being simplified, especially in South Asia. The problematic nature of the term itself also becomes evident when we look at the attempts of activists backing the 'indigenous' cause to find an equivalent for it in other languages, as in the case of $\bar{a} d i b \bar{a} s \bar{l}$, which carries a host of hermeneutic connotations.

Although the term $\bar{a} d i b \bar{a} s \bar{\imath}$ has only been used as the Bengali equivalent for 'indigenous' by activists in Bangladesh since the 1990s, its origins are older. For example, it formed part of the name of a political organisation inaugurated in 1938, the Adivasi Mahasabha (Rycroft and Dasgupta 2011: 1) (Hindi: ādivāsī mahāsabhā, i.e., 'grand assembly of $\bar{a}$ div $\bar{a} s \bar{\imath} \mathrm{s}$ ') in the region that is now the Indian state Jharkhand. Over the course of time, the Sanskrit neologism was taken up in various modern South Asian languages, including Bengali, in which it is pronounced [adibafi], leading to the anglicised version 'adibashi' (Tripura 2015, 28, among others). Nowadays, the term is often translated as 'original inhabitant' (ibid., 33), but it carries a wide spectrum of connotations, since $\bar{a} d i$ means, to name a few, 'first', 'original', 'primary', etc., and $v \bar{a} s \bar{\imath}$ 'dweller', 'inhabitant', 'resident', etc. However, usage of the term as a synonym for 'tribal' during British colonial times tainted $\bar{a}$ div $\bar{a} s \bar{\imath}$ with the negative connotation 'primitive', although Prashanta Tripura seems convinced that this association "has largely disappeared" (ibid.) in present-day Bangladesh. But, especially in Northeast India, most ethnolinguistic groups prefer the term 'tribe' to àdivāsi because of the pejorative connotations of the latter term, which in the Northeast region is now primarily used to refer to the often socioeconomically disadvantaged 'âdivāsì' migrants from other parts of India, many if not the majority of whom were settled there during British colonial times.

Apart from such philological musings on the term 'indigenous' and the appropriateness of its counterparts in other languages, another more problematic issue 
is the vagueness of definitions issued by the UN, NGOs, and other stakeholders (see Kuper 2003; Muehlebach 2001). Additionally, although the term 'indigenous' can be applied in a relatively open manner without reference to a specific territory (see Forte 2010), even to argue "that they represent not merely the first inhabitants of a country but the original human population of the world" (Kuper 2003, 390), in the case of the ethnic minorities in Bangladesh it is invoked by NGO activists first and foremost to validate claims to specific territories and safeguard them from members of the dominant ethnic group - Bengalis. And while in certain other states, e.g., Australia, Canada, and the USA, the question of who is 'indigenous', i.e., who settled there first, can be answered relatively simply, ${ }^{20}$ in other countries, especially on the African and Asian continents, that question often cannot be answered at all and repeatedly fuels highly charged debates. The migration and settlement patterns for the regions that form today's Bangladesh are complex and can rarely be proven, even though some groups are convinced that they know who settled where first. ${ }^{21}$

For instance, while the activists who lobby in the name of ethnic groups in the Chittagong Hill Tracts (CHT) in south-east Bangladesh, a border region between South Asia and Southeast Asia, argue that those groups are the true 'indigenous' people of that territory, the state vehemently refutes that claim. Under British colonial rule, the region was isolated to a large extent from the rest of the region that forms today's Bangladesh and its Bengali population, but it has seen a high influx of Bengalis, particularly since the creation of the Bangladeshi state in 1971 (see Mohsin 2002). State-sponsored 'Bengalisation' of this region resulted in a civil-war-like situation from the end of the 1970s onwards, which could only partially be resolved by a peace accord in 1997. In addition to the armed conflict of the past, there has also been a battle of words which continues to this day. For instance, in a meeting with foreign diplomats in 2011, Dipu Moni, at that time the foreign minister of Bangladesh, said, "They [the non-Bengali groups in the CHT] came here as asylum seekers and economic migrants. [. . .] The ethnic Bengalees are not colonial settlers, neither are they foreigners or non-indigenous to their own native land and never will be" (bdnews24.com 2011).

While in the case of the very heterogeneous non-Bengali groups living in the CHT it is indeed unclear who exactly lived there first and who migrated from where, for other groups living in the plains who also claim 'indigenous' status, the matter seems to be simpler. The majority of Santals, for example, settled in the plains of present-day north-west Bangladesh at the time of British rule (Ali 1998, 18). It is undeniable that these ethnic minorities - whether or not they are truly 'indigenous' to the soil they inhabit today - suffer particularly from socioeconomic and cultural marginalisation in today's Bengali-dominated Bangladesh and are constantly exposed to human rights violations, such as land grabbing by Bengali neighbours in the plains (Barkat 2009) or other violent conflicts with Bengali neighbours in the CHT. However, Dipu Moni brought up the most important point in her otherwise questionable statement: if ethnic minorities were to be recognised as 'indigenous', then what would that make the Bengalis in Bangladesh? Although the ancestors of some non-Bengali groups might indeed be more indigenous to 
some regions of today's Bangladesh than ancestors of the people known today as Bengalis, in other regions it might be the other way around. The complex migration and settlement patterns in the region cannot justify such demands for exclusive rights to certain areas of land by groups that, additionally, may have only begun to claim specific, self-determined group identities within the last one or two hundred years.

As Adam Kuper points out,

whatever the political inspiration, the conventional lines of argument currently used to justify 'indigenous' land claims rely on obsolete anthropological notions and on a romantic and false ethnographic vision. Fostering essentialist ideologies of culture and identity, they may have dangerous political consequences.

(Kuper 2003, 395)

In the case of Bangladesh, one of these consequences seems to be that the heated debate around the terms 'indigenous' and $\bar{a} d i b \bar{a} s \bar{\imath}$ hinders solutions to actual problems, particularly those that the lower strata of the ethnic minorities suffer from. While some ethnic minority leaders build their hopes on these highly contested terms attracting global solidarity and support, many cases serve to illustrate the failings of supposedly universal concepts and terms. Ultimately, whatever the reasons why activists and scholars might prefer the term 'indigenous', and whatever discourses and concepts they attribute to it, in the case of Bangladesh, the state takes the meaning literally and hence sees the term as a potential threat to its legitimacy and sovereignty. Thus, while identifying as 'indigenous' allows ethnic minorities in Bangladesh to be part of a global network, on a local level, doing so puts them at odds with the state. However, denying ethnic minorities' right to use the term 'indigenous' is also linked to the Bangladeshi state's self-positioning in a wider context, within a wider dichotomy of the so-called global South-global North that is remarkably reminiscent of the non-'indigenous'-'indigenous' dichotomy.

\section{Conceptual dichotomisations of human entities}

The conceptual dichotomisation that divides the world's human population into 'indigenous' and non-'indigenous' people is only one of several that are invoked to claim rights, to explain socioeconomic disadvantages, and in some cases even to justify violence ${ }^{22}$ on the basis of group and not individual identities. While the non-'indigenous'-'indigenous' dichotomy is officially upheld by various transnational institutions, e.g., the UN, and also many individual states, other voices that are not institutionalised nevertheless seem to play an important role, even in national and international politics. In the case of 'indigenous' people, a conceptual dichotomisation of human entities allows the representatives of real or imagined marginalised groups to raise their voice collectively on a global level by creating a common ground that forms the basis for demanding compensation, privileges, protection, and rights. One of the best-known dichotomies in this regard, which is 
often invoked for these causes, divides the human population into (former) colonising and (former) colonised societies, i.e., the 'West' and the rest. In this dichotomy, the first group is not only perceived as the socioeconomically and culturally dominant and thus dominating group but also as the one that must be held responsible for restoring a balance so that the second group can catch up, fulfil its potential, or retain its own characteristics. It goes without saying that this kind of dichotomy relies on simplified representations that often ignore the socioeconomic heterogeneity and hierarchies within the two groups on each side and the complex relationships between the groups.

Nonetheless, these dichotomies seem to be more important than ever before and are omnipresent in public discourses. Furthermore, they gain traction by activating the guilty conscience suffered by members of the first group in these dichotomies and a tendency to self-victimisation among members of the second group. Among other effects, this often produces simplified explanatory models and slogans such as 'They are poor because we are rich', or vice versa. This "mobilisation of shame" tied to group identities is part of the non- 'indigenous'- 'indigenous' dichotomy too (see Muehlebach 2001, 417). Additionally, such dichotomies rely on specific attributions ascribed to each side that portray the dominating group in a negative light, while the dominated group is often highly romanticised. For instance, 'indigenous' people are sometimes heralded as the potential saviours of humankind by virtue of their supposedly intrinsic relationship to nature and land, which non- 'indigenous' people only know how to exploit and destroy (ibid., 424-438). This attitude towards 'indigenous' people is also prevalent in Bangladesh, as can be seen from a comment by a well-known non-'indigenous' NGO consultant under his Facebook profile picture containing the word 'Adivasi', which he had set up after the Bangladesh government issued a press release (see earlier) requesting that the term be avoided: "Adivasis are the great activists for equality, freedom, secular spirituality and symbiotic relation with nature ... Their values and practises are crucial for saving humanity and nature, mother earth."

This kind of romanticism and support for the 'indigenous' cause on the part of a non-'indigenous' Bengali person should be considered in the light of the supporter's socioeconomic background. Some people from so-called developed 'Western' countries see themselves in a socioeconomically dominant and dominating position and feel called upon to attempt to redress the balance, for example, by supporting so-called development projects. Similarly, individual non-'indigenous' people in Bangladesh, overwhelmingly from the upper social strata, also publicly champion the 'indigenous' cause and invoke the non'indigenous'-'indigenous' dichotomy with all its inherent negative and positive attributions. This kind of support from outsiders relies not only on a guilty conscience - justified or not - but also on self-criticism and empathy for people in weaker socioeconomic positions. These preconditions, I argue, can only be found among individuals and groups that indeed see themselves as part of a dominant and dominating entity - as an actual or potential perpetrator - and thus are able to high-mindedly ${ }^{23}$ support a weaker entity without fearing that that might constitute a threat to their own present position. 


\section{Conclusion}

Although at first glance a modern state is a different kind of entity than groups labelled 'indigenous', the mechanisms surrounding the formation of identity in both types of entity may nevertheless be similar. While it is well documented that the collective imaginations of a modern nation-state can unite its citizens (Anderson 2003), in the case of 'indigenous' groups today, very similarly, the shared sentiments that keep their members together and prevent them from joining the 'mainstream' are also often imaginations, for instance, invented traditions or an imagined past. Furthermore, in both cases the self-perceptions and representations seem to be strongly linked to outsiders' perceptions and can in some cases be understood as direct counter-images or positive reinterpretations of imposed attributions. In the case of 'indigenous' people in Bangladesh, this is already reflected in the term 'indigenous' itself. Apart from its literal meaning and the ensuing claim that the groups labelled as such are the indigenous people of specific regions of today's Bangladesh struggling for cultural survival and self-determination, the term 'indigenous' was also introduced with the aim of shaking off the negative connotations of the word 'tribe'. The attempt to ban the term 'tribe', which in the public imagination does often carry connotations of ideas such as 'backward', 'pre-modern', 'primitive', and 'uncivilised', goes hand in hand with the positive reinterpretation of a simple rural lifestyle as one that is in harmony with nature.

The portrayal of Bangladesh and its citizens in the film Bideśini relies on similar constructions of meaning. First, there is nothing in the film to suggest that Bangladesh (bāmlādeś) is anything other than the region (deś) of Bengal (bāmlāa), and that its indigenous inhabitants are called Bangladeshis - and those are Bengalis. Having shed their blood for this soil since 1952, the independence of Bangladesh symbolises the Bengali people's successful fight for the survival of their culture and language. This fight is not yet over, as is reflected in the growing fear of the Wahhabisation of Islam in Bangladesh, which indeed constitutes a serious threat. In the film, this threat is represented by Joy's intolerant aunt who wears a niqab. In general, the history of Bengalis in the region is often constructed as a continuous struggle for cultural self-determination against outsiders, especially West Pakistanis and foreign-funded Islamist forces today, and as a victim of economic exploitation during Mughal times, British colonial domination, the Pakistan era, and contemporary globalisation (see Chowdhury 2004). This self-representation as struggling victims reminds us ultimately of "the histories of oppression" (Muehlebach 2001, 421) otherwise associated with 'indigenous' groups.

Hence, the Bangladesh portrayed in the film is by no means a dominant or dominating entity but rather one that is continuously obliged to resist domination from outsiders. The fact that Bengalis themselves dominate other ethnic groups is not shown in the film and is rarely a topic of public debate, and this is likely to remain the case as long as actual and potential domination from outside continues to take centre stage. Bangladesh's identity as a state that apparently emphasises the idea that Bengalis have always been victims - in the past and present - seems to absolve the majority of its citizens of a guilty conscience, self-criticism, or empathy for 
ethnic groups in weaker positions. On the contrary, ethnic minorities are sometimes even seen as accomplices of the powers that seek to harm Bangladesh:

Bengalis are the victims of regional and international machinations. Of forces who are infinitely more powerful. Forces external to the nation, with whom bad elements within the nation, ${ }^{24}$ the 'tribals', have ganged up.

(Ahmed 2010, 214)

Second, in general, Bangladesh is perceived as an underdog at a global level. Like 'indigenous' groups in the past (when they were still known as 'tribes'), it is perceived as 'backward'. While 'indigenous' groups counter this negative image by constructing an intrinsic relationship to nature, potentially able to save our planet, the film Bideśin - From Bangladesh with Love proposes that the poor people of Bangladesh can show citizens of economically superior countries a way back to emotional warmth in the form of happiness and love. In both cases, socioeconomic backwardness is reinterpreted to create a positive image in opposition to the economically dominant and dominating entities - non-'indigenous' people and the 'West' (the USA in the film) - that supposedly lack these positive characteristics. Interestingly, these counter-images are based on dichotomies and related attributions that have emerged within these socioeconomically dominant entities, which are today often portrayed as being 'backward' in terms of their relationship to nature and their emotional capacity. This becomes most evident when we look at the attributions against the backdrop of the long-standing 'Occident'-'Orient' dichotomy, which conveys all these essentialist attributions to the respective sides. While most scholars and activists reject that dichotomy today, terms such as 'indigenous' and 'Western' and their constructed counterparts continue to imply very similar attributions to those of the discredited dichotomy.

Consequently, as long as both the Bangladeshi state and the 'indigenous' groups of Bangladesh continue to base their identity politics upon "histories of oppression" and being dominated on a global level, the question of who is more indigenous to the soil of today's Bangladesh will continue to be heavily contested by both sides. And furthermore, as long as the Bangladeshi state refuses to see itself as an entity that is also dominant and dominating, and at times plays the role of a perpetrator, it will deny its ethnic minorities the label 'indigenous'. Ultimately, the UN's high-minded idea to unite the world's marginalised ethnic groups under a global 'indigenous' label has led to a deadlock situation at the local level that is unlikely to be resolved in the near future.

\section{Notes}

1 Apart from the ethnic minorities who claim the label 'indigenous', there are also other ethnic minorities in Bangladesh, for instance Rohingyas and so-called Biharis, Muslims that migrated mainly from Bihar to then East Pakistan following the partition in 1947.

2 Just one day after this statement was released, it could no longer be found on the website of the PID (The Daily Star 2014b).

3 International Day of the World's Indigenous Peoples. 
4 The additions in square brackets in this sentence are the terms used in the official English version of the Bangladeshi constitution (Government of Bangladesh 2011b). These terms are not only problematic in their English versions (cf. particularly 'sects'), but also in Bengali (Government of Bangladesh 2011c) as they are neologisms for English terms and concepts that were first introduced into South Asia during British colonial times. As they are formed from Sanskrit terms with their own traditional semantics, they may be translated in various ways, for instance, 'subnation' for upajäti (see Partha Chatterjee's article 'The Manifold Uses of Jati' [1996]) and 'small human group' for kșudra nrgoșthi

5 This is a literal translation; the intended meaning is "to university teachers, experts, newspaper editors and other members of civil society participating".

6 The Bengali original (correcting some mistakes obviously due to incorrect font conversion): 'ādibāầ' śabdațir byabahār parihār karā prasaìge: bāmlādeś sambidhāner

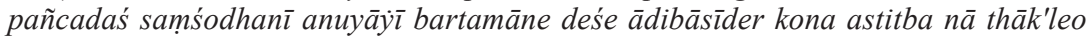
bibhinna samay biśeș kare jātisamgha ghoșita āntarjātik ādibāsī dibase 'ādibāsī' śabdați bār'bār byabahār haye thāke. ullekhya, pañcadaś samśodhanìte bāmlādeśe basabās'rata kșudra nrgoșthīke upajāti bā kșudra nrgoșthī bale ākhyāyita karā hayeche. āgāmī 9 àgast āntarjātik ādibāsī dibas upalakșe bibhinna anușthān, àlocanā o țak'śote 'ādibāsì'śabdațir byabahār parihār karār janya anurodh karā hayeche. e sakal ālocanā o țak'śote amnśagrahaṇ'kārī biśbabidyālayer śikșak, biśeșajña ebam sambād'patrer sampādak'saha suśīl samājer anyānya byaktibargake bāṃlādeśer kșetre ādibāsī śabdațir byabahār parihārer janya pūrbei sacetan thāk'te anurodh jānāno yācche. All translations from Bengali here and in the following strive to be as literal as possible.

7 To differentiate between the generic usage of this term with its wide spectrum of meanings, for instance as a synonym for 'local' or 'native' and its meaning as coined by the United Nations (UN), I will write the latter term in inverted commas and the former without any punctuation marks. This is to remind the reader that the latter is a problematic and at times highly contested term.

8 At that time, members of the so-called middle class rarely visited cinemas, which were reputed for screening films with violent and sexually explicit content. The most often denounced aspect was the phenomenon of 'cut pieces' - extra sequences featuring violent and/or sexually explicit content - that could even be cut into otherwise familyfriendly films (cf. Hoek 2013). Along with other reasons, for instance the introduction of satellite TV, VHS, VCDs and then DVDs, that was a major factor in the decline of the popularity of the Bangladeshi film industry, often referred to as Dhallywood, with its headquarters financed by the Bangladesh Film Development Corporation (BFDC) in Tejgaon, Dhaka.

9 Bengali original:

Lisa: sundar.

Joy: orā bara garīb.

Lisa: tāte duhkha āche ki?

Joy: oder ghar nāi bārì nāi.

Lisa: nidrā āche. śāntite ghumāte pāre.

Joy: orā dū'belā pet bhare khete pāy nā.

Lisa: tabuto orā sukhī. ār āmi? āmāder cār'dike bilās drabya āche, pracur āhār $\bar{a}$ che, nidrā yāoȳār gṛha āche. tāo . . . tāo āmāder jbālā yantranār śeș nei. kena? kena ei dūratba? kena ei byabadhān? āj āmerikār śataśata tarun tarun̄i

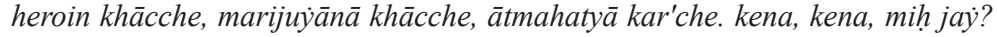

10 Unlike me, Helal Khan is a professional actor who is widely known in Bangladesh, especially for his role in the national award-winning film Hason Raja (Hāchan Rajjā) (Bangladesh 2002), directed by Chashi Nazrul Islam (Cāṣī Naj'rul Is'lām).

11 Bengali original: bhālabāsā. mānuș'ke bhālabās'te siikhāte pāre. 
12 Amit seems to be one of many people for whom funds are raised by newspapers to pay for urgent operations or other medical treatment.

13 The term 'Wahhabisation' as it is currently commonly used in South Asia refers to changes in Muslim practice and religiosity that have been strongly influenced by an exclusive form of Sunni Islam, which originated in the 18th century in a region that is now part of Saudi Arabia. These changes pertain to various fields, such as everyday practices, a more rigid gender segregation, more women wearing hijab and niqab, growing intolerance of other forms of Islam (e.g., Ahmadiyya, Shia, Sufism) and other religions in general, and, in today's Bangladesh, the targeted killing of atheists and people thought to be atheists along with followers of other beliefs. On the term 'Wahhabi' in discourses in South Asia, see Zaidi (2010, 209-220).

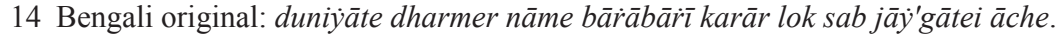

15 Since the majority of non-Bengalis in Bangladesh are also not Muslims, the exclusive amendments regarding Islam in particular suggest that defining Bangladesh's citizens as 'Bangladeshi' was not primarily done in order to include Bangladesh's ethnolinguistic minorities.

16 This fear is not unsubstantiated, given the fact that there have been several Islamist attacks, including one on the Bengali New Year celebrations in 2001 that caused 10 deaths.

17 Bengali original: deśer janya prān dite śunechi, dharmer janya prān dite śunechi, kintu mukher bhāṣā, mājer bhāṣār janya prān dite ei pratham śun'lām-ei pratham dekh'lām bāmlāàsés.

18 The lyrics are based on a poem written by Abdul Gaffar Choudhury in 1952; the music was composed by Altaf Mahmud in 1969 .

19 The figure of three million victims is part and parcel of the narrative of Bangladesh's genesis, especially among Awami League followers. There is no substantial documentation to support the number, yet anybody who doubts its accuracy comes under serious political fire and even legal action.

20 Adam Kuper showed that even there, e.g., in Canada, it is not that easy to ascertain who is more indigenous to which territory (Kuper 2003, 391).

21 Today, even the theory that groups speaking Indo-Aryan languages started migrating to South Asia more than 3,500 years ago is challenged by so-called Hindu nationalists in India (see Das 2003).

22 For instance, in the context of the terrorist attacks in Paris in November 2015 Tabish Khair criticised the way that discussions led by left-wing people, Muslims and nonMuslims, often portray Islamic terrorism solely as a result of 'Western' colonialism and imperialism, thereby denying the terrorists their own agenda (Khair 2015).

23 Although such support might appear altruistic at first glance, it often has paternalistic undertones that reflect many supporters' (conscious or subconscious) belief that they are not only superior in the field of economics but also in morality.

24 Apparently, Ahmed equates 'nation' and 'state'. After all, the whole nation-building process in Bangladesh has been based on the Bengali identity and thus has excluded ethnic minorities, making 'tribals' outsiders.

\section{References}

Ahmed, Rahnuma. 2010. "The Bengali Sense of Victimhood." In Between Ashes and Hope: Chittagong Hill Tracts in the Blind Spot of Bangladesh Nationalism, edited by Naeem Mohaimeen, 213-215. Dhaka: Drishtipat Writers' Collective.

Ali, Ahsan. 1998. Santals of Bangladesh. Midnapur: Institute of Social Research and Applied Anthropology.

Anderson, Benedict. 2003. Imagined Communities: Reflections on the Origin and Spread of Nationalism. Rev. \& ext. ed. 13th impr. London and New York: Verso. 
Barkat, Abul. 2009. Life and Land of Adibashis: Land Dispossession and Alienation of Adibashis in the Plain Districts of Bangladesh. Dhaka: Pathak Shamabesh.

bdnews24.com. 2006. "Bangladeshis Are the Happiest!: World Happiness Survey." bdnews 24. com, January 15. http://bdnews24.com/Bangladesh/2006/01/15/Bangladeshis-are-thehappiest-world-happiness-survey. Accessed on 25 January 2016.

bdnews24.com. 2011. "“Indigenous People' a Misnomer: Moni.” bdnews24.com, July 26. http://bdnews24.com/bangladesh/2011/07/26/indigenous-people-a-misnomer-moni. Accessed on 8 February 2016.

Brandt, Carmen. 2010. "Bangladesch als Fußnote sozialwissenschaftlicher Diskurse?" Orientalistische Literaturzeitung 105 (1): 7-20.

Carrier, James (ed.). 2003. Occidentalism: Images of the West. Repr. Oxford, et al.: Clarendon Press.

Chatterjee, Partha. 1996. “The Manifold Uses of Jati.” In Region, Religion, Caste, Gender and Culture in Contemporary India, edited by T.V. Sathyamurthy, 281-291. (Social Change and Political Discourse in India 3.) Delhi et al.: Oxford University Press.

Chowdhury, Mahfuz R. 2004. Economic Exploitation of Bangladesh. Dhaka: Shraban Prokashoni.

The Daily Star. 2014a. "Bangladesh 14th Most Corrupt Country: 'Influence on ACC and Cubing Its Powers Key Reasons Behind Worsening Situation'.” The Daily Star, December 3. www.thedailystar.net/bangladesh-14th-most-corrupt-country-53165. Accessed on 8 February 2016.

The Daily Star. 2014b. “Govt Call for Not Using 'Adivasi’ Term Questioned.” The Daily Star, August 9. www.thedailystar.net/govt-call-for-not-using-adivasi-term-questioned36381. Accessed on 8 February 2016.

Das, Rahul Peter. 2003. "The Invasion That Never Was: Das 'Neue' Geschichtsbild der Hindu-Nationalisten.” In Indien heute: Brennpunkte seiner Innenpolitik, edited by Subrata K. Mitra and Bernd Rill, 113-119. München: Hanns-Seidel-Stiftung.

Forte, Maximilian C. 2010. "A Carib Canoe, Circling in the Culture of the Open Sea: Submarine Currents Connecting Multiple Indigenous Shores." In Indigenous Cosmopolitans: Transnational and Transcultural Indigeneity in the Twenty-First Century, edited by Maximilian C. Forte, 17-37. New York, et al.: Peter Lang.

Government of Bangladesh. 2011a. "Citizenship." The Constitution of the People's Republic of Bangladesh. http://bdlaws.minlaw.gov.bd/sections_detail.php?id=367\&sections_ id=24554. Accessed on 8 February 2016.

Government of Bangladesh. 2011b. "The Culture of Tribes, Minor Races, Ethnic Sects and Communities." The Constitution of the People's Republic of Bangladesh. http://bdlaws. minlaw.gov.bd/sections_detail.php?id=367\&sections_id=41506. Accessed on 8 February 2016.

Government of Bangladesh. 2011c. "Upajāti, kṣudra jātisattā, nṛ-goșṭhī o sampradāyer saṃskṛti." Gaṇaprajātantrī bāmlādeśer saṃbidhān. http://bdlaws.minlaw.gov.bd/ bangla_sections_detail.php?id=957\&sections_id=41502. Accessed on 8 February 2016.

Hoek, Lotte. 2013. Cut-Pieces: Celluloid Obscenity and Popular Cinema in Bangladesh. New York: Columbia University Press.

Khair, Tabish. 2015. "Double Nature of Orthodox Truths: Reactions to the Paris Carnage." Economic \& Political Weekly 49 (1): 28-30.

Khātun, Sāỳmā, and Māh'mudul Suman (eds.). 2014. Ādibāsī āche? ... āche! ādibāsī nāmbitarker prabandha saṃkalan. Ḍhākā: Saṃbed.

Kuper, Adam. 2003. "The Return of the Native." Current Anthropology 44 (3): 389-395.

Mitter, Partha. 2007. The Triumph of Modernism: India's Artists and the Avant-Garde, 1922-1947. London: Reaktion Books. 


\section{0}

Mohsin, Amena. 2002. The Politics of Nationalism: The Case of the Chittagong Hill Tracts. 2nd ed. Dhaka: University Press Limited.

Muehlebach, Andrea. 2001. "'Making Place' at the United Nations: Indigenous Cultural Politics at the U.N. Working Group on Indigenous Populations." Cultural Anthropology 16 (3): 415-448.

Rycroft, Daniel J., and Sangeeta Dasgupta. 2011. "Indigenous Pasts and the Politics of Belonging." In The Politics of Belonging in India, edited by Daniel J. Rycroft and Sangeeta Dasgupta, 1-17. (Routledge Contemporary South Asia Series 43.) London and New York: Routledge.

Said, Edward W. 2001. Orientalism: Western Conceptions of the Orient. New Delhi, et al.: Penguin Books.

Tripura, Prashanta. 2015. "Identity Grabbing: The Official Position against Indigeneity Undermines Bangladesh's ‘Adibashi’ Minorities.” Himāl 28 (3): 28-38.

Uddin, Sufia M. 2006. Constructing Bangladesh: Religion, Ethnicity, and Language in an Islamic Nation. Chapel Hill: The University of North Carolina Press.

White, Sarah C. 1992. Arguing with the Crocodile: Gender and Class in Bangladesh. Dhaka: University Press Limited.

Zaidi, S.A. 2010. "Who Is a Muslim? Identities of Exclusion: North Indian Muslims, c. 1860-1900." Indian Economic and Social History Review 47 (2): 205-229.

\section{Film}

Bideśinī: From Bangladesh with Love. 2005. Directed and written by Shibly Sadik; with Carmen Brandt, Helal Khan. Dhaka: CMV. 


\section{Part III}

\section{Documenting and fictionalising indigeneity}


$\because$ Taylor \& Francis Taylor \& Francis Group http://taylorandfrancis.com 


\title{
10 Made in India
}

\section{Ethnographic films beyond visual anthropology}

\author{
Giulia Battaglia
}

At the end of November 2008, a well-known Delhi-based independent filmmaker, Rahul Roy, organised an ethnographic film festival in collaboration with the department of Sociology at the University of Delhi. The festival was called 'Delhi International Ethnographic Film Festival' (henceforth DIEFF) and ran from 26 to 30 November (see Figure 10.1). It hosted a tribute to the well-known visual anthropologists David and Judith MacDougall, who participated at the festival and whose classic films were screened in the 'retrospective' category across the five days (see Figure 10.2). The films of Jean Rouch were also screened as 'retrospectives' and introduced and discussed by Francoise Foucault, Rouch's associate at the Musée de l'Homme's Committee on Ethnographic Film. As the catalogue of the festival states, "the twenty nine documentaries selected for the open section showcase a wide range of ethnographic and documentary strategies employed by film makers in different parts of the world". The line-up also included seven films made by independent Indian filmmakers based in different parts of the country.

The seven 'ethnographic films' made by Indian filmmakers shown at the festival were Saba Dewan's Delhi-Mumbai-Delhi (2006), about the journey of a bar dancer from Delhi to Mumbai in search of work and a future; Nilanjan Bhattacharya's If It Rains (2007), a film shot over nine years about the lives of three generations of men of the Bhutia family, living in the mountains of Sikkim; Anjali Monteiro and K.P. Jayasankar's Irani Restaurant Instructions (2008), a short film about the time and space of an Iranian cafe in Mumbai founded by a migrant in the 19th century; Biju Toppo's Kora Rajee/Land of the Diggers (2005), about Adivasi labourers working in the tea gardens of North Bengal and Assam and the parallel journey of the director searching for the history of his ancestors; Rajula Shah's Word Within the Word (2008), a reflection on the formless essence of reality that lies between the indigenous spirit and the modern soul; Amudhan R.P.'s Pee/Shit (2003), about the daily conditions of one of the Dalit workers of the Madurai Municipal Corporation involved in manual scavenging; and Nandini Bedi's Notes on Man Capture (2007), about marriage practices in a village in Northeast India. Even though these films had not been originally conceived as 'ethnographic films', they shared stylistic elements characteristic of what in the global history of visual anthropology has been known as the 'ethnographic film' - such as the use of long observational shots, long-term engagement with the film's subject, a particular emphasis on 


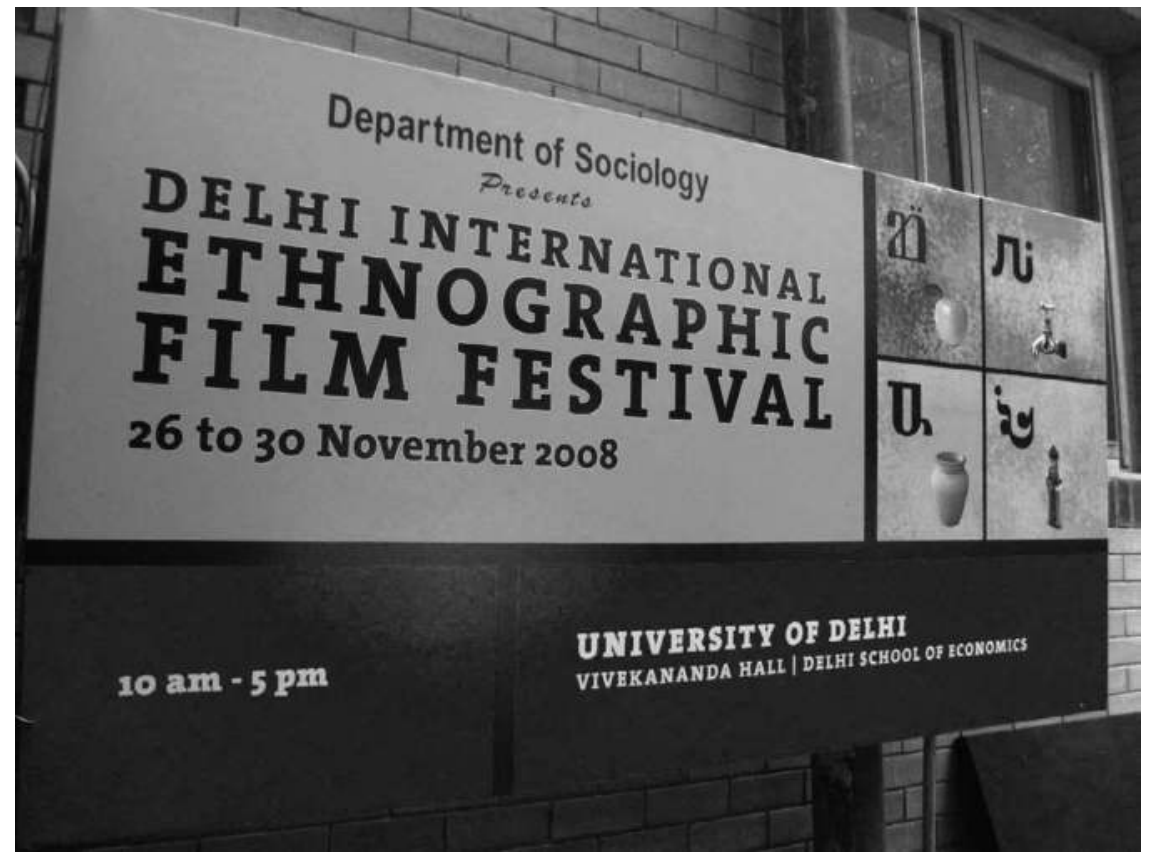

Figure 10.1 2008 Delhi International Ethnographic Film Festival (DIEFF) banner

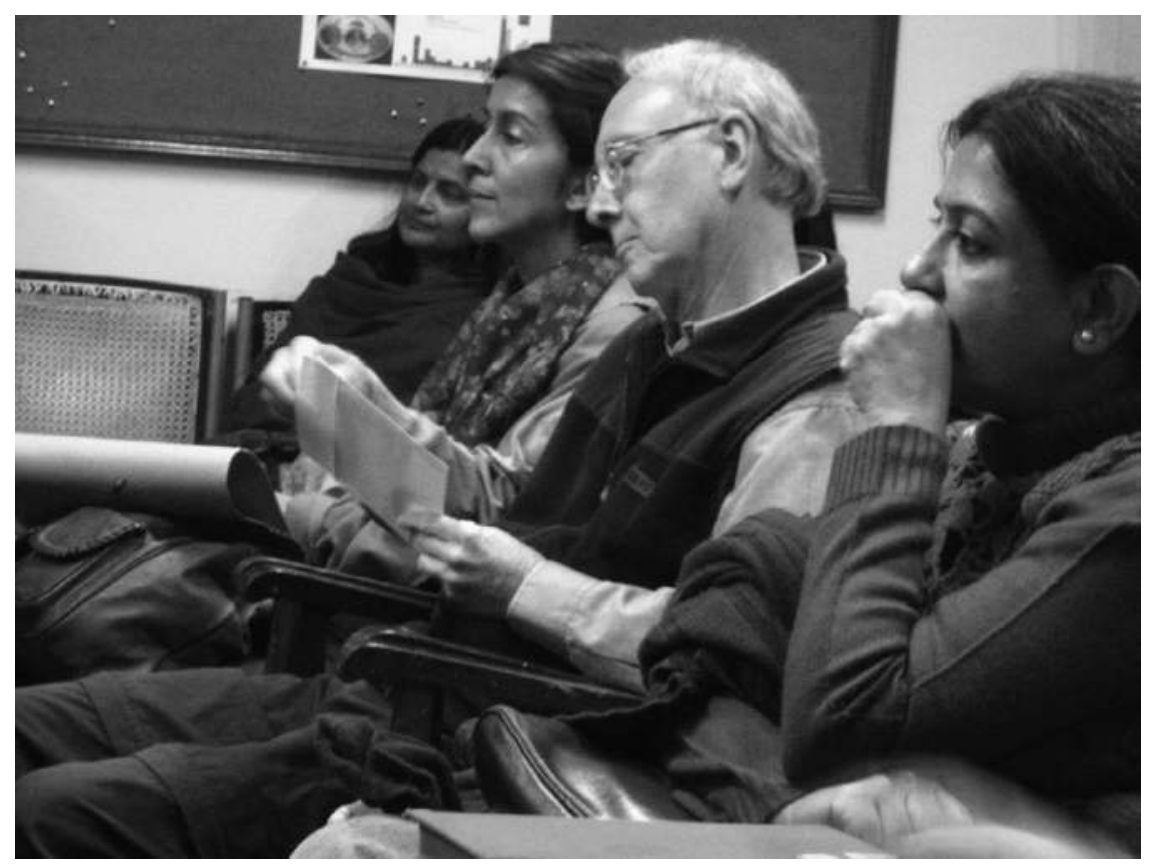

Figure 10.2 Audience listening to the seminar 'Practicing the Craft, Crafting the Practice' hosted by Delhi University during the 2008 DIEFF - among the audience, Saba Dewan and David MacDougall 
landscape, time and sound, etc. (see Hockings 1975; Heider 1976; Crawford and Turton 1992; Loizos 1993; Ginsburg 2011; Taylor 1994; Barbash and Taylor 1997; Banks and Morphy 1997; MacDougall 1998; Ruby 2000; Banks and Ruby 2011). Because of these similarities, for the first time independent 'ethnographic' films made in India were being given the chance to meet 'ethnographic' films made by anthropologists from all over the world in an international 'ethnographic film festival'.

The festival not only presented film screenings but also panel discussions in which some documentary practitioners from India (who were not presenting their films at the festival) could engage with internationally renowned visual anthropologists. In one of the panels in which I participated, Judith MacDougall was invited for a debate about the significance of ethnographic film in relation to Indian film practices. The panel was called 'Practicing the Craft, Crafting the Practice' and, in my view, demonstrated that the two filmmaking practices (documentary in India and ethnographic film in anthropology) could mutually benefit from constructive dialogue (see Figure 10.3).

What emerged quite clearly from this gathering was a striking lack of common ground from which to discuss the connection between ethnographic films, as theorised and practiced within the global discipline of anthropology, and documentary films with ethnographic 'value' made in contemporary India. Based upon personal experience and a 'constructed' knowledge about ethnographic film, filmmakers from India raised questions concerning the theme of 'authorship' in visual representations. Who has more control over the film and film subject, an anthropologist or a 'political' filmmaker? On this issue, well-known Delhi-based filmmaker Sanjay Kak and well-known visual anthropologist Judith MacDougall launched into an endless debate. While Sanjay was unaware of the multiple and mutable practices of

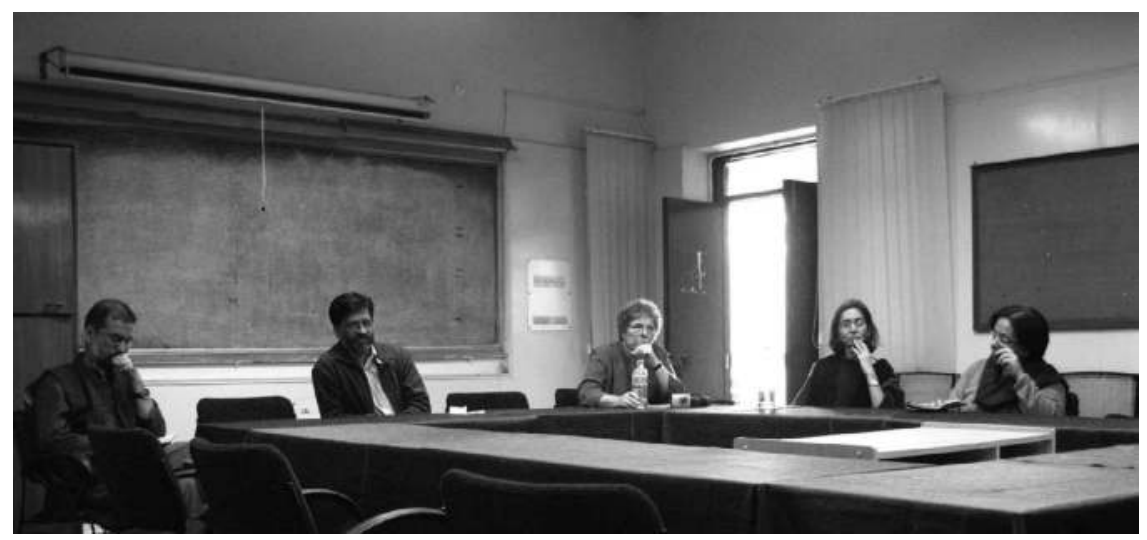

Figure 10.3 Invited participants at the seminar 'Practicing the Craft, Crafting the Practice' hosted by Delhi University during the 2008 DIEFF. Speakers include (left to right) Sanjay Kak, Rahul Roy, Judith MacDougall, Nandini Bedi and Reena Mohan. 


\section{6}

ethnographic filmmaking in the history of anthropology, Judith was oblivious to the enduring relationships of 'political' documentary filmmakers in India with their film-subjects (and film-viewers). Questions about content, form and reflexivity in filmmaking indeed have been central to the development of ethnographic film practices (as well as to documentary studies and visual anthropology at large). Likewise, as I argue elsewhere, documentary films in India have followed similar historical trajectories, yet without associating their film practice with ethnographic films (see Battaglia 2012). In other words, in the past ten years both visual anthropology and documentary practices in India have been consciously exploring the significance of authorship in filmmaking - but without engaging in dialogue with one another. For this reason, the debate that occurred between Sanjay Kak and Judith MacDougall was ahistorical and needs to be historicised in relation to the multiple possible connotations of the 'ethnographic film' made in India.

This chapter will explore the multiple possibilities of what constitute an ethnographic film made in India. Undertaking a kind of 'archaeology' (Foucault 1969) of the development of this 'film genre' (Altman 1999), I will focus more intensely on the 'discourses' (Foucault 1969) created around various film practices than on the analysis of films as 'texts' as for the semiotic tradition of image analysis. In doing so, I will identify some of the key actors that have contributed to the creation of categories such as 'ethnographic film' and/or 'anthropological film' in India, and show how they do not necessarily match the way in which the same categories have been used and discussed within global debates in visual anthropology. In order to make this point, I will start with a short excursus on how the categories of visual anthropology/ethnographic film have evolved so far in the global discourse of anthropology and show how this differs from the localised use of the terms and ethnographic filmmaking practices on the Indian subcontinent.

\section{Academic debate in 'global' visual anthropology}

Even though questions about the extent to which non-academic practitioners perceive and relate to visual anthropology have been gradually emerging (see Wright and Schneider 2010; Banks and Ruby 2011; Schneider and Pasqualino 2014; Sansi 2015; Cox, Irving and Wright 2016), international academia has so far paid little attention to the ethnographic audiovisual practices found outside the discipline of visual anthropology. For too long, visual anthropology has been overly preoccupied with a repetitive internal discourse centring on key anthropologists-filmmakers, their relationship with technology and the key historical moments at which those personalities have contributed to different ethnographic film styles (Wright 1998). This preoccupation has fostered the creation of a 'closed' sub-discipline disconnected from its wider context because it has focused more on understanding film as a methodological 'tool' (see Winston 1995; Hughes 2011) for social scientific research rather than as a 'documentary art' (see Davis 2000; Battaglia 2014). This tendency has also prevented the discipline from connecting better with other visual practices found outside anthropology. Let me explain how this has been possible. 
The emergence of visual anthropology can be traced back to the late 19th and early 20th centuries - that is, to the period when anthropology was acquiring institutional status and becoming a self-identified discipline and a profession, with a clear methodology, an object of study and a body of knowledge. At that time, the visual and material aspects of the discipline played a very important role, and early attempts to use film by personalities such as Alfred Cort Haddon (1855-1940), Walter Baldwin Spencer (1860-1929) and Franz Boas (1858-1942) constituted some of the most remarkable contributions in this sense (see Griffiths 2002; Grimshaw 2001; Pinney 2011). Of these, the work of Boas was of particular significance because in addition to his focus on visual and material culture he also saw anthropology as a science working to make discoveries together with other disciplines - in fact, he nurtured his interest in film as much as in other fields including food, linguistics, art, biology, history. In this respect, the turn of the 20th century should be considered a historical moment for the growing discipline of anthropology, when anthropologists were already thinking together with visual images and in particular in relation to popular culture and museum representations (Griffiths 2002). For many, however, the roots of visual anthropology are to be found in the work of Margaret Mead and Gregory Bateson in the 1930s as the first anthropologists who explicitly employed film as a 'tool' for conducting anthropological research (see Hockings 1975; Winston 1995; Hughes 2011). Yet, at that time, the Malinowskian disciplinary approach prevailed in consolidating the discipline of anthropology to exclude the 'visual' in favour of a much more 'rationalist discourse' composed of words. As Lucien Taylor (1994) puts it, this tendency has somehow created a sort of 'iconophobia' within the discipline of anthropology, which from that time onwards left its visual branch to develop separately from its wider discipline (see also Wright 1998; Banks and Morphy 1997; Cox, Irving and Wright 2016). Visual anthropology therefore started to constitute itself as "an experimental space within the [wider] discipline" (Grimshaw and Ravetz 2010, 149). This occurred more clearly in the late 1950s and early 1960s - when visual anthropology started going beyond the classic documentation of cultures through filmic forms (see MacDougall 1998) and started paying attention to the process of filmmaking per se - that is, to the relationship between the filmmaker, the anthropologist, the film's subject and its audience.

Specifically, it was thanks to the film practices and discourses fostered by the French anthropologist-filmmaker Jean Rouch that the paradigm moved from the 'recording' of the real to the 'questioning' of the real. This approach was not far from the concept of 'cinema-truth' (kino-pravda) developed in the Russian cinema of the 1920s and most notably in the work of Dziga Vertov, who pointed out how the camera had the power to reveal deeper levels of truth than the imperfect human eye could (see Vertov 1984; Vaughan 1979; Barsam 1992). In fact, in the late 1950s and early 1960s both visual anthropologists and (non-anthropologist) documentary filmmakers revisited the Russian idea of kino-pravda and transformed it into what today is more commonly known as cinema vérité. Moving away from the political context of the Russian cinema movement and yet continuing its reflexive approach to filmmaking, cinema vérité became both a documentary technique as well as a 
film style that had a widespread impact on visual anthropology and documentary film practices at large. Jean Rouch, himself an anthropologist, should be considered the key figure that has linked these two traditions. ${ }^{1}$

As well as becoming an example of a new film style in the documentary field, Rouch's films, especially Moi, un Noir (1958) and Chronique d'un Été (1961), also inaugurated a debate that is still pertinent today about 'shared anthropology' (Rouch 1978). This approach sees the anthropologist creating a close (and visible) relationship with a film's subject, who is at the same time actively involved in the process of thinking about and making the film - perceived as a form of anthropological knowledge. In other words, these films introduced the concept of "performance' in and of filmmaking; inspiring anthropologists, filmmakers, film subjects and audiences to actively engage with such performance as a fruitful aspect of the 'interpretive' reality. In other words, we can say that Rouch began a tradition in which the filmmaker started to work in close relation with his or her subject of study, aiming to create an 'engagement' or a 'togethering' (Ingold 2011) rather than a representation of the traditional anthropological 'Other'.

Nevertheless, for too long, Rouch remained a key figure solely for the subdiscipline of visual anthropology. Neither by its 'wider discipline' (Banks and Morphy 1997), nor by its cousin disciplines such as visual studies and documentary film, was this filmmaker-anthropologist adequately recognised. He was "a liminal figure par excellence", as Paul Stoller underlines, who "understood the creative power of being between things" $(2009,5)$ - namely, between filmmaking at large and anthropology beyond its visual branch. One of the reasons for this is actually due to the way in which, at a global level, visual anthropologists have appropriated the figure of Jean Rouch for their own tradition and have discursively contributed to the development of a closed sub-discipline (see Wright 1998; Suhr and Willerslev 2012; Cox, Irving and Wright 2016). Over time, this attitude has also reinforced the notion that ethnographic image-making practices are "something done solely by established professional anthropologists" (Wright 1998, 16; see also Russell 1999) and something that cannot be appropriated by other disciplines (Ruby 2000) - thus, excluding the possibility of creating productive relationships between the discipline of (visual) anthropology and others interested in visual cultures at large.

It is only recently that a much more open and inclusive debate has emerged in the discipline of anthropology. Disconnected from traditional social anthropology (which is not necessarily interested in visual forms, see Taylor 1994), from the recognised sub-discipline of visual anthropology (discussed earlier) and from the parallel discipline of documentary film studies (see Barnouw 1993; Renov 1993; Winston 1995; Nichols 1991, 2001; Bruzzi 2006), these debates have come from those more interested in understanding contemporary art practices and specifically the way in which art and film intersect with anthropological knowledge, science and method (see Schneider 2008, 2011; Basu 2008; Wright and Schneider 2010; Schneider and Wright 2013; Banks and Ruby 2011; Grasseni 2004, 2011; Ramey 2011; Schneider and Pasqualino 2014; Sansi 2015; Cox, Irving and Wright 2016). At present, these new perspectives are challenging conventional understandings 
of ethnographic films as well as that of images at large and are creating a space within the wider discipline of anthropology for serious engagement not only with its visual counterpart but also with film/art practices found outside the canonical tradition of visual anthropology (see also Battaglia 2018).

It is in this context that I believe India plays a significant role; yet, as I am going to show, to understand how the Indian contribution is significant to this debate, it is necessary to look more closely at localised practices of 'ethnographic' filmmaking and discourses about a local visual anthropology. Indeed, is it possible to talk about 'ethnographic' films made 'outside' the tradition of 'global' visual anthropology as explained earlier? After all, international film festivals of ethnographic films are increasingly including films made by non-anthropologists because of their anthropological value; and since Rahul Roy was awarded the Basil Wright prize by the RAI ethnographic film festival in 2005, India has gradually come to occupy a significant space at ethnographic film festivals and thus in anthropology.

In this chapter, I will attempt to explore the place that ethnographic films made in India may occupy within anthropology by looking at the discourses about visual anthropology and ethnographic film that have developed in India since the time of independence. I shall point out that failure to recognise the specifics of different parallel discourses about production practices may limit the extent to which global visual anthropology and ethnographic film practices in India can engage in mutually beneficial dialogue.

\section{Multiple articulations of visual anthropology in India}

In the time since India became independent until the present day, we can identify four main actors that have made direct or indirect use of the category of 'ethnographic film' to talk about their own practice. These are the Anthropological Survey of India, the Films Division, independent filmmakers, and visual artists. As I have shown in my past research (see Battaglia 2012, 2018), each has created its own categorisation of the genre in relation or opposition to one another - that is, to historical practices they are familiar with. Despite their diversity, however, these actors can be easily classified into two main groups: one that articulates the genre of ethnographic film within state institutions and the other that practises the same outside state institutions. Interestingly, in neither case has 'global' visual anthropology (discussed earlier) been central to their discourse and practice, yet on the other hand, the perception of anthropology at large as a colonial academic practice of the representation of others has played an important role. This latter connotation has been particularly significant for the development of a discursive understanding of a local visual anthropology among independent artists, whether working in the more classic documentary film domain or in visual arts.

\section{Contemporary independent visual artists}

Over time, several independent image-makers in India (including filmmakers and artists of various kinds, working without state or private funding) have developed 
different understandings of what constitutes anthropological visual representation. Many with whom I interacted during my 2007-2009 fieldwork saw anthropology (and specifically the figure of the European anthropologist) as a discipline still primarily concerned with reproducing colonial forms of "othering'. "You are an anthropologist" - a filmmaker told me as I stepped in one of my first film festivals in India - "so, tell us, what is the ideology that brings you here to study us?" The question took me by surprise and I gave a somewhat vague answer, which obviously did not particularly convince my interlocutor. Over time, however, my own personality was able to override my 'fixed' anthropological, professional identity in the eyes of several filmmakers. This has allowed me to become part of a community of practice and to conduct an anthropological study of the development of documentary film practices in India (see Battaglia 2018). Yet, even if I have come to be considered an exception, the idea that independent filmmakers associate 'anthropology' with colonial practices of othering is a persistent one that I encountered on several other occasions during fieldwork. The underlying perspective was succinctly revealed when a friend-filmmaker once told me jokingly, "do you know the story that we filmmakers tell about you anthropologists?. . An anthropologist sees an Indian woman beating a piece of cloth against a rock [which is a traditional way of washing clothes] and says, 'she's trying to break the rock!'” By telling the joke, this person wanted to stress the intrinsically different ways of viewing India by Indian filmmakers - citizens rooted in Indian history and hence able to 'correctly interpret' local practices - and the 'distant', 'interpretative' anthropologicocolonial gaze. The story implied that neither anthropology nor anthropologists had evolved since colonial times. ${ }^{2}$

This observation was not necessarily a postcolonial critique of the colonial foreign gaze directed at local practices. Rather, for some filmmakers, such critique was also warranted by the documentary films produced by the state-run Films Division (FD) which has continued, in the eyes of many, a colonial tradition that until recently was geared towards aestheticizing the 'other'. ${ }^{3}$ In an essay written in 2007 for Himal Southasian, and in its longer version published online for InfoChange, Madhusree Dutta (a well-known Mumbai-based image-maker) describes films produced by the FD as "a mix of the war film and the anthropological film". In her words,

The vast, top-angle shots of the land where human beings are part of one linear category, made so popular by war films, coupled with close shots and detailed depictions of the alien customs and people, an anthropological device, were held in consecutive shots. The wide, top-angle shots were to establish the authenticity of locales that are not part of the mainland. The closer shots were for anthropological curiosity, presenting a few chosen details of the 'others' that exist outside normative practices - the Mizos, the Kukis, the Kashmiris, the Banjaras - and thereby outside the Benevolent State.

(Dutta 2007a)

In this article, Dutta describes the entire range of FD's films as a mixture, 'in style and aesthetics', of 'war' and 'anthropological' films (Dutta 2007a, 2007b). Here 
Dutta seems to apply the category of 'anthropological' film in association with both colonial and postcolonial film practices in India.

Following this classification, other filmmakers and artists in India have also made use of the category of 'anthropological' as a way to denigrate ethnographic film practices in contrast to their own - failing, in my view, to engage with contemporary ethnographic film practices in 'global' anthropology that no longer take a 'colonial' approach (as discussed earlier). The recently launched Project Cinema City (http:// projectcinemacity.com/) is surely one example of this. When presented at the Mumbai International Film Festival (MIFF) in 2014, it was introduced as follows:

Documentary, once related to a fixed anthropological gaze and didactic strategy, has come a long way to be a discipline comprising multiple practices and disperse forms. Some of these developments have happened due to the democratisation of technology but a substantial part of it is also connected with the general change in the perceptions of the world order that fix the meanings of fact, truth and representation.

(in Vikalp yahoogroups, 4/02/14)

Although the definition of documentary as a 'fixed anthropological gaze' may in this case refer to state-produced documentary films (such as those made by the Films Division), what I would like to stress here is that the connotative use of the adjective 'anthropological' may serve to alienate from one another practices that are actually similar in their approach and principles. Let me better explain this point by presenting a further example.

Outside the more classic independent filmmaking tradition in India (which is by and large perceived to have developed historically independently of other visual arts), in a recent presentation at the Institut National d'Histoire de l'Art in Paris on 18 June 2014, Parul Dave-Mukherji presented a paper titled "Art History in India and Its Discontent in Global Time" with which she convincingly argued that in line with the international contemporary art scene, since the turn of the 21 st century various contemporary artists in India had turned their attention towards 'anthropological' approaches (see also Kaur and Dave-Mukherji 2014). Among the various examples that Dave-Mukherji cited to make her point was a much-discussed artwork by Pushpamala N.: Native Women of South India: Manners and Customs (Bangalore 2000-2004). This was a photographic performance that evoked the colonial system of classification of indigenous others. In this piece, the artist reenacts anthropological objectifications through an 'exaggerated' performance of women's indigenous-ness in the Toda. Pushpamala perfects the effect with her careful selection of clothes and of skin tone as well as by replicating the specific posture and gaze of the anthropometric studies of the Andamanese from 1894, in order to precisely recreate the particular 'colonial aesthetic' of photographic representation (Pinney 2011, 139). In Kaur and Dave-Mukherji's words, when

Pushpamala revisits the colonial archive and fashion herself as a tribal, she enacts a performative mimesis through the lens of anthropology and 
confronts the viewer through the double gaze of a Toda woman and a contemporary artist.

While on the one hand, this work (among others) can be perceived as a way "to overcome primitivist and Orientalist misapprehensions [. . .] looking more deeply [...] at the historical edifice and politics of representing the Other" (Kaur and Dave-Mukherji 2014, 10), on the other, it can reinforce a 'misconception' of the role and function of 'anthropological' representation today. The question here, indeed, is not about analysing a particular artwork, its author's intention and the way the artwork is perceived, but it is rather to focus on the way in which through that particular artwork and its discursive articulation we risk creating a Foucauldian 'discursive' understanding of an art practice, the use of which can travel much further than the work itself and its original intention. To be more explicit, while Pushpamala N. targeted colonial anthropology, at the same time she made use of the adjectives 'ethnographic' and 'anthropological' in general terms implicating anthropology at large and not specifically its colonial practices. In other words, if her intention was to critique colonial practices, the discourse that she created ended up critiquing the wider scope of anthropology as a discipline even today. The example mentioned earlier of the discursive presentation of the project Cinema City, defining itself in opposition to the 'fixed anthropological gaze', becomes clearer when placed in this context.

On the day when that Parul Dave-Mukherji presented her paper citing the example of Pushpamala N.'s artwork, we had a chance to discuss this matter in a private post-seminar conversation. She agreed with my view that if it is true that the 'social', 'documentary' or 'ethnographic' turn in art (see Foster 1995; Bourriaud 1998) has affected contemporary art practices in India, this has not necessarily occurred in the positive, collaborative sense that some anthropologists have discussed at a more global level (see Wright and Schneider 2010; Schneider and Wright 2013; Sansi 2015; Cox, Irving and Wright 2016). Rather, the words 'anthropological' and 'ethnographic' seem to take on different significations in India. For some contemporary artists and filmmakers in India the terms may still be associated with the 'colonial anthropological gaze'. In other words, there appears to still be a discrepancy between the way in which the international academic world refers to this turn (namely as a collaborative intellectual endeavour) and how some practitioners in India make use of the same vocabulary to critique anthropology (as a colonial, patronising way of viewing others).

If we return to the opening scene of this chapter - the encounter between Indian documentary filmmakers and internationally known visual anthropologists at a seminar held during the Delhi International Ethnographic Film Festival in 2008 we can now better understand the way in which this double take on the meaning of 'anthropological' may sometimes hinder rather than facilitate a productive dialogue between different practitioners-interlocutors. The question that remains, however, is why several Indian art practitioners hold onto a particular colonial understanding of anthropology, which continues to resonate in their contemporary 
discourse and practice? I have already mentioned that, as in Madhusree Dutta's (2002) analysis, the adjectives 'anthropological' and 'ethnographic' have been used by filmmakers to criticise the style of documentary films produced by the state-run Films Division. I would now like to take this further, not by analysing the actual 'practices' of a specific state institution, but rather to examine the 'discourses' that have 'institutionalised' certain practices.

\section{State institutions and the emergence of the ethnographic film in India}

In the course of my past and current research activities, I have come across three manuscripts that specifically address the relationship between visual anthropology and film practices in India. ${ }^{4}$ These three books were published between the late $1980 \mathrm{~s}$ and early 1990s, and all of them refer to a particular genealogy of ethnographic filmmaking and local visual anthropology associated with the government of India (see Figure 10.4, Figure 10.5 and Figure 10.6). Among other things, they refer to the

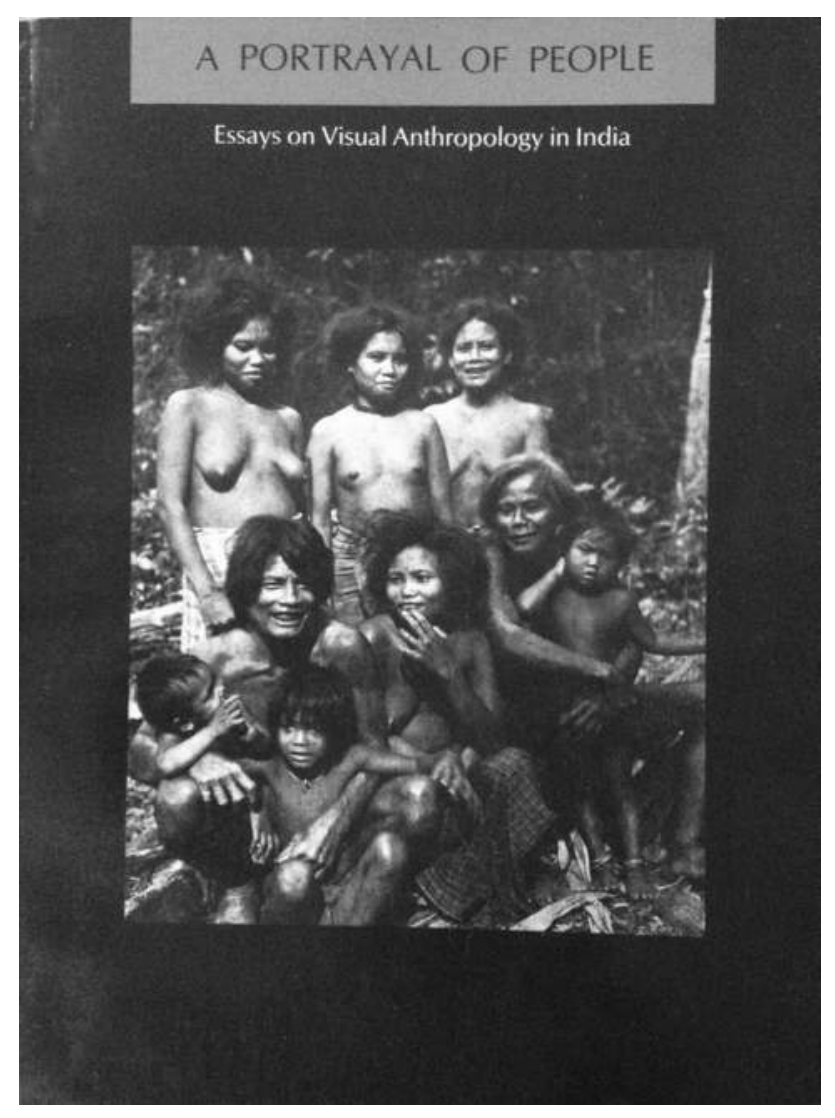

Figure 10.4 Cover of the book: A Portrayal of People: Essays on Visual Anthropology in India (Singh and DasGupta 1987) 


\section{Visual \\ Anthropology and India}

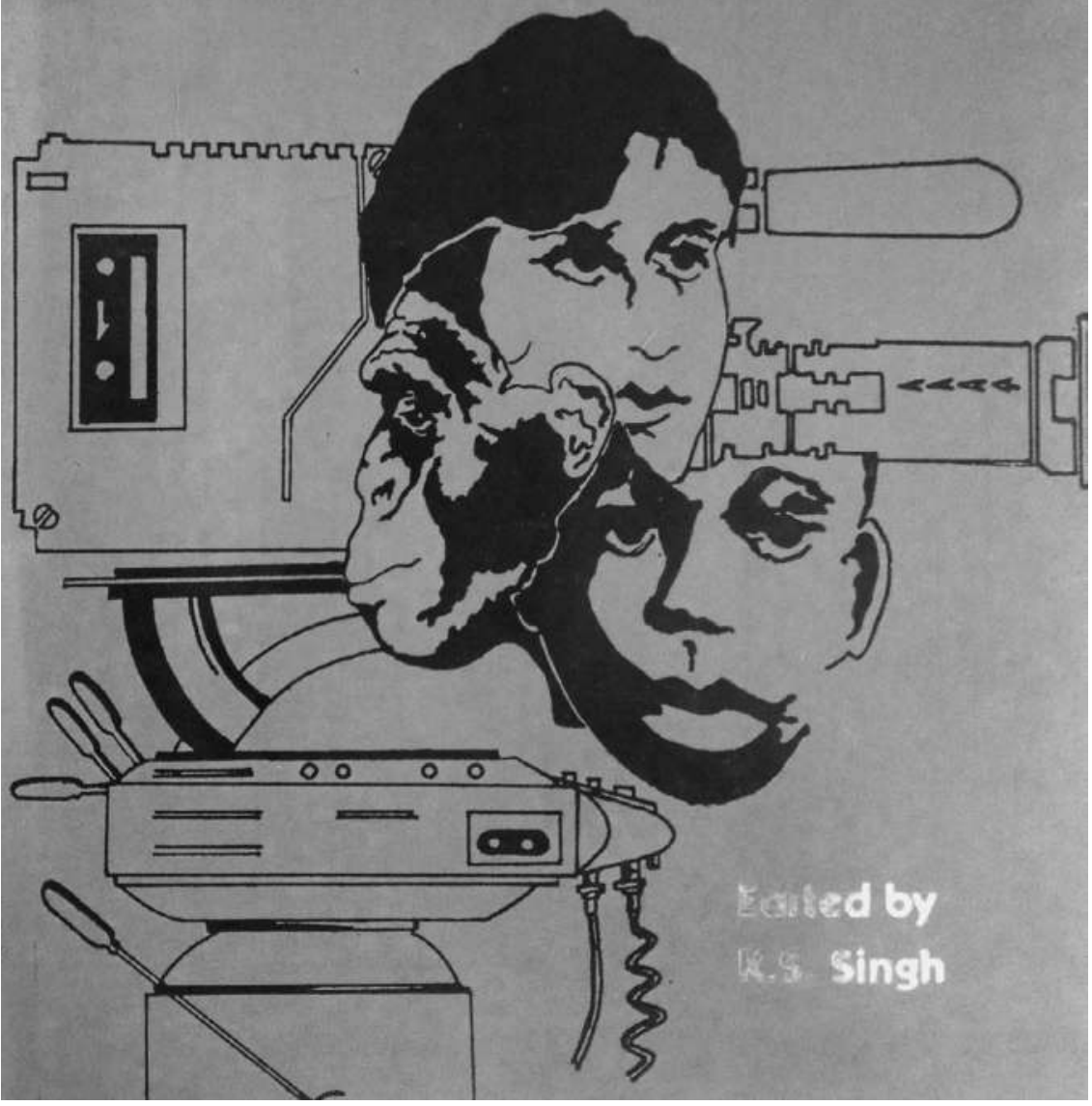

Figure 10.5 Cover of the book: Visual Anthropology and India: Proceeding of a Seminar (Singh 1992) 


\section{VISUAL}

\section{ANTHROPOLOGY}

IN INDIA AND

ITS DEVELOPMENT

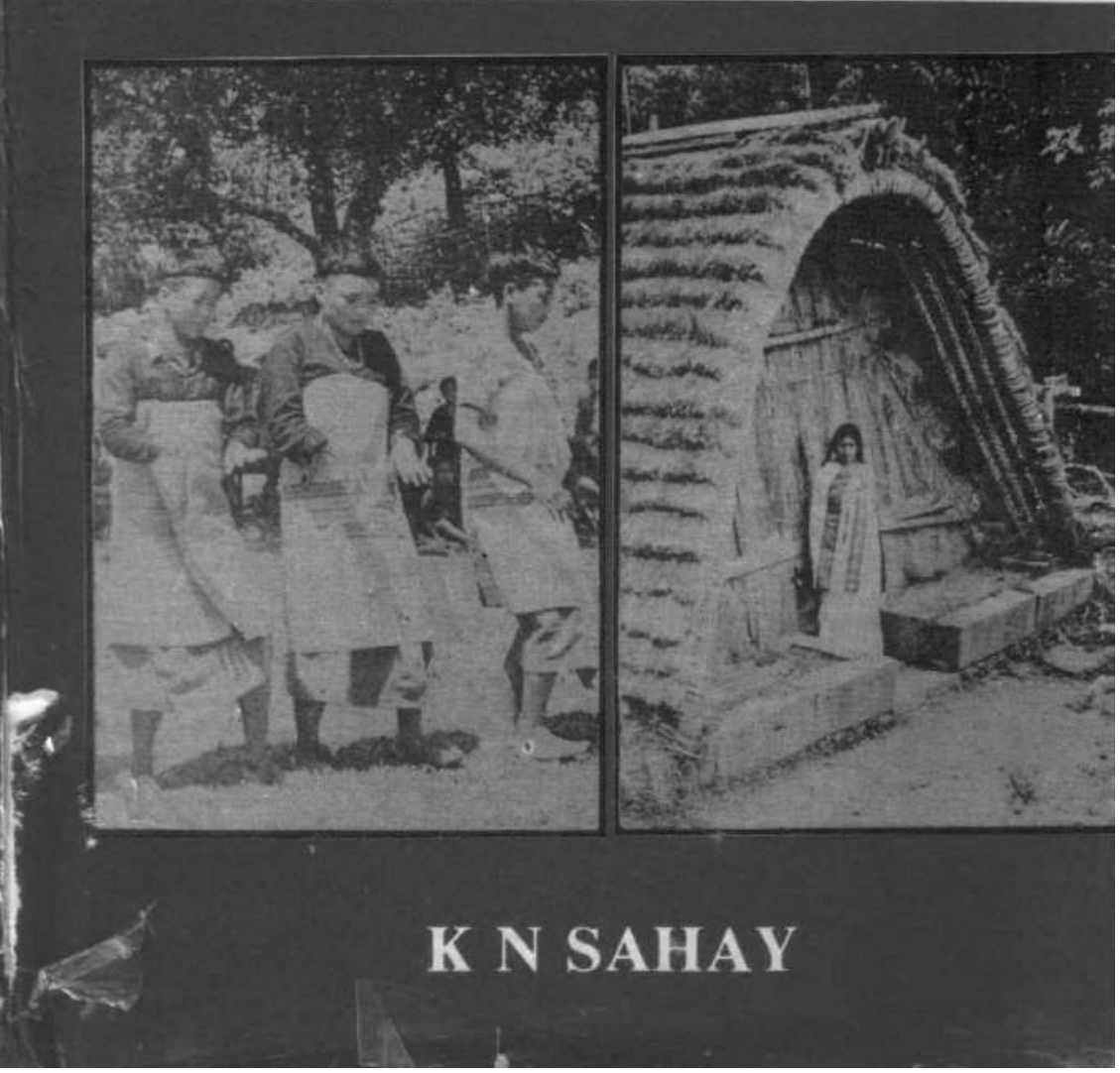

Figure 10.6 Cover of the book: Visual Anthropology in India and Its Development (Sahay 1993) 
practices of a government institution, the Anthropological Survey of India (AnSI), where I conducted archival research in February and March 2014. Moreover, the books are concerned with ethnographic practices that developed outside the global discourse of visual anthropology outlined earlier in this chapter.

Equally significant, yet not in strict relation to the AnSI and during a different period of my research in India, I discovered that between 1986 and 1987, the government of India instituted a new national award (for Indian nationals making films in India) within the category of 'Non-feature Films' entitled 'Best Anthropological/ Ethnographic Film'. During the same period, as I have noted elsewhere, film historian B.D. Garga was contributing to an already growing nationalist historiography of documentary films with a series of articles for Cinema in India (see Battaglia 2012). In one of his articles, "Hope It Revived: the Indian Documentary", Garga talks about a particular type of documentary film practice produced by the state-run Films Division that was concerned with "the exploration of people of various ethnic groups" $(1987,28)$. While this may sound like an ordinary statement in relation to film practices produced by the Indian government since independence, what interested me in my research was that when Garga republished the article in 2007 in a single volume about documentary films in India, he altered his terminology from the 'exploration of ethnic groups' to the 'ethnographic film' - suggesting that by 2007 the category of 'ethnographic film' had become established as a way of denoting specific practices of looking at 'ethnic groups' within India.

Film categories or 'genres', as Rick Altman (1999) argues, are indeed constantly created and recreated by individuals, institutions, festivals and funding bodies, as well as by film critics and intellectuals who 'read' and 'classify' films. Accordingly, they must be always considered as in process (and hence in relation to the time at which they are articulated) and not as fixed to a specific meaning (as in the example given earlier of the adjective 'anthropological' being used in a narrow sense to refer solely to 'colonial' anthropological practices). In fact, it is precisely when categories become fixed and universalised in their meanings that they become the first agents of the discursification of a practice. Hence, the question to be asked is, where does the category of 'ethnographic film' stem from in the Indian subcontinent, and to what extent has it been 'objectified' over time? Unlike several contemporary filmmakers and artists, I would argue that the state-run Films Division does not play a central role in answering this question. Rather, as I point out elsewhere, I believe that the FD has been the 'victim' of a discursification about its documentary film practices (see Battaglia 2018). The roots of discursive institutionalisation of the ethnographic film in India, instead, are to be found in relation to the activities undertaken by the Anthropological Survey of India (henceforth AnSI).

Since December 1945, the AnSI has acted as a government institution in charge of documenting the multiple cultural practices found in India: a vast country with many ethnic compositions, linguistic families, religions and cultural practices (Singh 1987, 1992; Bose 1967). From its inception, the AnSI specialised in representing tribal communities in the subcontinent - that is, studying what the institution calls "their biological composition" as well as documenting and disseminating their oral and material practices (Singh 1987, 1992). Significantly, from the 
beginning, 'photography was considered an intrinsic part of documentation' (Singh 1987, 28). Indeed, as early as 1946 the AnSI had already set up a 'Photographic Unit' (Das 1967) followed in 1949 by a 'Cine Unit'. The latter was originally run by 'photo-artists' and from 1953 by a specialised 'cine-technician' (Chattopadhyay 1967; Singh 1987). In other words, the activities of the AnSI developed in relation to the concept of image-making - regarded as a key method in anthropological research and representation. As remarked in several of the regular reports compiled after each AnSI fieldwork activity, an artist, filmmaker and/or photographer always accompanied anthropological 'expeditions' organised by the institution. Ironically, however, at a practical level, imaging practices undertaken by the AnSI never received their due acknowledgement. Unlike for the Films Division, the government never invested in technological equipment for the AnSI because the latter was perceived merely as a research institution.

For a long time, the AnSI was not provided with sound cameras and was only able to produce silent films. Furthermore, the government never employed a team of people for the Cine Unit. From 1953, a single man, the cine-technician, operated the whole unit. This person was in charge of filming, editing, writing commentary, subtitling and screening each film (Chattopadhyay 1967, 1987; Sahay 1993). Until very recently, the appointed cine-technician was Susanta Chattopadhyay, a man who had worked in the feature film industry before he was asked to "tour [. . . all over India to make documentary films of the various tribal communities ... [and] film those unique cultural aspects which are relevant to social anthropology" (Chattopadhyay 1987, 97).

If on the one hand, through the films and writings of a single individual working for the AnSI we can understand the potential and constraints of the film activities undertaken by this state institution, on the other, we can also anticipate the limited innovation in the work produced. Although the original intention of the AnSI was to introduce audiovisual material as a constitutive part of its anthropological studies, ultimately the institution was always restricted by being poorly equipped technically, or as Chattopadhyay puts it, by simply being government servants (1987, 110-111). As contemporary anthropologists working for the AnSI pointed out to me after I delivered a paper at one of their seminars during the time of my archival research in their institution, 'our films neither were ethnographic films nor documentary films. Ours were 'pure' documentation because the 'real films' were already made by the Films Division' (fieldnotes 21/02/2014). Having had the opportunity to sit in the AnSI and watch 20 of the films it had produced since the mid-1950s, I could understand that non-visual anthropologists might see them as audiovisual material that was simply raw footage produced to support written ethnography. However, I do not believe that films can be 'pure' documentation, nor would I describe the ethnographic films produced by the AnSI as mere footage from fieldwork. On the contrary, in my view the material reveals a clear agenda on behalf of the filmmaker, as a 'government servant' (Chattopadhyay 1987): to 'study' communities. Moreover, the 'strategies' that he employed in doing so contributed to the creation of a discourse about what constitutes (or should constitute) an 'ethnographic film' in India. 
Aside from those made in the 1950s and early 1960s, the majority of these films are accompanied by either text or voiceover in which the director tells the viewers the importance of what is shown. Furthermore, lengthy mid shots of body movements in rituals, of teaching techniques in dances and close-ups of everyday activities are always accompanied by what filmmakers in India may call 'portray shots' - that is, a camera movement that starts from the feet and smoothly tilts up to the face of each person involved in the main activity that is subsequently represented in the film. These shots closely resemble the anthropometric photographic practices of the early 20th century which, as pointed out before, are used today by contemporary Indian artists to critique 'visual anthropology' at large for its perpetuation of colonial practices of representation. If these critics were to turn their attention to contemporary global practices and debates in visual anthropology (outlined at the beginning of this chapter) or to local Indian practices in documentary filmmaking with strong ethnographic sensibility (such as those screened at DIEFF 2008), they would realise that the 'ethnographic' films produced by the AnSI are far from representative of contemporary ethnographic practices. Yet, as I shall show, these layers of contradictions are precisely the key elements that make the 'ethnographic film' in India such a volatile category today.

In addition to producing these films, until the 1990s the AnSI actively contributed to the development of visual anthropology in India at a discursive level. This emerges clearly from the three manuscripts about visual anthropology in India mentioned earlier, and it was also confirmed to me by the renowned visual anthropologist, David MacDougall, in a conversation in April 2014 at the Royal Anthropological Institute in London during one of his visits at a screening of his films. As David remembered, a few key personalities such as K.N. Sahay, Rakhi Roy, Jayasinhji Jhala and Kumar S. Singh were some of those who most strongly fostered discourse on visual anthropology between the mid-1970s and early 1990s. Singh was the only one of these who worked for the AnSI at the time, but the others collaborated with the institution in setting up international symposia and publishing books about visual anthropology in India. While Roy, Jhala and Singh were somewhat cautious, Sahay was the most outspoken. In their articulation of the genre Roy and Jhala $(1987,1992)$ focused on the 'potential' of visual anthropology for and in India, while Singh praised the constructive and multidisciplinary collaboration between image-makers and anthropologists in institutions like the AnSI (Singh 1987, 1992). More audaciously, in a book titled Visual Anthropology in India and Its Development, Sahay (1993) claimed that the category of 'ethnographic film' had already been articulated in India in the late 1950s in relation to the films produced by the AnSI, and that films of 'ethnographic interest' in India could be identified in various other film industries in the 1950s and 1960s including the FD's films, Burmah Shell's films and fiction films associated with the category of the 'new wave' cinema.

According to Sahay, the first public debate about visual anthropology in India was articulated in December 1978 in New Delhi, during a symposium on visual anthropology sponsored by the International Union of Anthropological and Ethnological Sciences (IUAES). Anthropologists and filmmakers from Japan, Korea, 
Tunisia, Australia, France, Austria, the Federal Republic of Germany, Canada, the USA and India participated in the event. Of the participants, Marielle Delorme, from Paris, was in charge of the overall programme. Sahay, from Ranchi University, covered aspects of visual anthropology in India; Jean Rouch, from the Musée de l'Homme oversaw the film screenings; and Roger Sandall from Australia and Richard Sorenson from the USA organised the sessions on 'urgent need', 'future of visual anthropology' and 'film as methodology' (Sahay 1993, 143-145). As Sahay points out, the follow-up to this symposium was the publication of a biannual Visual Anthropology Bulletin (1979-82) and nine articles on visual anthropology with a focus on India (Sahay 1993, x) which he later on edited together in his monograph on visual anthropology in India.

In contrast, Singh argues that the "first-ever international seminar on visual anthropology in India was held in Jodhpur" at the end of 1987, and that the one held in New Delhi almost ten years before was only part of the larger IUAES congress $(1992,1)$. David MacDougall confirmed this point to me in our conversation about the Jodhpur seminar, where he himself participated. And he added that, among the aforementioned personalities responsible for the event, it was thanks to 'the Jhala couple' (Rakhi Roy and Jayasinhji Jhala, based in US universities) that the seminar had proved so significant and fruitful - it also led him to make the acclaimed film Photo Wallahs and to establish a filming relationship with India. The international seminar, entitled 'A Portrayal of People', was co-sponsored by the Indian National Trust for Art and Cultural Heritage (INTACH) and the AnSI, and aimed to bring together different perspectives on visual anthropology in India. In other words, the goal of the seminar was to share ideas generated by the AnSI, international anthropologists and professional filmmakers (Singh and DasGupta 1987, vii). Academics from India and abroad as well as anthropologists-filmmakers including Timothy Asch, Asen Balikci, Melissa Llewelyn-Davies, David MacDougall, John Marshall and Trinh T. Minh-ha all took part in the event. David MacDougall recalls that the gathering took place in a grand old palace in Jodhpur, with participants seated around a huge round table that was "too big to see and hear each other" (personal communication, April 2014).

The gathering resulted in the publication of two different edited volumes, $A$ Portrayal of People: Essays on Visual Anthropology in India (1987) and Visual Anthropology and India (1992). When I was conducting archival research at the AnSI, I had difficulty finding anyone who knew about the second of these two books. Later on, I discovered that not even participants like David MacDougall were aware of it - it was "probably made from a collection of old essays combined with a few interventions from the seminar", David said (personal communication, April 2014). The former book, by contrast, was a collection of essays written by "Indians presenting their experiences within the Indian arena [ . . . looking forward to fruitful discussions regarding the domain and potential of visual anthropology, between anthropologists and filmmakers and photographers from different parts of the world" (Sinha 1987, xvi). This volume circulated more widely. However, as confirmed to me by Kanchan Mukhopadhyay, an anthropologist who was in charge of the visual anthropology section at the AnSI at the time of my archival research there, "despite 
the great initiative and positive spirit there has never been a follow up of such discussions" (personal communication, February 2014).

In short, it is as if visual anthropology and the 'film genre' (Altman 1999) of the 'ethnographic film' began to be discursively articulated in India between the late 1970s and early 1990s as a response to filming practices that had already been part of the AnSI's work since the early 1950s. In an issue of the Indian Documentary dated October-December 1955, we can indeed already read about this particular 'typology' of film in India. While the adjective 'ethnographic' and the 'anthropological' film are conspicuously absent, the author M.V. Krishnaswamy emphasises the need to employ an 'anthropological approach' in making 'educational films' about the 'social and material development of village communities' $(1955,9)$. To this end, he calls upon anthropologists to assist local filmmakers. In his words, "a knowledge of the customs, beliefs and practices of people in their daily life and activities is essential more than one might imagine for specialised rural film-makers" (Krishnaswamy 1955, 10). Perhaps this also supports Sahay (1993) in his genealogy of visual anthropology in India, the origins of which he traces back to filming activities undertaken in the $1950 \mathrm{~s}$.

If early practices of ethnographic filmmaking may be identified in 1950s India, and if the discursive articulations of the genre may date back to the $1970 \mathrm{~s}$, what is interesting to observe here is that from the 1990s until the present day such 'indigenisation' of visual anthropology has not developed further, neither within state institutions nor in state-independent practices; indeed, it has disappeared from public discourse. The 2008 international film festival of ethnographic film held in Delhi discussed at the beginning of this chapter is one contemporary example to support this. In fact, neither the organisers nor the participants at the festival ever referred to the debates in India in the 1970s and 1980s about visual anthropology, even though the national award of 'Best Anthropological/Ethnographic Film' has symbolically continued to be presented annually in India - sometimes to statefunded producers of documentary films (such as the FD) but also to independent filmmakers who take part in international film festivals organised by initiatives independent of the state.

According to Kanchan Mukhopadhyay, the period of the early 1990s saw a number of changes of direction within the AnSI (personal communication, February 2014). Ultimately, its subsequent directors were simply no longer interested in audiovisual representation. Nevertheless, we may also speculate that this period coincided with a disruption to FD screening activities in cinema halls across India and with the growth of public and private televisions channels (see Battaglia 2012, 2018). In other words, it was a period in which 'cultural' (and arguably 'ethnographic') audiovisual representations were pushed aside by new technological developments and new state policy - an area of research worthy of further investigation.

\section{Conclusion}

Building on different examples from the Indian subcontinent, what I have sought to point out in this chapter is that it was a synthesis of historically articulated 
discourses and practices about visual anthropology and ethnographic films (at both a global and local level) as well as categorisations of the genre imposed by the state that have most likely influenced contemporary independent filmmakers and artists' understandings of what the adjective 'anthropological' may signify in visual representations in India today. Yet, this perception of 'anthropology' is not the only one held in India. Historically, the significance of anthropological representation has always been multifaceted since it has been articulated by different actors that were not in dialogue with one another. For contemporary 'anthropologists' working for the AnSI, for instance, 'anthropological' filmic representation needs to be reconnected to the practices of 'documentation' of indigenous cultures within India as developed over the years by their state institutions. By contrast, for some independent documentary practitioners (such as those who participated at the DIEFF 2008) the appellative 'ethnographic' or 'anthropological' is foremost a way of classifying a film for submission to a film festival where it may be viewed by an international audience. This last position is a minority one, however. Several other independent documentary filmmakers use the words 'ethnographic' or 'anthropological' to criticise films deemed to lack social and political commitment (as in the examples of Dutta's descriptions). Taken together, these diverse practices and discourses coexist in contemporary India without necessarily creating conflict. It is only when they encounter a global canonical tradition of visual anthropology (as happened at DIEFF 2008 in the conversation between Sanjay Kak and Judith MacDougall) that they become problematic.

In this respect, a genealogy of ethnographic film practices and discourse 'made in India', as proposed in this chapter, should also be considered a way to challenge a 'single', 'universal' notion of 'global' visual anthropology and a particular historiography of visual anthropology as a sub-discipline that only includes certain ethnographic films and authors within its canon. As we have seen, parallel to the development of a global discourse on visual anthropology, both state-funded and independently produced 'indigenous' forms of 'ethnographic films' and debates around localised forms of visual anthropology have also emerged in India. If these debates have not developed further since the 1990s and have therefore never challenged international debates on visual anthropology, it is not only because of lack of development of the 'film genre' (Altman 1999) on the subcontinent, but also because of lack of collaboration from the international academic community of visual anthropologists, which, as I have pointed out earlier, has always insulated itself as a closed sub-discipline rather than exploring the potential to engage with its wider 'whole' (Banks and Morphy 1997) by engaging with visual practices and discourses found outside anthropology. It is also because of this insularity that I believe different (often negative) understandings of ethnographic film have prevailed among independent practitioners in contemporary India. And as such, it is for contemporary visual anthropologists to restore the potential of this film genre by creating more possibilities for collaboration and cross-fertilisation between practices. In my own limited way, I hope with this chapter to have started initiating such fruitful rehabilitation. 


\section{Notes}

1 To read more about Jean Rouch, refer to his own writings (Rouch 1975, 1978, 2003) and well as monographs entirely dedicated to Rouch's work (see Eaton 1979; Feld 1989; Stoller 1992; ten Brink 2007; Henley 2009).

2 While emphasising the differences between colonial anthropologists and contemporary anthropologists, I certainly do not mean to downplay questions of power in (visual) representation. Rather, what I am trying to point out here is that a 'critical' or 'engaged' anthropologist today can be just as self-reflexive (or not) about his/her own practice and power relations when producing representations as an Indian upper-middle class filmmaker may (or may not) be when making a documentary film in India that features 'minority' or less advantaged members of the population (see also Battaglia 2014).

3 To read more on this perspective see Roy (2003, 2007), Sarkar (2009), Jain (2013); for a critical reading about the multiple significations of the FD in the past and in present perceptions see Battaglia (2018).

4 A Portrayal of People: Essays on Visual Anthropology in India (Singh and DasGupta 1987); Visual Anthropology and India: Proceedings of a Seminar (Singh 1992); Visual Anthropology in India and its Development (Sahay 1993).

\section{References}

Altman, Rick. 1999. Film/Genre. London: British Film Institute.

Banks, Marcus, and Howard Morphy (eds.). 1997. Rethinking Visual Anthropology. New Haven: Yale University Press.

Banks, Marcus, and Jay Ruby (eds.). 2011. Made to Be Seen: Perspectives on the History of Visual Anthropology. Chicago: University of Chicago Press.

Barbash, Ilisa, and Lucien Taylor. 1997. Cross-Cultural Filmmaking: A Handbook for Making Documentary and Ethnographic Films and Videos. London: University of California Press.

Barnouw, Erik. 1993 [1973]. Documentary: A History of the Non-Fiction Film. New York and Oxford: Oxford University Press.

Barsam, Richard Meran. 1992 [1973]. Non-Fiction Film: A Critical History. Revised and Expanded. Bloomington: Indiana University Press.

Basu, Paul. 2008. "Reframing Ethnographic Film." In Rethinking Documentary, edited by T. Austin and W. de Jong. Maidenhead: Open University Press.

Battaglia, Giulia. 2012. Documentary Film Practices in India: History of the Present. PhD Diss., London: SOAS, University of London.

Battaglia, Giulia. 2014. "Who's the Author? Whose Vision? Crafting 'Participatory' and 'Collaborative' Film-Projects in India.” Anthrovision [Online] 2.2 | . http://anthrovision. revues.org/1416.

Battaglia, Giulia. 2018. Documentary Film in India: An Anthropological History. London: Routledge.

Bose, N.K. 1967. "Inaugural Address.” In Research Programmes on Cultural Anthropology and Allied Disciplines, edited by S.C. Sinha. Kolkata: Anthropological Survey of India, Government of India, Indian Museum.

Bourriaud, Nicolas. 1998. Esthétique Relationnelle. Dijon: Les Presses du Réel.

Bruzzi, Stella. 2006. New Documentary. 2nd ed. London: Routledge.

Chattopadhyay, Susanta K. 1967. "Cinematography in Anthropological Survey of India." In Research Programmes on Cultural Anthropology and Allied Disciplines, edited by S.C. Sinha. Kolkata: Anthropological Survey of India, Government of India, Indian Museum. 
Chattopadhyay, Susanta K. 1987. "My Experiences as a Cameraman in the Anthropological Survey." In A Portrayal of People: Essays on Visual Anthropology in India, edited by K.S. Singh and C. DasGupta. New Delhi: ASI and INTACH.

Cox, Rupert, Andrew Irving, and Christopher Wright (eds.). 2016. Beyond Text?: Critical Practices and Sensory Anthropology. Manchester: Manchester University Press.

Crawford, Ian, and David Turton. 1992. Film as Ethnography. Manchester: Manchester University Press.

Das, P.R. 1967. "Photography in the Anthropological Survey of India." In Research Programmes on Cultural Anthropology and Allied Disciplines, edited by S.C. Sinha. Kolkata: Anthropological Survey of India, Government of India, Indian Museum.

Davis, Christopher. 2000. Death in Abeyance: Illness and Therapy among the Tabwa of Central Africa. Edinburgh: Edinburgh University Press.

Dutta, Madhusree. 2002. "What happened to the Political Documentary?" Cinema in India 1(3): 50-52.

Eaton, Mick (ed.). 1979. Anthropology-Reality-Cinema: The Films of Jean Rouch. London: British Film Institute.

Feld, Steven. 1989. "Themes in the Cinema of Jean Rouch." Visual Anthropology 2(3-4): 223-247.

Foster, Hall. 1995. “The Artist as Ethnographer?” In The Traffic in Culture: Refiguring Art and Anthropology, edited by G.E. Marcus, 203-309. Berkeley: University of California Press.

Foucault, Michel. 1969 [2012]. The Archaeology of Knowledge. New York: Vintage.

Garga, B.D. 1987. "Hope Revived: The Indian Documentary (2)." Cinema in India 1 (2): $24-28$.

Garga, B.D. 2007. From Raj to Swaraj: The Non-Fiction Film in India. New Delhi: Penguin Viking.

Ginsburg, Faye. 2011. "A Short History of Debates on Indigenous Media and Ethnographic Film." In Made to Be Seen: Perspectives on the History of Visual Anthropology, edited by M. Banks and J. Ruby. Chicago: University of Chicago Press.

Grasseni, Cristina. 2004. "Skilled Vision: An Apprenticeship in Breeding Aesthetics." Social Anthropology 12 (1): 41-55.

Grasseni, Cristina. 2011. "Toward an Ecology of Visual Inscriptions." In Made to be Seen: Perspective on the History of Visual Anthropology, edited by M. Banks and J. Ruby. Chicago: University of Chicago Press.

Griffiths, Alison. 2002. Wondrous Difference: Cinema, Anthropology and Turn-of-theCentury Visual Culture. New York: Columbia University Press.

Grimshaw, Anna. 2001. The Ethnographer's Eye: Ways of Seeing in Anthropology. Cambridge: Cambridge University Press.

Grimshaw, Anna, and Amanda Ravetz. 2010. Observational Cinema: Anthropology, Film, and the Exploration of Social Life. Bloomington, IN: Indiana University Press.

Heider, Karl G. 1976. Ethnographic Film. Austin: University of Texas Press.

Henley, Paul. 2009. Adventure of the Real: Jean Rouch and the Craft of Ethnographic Cinema. Chicago: University of Chicago Press.

Hockings, Paul. 1975. Principles of Visual Anthropology. Berlin: Mouton de Gruyter.

Hughes, P. Stephen. 2011. "Anthropology and the Problem of Audience Reception." In Made to Be Seen: Perspectives on the History of Visual Anthropology, edited by M. Banks and J. Ruby. Chicago: University of Chicago Press.

Ingold, Tim. 2011. Being Alive: Essays on Movement, Knowledge and Description. London: Routledge. 


\section{Giulia Battaglia}

Jain, Anuja. 2013. "The Curious Case of the Films Division: Some Annotations on the Beginnings of Indian Documentary Cinema in Postindependence India, 1940s-1960s." The Velvet Light Trap 71 (Spring): 15-26.

Kaur, Raminder, and Parul Dave-Mukherji (eds.). 2014. Arts and Aesthetics in a Globalizing World. London: Bloomsbury Publishing.

Krishnaswamy, M.V. 1955. "Films for the Villagers." Indian Documentary 2 (2): 9-11.

Loizos, Peter. 1993. Innovation in Ethnographic Film: From Innocence to SelfConsciousness, 1955-1985. Manchester: Manchester University Press.

MacDougall, David. 1998. Transcultural Cinema. Chichester: Princeton University Press.

Nichols, Bill. 1991. Representing Reality: Issues and Concepts in Documentary. Bloomington, IN: Indiana University Press.

Nichols, Bill. 2001. Introduction to Documentary. Bloomington, IN: Indiana University Press.

Pinney, Christopher. 2011. Photography and Anthropology. London: Reaktion Books Ltd.

Ramey, Kathryn. 2011. "Productive Dissonance and Sensuous Image-Making." In Made to Be Seen: Perspective on the History of Visual Anthropology, edited by M. Banks and J. Ruby. Chicago: University of Chicago Press.

Renov, Michael (ed.). 1993. Theorizing Documentary. New York: Routledge.

Rouch, Jean. 1975. "The Camera and the Man." In Principles of Visual Anthropology, edited by P. Hockings. Berlin: Mouton de Gruyter Publishers.

Rouch, Jean. 1978 [1971]. "On the Vicissitudes of the Self.” Studies in Visual Communication 5 (1): 2-7.

Rouch, Jean. 2003. Ciné-Ethnography. Introd. and Translated by Steven Feld. Minnesota: University of Minnesota Press.

Roy, Srirupa. 2003. "Moving Pictures: The Postcolonial State and Visual Representations in India." In Beyond Appearances? Visual Practices and Ideologies in Modern India, edited by Sumathi Ramawamy. London: Sage Publication.

Roy, Srirupa. 2007. "Moving Pictures: The Films Division of India and the Visual Practices of the Nation State." In Beyond Belief: India and the Politics of Postcolonial Nationalism, edited by S. Roy. Durham and London: Duke University Press.

Roy, Rakhy, and Jayasinhji Jhala. 1987. "An Examination of the Need and Potential for Visual Anthropology in India." In A Portrayal of People: Essays on Visual Anthropology in India, edited by K.S. Singh and C. DasGupta. New Delhi: ASI and INTACH.

Roy, Rakhy, and Jayasinhji Jhala. 1992. "An Examination of the Need and Potential for Visual Anthropology in the Indian Social Context." In Visual Anthropology and India: Proceedings of a Seminar, edited by K.S. Singh. Calcutta: Seagull Books.

Ruby, Jay. 2000. Picturing Culture: Explorations of Film \& Anthropology. London: University of Chicago Press.

Russell, Catherine. 1999. Experimental Ethnography. Durham, NC: Duke University Press.

Sahay, K.N. 1993. Visual Anthropology in India and Its Development. New Delhi: Gyan Publishing House.

Sansi, Roger 2015. Art, Anthropology and the Gift. London: Bloomsbury Publishing.

Sarkar, Bhaskar. 2009. Mourning the Nation: Indian Cinema in the Wake of Partition. Durham and London: Duke University Press.

Schneider, Arnd. 2008. "Three Modes of Experimentation with Art and Ethnography." Journal of the Royal Anthropological Institute (N.S.) 14: 171-194.

Schneider, Arnd. 2011. "Unfinished Dialogues: Notes Towards an Alternative History of Art and Anthropology." In Made to Be Seen: Perspective on the History of Visual Anthropology, edited by M. Banks and J. Ruby. Chicago: University of Chicago Press. 
Schneider, Arnd, and Christopher Wright. 2013. Anthropology and Art Practice. London: Bloomsbury Publishing.

Schneider, Arnd, and Catarina Pasqualino. 2014. Experimental Film and Anthropology. London: Bloomsbury Publishing.

Sinha, K.S. 1987. "Introduction." In A Portrayal of People: Essays on Visual Anthropology in India, edited by K.S. Singh and C. DasGupta. New Delhi: ASI and INTACH.

Singh, K.S. 1987. "Anthropological Survey of India and Visual Anthropology.” In A Portrayal of People: Essays on Visual Anthropology in India, edited by K.S. Singh and C. DasGupta. New Delhi: ASI and INTACH.

Singh, K.S. (ed.). 1992. Visual Anthropology and India: Proceedings of a Seminar. Calcutta: Seagull Books.

Singh, K.S., and C. DasGupta (eds.). 1987. A Portrayal of People: Essays on Visual Anthropology in India. New Delhi: ASI and INTACH.

Stoller, Paul. 1992. The Cinematic Griot: The Ethnography of Jean Rouch. Chicago: University of Chicago Press.

Stoller, Paul. 2009. The Power of the between: An Anthropological Odyssey. Chicago: University of Chicago Press.

Straw, Will. 2005. "Pathways of Cultural Movement." In Accounting for Culture: Thinking Through Cultural Citizenship, edited by C. Andrew, M. Gattinger, M. Jannotte and W. Straw. Ottawa: University of Ottawa Press.

Suhr, Christian, and Rane Willerslev. 2012. "Can Film Show the Invisible? The Work of Montage in Ethnographic Filmmaking." Current Anthropology 53 (3): 282-301.

Taylor, Lucien. 1994. Visualizing Theory: Selected Essays from V.A.R., 1990-1993. London: Routledge.

ten Brink, Joram (ed.). 2007. Building Bridges: The Cinema of Jean Rouch. New York: Wallflower Press.

Vaughan, Dai. 1979. "The Man with the Movie Camera.” In The Documentary Tradition, edited by L. Jacobs. London: W. W. Norton.

Vertov, Dziga. 1984. Kino-Eye: The Writings of Dziga Vertov. London: Pluto.

Winston, Brian. 1995. Claiming the Real: The Griersonian Documentary and Its Legitimations. London: British Film Institute.

Wright, Chris. 1998. "The Third Subject: Perspectives on Visual Anthropology." Anthropology Today 14 (4): 16-22.

Wright, Christopher, and Arnd Schneider. 2010. Between Art and Anthropology: Contemporary Ethnographic Practice. New York: Berg Publishers. 


\title{
11 Critiquing stereotypes? Documentary as dialogue with the Garo
}

\author{
Erik de Maaker
}

\section{Introduction $^{1}$}

The classic documentary film Wangala, A Garo Festival opens with a series of slides, which show swiddens with rice ready for harvesting, village houses, and people engaged in various ritual activities relating to the community religion. A male narrator with a deep baritone starts to speak:

Strange indeed, are the tales of discovery. Stranger still, is our story. The story of the Wangala, and yet not quite. The story of a celebrated dance form, and yet, not quite. Strange indeed. We had braved many seasons and the unfathomed terrains of the forbidding Garo Hills in Meghalaya to witness a celebration, but instead we discovered 'life'.

The title of the film appears, on a black background: Wangala, a Garo Festival. Next, the image cuts to a night (or morning) sky, then pans down to a woman sitting with a child on her lap. A female voice, speaking a kind of Shakespearean English, addresses the Sun God:

A tough dweller in the serene ethereal heights of heaven, thou hast been kind and good to me beyond expression. Thou hast made the shaky plants firm, thou hast nursed them throughout. Thou hast helped the paddy stalks fructify, yea, thou. My friend, my partner, my ally, thou willst partake the first fruits of my paddy harvest, before my family and I taste them.

Scenes showing Wangala rituals follow, as the male narrator asks, "Do the gods hear the voices of the Garo?" He then muses further on the significance that people attribute to such rituals, and how they relate to agriculture.

I saw this documentary film for the first time many years ago, when I attended the Hundred Drums Wangala festival. This two-day state-sponsored cultural festival is held annually at Asanangri in the Garo Hills of Meghalaya. It derives from the post-harvest celebrations of the Garo community religion, and is in many ways the most important 'national' celebration of Garo culture, as I have argued elsewhere (de Maaker 2013). In villages, Wangala is a celebration that lasts several 
days and is jointly hosted by all Songsareks (those who follow the community religion) and open to anyone else who wishes to participate. The state-sponsored Hundred Drums Wangala festival, by contrast, draws visitors from the entire Garo Hills area. What is more, while in villages only practitioners of the community religion act as hosts, the Hundred Drums Wangala festival is organised by state officials who are all Christians and is attended by both Christian and Songsarek Garo. The festival has come to epitomise a shared Garo culture that transcends the religious divisions existing within the community.

One of the first times that I attended the Hundred Drums Wangala Festival, its grounds included a huge open space where a large piece of white cloth had been stretched out as a screen. A powerful video projector, the property of Meghalaya's Department of Information and Public Relations, brought the film to life. The predominantly Garo audience of approximately one hundred people was entertained by the documentary Wangala, a Garo Festival. Many were educated middle class Christian Garos from Tura, the largest town in the Garo Hills. For townspeople, village life, especially the community religion, was not something they encountered in their everyday lives. As second or third generation converts, they associated the community religion with their (grand)parents and had learned about it from films, photographs, and perhaps books, rather than from personal experiences. The audience reacted to quite a few of the scenes with laughter, for example, when women were shown with bare breasts. Christianity has rendered such forms of public bare-chestedness taboo, and the audience most probably regarded topless women as unchaste. While people who continue to practise the community religion make no bones about (married) women baring their breasts, it struck me that the inclusion of such images in the film was seen by the audience as a stereotypical portrayal of 'traditional' Garo culture. Indeed, the association of tribal people with public nudity is well established throughout South Asia, rooted in colonial era attempts to relegate indigenous communities to a culturally lower stage of evolution (Van Schendel 2002). This keys in with the idea, prevalent among South Asia's majorities, that 'tribals' lack sexual morality and personal hygiene; an idea that is then used to explain and justify situating them at the bottom end of South Asia's 'civilisational pyramid'. Urban, educated, middle class Garo are well aware of these stereotypes and express a certain ambivalence towards practices associated with the community religion. In my understanding, the laughter provoked by the scenes suggested that the audience felt 'primitivised'. Garo urban middle class women would never dream of going around bare-breasted, but since the film consistently referred to 'the Garo' as a unified and homogeneous group, it seemed to include them as well.

Assuming that at least some Garo people have mixed feelings about this film, as well as others of its sort (judging by the audience's reactions at the open-air screening mentioned above), it is remarkable that - to my knowledge - no one from the Garo community has ever publicly spoken out against the genre. Clearly, films such as Wangala of Garos (alternatively referred to as Wangala: A Garo Festival) exemplify the 'anthropologising gaze' criticised by Dutta (2007) (see Battaglia, this volume). Such a gaze, she argues, emphasises the diversity of the Indian population by 
including its tribal communities, but it also renders them 'alien' and 'other'. With its cinematic encapsulation, the exotic is contained as an 'object' that can be known, controlled, and governed. Interestingly, to my knowledge, no Garo folklorists or politicians who patronise the cultural heritage of the Garo community have ever voiced criticism along such lines. Yet, Garo themselves are certainly aware that even villages in which the community religion continues to dominate, and in which a film such as Wangala of Garos could be recorded today, are more dynamic, diverse, complex, and entangled in regional, national, and global networks, markets, and policies than such documentaries concede. How can the absence of a public debate on these cultural stereotypes be explained? To be more specific: How do Garo people reflect on the filming of Garo 'culture' and the objectifications of Garo culture that that necessarily involves? How do they experience being 'carriers' or 'enactors' of Garo culture? In this chapter, I start out by discussing the intentions of the filmmaker who produced the documentary Wangala of Garos and describe the context in which the film was made and continues to circulate. Expanding on the portrayal of 'the Garo' in the documentary, I then discuss how 'custom' has emerged as a relevant category, both historically and contemporarily. I show how ideas about custom are central to the filmmaking process, reflecting here in part on my own experiences with the production of audiovisual research footage. In conclusion, connecting audience reactions to the films to the perspectives of the people filmed, I argue that Garo do not necessarily perceive the reproduction of cultural stereotypes as problematic. Rather, they generally accept these, some more reluctantly than others, as a reasonable and necessary cost of the creation of 'lasting' cultural records.

\section{Picturing the Garo}

Wangala of Garos was made in 1992 by the New Delhi-based documentary filmmaker Bappa Ray. In an interview that I conducted with Ray in Delhi in January 2014 , he told me about the large number of documentaries that he had made in India over the past 40 years. Most of these focused on what are commonly referred to as 'tribal' communities. He produced Wangala of Garos for the Indira Gandhi National Centre for the Arts (IGNCA), a New Delhi-based cultural institute that obtains its funding directly from the national Ministry of Culture. The IGNCA's stated mission is the documentation and preservation of 'Indian' arts, and it has a budget for the production of documentary films. The IGNCA's approach is guided by the Nehruvian 'unity in diversity' paradigm which, in principle, assumes that all cultural traditions are equally valuable (IGNCA n.d.). In practice, classic 'Sanskritic' arts, rituals, and performances are at the core of the effort, whereas 'tribal' traditions represent the 'fringes' of what is regarded Indian civilisation and culture.

Wangala of Garos focuses on 'village life' in an unnamed location in the Garo Hills of Meghalaya, which appears to be exclusively inhabited by followers of the Garo community religion. Only in the final minutes of the documentary does the viewer learn from the voiceover that, actually, "Christianity" has "shaken" the "resolute faith of many". For the filmmakers, the impact of Christianity meant that "in its entirety, Wangala was nowhere there in the Garo Hills". In fact, the film 
crew had to be "shuttled from village to village", "picking up one facet here, another one there, and yet another one perhaps a hundred and fifty kilometres away", as the film's narration reveals (Ray 1992, min. 49:08-49:36). In other words, the consistency of place and time that had been implied by the film until that moment had been constructed solely in its editing.

In the film, the Wangala festival serves as an entry point to picturing a Garo way of life that is structured by shifting cultivation and the community religion. As the synopsis of the film puts it:

The life of Garos revolves around the Sun God, who rules their jhum or shifting cultivation, and envelops the dynamics of their life ways. [. . .] The film places the life and times of Garos in the background of their traditional philosophy and belief systems, and provides a mirror to the Garo mindscape. ${ }^{2}$

In this way, it presents Garo culture as predicated on a cosmology that is closely linked to shifting cultivation. As the documentary continues, it shows men and women dancing, performing rituals, and engaging in shifting cultivation. The images portray a people surrounded by nature, living in houses of wood and bamboo, with no brick, concrete, or corrugated iron roofing sheets to be seen. Modern technology is absent, even though the metal buckets used to carry water and the factory-made clothes that people wear reveal that they trade at markets. The documentary, in other words, presents 'the Garo' as a people living in virtual isolation. With this absence of ties to an outside world, the film creates an eternal 'ethnographic present': the people filmed are portrayed as timeless, devoid of history (Fabian 1983). They occupy their own self-contained space, which is apparently unconnected to any external political structure. The film's narration confirms this interpretation. The male voice establishes the 'strangeness' of the Garo, rendering them worthy of 'discovery'. The female voice corroborates that strangeness, and, supposedly speaking on behalf of the people portrayed, she uses an outlandish medieval English to make statements of an esoteric nature. ${ }^{3}$

Ray told me that for Wangala of Garos he had consciously adopted what he called a "romantic storytelling" approach. Contrary to what the film suggests, even at the time that it was shot, shifting cultivation (jhum) had become extremely rare. According to Ray, shifting cultivation was formerly central to the existence of the Garo, and when they ceased to practise it "their whole world collapsed". Hence, he saw the documentary as an enterprise in what he called the "preservation" of culture. He was not interested in social or economic change. It was not that he had been unaware of the dominance of Christianity among the Garo or of their growing dependence upon markets and increased integration within the Indian state, but that he had consciously decided to leave those topics out. For him, such developments simply represented "cultural loss". Speaking about the Hundred Drums Wangala festival, Ray told me:

In the Garo Hills, they organise this annual festival, and they say that that is 'Wangala', but in fact it is not. The 'real' Wangala used to be in villages, where 
it was closely connected to people's agricultural pattern, and to nature. Its dances mimic the movements of animals, and the sowing and harvesting of crops.

"But nowadays", he continued, "the Wangala songs have been taken over by Christians, and are being played on the guitar." Clearly, Ray was genuinely concerned about what he saw as the 'disappearance' of tribal culture. He wanted to show how what he regarded as tribal culture was unique and characterised by cultural features that genuinely differed from those that shaped 'mainstream' society. He explained to me that he wanted to highlight the value of cultural expressions deemed marginal, if not redundant, in a country that is overly dominated by an ideology of modernisation that is to be achieved through formal education, urbanisation, and industrial development.

Ray's fear of 'cultural loss' is not entirely unwarranted; the Garo Hills, and other upland regions of Northeast India, have indeed seen radical cultural, social, and economic transformations in the recent past. Many people who have grown up as Christians remember that their grandparents or even parents used to practise the community religion. Subsistence agriculture, until a couple of decades ago the mainstay of the upland economy, has been superseded by market-oriented forms of production. Particularly worrying, especially to local folklorists, is the rapidly decreasing involvement of youth in what is regarded as 'traditional culture'. However, even though Christianity has brought a radical reorientation in terms of behavioural style, clothing, music, and so on, there is really no sign of a 'collapse' of the Garo cultural realm. On the contrary, Christian denominationalism has inspired the emergence of new cultural configurations. Church services and festivals such as Christmas and Easter intrinsically combine religious, social, and political functionalities. And, perhaps even more importantly, social networks continue to call on loyalties of (extended) kinship; transforming former practices rather than rendering them obsolete.

The year after its release, Wangala of Garos received a National Award from the Indian Directorate of Film Festivals (Ministry of Information and Broadcasting of the Government of India) as the best anthropological/ethnographic film for "competently representing the lifestyle of the Garo community of Meghalaya" (Anantharaman 1993, 98). In India, National Awards are generally regarded highly by filmmakers as an important sign of recognition. The documentary continues to be distributed to this day, on DVD, by the Indira Gandhi National Centre for the Arts as part of the 'IGNCA's Intangible Heritage Series'. ${ }^{4}$ The IGNCA website advertises Wangala of Garos as "A highly research based film, projecting the sociological background and cultural splendour of the Garo tribe, with special reference to their festival, Wangala, which reflects their life-style". Again, the blurb quoted refers to "the Garo tribe", suggesting that everyone who identifies as Garo today lives the kind of life the film portrays.

Perhaps the longevity of Wangala of Garos is less remarkable than it might seem. After all, films of a similar ilk continue to be made, even if their portrayals are slightly more subtle. Still, The Children Are Here, a more recent documentary 
film, proclaims in its opening sequence that "Rice has been cultivated by mankind for 6000 years", to subsequently state that "The indigenous Garo of North East India still adhere to the original ways". From start to finish, the film emphasises Garo proximity to nature and the sacrality of community in a fairly stereotypical manner. Documentary films about other tribal communities often follow a similar line of argumentation, although there are also many examples of documentaries produced in India that challenge such stereotypes, including the very successful series produced by the Public Service Broadcasting Trust, which is aired on the main national television channel Doordarshan. But the latter documentaries are not very well known within the Garo community, unlike the more traditional ones, which continue to be appreciated locally. In my view, part of that appreciation is due to the way such films can serve as a cultural repository, which makes them invaluable, since written cultural records of the upland people of Northeast India are all but non-existent.

\section{Framing Garo culture and society}

An important characteristic of Northeast India is the ethnic, linguistic, and religious diversity of its residents. Based on social categories that were defined in the colonial era, the population of Northeast India comprises communities that belong to the Hindu and Muslim mainstream as well as people who belong to 'tribal' groups. In Northeast India, like elsewhere in South Asia, colonial administrators assumed that the communities that later came to be categorised as tribes had not been part of the earlier (pre-colonial) states of the region. As those early states were mainly located in the valley along the Brahmaputra river, the tribal groups were located, primarily, in the uplands and mountains surrounding the basin. As a consequence of colonial state-making, the tribal communities were 'fixed' in 'tribal homelands' (Baruah 2003, Murray Li 2010), implying discrete configurations of people, culture, and place.

This has contributed to a conception of the uplands of Northeast India as comprising a multitude of tribal 'nations', each occupying its own dedicated patch of land, but reality is far less clear-cut (Mandal, Mukherjee and Datta 2002). Demarcations between communities are often ambiguous. People with distinct ethnic backgrounds often live next to one another in both villages and towns, which renders the allocation of any territory to a single ethnic community utterly problematic. As Ramirez (2013) has shown from his research among the Karbi, some people can even assert or withhold tribal membership at will, dependent on which social identifications or alliances are preferable at any given moment in time. Commonly, however, membership of a community is not seen to be characterised by such openness, since belonging to a caste, tribe, or other community obliges an individual to marry within that same community (Mines and Lamb 2010, 146). This does not necessarily make it impossible for marriage partners to be chosen from outside a community, certainly not among 'tribals', but it does mean that the children of mixed marriages will be primarily located in the community that is dominant in the given context. 
In India, belonging to a tribal community is often accompanied by stigmatisation and/or deprivation, because, according to the evolutionary perspectives on culture that continue to prevail among Hindu and Muslim majorities in South Asia, tribal cultures are seen to represent earlier stages of human development; less advanced if not 'backward'. Consequently, people belonging to tribal communities are often subjected to discrimination, as is evident, for instance, from the experiences of tribal people living in India's metropolitan cities (McDuie-Ra 2012). Yet, in India, belonging to a tribal community can also be grounds for preferential discrimination, resulting in a variety of valuable benefits. In Meghalaya state, the Garo are one of the communities categorised as a 'Scheduled Tribe' (ST). This brings important legal, fiscal, educational, and political benefits. Only Garo may buy land or start up commercial enterprises in Garo Hills, and STs in the state of Meghalaya are also exempted from income tax. In India, there is a great shortage of seats in educational institutions, but for tribal students there are substantial 'reservations'. Even more significantly, many of the government jobs in Meghalaya state may only be given to members of tribes designated as 'native' to the state, such as the Garo. Lastly, there are seats reserved for persons of Garo descent in many of the political representative bodies of the state. In a region where industry is virtually absent, and commerce is dominated by trading communities that trace their origins to eastern India, such benefits translate into valuable salaried positions and political power for people of tribal descent. While such measures aim to redress long-standing structural economic inequality and social deprivation, they do not necessarily uplift the rural poor. Rather, the tribal middle classes reap the benefits, and consequently have the greatest interest in ensuring that the measures remain in place. The administrative labelling of communities as tribe or caste draws upon local understandings of community and culture, but has at the same time produced 'tribe' as a social category (Rycroft and Dasgupta 2011). In order to retain benefits, it becomes imperative for cultural communities such as 'tribes' to maintain their cultural idiosyncrasies. After all, should they cease to be recognisably distinct, the grounds on which they receive preferential treatment would become obsolete.

With a population of approximately one million, the Garo are one of the larger tribal communities of the Northeastern region. The vast majority of the Garo live in the western part of the state of Meghalaya, with substantial minorities residing in neighbouring parts of Assam and Bangladesh. A prerequisite of 'being Garo' is the ability to speak the Garo language, although in practice not all Garo dialects are mutually intelligible. Since Garo are matrilineal, having a Garo mother is of primary importance. Due to the extended and categorical notions of kinship that are observed, each Garo is - at least in principle - able to trace a relationship to every other Garo as either a consanguineal relative or an in-law. Moreover, Garo are differentiated culturally from 'neighbouring' communities such as Hajong, Rabha, Khasi, and Bengali. In this latter respect, practices and beliefs relating to the Garo community religion serve a political and practical purpose, since they play an important role in defining the profile of Garo culture. 
As mentioned earlier, the vast majority of the Garo today are Christians. The Garo community religion continues to be practised in a few rural pockets, but on the whole it is rather marginal. This Christian dominance is a relatively recent phenomenon. The earliest conversions date back to the mid-19th century, when Baptist and later Roman Catholic missionaries began proselytising among the Garo. But it was not until the expansion of primary education into rural areas in the 1970s and 1980s that the community religion started to become marginalised. Conversion to Christianity allowed and demanded that people distanced themselves from the lifestyle and practices associated with the community religion. This included renouncing allegiance to the Songsarek deities, and prohibited women from baring their breasts in public.

Conversion to Christianity has led to rather negative views of the community religion. This is the result, by and large, of the endeavours of missionaries who actively 'demonised' the community religion in order to convince people to convert. The missionaries identified the Songsarek deities as demons, and declared the afterworld that the community religion projects to be equivalent to hell. Contrary to the tranquil, harmonious image called up by classic ethnographic films such as Wangala of Garos, religious conversion, and even more profoundly the class differentiation it produced, has created cultural divisions within the Garo community. Given the political significance attached to recognition as a tribal community, Garo intellectuals express concern about this cultural divide, and where possible make efforts to bridge it.

\section{'Reading' visual ethnographies}

Bappa Ray, the director of Wangala of Garos, told me that he wants his films to bestow value on the lifestyles of people who live in remote areas. The question asked by many of his films is, "What lives do they have?" In his films, he wants to show the hardships people face, how they walk through the forests, and how they hunt animals. Ethnographic films in general, he said, cater to a desire for realism. I would argue that more generally, ethnographic films derive the credibility that their viewers attribute to them from the presumption that they show 'real' people, involved in real events, who speak the truth. The films document events that have actually taken place, which makes viewers see them as informative or even educational (Banks 1992, 121). Recorded documentary images and sounds have what Nichols $(1992,153)$ has called an "indexical stickiness", they are somehow close to what the viewers themselves 'can observe' or 'have observed' or 'could have observed'. Film and video can thus record and project events that actually happened in front of the camera, within range of the microphone. This suggestion of 'realism' and 'directness' is essential if a documentary audience is to be convinced of the truth-value of what they see. Yet, to tell their stories, documentaries make use of film language and cinematic conventions that closely resemble those that structure fictional movies. Audiences may not always be aware of it, but as Loizos (1993, 6-7) put it, "documentaries do not differ from fiction films in their constructedness as "texts", and are never "simple unmediated 
carbon-copies of real world events". Rather, documentary films provide viewers with a suggestion of realism.

Over the last two decades, a number of studies have been conducted into how audiences relate to ethnographic films (Ruby 2000). Reception studies have recognised that documentaries, like other media, are not unequivocal, and "that what is perceived or understood by media audiences depends largely on the characteristics of the audience, rather than the intentions of the communicators, or any intrinsic features of the media programs" (Caldarola 1990, 3-4). Moving and still images (and sounds) have a great 'openness' to interpretation, depending on how they are contextualised by viewers. Images will therefore, as a rule, carry multiple potential meanings and allow for multiple readings (Edwards 2012, 224). This is not to say that ethnographic filmmakers cannot aim to structure their films in such a way as to convey an argument to the viewer, and in fact they generally attempt to do so. But in relation to the aims of the filmmaker, audiences' readings can be either conventional, divergent, or run counter to his or her intentions. It is notably in the latter two situations that still and moving images can contribute to alternative readings of history and culture in the Garo Hills.

A conventional interpretation of Wangala of Garos would be one in which the narration guides the audience, explaining and situating the images as they appear. Viewers are most likely to 'go along with' and 'accept' the interpretation of the narrator if they share the referential framework of the filmmaker. In this way, a film such as Wangala of Garos confirms the existence, in the eyes of the average middle class Indian (the viewer anticipated by the filmmaker), of a community such as the Garo that is 'tribal' and 'other.' It could do the same for a global audience, although some viewers might not share the Indian middle class evolutionist understanding of 'tribe' to the same extent. This evolutionist perspective was and continues to be in line with government policies that project the Indian 'nation' as one characterised by unity in diversity; a perspective that public broadcasters and funding bodies sustained by the central government have taken for granted for decades. It is important to note that the standing that has recently been attained by promoters of Hindutva (or Hindu nationalism), who assert the centrality and predominance of Hindu Sanskritic traditions for India if not the whole of South Asia, makes the 'unity in diversity' perspective appear more progressive in hindsight than has hitherto been acknowledged by critical intellectuals such as Dutta (Dutta 2007).

A divergent reading of an ethnographic film - to continue with the modalities of viewing identified by Edwards (2012) - such as Wangala of Garos, would be that the audience accepts that there are people who live the kind of lives and share the kind of outlook suggested by the film, but may not accept that these are representative of all Garo.

Lastly, audience readings of ethnographic films may in fact run counter to the intentions of the filmmaker. Research conducted by Martinez $(1990,1992)$ among North American anthropology students suggests that the more restricted the interpretation a filmmaker imposes upon the images in a film, the greater the chance that the viewer will 'rebel' against it and opt for a divergent if not contradictory 
reading. Wangala of Garos has a lengthy and deeply interpretive voiceover, which students at my home university in the Netherlands, for instance, found very hard to digest. Consequently, they deemed the film's portrayal of the Garo as living a 'remote' life 'close to nature' implausible, and rejected it. Similar counterinterpretations occur when a film like this is seen today by South Asian public intellectuals, who are even more strongly put off by the 'ethnographic present' suggested in the film. In the case of Wangala of Garos these counter-readings are likely to become ever more common over time. An evolutionary understanding of culture that used to be acceptable, and perhaps even appealing for its appreciation of the quaintness and vulnerability of an indigenous community, is increasingly likely to be reinterpreted as derogatory, thus losing its former credibility.

So far, research on audience reception of ethnographic films has primarily been conducted with university students, rather than with the people filmed. So, how do the people who feature in these sorts of films reflect on Garo culture being filmed? How do they read their own culture through film? How do people experience being 'carriers' or 'enactors' of Garo culture?

\section{Assessing local engagement}

Following the 'literary turn' in anthropology (Clifford and Marcus 1986), visual anthropologists have become increasingly aware of how the filmmaking process influences the content of documentary films. Obviously, the act of filming, of recording whatever people do and say, influences their behaviour. Here the intentions and agenda of the filmmaker and the media literacy and reasons for participation of the people filmed play a major role. A filmmaker can attempt to film people as they go about their business, interfering as little as possible. Various strategies have been developed to this end, such as the famous 'fly on the wall' approach (Young 2003, 101). This approach, which first became feasible with the development of lightweight film and sound recording equipment in the 1960s, dictates that film shooting should be done as unobtrusively as possible. However, a film crew never really becomes 'invisible' as some of the proponents of the approach have suggested. And if it does, as in some of the reality TV shows of the 1990s and 2000s, filmmaking loses its dialogical nature, posing huge ethical dilemmas (Mathijs and Jones 2004). Other ethnographic filmmakers have experimented with protagonists acting out their 'own' lives. Or, even more radically, with protagonists directing and recording videos themselves, rendering the filmmaker a kind of external advisor. In all these approaches, the degree of media literacy of the protagonists, that is, their understanding of the processes of filmmaking and their conceptualisation of the various audiences who will eventually watch the recordings made, is critical. They need to be in a position to 'read' the intentions of the filmmaker, so that they can define, at least to a certain degree, how they want to expose themselves. In addition, at least some basic knowledge of video technology and its capacities of dissemination are required if participants are to be able to imagine the possible trajectories of circulation of any recorded footage. 
I want to develop the issue of media literacy and what I would like to call 'media anticipation' in relation to my own filmmaking experiences in Northeast India. Between 1999 and 2001, I conducted two years of ethnographic fieldwork on changing religious practices and their impact on social relationships and livelihoods. Producing video recordings of major social events was central to this fieldwork. Analysis of the video recordings and, most importantly, participants' readings of the filmed events, provided much of the data upon which I based my $\mathrm{PhD}$ thesis.

Many of the social activities that I was interested in occurred ad hoc, often either late at night or early in the morning. Therefore, I had to stay among the people whom I was researching. Moreover, I believed, this would generate a lot of dayto-day interaction, which would create opportunities to encourage people to work with me on the analysis of the video material recorded. The village from which I conducted fieldwork was a relatively large one with about 1,600 inhabitants, located near a road that had been a major thoroughfare from the plains to the largest town in the area until one or two decades previously. The area did not have electricity from the national grid. Several people owned televisions, however, which provided them with access to terrestrial television broadcasts. These TV sets were powered by car batteries, which were recharged from solar panels. My own use of video as a research tool required the installation of quite an extensive technical infrastructure. Thanks to an individual $\mathrm{PhD}$ project grant from the Netherlands Organization for the Advancement of Tropical Research (NWO/WOTRO), I was able to acquire technical equipment with which I could produce good quality recordings. To familiarise people with filmmaking, I started out by making video recordings of events that people did not attribute much significance to, such as river fishing. In the evenings, I showed the recordings that I had made on a small television to anyone interested. While this initially seemed a good idea, it became problematic when I began to make video recordings of events that exposed conflicts between relatives and neighbours.

Garo villages have a certain judicial autonomy, and the village head, together with important elders, is entitled and obliged to settle 'minor' disputes. These include fights among neighbours, marital conflicts, and so on. Obviously, these sorts of negotiations reveal a great deal about the relationships that people maintain, and their roles and responsibilities, so I was very pleased to have the chance to record some of these sessions at the 'village court', as it is officially known. However, these 'court sessions' proved to be very sensitive affairs. Each person brought on trial was backed up by a group of relatives, who would either support the accused or turn against him or her if they felt that their honour was compromised. Village court sessions frequently involved the hurling of insults, as well as attempts - which sometimes succeeded - at beating up the accused.

Before I made any video recordings on such occasions, I would ask for the consent of those present. Obviously, in a room holding about 50 to 100 people, any request for permission had to be primarily directed towards the 'seniors' presiding over the court session. Once they agreed, so did everyone else - or at least they did not voice any objections. In addition, I asked for the consent of the accused 
and the accuser. By the time I started to record the sessions at the village court, I had already been staying in the village for an extensive period of time, so it is perhaps unsurprising that most people did not object to me making video recordings. More than once, in the days following such a dispute, people would come to the place where I lived and ask to see the videos. Initially, and as long as I had filmed activities such as fishing or working the land, screenings had always been public. I wanted to avoid creating the impression that I was doing anything secretive. However, during one particular court session that I had recorded, the accused was a man who was not particularly well respected. His own relatives were ashamed of him, and he was not only severely scolded, but also publicly beaten up. When the ones who were responsible for inflicting this violence showed up the next day, keen and determined to watch the footage, I felt uncomfortable. The person who had been beaten up had been taken to a medical post afterwards because he needed a few stitches. He had been badly humiliated, and I imagined that he and his family would not be too happy about me publicly screening the recordings that I had made of his humiliation. Yet, at the same time, I felt that the people who had been among those who 'performed' the beating were also entitled to see the video recordings. After all, they had allowed me to make them. And so I decided that they could see them, but only during a 'private' (i.e., non-public) screening.

While I was conducting my research, and even more so in hindsight, I realised that my video-oriented research work was shaping the media consciousness of the people among whom I lived. People often asked me why I stayed in the village, and I would tell them that it was my intention to study 'customs and culture' (niam aro dakbewal); two terms that proved helpful in explaining my rather unusual interests in apparently unrelated issues such as village court sessions, bridegroom capture, and above all, ways of coping with death. People were well aware of the fact that I came from far away (Europe), and that the video recordings, photographs and notes that I collected would be taken abroad. At that time, very few people in the place where I stayed had travelled outside the Garo-speaking region, and virtually no one had visited any of India's metropolises. Likewise, they had very little idea about the place where I came from (the Netherlands), but thanks to the radio broadcasts people listened to and the Bollywood films that they watched, they had a clear idea of what the 'outside world' looked like. However, they did not express much curiosity or concern about my usage and dissemination of the video recordings to that 'outside' world. Rather, as mentioned, their concern was the 'local' dissemination and exposure of the recordings.

Some years later, when I returned to the place where I had earlier done much of my fieldwork, I brought an edited video film of one of the mortuary rituals that I had recorded previously. It had been a particularly traumatic event: a young woman had been killed by a snakebite. I showed the video to her widower and uncle, and was relieved but also a bit surprised that they did not have any objections to my showing it to 'outside' audiences. I had also brought an edited video of a court session, in which a man divorced his wife. During the dispute, he swore, holding both his ears, that he would never reunite with her. But a couple of weeks later they 
came back together, which made him a victim of ridicule. I am convinced that at the time, screening the video recordings in the village would have been very painful for him. Yet, a couple of years later, he and his wife were still together, and they could laugh about their earlier marital quarrels. They told me that they were not bothered about the dissemination of the video. Apparently, the scenes had lost their earlier 'edge', and now that they were 'history' they had become socially harmless. In other words, for the people whom I filmed, the video recordings of social conflicts were primarily of concern with respect to their local circulation, close to the time of recording. As time passed, such events ceased to have a bearing on dayto-day social relationships and became mere reflections of the past.

Yet it would be incorrect to conclude that people did not relate to, or were not interested in, more general representations of their customs and culture. The village where I stayed most of the time was (and still is) home to many followers of the community religion. Even before my arrival, as I later learned, its residents were already familiar with television crews, who would come for a day and ask people to enact 'ancient customs.' People described this as 'playing' (kala) in films, and it was considered a perfectly reasonable thing to do. Due to my stay, probably, the area became even better known within the region for its followers of the community religion, and more film crews made their way there to record 'true' Garo culture in the years that followed. One of the highlights among these has no doubt been the recording of Still, The Children Are Here, a documentary on Garo village life by UK based filmmaker Dinaz Stafford, which was shot on $35 \mathrm{~mm}$ film with a crew of about 15-20 people and a budget of at least half a million US dollars. As before, people were asked to 'act out' their own lives in the film, albeit essentially following a script written by the filmmaker. The result was an 85-minute documentary that has been screened at international film festivals as well as at the UN in Rome and New York. The film received mixed reviews, partly because it wasn't very clear to some of its viewers that it had been entirely acted out. One reviewer commented that the film

relies on re-creations to get what [the] cameras missed the first time, which becomes starkly noticeable when she [the director] has a married couple commiserate about their recently dead child while lying in bed at night - a moment that no documentary would catch naturally.

(Murray 2004)

Reflections on the production of these films by the people who featured in them indicated that they themselves had no problem with enacting 'cultural practices' that they no longer engaged in, but remembered from their youth or had heard about from people who were senior to them. In fact, many people expressed a certain pride that they had been asked to enact practices from 'grandmother's and grandfather's time' (atchu-ambini somoi). After all, this won them recognition for having skills and knowledge that were not possessed by either urban Garo or outsiders. The attribution of this cultural authorship even allowed them to invent certain 'customary' practices, as is evident, for instance, in the clothes worn by the 
women in the documentary film Still, The Children Are Here. For the film, women wear a cloth tied around the upper part of their body, in a style hitherto unseen. This allows them to cover their breasts in line with Christian notions of decency, while the clothing style chosen clearly distinguishes them from Christians. The Garo who had enacted these 'traditions' enjoyed seeing themselves in the film. They had no objection to being presented as carriers of 'ancient Garo traditions', either in films or in staged music and dance performances, as I have argued elsewhere (de Maaker 2013). And they were all the happier to participate for appropriate payment, which was certainly the case with Still, The Children Are Here, as they proudly told me in detail.

'Enactment' of culture was also not an issue for the people concerned, I argue, because the films ended up circulating primarily, if not exclusively, outside the direct social environment of the people they featured. Given that whatever is recorded for these types of documentary films is 'played', it does not have a bearing on 'real' social relationships. For instance, Still, The Children Are Here shows a household that has been put together artificially. Its members act as if they are a household in the film. Doing so was a source of fun and laughter for them, but had no impact upon the social relationships that the actors maintained in everyday life. I argue, therefore, that the significance that people attribute to 'playing' in documentaries is rather different from when they appear in research video recordings for which they do not 'act'. Video recordings of the latter type relate to real relationships, and if their content is controversial it takes time, sometimes years, before it can be disseminated.

Obviously, just because people distinguish between cultural practices that have a bearing on actual social relationships and those that are meant for an 'outside' audience, the latter are not necessarily rendered meaningless. 'Outside' audiences have their own preconceptions regarding the Garo community religion and the 'timeless' practices that it incorporates. This holds both for Garo Christian audiences (notably 'urban Garo'), as well as for general Indian viewers, and, if applicable, audiences located elsewhere in the world. At the location where I did most of my fieldwork, many people take pride in showcasing what they claim is 'true' Garo culture, often in line with the expectations of the filmmakers. Perhaps this is where essentialising ideas about 'tribal culture' feed from a national or even global context into a local context and begin to influence it (Tsing 2005). What impact does it have when people start enacting 'culture' in accordance with 'mainstream' expectations? Without giving any decisive answers to this question, I am convinced that acting in films has made people aware which aspects of their customs are particularly valued by 'outside' audiences and has encouraged them to think in an objectified manner about Garo culture.

\section{Conclusion}

In this chapter, I have discussed how people experience being 'carriers' or 'enactors' of Garo culture. Drawing, in part, on my own experiences as a recordist of visual research footage, I have discussed the different degrees to which those 
filmed can be involved in the filming process. I have argued that people who are filmed do not necessarily object to the reproduction of cultural stereotypes, but rather view such stereotypes as essential to the production of 'objectifications' of culture that are appropriate and authoritative enough to convey their cultural distinctiveness to audiences within India and beyond.

At a national level, within India, the Garo qualify as a 'tribe'. This means that they are seen to possess a unified culture that is clearly distinct from that of neighbouring communities. At the global level, 'tribe' is often translated as 'indigenous community', even though the latter definition is highly controversial. The objectified and reified Garo culture that is put forward in depictions of 'the Garo tribe' foregrounds the Garo community religion. Ethnographic films such as Wangala of Garos (1992), and Still, The Children Are Here (2003) imply that, in principle, Garo practise the community religion, and only briefly allude to the existence of a few Garo Christians, whereas in fact the latter comprise the grand majority.

In the wider region, Garo Christians, including those living in towns, express ambivalence towards this objectified, reified Garo culture. On the one hand, many of them reject the community religion, and particularly the lifestyle that is thought to accompany it, claiming that it is a thing of the past that has been outlived. On the other hand, they are aware of the political significance of the Scheduled Tribe status that applies to the Garo of Meghalaya (from which primarily the urban middle class benefit). This certainly provides an incentive to be in favour of the propagation of a 'true' and 'ancient' Garo culture. Evidence of this 'true' culture is thus required, in part, to meet the demands of a higher level of politics. However, the performance of this culture is the prerogative of the 'real' Garo who practise the community religion. Consequently, given the relative cultural distance between urban Christians and followers of the community religion, visual ethnographies play an important role in informing urban Christians about 'true' Garo culture. Nevertheless, urban Garo are reluctant to be pigeon-holed into what they themselves look down upon as a rather 'primitive' position, since the reificatory and objectifying approach towards culture that characterises the documentary films discussed ultimately questions the extent to which Garo have actually attained modernity.

Locally, the people among whom the documentaries that present stereotypical accounts of Garo culture are made are not particularly concerned about the benefits that the Scheduled Tribe status bestows upon the Garo. Yet, they know that they are expected to make themselves appear as 'traditional' as possible for the documentaries, and they take great pride in the 'acting out' of 'ancient customs'. They have no objections to enacting whatever is asked of them, and by no means do they consider practices related to the community religion to be inferior to those of urban Garo. Their performance in films is directed towards imagined 'national' and 'global' audiences, as instructed by the filmmakers. Since the films are staged, the scenes shot are not seen to reflect actual social relationships. Furthermore, participants take care to ensure that they receive appropriate payment for acting in the films.

The enactment of tradition for documentary films makes their protagonists aware of what content is seen as 'true' culture, but that does not affect their 
everyday practices. In real life, people continue to act in accordance with the demands made by the complex multi-layered social, economic, and political relationships that they maintain with each other. And, ironically, these everyday practices, which do reflect the real tensions that people experience due to their growing dependence on markets and their increasing integration within the Indian state, have so far seldom been considered relevant to depictions of Garo customs and culture.

\section{Notes}

1 Draft versions of this chapter have been presented at the Frobenius Institute in Frankfurt am Main, and at the workshop "Tribes' on Screen: Mediatizing South Asian Indigeneity" at the Ethnographic Museum of the University of Zürich, both of which yielded many valuable comments. I am also grateful to the Dutch National Science Foundation (NWO), the Indian Council for Social Science Research (ICSSR), and Leiden University's profile area Asian Modernities and Traditions (AMT) for their generous financial support of the research that this chapter draws upon.

2 IGNCA. Wangala: A Garo Festival. https://archive.org/details/ignca.Wangala. [accessed on 23.05.2019].

3 The male and the female voice continue to alternate, with the male voice speaking as the 'external' observer and enquirer, the female voice apparently expressing the perspective of the people filmed. When I interviewed him in January 2014, Ray explained that the 'inner' voice (the woman) is in dialogue with the 'outer' voice of the man.

4 IGNCA. Wangala: A Garo Festival. https://archive.org/details/ignca.Wangala. [accessed on 23.05.2019].

\section{References}

Anantharaman, Latha. 1993. 40th National Film Festival 1993. New Delhi: Directorate of Film Festivals, Ministry of Information and Broadcasting, Government of India.

Banks, Marcus. 1992. "Which Films are the Ethnographic Films?" In Film as Ethnography, edited by Peter I. Ed Crawford and David Turton, 116-130. Manchester: Manchester University Press.

Baruah, Sanjib. 2003. "Citizens and Denizens: Ethnicity, Homelands, and the Crisis of Displacement in Northeast India." Journal of Refugee Studies 16 (1): 44-66. doi: 10.1093/jrs/16.1.44.

Caldarola, Victor J. 1990. "Reception as Cultural Experience: Visual Mass Media and Reception Practices in Outer Indonesia." PhD diss., University of Pennsylvania, Ann Arbor.

Clifford, James, and George E. Marcus. 1986. Writing Culture: The Poetics and Politics of Ethnography. Berkeley and London: University of California Press.

de Maaker, Erik. 2013. "Performing the Garo Nation? Garo Wangala Dancing between Faith and Folklore." Asian Ethnology 72 (2): 221-239.

Dutta, Madhusree. 2007. "Truth and the Indian Documentary." Film South Asia (for Himal Magazine). http://www.filmsouthasia.org/2007/10/06/truth-and-the-indian-documentary. Accessed on 23 May 2019.

Edwards, Elizabeth. 2012. "Objects of Affect: Photography Beyond the Image." Annual Review of Anthropology 41 (1): 221-234. doi: 10.1146/annurev-anthro-092611-145708.

Fabian, Johannes. 1983. Time and the Other: How Anthropology Makes Its Object. New York, NY: Columbia U.P. 


\section{Erik de Maaker}

Indira Gandhi National Centre for the Arts (IGNCA). n.d. About_IGNCA, edited by Indira Gandhi National Centre for the Arts. New Delhi: Indira Gandhi National Centre for the Arts.

Indira Gandhi National Centre for the Arts (IGNCA). Wangala: A Garo Festival. https:// archive.org/details/ignca.Wangala. Accessed on 23 May 2019.

Loizos, Peter. 1993. Innovation in Ethnographic Film: From Innocence to Self-Consciousness, 1955-1985. Manchester: Manchester University Press.

Mandal, Hrisikesh, Sumit Mukherjee, and Archana Datta. 2002. India: An Illustrated Atlas of the Tribal World. Calcutta: Anthropological Survey of India.

Martinez, Wilton. 1990. "Critical Studies and Visual Anthropology: Aberrant vs. Anticipated Readings of Ethnographic Film." Commission on Visual Anthropology Review (Spring): 34-47.

Martinez, Wilton. 1992. "Who Constructs Anthropological Knowledge? Toward a Theory of Ethnographic Film Spectatorship." In Film as Ethnography, edited by David Turton and Peter Crawford, 130-161. Manchester: Manchester University Press.

Mathijs, Ernest, and Janet Jones. 2004. Big Brother International: Formats, Critics \& Publics. London and New York: Wallflower Press.

McDuie-Ra, Duncan. 2012. Northeast Migrants in Delhi: Race, Refuge and Retail: Amsterdam: Amsterdam University Press.

Mines, Diane P., and Sarah E. Lamb. 2010. Everyday Life in South Asia. 2nd ed. Bloomington, IN: Indiana University Press.

Murray Li, Tania. 2010. "Indigeneity, Capitalism, and the Management of Dispossession." Current Anthropology 51 (3): 385-414. doi: 10.1086/651942.

Murray, Noel. "Movie review: Still, The Children Are Here" 2004. www.avclub.com/ review/still-the-children-are-here-4835.

Nichols, Bill. 1992. "The Ethnographers Tale." In Ethnographic Film, Aesthetics and Narrative Traditions, edited by Peter I. Ed Crawford and Jan Ketil Ed Simonsen, 43-74. Aarhus: Intervention Press in association with the Nordic Anthropological Film Association.

Ramirez, Philippe. 2013. "Ethnic Conversions and Transethnic Descent Groups in the Assam-Meghalaya Borderlands.” Asian Ethnology 72 (2): 279-297.

Ray, Bappa. 1992. Wangala: A Garo Festival. New Delhi: Indira Gandhi National Center for the Arts.

Ruby, Jay. 2000. Picturing Culture: Explorations of Film and Anthropology. Chicago: University of Chicago Press.

Rycroft, Daniel J., and Sangeeta Dasgupta. 2011. The Politics of Belonging in India: Becoming Adivasi. Abingdon: Taylor \& Francis.

Stafford, Dinaz. 2004. Still the Children Are Here. New York: Icarus Films.

Tsing, Anna Lowenhaupt. 2005. Friction: An Ethnography of Global Connection. Princeton, NJ: Princeton University Press.

Van Schendel, Willem. 2002. "A Politics of Nudity: Photographs of the Naked Mru of Bangladesh.” Mod. Asian Stud. 36 (2): 341-374. doi: 10.1017/S0026749X02002032.

Young, Colin. 2003. "Observational Cinema.” In Principles of Visual Anthropology, edited by Paul Hockings, 99-113. Berlin and New York: Mouton de Gruyter. 


\title{
12 YouTube and the rising trend of indigenous folk dance
}

\author{
The case of the sakela dance of \\ the Rai in Nepal and their diaspora
}

\author{
Marion Wettstein
}

Being Kirati I never got the chance to watch all this sakela sili, but I could see it all because of YouTube and thanks to Kishor Sir who has posted this on YouTube. ${ }^{1}$

Sakela is a ritual festival celebrated by most of the approximately 30 indigenous Rai communities of Eastern Nepal who, together with the Limbu, Sunuwar and Yakkha, are subsumed under the Kirat ethnic group. Sakela rituals include a group dance performed in a circle, the bodily movements of which are termed sili. It was around 2005 when the first short clips of the sakela dance were uploaded to YouTube; meanwhile the platform hosts several hundred entries for the dance, its related songs and ritual activities. The number of postings of sakela clips has risen continuously and reflects the popularity of the dance and its performance among persons of all ages and social strata of the Rai communities in Nepal and in the diaspora. According to many Rai people, sakela dance was a fairly local and rural phenomenon until two or three decades ago. The dance used to be performed only by specialised ritual dancers during the spring and harvest festivals. But during and after the Civil War in Nepal (1996-2006), cultural policies of the influential Maoist and other leftist parties made efforts to foster ethnic identification, drawing upon an essentialist ethnicity discourse that focused on cultural traits. The influential Rai cultural organisation Kirat Rai Yayokkha (henceforth KRY), in many respects an ethnic activist organisation, started to use the sakela dance - together with other features such as indigenous languages, dress and ritual - to strengthen notions of Rai ethnicity. Through festivals and the integration of the dance into cultural programmes, the dance and its related songs and ritual performances have gained popularity in rural and urban regions alike. In addition to local events with speeches and performances, the KRY - with its headquarters in Kathmandu, local offices in the Rai villages of Eastern Nepal and overseas branches for the diasporahas recently started to use videos to propagate their aims, which include maintaining and promoting the cultural identity and linguistic diversity of the Rai and, at the time of the constitution writing process, called for an autonomous Kirat Rai homeland within Nepal. The videos have been released on VCDs, on the organisation's websites and now increasingly on video sharing portals. For several years now, sakela dance, song and ritual has featured prominently in these media 


\section{Marion Wettstein}

releases. The focus on music and dance videos can be related to the agenda of the Nepal Federation of Indigenous Nationalities, a national-level umbrella organisation of indigenous peoples in Nepal that provided financial support for such productions shortly after the turn of the millennium.

The analysis in this chapter centres on an examination of sakela YouTube video clips. Their visual content conveys specific messages about the sakela dance and the traditions related to it. And the videos also provide a platform for discussion via the comment function of YouTube's user interface. The aim of this chapter is to show how online video clips, which to a significant degree stem from diaspora communities, impact upon the dance itself, and how both the dance and the video clips are linked to the agenda of Rai ethnic activist organisations, which embed the videos on their websites and foster discourse via comments.

\section{Ethnographic background: the sakela dance embedded in its ritual and social context}

Many Rai living in the diaspora in urban centres only know the sakela dance in its new transformed forms, which by and large have lost their link to the ritual context. It is therefore not surprising that a commentator watching the documentary "Kirat Rai Sakela Silee" uploaded to YouTube in 2011 (clips 02 to 06) wrote approvingly, "That's a real ritual, our dignity and pride" (clip 04). The comment is accompanied by the remark that in this clip one can see what the Rai mudum (custom/oral tradition/local knowledge) really is or once was. The documentary, when all its five parts are viewed, is a rare exception among the various online clips featuring the sakela ritual and dance of the Rai. Unlike other sakela clips, it shows the dances in their rural settings, explains how they are embedded in ritual and mythology, and also includes a few scenes that show how the ritual is performed in some detail.

In the following I shall first describe the ritual setting and the kind of sakela festivals and dance that I saw performed in the hills of Eastern Nepal during my field research studying dance among the Rai, especially the Dumi Rai (20102012). ${ }^{2}$ The various Rai groups are neither Hindu nor Buddhist but follow their own local religious and ritual practices, which have been termed "ancestral religions" by Martin Gaenszle (2016) and are often subsumed under the 'shamanic' traditions of Nepal. In Rai rituals the main addressees are the ancestors, who are believed to be responsible for all forms of physical, psychological, social and economic well-being. ${ }^{3}$ In the rural areas of Eastern Nepal, sakela is usually practised in a ritual context. The term sakela, also known as sakhenwa or shakala, may refer to the whole ritual, the deity for whom it is performed, or the dance that is part of the performance. A translation of the term has yet to be arrived at. The ritual as a whole is an agricultural festival held once or twice a year, in spring before the commencement of the planting season (ubhauli), and in some groups also in autumn at around harvest time (udhauli). The rites that are performed by a nagire nakcho, a village priest, aim to please the sakela deities who are responsible for prosperity and the fertility of the land. The way the ritual is performed differs 
between the different Rai groups, sometimes even between villages within the same group. Among the Dumi Rai, for instance, the ritual usually starts in the morning, with the village priest making offerings to the ancestors of the different village households by chanting recitations and pouring local brandy and rice into the hearth fire. He is accompanied by one or two ritual dancers who circle around the fire, and others who dance in the courtyard of each of the houses. Once the household deities have been honoured, the priest, together with a growing number of people, proceeds to the dwelling place of the sakela deity (also known as bhume in Nepali), which is physically manifest as one or several stones that are generally kept beneath a large banyan tree. By the time the procession arrives at the main offering site, a large number of people will usually have already assembled there in anticipation of the offerings of cocks and pigs, hoping to get a glimpse of the small sakela stones in which the deities manifest themselves. The stones have been dug out of the ground in which they are kept during the rest of the year. Here the sakela dance is performed in a circle around the banyan tree, with the first spontaneous dance circles emerging separately from it. Once the offerings have been completed, the whole group shifts to a larger flat area - the courtyard of the village school, for instance - and after a short ritual inauguration of the first dance circles, the villagers continue dancing well into the night.

The dance itself, which I shall focus on in the following, is locally referred to as 'sakela sili'. 'Sili' is a general Rai term, which the Dumi Rai officially translate into English as 'acting' (as a noun, Dumi Kirat Rai Fansikim 2011). Colloquially it is also often translated as 'dance' and has also been explained to me as "the Rai way of moving". Performing in circles around a leafy branch of a tree stuck into the ground or the tree where the deity resides, the dancers keep moving in a basic, ever-repeating step while singing accompanying songs. Every once in a while they perform what I call special units of gestural movements. Here 'gestural movements' are understood as bodily movements that can include the whole body and that have a specific coded meaning. This meaning does not actually have to be understood or agreed on by the whole community. Rather, the general local opinion is that these units of gestural movement supposedly have (or once had) a specific meaning. The dancers are led by a dance leader who signals when such a unit of gestural movement is to start. Some sequences in these units are well known and are always performed in the same order, others are chosen according to the dance leader's preferences. The other dancers then try to join in synchronously as soon as they have recognised or grasped the movement. Most of these gestural units focus on abstracted mimetic hand movements, while others are primarily leg movements. A certain set of these gestural units is known to most Rai groups who perform the dance, but some are restricted to specific communities. In my ongoing research on the sakela dance among the Dumi Rai, I have so far been able to record around 180 different gestural units that can be grouped into sequences relating to (1) agricultural work involved in planting and harvesting; (2) leisure activities; (3) imitations of animals, many of which have mythological significance; (4) pure 'foot' movements; and (5) gestures of greeting and respect at the beginning and farewell at the end, which frame the dance performance (see also Wettstein 2018). 


\section{Marion Wettstein}

At the rural festivals there are two different sets of dancers. The first, smaller group is locally considered to be the actual 'ritual' dancers. They are often elderly women, sometimes also men, who have a special designation (masumadi) and are permanent assistants to the local priest. It is their duty to move along with the priest, performing the dance in the households, in the courtyards and at the place of the bhume deity, whenever dancing is ritually required. But it is not forbidden for other people to join the masumadi dancers once in a while. The second group of dancers comprise the majority of villagers who dance in the afternoon at the dwelling place of the deity, or later on when the social part of the ritual comes to the fore. While the masumadi dancers often limit themselves to just a handful of gestural units during their ritual duty, the social dancers enjoy performing as many different units as possible. Here the young dance leaders can show off their talents, and sometimes several circles of dancers perform simultaneously. While during the day the songs of the ritual dancers are focused on the ritual events, themes of agriculture and mythological stories, towards the evening the lyrics, which also include improvised stanzas, can drift off to other topics, such as the hardship of life in the mountains, feelings of love and longing and joking and flirting (see also Wettstein 2017).

In the rural areas, the dancing season is brought to an end by the custom of formally closing or 'killing' the dance (sili marne) on the conclusion of the ritual day. As soon as this formal closure has been accomplished by the ritual dancers, it is forbidden to dance sakela in that village until a couple of days before the next festival. The villages do not all perform their major festivals on the same date, but one after the other, so that the dancers and audiences can visit all the neighbouring villages, take part in the rituals, indulge in dancing and enjoy social interaction. Sakela events are therefore considered a good opportunity for contacts to be made between potential marriage partners.

\section{Social and political change: Nepal's ethnicity discourse and its impact on the sakela dance}

Since the 1990s, Nepal has seen a major process of political restructuring and, triggered by the agenda of the different leftist parties, a strong emphasis has been placed on the notion of cultural and ethnic identity. The debate around ethnic federalism in Nepal mainly focuses on groups known as janajati, the 'indigenous castes'. In Nepal as in India (Karlsson and Subba 2006), debates around the contested terminology, concepts and definitions of 'indigeneity' have mainly been triggered by the use of such terms by international organisations including the International Labour Organization, the World Bank and the United Nations (Suhrke 2014). As Subba has shown for the case of the Limbu (Subba 2006), 'tribes' are not an issue in the discourse in Nepal. In Nepal, the concept of 'indigenous groups' or 'indigeneity', which has only recently begun to be taken up by local groups, is largely associated with notions of 'ethnicity' or 'ethnic belonging' as the case of the Thangmi has shown (Shneiderman 2015). In the long process of rewriting Nepal's constitution (2007-2015), the question of ethnic communities and the boundaries of such groups was fiercely debated and still remains a major issue of 
contention. This climate has made it important for groups to define themselves in order to ensure political visibility, and one of the strongest ethnic 'minorities' in this process are the Kirat, which include the Rai. ${ }^{4}$ Like many such organisations in Nepal, the agenda of the KRY is to

focus on revitalizing the religions, languages, and cultures of ethnic groups. In order to achieve these goals, they hold seminars, publish magazines and books, and hold language classes. Cultural programmes (sanskritik karyakram), performances in which people perform dances, sing songs, and wear clothing that is meant to represent the identity of an ethnic group, have also been a mainstay.

(Hangen 2007, 26)

It is within this context that the sakela dance has undergone a remarkable transformation. It has spread throughout the Rai communities, even to groups that did not practice the dance as little as 20 years ago. It has caught on among youth who had previously only been interested in 'modern' music and dance. A new event category has emerged: the sakela dance competition. And meanwhile, sakela has become a key marker of ethnic identification among Rai in the diaspora. Rai ethnic belonging has found its main symbolic expression in the sakela dance. Currently, therefore, sakela dance is a crucial factor in uniting the global Rai community, and new media platforms are the most significant of mechanisms that enable interaction among members of that community.

Whenever an official Rai event takes place - jubilees, festivals, honorary programmes - a group of 'traditionally' clad dancers performing at least a few rounds of sakela will be included. In general, a process of folklorisation can be observed, which in the case of the Rai is characterised by slowly detaching the dance from its ritual context, introducing standardised costume, forming official and practised dance groups, reducing the complexity and individuality of body posture and gesture in the dance movements, adapting the spatial orientation to stage performance and incorporating the dance into 'folk dance' presentations at tourist locations. ${ }^{5}$

Although most such events and the bodies that organise them are not political per se, the idea that it is necessary to preserve or revive one's own culture is often accompanied by calls for an autonomous Kirat homeland and the assertion that the Kirat are one people and must unite. Many larger festivals include a stage and several hours of speeches, some of which address these themes, as well as stalls with local pamphlets, books and magazines that present the same set of topics.

Larger urban events are always covered by a camera team or two from local TV stations. Mobile phone cameras are ubiquitous, even in the remotest rural villages that are inaccessible by road and where charging a phone involves walking for half a day to the next working solar panel. Only rarely do the short videos shot on phones find their way onto the internet. They are usually just played to friends on the phone itself. The clips that can be found online are often (but not always) produced to document an event at the request of its organisers or private patrons. Right from the start, such videos are intended for public dissemination. 


\section{Marion Wettstein}

\section{Visual content analysis: what "the world" sees of sakela online}

"Thank you for this priceless documentation, can we discuss if we can do a subtitling/translation in English . . . I would like the world to know about our people" (clip 02). This comment posted under a sakela YouTube clip expresses the wish shared by many commentators that the dance, as well as Rai culture of which they are so proud, should be made visible and known to the world. YouTube is seen as an ideal channel for this endeavour, as the videos can be watched for free by anyone with access to the internet. But a major obstacle is addressed in the comment cited above: the world speaks English - or at least the world that most users have in mind when they think about extending the reach of their sakela films - and the spoken or written texts of many of the videos are in Nepali. But the reach of sakela clips is also limited by other factors: viewers have to find them online in the first place, and whether they appear on a playlist depends on the titles and tags they are labelled with. It can be assumed that the clips are mainly sought out and watched by Rai communities themselves, and perhaps sometimes by other Nepali groups. It is necessary to know the name of the dance (sakela) in order to find a corresponding online entry, and to obtain a satisfying result list similar terms (such as shakela) have to be excluded or others (such as Nepal or Kirat, Rai) added. Someone who does not know that the dance actually exists - i.e., most YouTube users outside Nepal and even many Nepalis from other ethnic groups - is unlikely to encounter the clips by chance. Even related searches such as 'folk dance Nepal' or 'traditional dance Nepal' do not lead to sakela clips but to films of other Nepalese dance performances. Comments on the clips are often in Romanised Nepali or in Devanagari script, which again indicates that the audiences of sakela videos are part of a rather small online community. With between a few hundred and several tens of thousands of views (after five years) and only rarely more than a dozen comments, the sakela clips are far from achieving 'viral' status, ${ }^{6}$ even within a community of Rai that officially numbered 620,004 people according to the 2011 Census - which does not take account of the large diaspora communities outside Nepal. ${ }^{7}$ The idea that disseminating sakela videos will introduce the world to the culture of the Rai is thus based on the assumption that YouTube is the largest platform for sharing video content.

Having examined their limited reach, we now come to the question of what exactly can be seen in the sakela clips. How does the content of the online sakela clips compare to the urban festivals at which most of them are filmed and to the ritual events in the villages? To address these questions I have categorised the different types of clips that were to be found online at the time of my main survey (2014/2015). Since new films are uploaded every sakela season, this overview offers but a momentary snapshot, given here in the order of their frequency:

- $\quad$ Specific, practised dance groups performing at dance competitions. This is the largest category of sakela clips at present. Most of them follow the pattern of the performance. The first one or two minutes show the group entering 
the dance ground. Two members at the front carry a banner bearing the name of the group. In clips uploaded by members of the diaspora (which comprises the majority of the clips, in fact most are from the UK) the group is usually a geographical sub-branch of KRY; in Nepal it might be a group from a certain village. They are accompanied by the 'priest', who may be a real priest from the community or a member of the group enacting the priest's role, and by a woman carrying a basket with rice, which in the rural context has a specific ritual function, but otherwise serves as a symbol. Next follow the drummers, who generally jump around in well-rehearsed disorder, followed by a line of dancers who slowly close to form a circle around the central tree branch. In most cases, the camera remains trained on the dancers, viewing them from outside the circle. From time to time the focus may shift to the events at the centre, where in recent performances rice beer is distributed or the priest is chanting. A shot of the judges may be cut in, and at the end the camera follows the last few dancers as they leave the dancing ground once again in a line. A group photo of the dancers may be added to round off the clip. Some videos end with titles indicating the name of the dance group or the event. In most cases, the soundtrack is solely original sound recorded at the event (sakela dance is characterised by a very regular and loud rhythm played on the drum and cymbals, some groups may also sing) without a voiceover commentary. The length of such clips is generally dictated by the length of the performance, which in the dance competitions is not much longer than ten minutes and allows about five or six different gestural units to be danced at a relatively fast pace. Some videos show several dance groups one after the other, compiled as films of up to an hour in duration. In most cases, the films have been recorded and disseminated at the request of - or at least in collaboration with - the organisers of the respective event (for instance, clip 07).

- Compilations of urban ritual sakela events. These videos combine a variety of footage from the main festival days, of which the above competitions may be a part. Some of these clips are produced in collaboration with the organisers, others are made by independent individuals. Durations vary from approximately five to 15 minutes, and typically the videos show the banners and posters announcing the event, the participants arriving, the dignitaries taking their seats, some very short excerpts of welcoming speeches, and several dance circles often featuring local VIPs, with the camera held at eye level and filming from outside and inside the circle of dancers. Titles of the event and a 'goodbye' may be faded in at the end. Sound may have been recorded live, but in versions produced for the organisers it often consists of professionally produced sakela songs with the original sounds kept very low in the background (as in clip 08, for example).

- Professional music video productions of sakela tunes. Rai singers and musicians have recently started to produce professional music videos with sakela tunes and song texts as their theme. The stanzas are often taken from the best-known and most widespread samples of song texts and are a slow-paced 
replica of traditional songs. Typically lasting three to five minutes, the videos are produced with professional cameras and audio recorders and are professionally edited. Stylistically they reveal the influence of mainstream Nepali Bollywood-esque music and dance videos. These video productions stand out from the other sakela clips in that the dancing is staged for the camera: the dancers are filmed from multiple angles and shot sizes, every step is choreographed directly for the camera and thus for the viewer of the film (rather than the physical audience or the judges at a competition, let alone the deities), and elements of other Nepali dance traditions are interwoven into the sakela parts (clip 09).

- Diverse amateur recordings of sakela dances. These can take many forms, but are usually very short (one to two minutes) and feature the circle of dancers filmed from the outside. There are exceptions to this, such as choosing an unexpected camera angle and showing the circle of dancers from above - as in, for example, the clip recorded in Dharan at the Bhanuchowk crossing, a town at the feet of the mountains in Eastern Nepal where many Rai have come to settle (clip 10).

- $\quad T V$ programmes featuring the sakela festival. Such clips are rarely found online, but a prominent example that has received many views is the recording of a sakela event in 2012 in New York which was shown on Nepali TV (clip 11).

- Documentary films. This category of clips is also extremely rare, but as with the TV programmes, the one example that is available is accorded all the more significance and authority as a result (clips 02 to 06 , mentioned in the opening paragraph of this chapter).

What is obvious at first glance is that, in terms of the number of videos of particular types of contents on YouTube (and therefore on the web in general), the actual ritual dance ranked second and dance competitions and urban festival contexts were the highest (based on the data from 2014-2015). This is probably not only due to active promotion by events' organisers, but also because competition performances have an ideal length for video clips. It is also clear that urban events are easier to film, because the rural locations where Rai live are less easily accessible. Most Rai villages could only be reached by foot and still lacked electricity until recently, so that filming involved undertaking considerable technical preparation in advance. What "the world" could see of sakela thus had little to do with the ritual event that the dance originally stems from. The situation had changed slightly by the time of my second survey in 2018: rural events, such as the festival on Tuwachung hill that has become one of the main ritual centres in Eastern Nepal in the last decade, are also shown on YouTube now (clip 12) and ritual elements are focused upon in clips of diaspora events (clip 13).

Clips of competitions and urban events (and not, for instance, excerpts from the documentary film mentioned earlier) are prominently embedded into the official websites of influential ethnic cultural activist organisations. As a result, they come to be seen as representative of 'Rai culture' by the younger generation of 
media-savvy opinion-makers and active members of the organisations that shape current and future attitudes. It is well known that internet content is short-lived, and its trends fickle. However, the basic structures of websites are much slower to evolve, and since sakela has become integrated into many of the KRY websites, it is likely to stay there for quite some time. Once a website has started to build up a collection or a small archive, the likelihood that the content will be taken down completely, or that its theme will be changed, diminishes. This archiving process can be observed in the case of sakela competition clips, for example on the website of KRY UK, ${ }^{8}$ which featured a collection of 15 video clips from competitions and events from 2012 to 2014 on its home page in 2015 . Every year, the clips on the front page are updated to showcase the latest seasonal edition of the sakela dances.

A considerable number of video clips of sakela dance events stem from diaspora communities, especially from the UK. The Encyclopedia of Asian American Folklore and Folklife correctly states that the variety of Nepalese folk dances is immense. But a further assertion is more contentious: "While it is a taxonomist's job to classify each dance, a Nepali American is less concerned about the origin or ethnicity of a dance than to identify it as a Danphu dance or a Madal dance" here Lama $(2010,861)$ refers to two different types of drum. Material posted online by Kirat diaspora communities suggests the contrary. In 2015, the best documented sakela dance competitions shown online had been produced by different diaspora groups in the UK. ${ }^{9}$ In 2018, a number of clips from the diaspora in Arab countries were added (clips 14 and 15). It has often been asserted that diaspora groups tend to strongly emphasise their culture of origin and create their own versions of it, and folk dance is known to be one of the elements they focus on. For example, Shay notes that in the USA in the 1950s and 1960s, active members of the folklore scene from among diaspora groups travelled to the original villages of their respective communities, armed with film cameras and other recording devices in a "desperate search for authenticity" (Shay 2006, 39, quoting Elizabeth Freeman). Through today's mediatised world, diaspora dance films very easily find their way to the communities 'back home' or 'of origin' especially via channels such as YouTube. These diaspora films in turn have an impact on the dance practices "back home", as I will show in the following.

\section{Synchrony and gestural standardisation: how video and film influence sakela dance practice}

When it comes to the actual dance sequences shown in the clips, we are presented with a very narrow selection of movement units that does not mirror the great number and variety of gestural units found both in rural Nepal and at urban festivals. Most of those we see are the movements chosen by rehearsed dancing groups for competitions, since these are the events shown most frequently in clips. Often, the time slot a dance group is given in a competition is fairly short and only allows about five or six units of gestural movement to be performed. The groups also tend to choose the same movements, for instance mimetic performances of easily recognisable agricultural techniques. It is noticeable that recordings of sakela events 
in non-competitive contexts often show no meaningful gestural units at all, but only basic steps. This might be due to the relatively recent idea that 'good dancing' requires above all that movements should be performed synchronously and in a stylistically uniform manner. This trend is also traceable in comments posted under video clips. In the ritual context of a village, synchrony plays a subordinate role and the stylistic execution of each dance movement varies greatly from one person to the next. In the village rituals, it is not considered problematic if a dancer does not know a particular movement or is unable to perform it correctly. But in the context of dance competitions and visual conventions in films, the precision and timing of movements have become ever more crucial. This might be a reason why video clips of spontaneous dance circles, as opposed to rehearsed groups, at sakela events actually seem to focus less on the meaningful mimetic gestural units themselves than on the basic steps - which are the only movements that everybody is able to perform synchronously. As soon as a mimetic gestural movement sequence comes into play, the synchrony tends to break down. Showing that in a video could create an impression of chaos, and this is not what one wants to "show to the world". Perhaps a further indication of standardisation, clips labelled as dance tutorials have recently started appearing, in which different gestural units are demonstrated explicitly to aid rehearsal (clip 16), or instructions are given on how to perform "correctly". These videos elicit comments that discuss techniques and notions of correctness (clip 17). With these observations we have arrived at a point that might lead us to some more general thoughts on Asian folk dance on film, and on how the camera shapes new conventions in folk dance.

Considering that Bollywood film is a popular genre in Nepal, one obvious conclusion would be that the emphasis on synchrony and uniformity of movement in group dances in sakela films are visual conventions adopted from certain genres of Bollywood film dance. This would correspond with the observation made by Ann David and Linda Dankworth (2014) that the choreographic style of Bollywood film dance - not only in the classic Bollywood movies with their short but numerous dance sequences, but also TV formats such as talent shows and dance competitions - has had, and continues to have, a huge impact on dance traditions all over Asia. Particularly in the commercially produced music videos of sakela songs, we can recognise the Bollywood-inspired idea of cutting together interludes in which one protagonist or a male-female couple appears in ever-changing costumes as they dance to a single song. The leading protagonists are supported by a group of synchronised background dancers. In the professionally produced sakela music videos, the circular structure that is so characteristic of the dance is often opened out into straight rows of dancers, enabling the camera to obtain clearer shots. The style of gesture in sakela performance also appears to have been shaped by some of the visual conventions of Bollywood dance - or 'filmi dance' as it is called in Nepal (Shresthova 2011, 73ff.). I suggest that these adaptations have not only been in response to Bollywood as a genre, but rather to film as a specific medium: dance and gestural bodily movements have been recognised as a key subject of the medium of film since the invention of the film camera (Brannigan $2011,19)$, and synchronous group dance choreographies were a visual effect that 
already featured in the very earliest movies in the late 19th century (Cowan and Hales 2010). The interrelatedness of dance and film was researched conceptually by early pioneers of film theory such as Maya Deren in the 1930s, whose cinematic strategies focused on 'verticality', 'depersonalisation', and 'stylisation of gesture' (Brannigan 2011, 101). Of these three, the last is of the greatest interest to our topic (also see Meyer 2009).

As Görling states $(2009,10)$, bodily gesture as a basal form of communication is difficult to analyse by means of the concepts of linguistic communication through signs in the tradition of Saussure. In the sakela, the mimetic bodily gestures serve as condensed symbols of complex cultural activities and concepts. These activities or concepts can often only be understood or recognised if one is familiar with the cultural background: if you don't know that baskets are carried on the back with the help of a strap passed over the forehead and that the strap must be held at the temples for stability, you might mistake the respective dance gesture as indicating some kind of horns. However, even if one does not know the meaning or message of the gesture, one recognises in all likelihood that it is, or once was, a meaningful gesture. (Dance) gestures are therefore a form of communication that needs to be learned culturally, just as different spoken languages do. Film, when editing techniques are used skilfully, has the capacity to tell a story visually or to put forward an argument through the moving body. Hence, gesture appears well suited to be the core visual feature for such a narrative. In this way film, or a specific genre of film that in our case is the Bollywood genre, can influence and change other dance traditions; in our case the sakela of the Rai. But beyond that, gesture - or gestural dance - and film in combination have the potential to create new forms of kinetic languages altogether. On interactive media channels such as YouTube, this combined potential of gesture and film is extended by a third factor: the viewer discourse enabled by the comment function, which I will examine next.

\section{Negotiating ethnic and religious identity: sakela video clip comments and the activist agenda}

Most of the comments that are posted under sakela video clips are short statements of approval, such as "nice dance". But some of the sakela clips have elicited a considerable number of more complex and controversial comments over the years. In such discussion threads, three topics come up frequently: (1) religion, (2) demarcations of ethnic entity, and (3) the use of designations. These topics overlap substantially with the agenda of ethnic activist organisations such as the KRY. The sakela video clips are not only linked to the agenda of ethnic activists by being embedded into ethnic organisations' websites, but also by the comments posted beneath the films.

\section{Religion}

In comments on clips, discussions concerning the topic of religion mainly focus on two aspects: conversion to Christianity and the definition of 'Kiratism', as 


\section{Marion Wettstein}

local Rai religious practices have been termed for several years. Conversions to Christianity are a matter of great concern, not only in relation to the Rai or Kirat who dance sakela, but also to the whole of Nepal. "Let's defend our culture and religion against Christianity. Christianity is the biggest threat to our culture and identity", a commentator warns under one of the sakela clips (clip 18). Several comments argue that if a Nepali wants to convert to another religion then it should be to the one that he or she 'originally' had; why should they turn to Christianity? An indigenous religion would be much more suitable: 'Kiratism'. Among the comments we also find discussions about what the religion of Kiratism actually is. Briefly summarised, the commentators more or less agree that 'Kiratism' is a 'shamanic' tradition that has been taken over by 'Hindus' who had built upon older concepts and renamed them. Such assertions are often backed up by quotes from indigenous academic or political literature cited directly within the comments to give them scientific 'proof' (under clip 19, for instance). Some commentators suggest that before converting to anything else, one should know one's own culture properly, otherwise one will lose one's own identity. These discussions reflect a genuine concern that indigenous culture is under threat. Christian missionaries have in fact embarked on aggressive proselytising programmes, not only among the Rai. ${ }^{10}$ The local religious practices have little to pit against the missionaries' methods, partly because Christianity is strongly linked to notions of modernism and financially backed from Western branches of the respective Churches.

\section{Demarcation of ethnic identity}

Some comments focus on the question of who is Kirat and who is not. The majority of the Nepalese population categorises four ethnic groups as Kirat: the Rai, Limbu, Sunuwar and Yakkha. But some people also include other groups, such as the Thangmi, and others claim that almost everybody who is neither a Brahmin nor Chetri is Kirat. Some comments state that the Kirat are a "Mongolian race" and belong to the "great Mongolian culture", and others that the Indians are the enemies of the Kirat. Such comments are sometimes supported by references to the Mahabharata War, including quotes from Vedic literature.

\section{Use of designations}

Another recurrent cultural activist theme among the comments on the sakela clips concerns the name of the dance itself. In the early years, when sakela videos first started to appear online, the dance was often also referred to as chandi, a designation it was known by until a few years ago. But this term is increasingly seen to have come from outside the Kirat community. Cultural activists claim that 'Hindus' have started to call the sakela dance chandi nac because it is performed for a female deity, whom they interpret as being the Hindu goddess Chandi. Commentators who have used the word in their posts are informed that it is 'wrong'. Likewise, users who used the name 'chandi' in the titles of their uploaded video clips 
are advised in comments to change the title of the film, even though the search term 'chandi' increases the likelihood of the clip being found and viewed.

These three topics seem to have created some upheaval among the Rai online community. Many of the most controversial comments that were online in 2015 had been deleted by 2018 , but the discussion topics are continuously being taken up again.

\section{Conclusion}

The case of sakela online video clips can be interpreted as an example of successful symbolic policy making. It shows that by combining the right media of communication - film, gestural dance and interactive media comment interface political messages reach audiences, become embodied in practice and achieve the desired effect of a specific political notion. But why was the sakela, and not another dance, chosen for this endeavour? Probably because the gestural repertoire of sakela is closely linked to Rai mythology and everyday experience. This specific expression of cultural identity is rooted in the basal form of communication of bodily gestures in general and the Rai's culturally specific gestural repertoire in particular. Due to the close relation between dance, the camera as the prime medium for capturing movement and video as the prime medium for editing gestural statements, it is precisely these dances that are filmed and disseminated as emblems of cultural heritage and identity. At dance competitions and in video clips the dance can be reduced to a few representative gestures without losing its power, because each dance gesture is part of a whole communication system that expresses cultural identity and hence implicitly stands as a proxy for all the other gestures. This can explain why short clips of sakela dance are such influential representations of Rai culture online and are so prominently featured on the websites of ethnic cultural activists. They are a communicative trigger that, by means of basal gestural language, evokes the full spectrum of cognitive and emotional attachment to a specific cultural identity; something greatly longed for in the context of the diaspora.

\section{Notes}

1 A comment posted under a YouTube video (clip 01). All Nepali comments have been translated into English; original English comments have been edited for better comprehensibility.

2 "Ritual, Space, Mimesis: Performative Traditions and Ethnic Identity Among the Rai of Eastern Nepal" funded by the Austrian Science Fund (FWF), 2010-16.

3 For a more detailed description of Rai ritual practice, cosmology and worldview, see McDougal (1979), Hardman (2000), Gaenszle (2002), Schlemmer (2004), Nicoletti (2006).

4 On issues of ethnic identity among the Rai, see Wettstein, von Stockhausen and Gaenszle (Forthcoming), Gaenszle (1997); on ethnicity in Nepal in general, see Pfaff-Czarnecka, Gellener \& Whelpton (2008), Shneiderman (2014); and on discussions about affirmative action, see Middleton \& Shneiderman (2008).

5 See McDowell (2010) for a discussion on the concept of folklorisation and other characteristics it is identified with. 
6 By comparison: the most viral YouTube clips are usually professionally produced music videos that accumulate several hundred million views and several hundred thousand comments. For studies on very popular YouTube content see, for example, Burges and Green (2009), Vernallis (2013), and for discussions on different aspects of larger YouTube communities see, among others, Strangelove (2010), Juhasz (2011), Wesch (2008).

7 Central Bureau of Statistics $(2012,4)$. Ethnic activists suggest the official numbers are way too small as a result of the methods employed for data collection. They estimate the total number of Rai in Nepal and in the diaspora at roughly two million people (personal communication with Chatur Bhakta Rai, former president of Kirat Rai Yayokkha on several occasions between 2010 and 2012).

8 www.kryuk.org, the official website of Kirat Rai Yayokkha United Kingdom (last accessed 02.06.2016).

9 www.kryuk.org, the official website of Kirat Rai Yayokkha United Kingdom (last accessed 02.06.2018).

10 For a more detailed account of these developments among the Rai, see Wettstein and von Stockhausen (2013).

\section{References}

Online sakela video clips. Accessed on 2 July 2018.

(In the order of appearance in the text. For more results enter keyword combinations comprising 'sakela', 'sili', 'kirat', 'rai', 'dance').

01: www.YouTube.com/watch?v=UGVaaHxcg6A: "sakela sili competition 2012 UK part - 3 Ashford, Maidstone and Rushmoor branch" (uploaded 22.05.2012).

02: www.YouTube.com/watch? $\mathrm{v}=$ _UoumQdvRYU: "kirat rai sakela silee part-1" (uploaded 27.06.2011).

03: www.YouTube.com/watch?v=FfY79VBqom4: "kirat rai sakela silee part-2" (uploaded 27.06.2011).

04: www.YouTube.com/watch?v=Zeqx652jxqc: "kirat rai sakela silee part-3" (uploaded 27.06.2011).

05: www.YouTube.com/watch?v=LKPNNgZxukY: "kirat rai sakela silee part-4" (uploaded 27.06.2011).

06: www.YouTube.com/watch?v=BWNCfh3Sboo: "kirat rai sakela silee part-5 last part" (uploaded 27.06.2011).

07: www.YouTube.com/watch?v=afq1rQ616Ak: "Sakela UK 2014 competition - 1 Ashford HD" (uploaded 17.05.2014).

08: www.YouTube.com/watch? $\mathrm{v}=$ diPoZ4TULoM: "kirat rai yayokkha sakela ubhauli uk 2014 main part (opening)" (uploaded 18.05.2014).

09: www.YouTube.com/watch?v=1WJLtcRzxfw: "rajesh payal rai (KIRAT SAKELA SONG)" (uploaded 27.10.2013).

10: www.YouTube.com/watch?v=EWqRnLWtlEw: "Sakela Dharan Bhanuchowk.MOV" (uploaded 24.05.2011).

11: www.YouTube.com/watch?v=A1eXqA8dsD8: "Sakela Nepal in New York" (uploaded 14.05.2012).

12: www.youtube.com/watch? $\mathrm{v}=14 \mathrm{NNd} 8 \mathrm{RXm} 8 \mathrm{M}$ : "Kirat Rai Sakela at Tuwachung, Khotang" (30.05.2018).

13: www.youtube.com/watch?v=E1R7IUoC8so: "KIRAT RAI SAKELA 2018 UK HIGHTLIGHTS" (uploaded 07.05.2018).

14: www.youtube.com/watch? $\mathrm{v}=4 \mathrm{NcVRkU8ito:} \mathrm{"sakela} \mathrm{in} \mathrm{abudhabi} \mathrm{UAE,} 27$ May 2016 (5076). Kirat Rai Yayokkha-UAE.” (uploaded 31.05.2016).

15: www.youtube.com/watch? $v=r B p 3 Z n s 37 R E$ : "किरात साकेला | Sakela in Abu Dhabi UAE" (20.05.2017). 
16: www.youtube.com/watch? $\mathrm{v}=8 \mathrm{UBQDIRTD} 9 \mathrm{M}$ : "Kirat Rai dance sili tutorial usa us Cincinnati" (05.05.2018).

17: www.youtube.com/watch?v=x86o6Lh3A6Y: "Kirat Rai Dance sakela sili tutorial (Hong Kong)" (uploaded 16.05.2015).

18: www.YouTube.com/watch? $\mathrm{v}=$ BmCatcmKuEA: "Kirat - First People of Nepal celebrating harvest festival Sakela |video credit shyam magar|" (uploaded 24.03.2014).

19: www.YouTube.com/watch?v=7KH860PZRLk: "साकेलासिली Sakela sili (sakela dance)" (uploaded 30.04.2006).

\section{Other references}

Brannigan, Erin. 2011. Dancefilm: Choreography and the Moving Image. Oxford: Oxford University Press.

Burgess, Jean, and Joshua Green. 2009. YouTube: Online Video and Participatory Culture. Cambridge and Malden: Polity Press.

Central Bureau of Statistics, Government of Nepal. 2012. National Population and Housing Census 2011 (National Report). Kathmandu: Government of Nepal, National Planning Commission Secretariat, Central Bureau of Statistics.

Cowan, Michael, and Barbara Hales (ed.). 2010. "Moving Pictures, Bodies: Dance in German and Austrian Film 1895-1933." Special Issue of Seminar 46, 3 September.

David, Ann R., and Linda E. Dankworth. 2014. "Introduction: Global Perspectives in Ethnographic Fieldwork, Theory, and the Representation of Traditional Dance." In Dance Ethnography and Global Perspectives: Identity, Embodiment and Culture, edited by Ann R. David and Linda E. Dankworth, 1-12. Houndmills and New York: Palgrave Macmillan.

Dumi Kirat Rai Fansikim (Dumi Kirat Rai Organisation). 2011. Dumi-Nepali-English Dictionary. Baksila: Dumi Kirat Rai Fansikim.

Gaenszle, Martin. 1997. "Changing Concepts of Ethnic Identity Among the Mewahang Rai." In Nationalism and Ethnicity in a Hindu Kingdom: The Politics of Culture in Contemporary Nepal, edited by David N. Gellner, Joanna Pfaff-Czarnecka and John Whelpton, 351-373. Amsterdam: Harwood Academic Publishers.

Gaenszle, Martin. 2002. Ancestral Voices: Oral Ritual Texts and Their Social Contexts among the Mewahang Rai of East Nepal. Münster: LIT Verlag.

Gaenszle, Martin. 2016. "Redefining Kiranti Religion in Contemporary Nepal." In Religion, Secularism, and Ethnicity in Contemporary Nepal, edited by David N. Gellner, Sondra S. Hausner and Chiara Letizia, 326-352. New Delhi: Oxford University Press.

Görling, Reinhold. 2009. "Einleitung.” In Geste: Bewegung zwischen Film und Tanz, edited by Reinhold Görling, Timo Skrandies and Stephan Trinkaus, 9-18. Bielefeld: Transcript Verlag.

Hangen, Susan. 2007. Creating a New Nepal: The Ethnic Dimension. (Policy Studies 34). Washington: East West Center.

Hardman, Charlotte E. 2000. Other Worlds: Notions of Self and Emotion among the Lohorung Rai. Oxford and New York: Berg Publishers.

Joanna Pfaff-Czarnecka, David Gellner, and John Whelpton. 2008. Nationalism and Ethnicity in Nepal. Kathmandu: Vajra Publishers.

Juhasz, Alexandra. 2011. Learning from YouTube. Cambridge, MA: The MIT Press.

Karlsson, Bengt G., and Tanka B. Subba. 2006. Indigeneity in India. London etc.: Kegan Paul. Lama, Uday. 2010. "Folkdance and Performance." In Encyclopedia of Asian American Folklore and Folklife, Volume 1, edited by Jonathan H.X. Lee and Kathleen M. Nadeau, 861-862. Santa Barbara: ABC-CLIO. 
McDougal, Charles. 1979. The Kulunge Rai: A Study in Kinship and Marriage Exchange. Kathmandu: Ratna Pustak Bhandar.

McDowell, John H. 2010. "Rethinking Folklorization in Ecuador: Multivocality in the Expressive Contact Zone." Western Folklore 69: 181-210.

Meyer, Petra Maria. 2009. "Maya Deren: Die Filmische als choreographische Geste Traumwandlerisch.” In Geste: Bewegung zwischen Film und Tanz, edited by Reinhold Görling, Timo Skrandies and Stephan Trinkaus, 53-74. Bielefeld: Transcript Verlag.

Middleton, Townsend, and Sara Shneiderman. 2008. "Reservations, Federalism and the Politics of Recognition in Nepal." Economic \& Political Weekly (EPW) May 10: 39-45.

Nicoletti, Martino. 2006. The Ancestral Forest: Memory, Space and Ritual among the Kulunge Rai of Eastern Nepal. Kathmandu: Vajra.

Schlemmer, Grégoire. 2004. Vues d'esprits; La conception des esprits et ses implications chez les Kulung Rai du Népal. Lille: Atelier National de Reproduction des theses.

Shay, Anthony. 2006. Choreographing Identities: Folk Dance, Ethnicity and Festival in the United States and Canada. Jefferson: McFarland.

Shneiderman, Sara. 2014. "Reframing Ethnicity: Academic Tropes, Political Desire, and Ritualized Action between Nepal and India." American Anthropologist 116(2): 279-295.

Shneiderman, Sara. 2015. Rituals of Ethnicity: Thangmi Identities between Nepal and India. Philadelphia: University of Pennsylvania Press.

Shresthova, Sangita. 2011. Is It All about Hips? Around the World with Bollywood Dance. New Delhi etc.: SAGE.

Strangelove, Michael. 2010. Watching YouTube: Extraordinary Videos by Ordinary People. Toronto, Buffalo and London: University of Toronto Press.

Subba, Tanka B. 2006. "Indigenising the Limbus: Trajectory of a Nation Divided Into Two Nation-States." In Indigeneity in India, edited by Bengt G. Karlsson and Tanka B. Subba, 134-158. London etc.: Kegan Paul.

Suhrke, Astri. 2014. "Restructuring the State: Federalist Dynamics in Nepal." CMI Report R 2014:2. Bergen: Chr. Michelsen Institute.

Vernallis, Carole. 2013. Unruly Media: YouTube, Music Video, and the New Digital Cinema. Oxford: Oxford University Press.

Wesch, Michel. 2008. "An Anthropological Introduction to YouTube." Presented at the Library of Congress June 23rd 2008. Uploaded 26.07.2008. www.youtube.com/ watch?v=TPAO-1Z4 hU. Accessed on 02 July 2018.

Wettstein, Marion. 2017. “'Sakela': Verkörperung und Leibhaftigkeit lokaler Mythen in den rituellen Tänzen Ostnepals.” In Kosmischer Tanz: Eranos 2015 und 2016, edited by Armin Morich, 63-101. Basel: Schwabe Verlag.

Wettstein, Marion. 2018. "Dancing Who We Are: The Embodiment of Rai Ethnic Identity in Sakela Performance.” In Conference Proceedings 2012: The Annual Kathmandu Conference on Nepal and the Himalaya, edited by Social Science Baha, 271-293. Kathmandu: Social Science Baha.

Wettstein, Marion and Alban von Stockhausen. 2013. "Contesting Power, Negotiating Influence: Rai Shamans and New Religious Movements in Eastern Nepal.” In Shamanism and Violence, edited by Davide Torri and Diana Riboli, 103-118. Surrey and Burlington: Ashgate Publishers.

Wettstein, Marion, Alban von Stockhausen, and Martin Gaenszle. Forthcoming. "Increasing Materiality and Emerging Concepts of Ethnic Religious Identity: The Case of 'Kirat Religion' in Nepal." Manuscript submitted. 


\title{
13 Identity, indigeneity, and cultural props
}

\author{
Portraying the Tai-Ahoms in two \\ Assamese films based on the \\ legend of Joymati
}

\author{
Arzuman Ara
}

Assam has been a land of diversity. The geographical space of Assam has been accommodating people from different cultures and communities since a time immemorial. Both in the pre-colonial and the post-colonial era, people have settled in this region coming from different parts of the world. Though their cohabitation and contributions have enriched the region culturally, still, identity has been a major issue in the political arena in this region. Issues of languages, ethnicity and indigeneity, migration, land encroachment etc. have been storming the region from time to time resulting in many political conflicts that did not leave the creative artists untouched. The popular song of Bhupen Hazarika is worth noting here. One of his popular songs includes lyrics such as, "Ami Axomiya, nohou dukhiya, buli xantona lobhile nu hobo, Ajir Axomiyai nijoke nisinile Axom roxatole jabo", which can be translated into English as "Do not be complacent thinking 'We the Assamese people, so we are not wretched'; if today's Assamese do not know themselves then Assam will be ruined" (as quoted in Dutta 2014: 183-84, translation mine). The songwriter expresses his anxiety regarding the territorial and demographic unity and integrity of the Assamese community. This song was first sung in 1968 and later revised in 1979, at a time of political unrest in Assam fuelled by fears that its residents could become outnumbered and dominated by so-called outsiders, as increased numbers of non-Assamese people migrated to the state from Bangladesh (erstwhile Pakistan and British India) and other parts of India. The song continues to enjoy popularity and is often sung as a call for the re-assertion of an 'Assamese' identity. What might constitute such an identity, however, is a matter of debate; to be 'Assamese' has meant different things for different people at different times. The population of Assam is, like that of other states in Northeast India, characterised by extreme diversity in terms of ethnicity, culture, language, and religion. Issues of identity and identity politics have shaken the entire state of Assam time and again with violence, agitations, insurgency, and federal interventions. ${ }^{1}$ The controversial issue of identity pervades social life, and different standpoints are expressed not only in the press and non-fiction, but also in entertainment media such as popular songs, local Bhramyamaan theatre (mobile theatres), and movies. Historical legends, popular myths, and tales that reflect contemporary life are often the themes and subject matter of these popular media. Their producers draw on local culture(s) 
and make use of culturally specific props ${ }^{2}$ in order to evoke the time, location, and community portrayed. Particularly in the case of visual media like Bhramyamaan theatre and movies, symbolically loaded props that are familiar to specific audiences are often used as visual shorthand to set the scene.

\section{The legend of Joymati}

In this chapter, I look closely at two Assamese films that are both based upon the same legendary narrative about an Ahom princess known as Joymati (alternative spellings in English include Joimati or Joymoti). The Ahoms were an ethnic group believed to have migrated from eastern territories to the Brahmaputra valley and established a kingdom there in the early 13th century, ruling from 1228 to 1826 over an area that included much of what today comprises Northeast India, including the state of Assam. While colonial anthropologists sought and failed to identify a distinct Ahom community in Assam in the early 20th century, since then a 'TaiAhom' identity movement of people claiming to descend from the Ahoms has gained such force that now approximately six hundred thousand of the 14 million Assamese-speaking people claim to be Tai-Ahom (Saikia 2006, 35, with reference to Bose 1998, 155).

Certainly, the Ahom legend of Joymati is a popular narrative in Assam and has inspired songs, tales, Bhramyamaan theatre, and movies. Princess Joymati sacrificed her life to save her husband Godapani and the Ahom kingdom from the despotic King Syulikfa, who was also known as the Lora Raja (literally "young king") and ruled from 1679 to 1681; one of the most tumultuous periods in Assam's history. Joymati is revered for her extraordinary sacrifices. She is seen as a symbol of endurance, patriotism, and dignity; her life story thus lends itself well to assertions of dignity, indigenous identity, and self-determination. The first filmed adaptation of the legend, Joymoti $(1935)^{3}$ by Jyotiprasad Agarwala, was produced during the time of India's movement for independence from British rule. It was not only the first film to be shot in Assam in the Assamese language, but also ground-breaking in its portrayal of an empowered female as its central character. The second film, also entitled Joymati, was produced in a very different political context almost 70 years later, in 2006, by the feminist filmmaker Manju Borah. While both films depict the same historical period, they actually reveal a great deal about the different socio-cultural and political contexts in Assam at the times of their respective production. Both filmmakers situate their films in time and place (Assam in the late 17 th century) by including props that are recognisable as specific to Assam. Yet, while often nominally the same, the objects featured in the two films are used in different ways, evoking subtly yet significantly different cultural allusions.

\section{Joymati's props}

In the edited volume Axomiya Sanskritir Kanika (Elements of Assamese Culture), Narayan Das and Paramananda Rajbanshi (2006) identify certain objects as markers of Assamese cultural identity. These include jaapi (headwear that protects the 
wearer from the sun and rain), mekhela chador and dhoti/kurta (clothing), gamosa (used both as a towel and as a male item of clothing), xorai (a plate-like utensil on a pedestal, used for presenting offerings as a sign of welcome, respect, and gratitude), and tamul-paan (areca nut and betel leaves prepared for chewing). In the following, I will summarise Das and Rajbangshi's observations regarding each of these items, and then look more closely at the ways that these symbolically loaded objects are staged in Agarwala's and Borah's filmed versions of the legend of Joymati.

The xorai is considered unique to Assamese culture. It is used for making offerings to the gods and to respected persons as an expression of dignity and respect. There are various types of xorai. Those used for religious offerings are often larger than the ones used for offering tamul-paan (areca nut and betel leaf) to guests. A further type of xorai has a closed pointed top: in modern practice these are given as gifts and/or displayed as showpieces. A xorai is found in almost every Assamese household. They also frequently appear in media productions and advertisements as markers of Assamese cultural identity. Unsurprisingly, xorais appear in both Agarwala's and Borah's films. Figure 13.1 shows an offering to the gods presented on a xorai in Agarwala's Joymoti, while in Borah's film the utensil is used to offer guests paan-tamul in Figure 13.2.

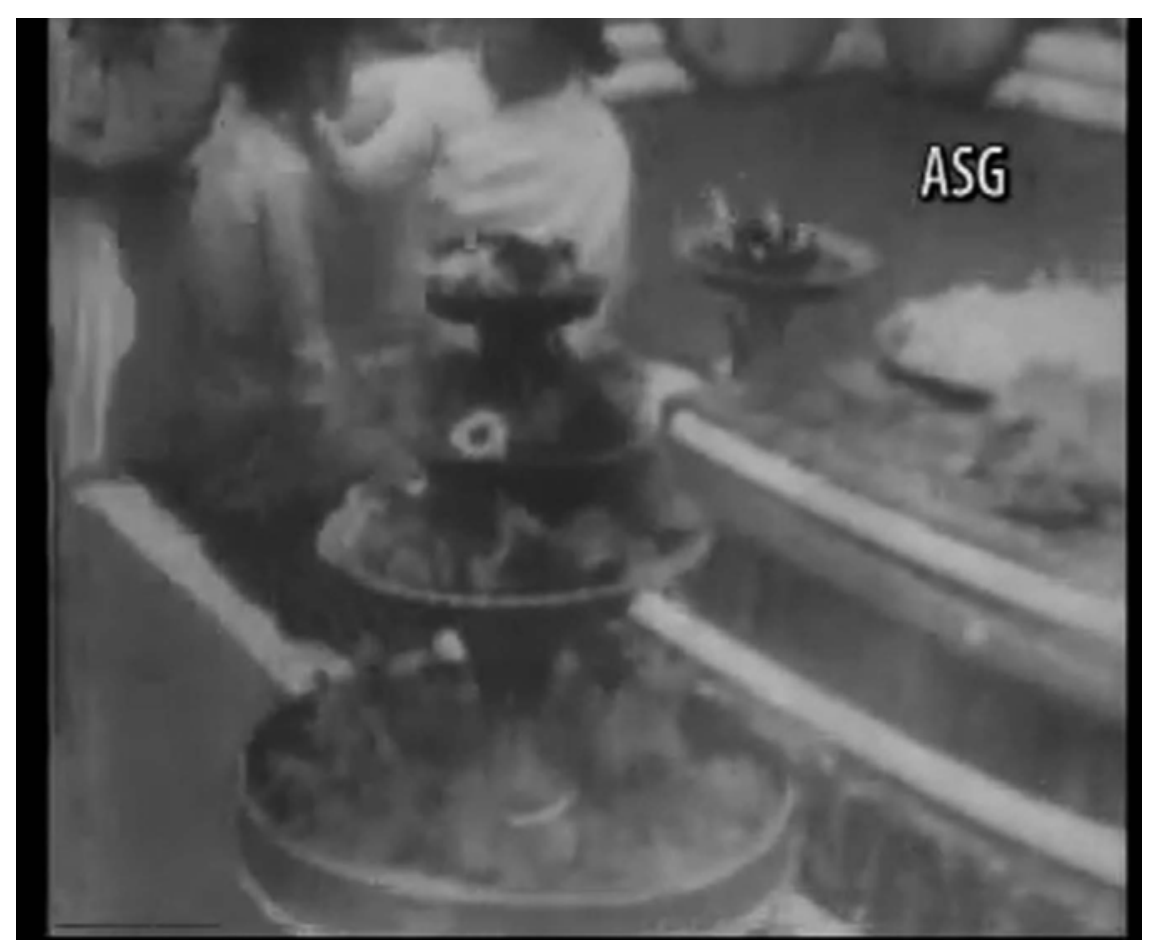

Figure 13.1 Xorai in Agarwala's Joymoti used for offering to gods 


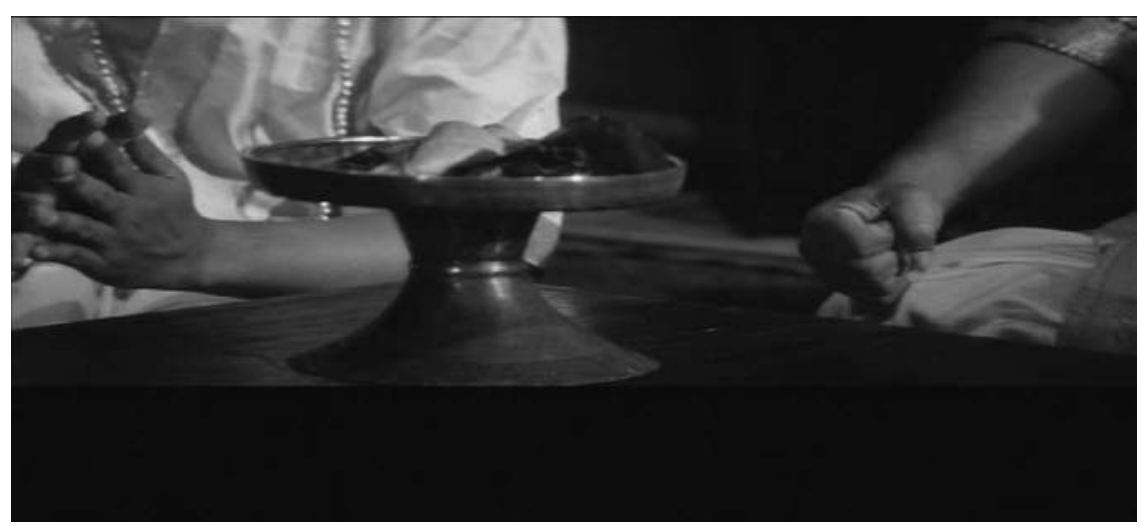

Figure 13.2 Xorai in Borah's Joymati used for offering paan-tamul

It is not known when xorais first came into use.

In the middle ages, xorais were used for making offerings to gods' thrones, and were given to Vaishnavite priests [. . .] for making offerings to Lord Vishnu [.... D During the Ahom rule, xorais were used for making offerings to show respect to kings, elders, and dignitaries.

(Das and Rajbanshi 2006, 299-300, translated by the author from Assamese.)

Thus, Agarwala shows xorais being used for religious offerings as practiced by the Vaishnavite and Aryanised ${ }^{4}$ Hindu community of Assam, whereas Borah features the same utensil being used for the Ahom practice of offering paan-tamul to dignitaries and elders.

A jaapi is a hat made from palm leaves that is worn by farmers while working in the fields, to shield themselves from the sun and rain. They feature in both films as props that evoke an Assamese setting: the jaapis are exhibited as decorative items in the home, which did not used to be a traditional practice (see Figure 13.3). Formerly, jaapis were simply utilitarian objects that would have been hung in a corner of the home, barn, or storehouse when not in use but were not overtly displayed. They have only recently become decorative items.

Yet Borah also shows jaapis being worn by migrant Ahoms (see Figure 13.4). This can be seen as an attempt to connect the visual cultural marker jaapi to the place of origin of the Ahoms. ${ }^{5}$ Das and Rajbanshi $(2006,142)$ note, "It is believed that jaapis were invented in China [. . . ] Chinese jaapis have a pointed top and are round in shape. When they came to Assam via Southeast Asia they assumed a lotus-like, more spread out shape." (translated by the author from Assamese). By choosing jaapis as headwear for the migrant people in her film, Borah makes a visual connection to the ethnic roots of the Ahoms.

Such an allusion connecting Assamese people to China or Southeast Asia is absent in Agarwala's Joymoti, in which jaapis merely add 'generically' Assamese 


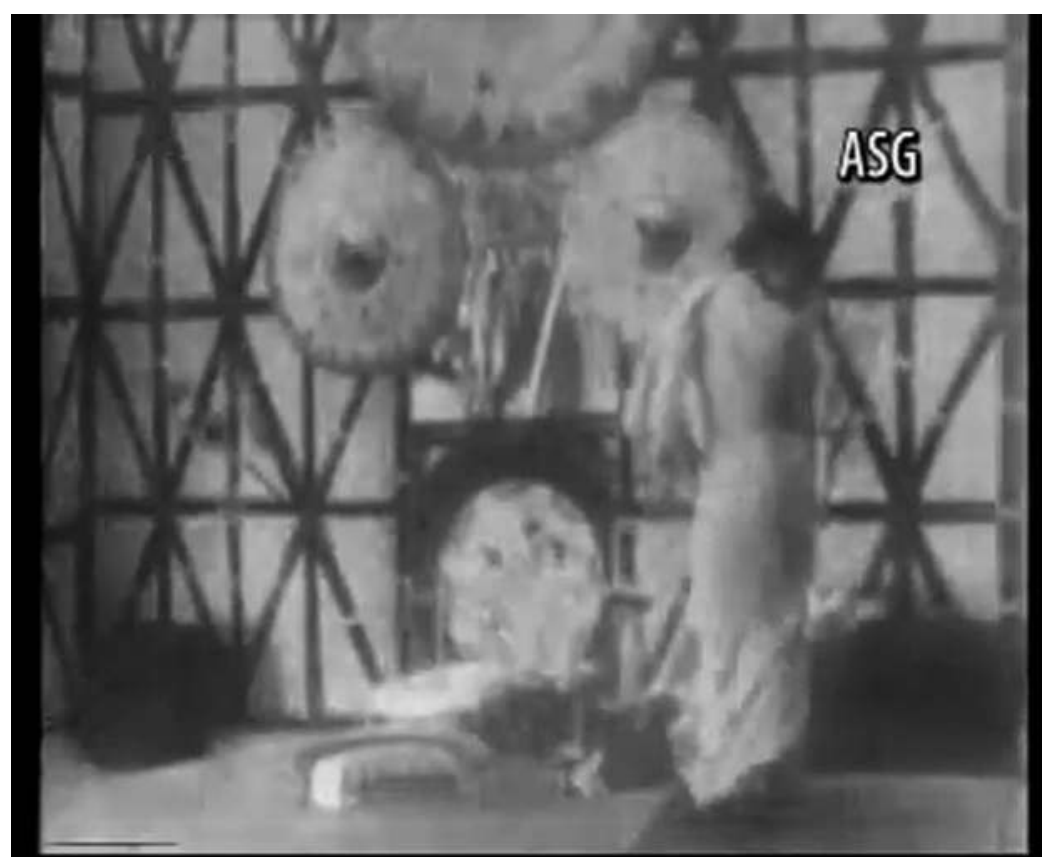

Figure 13.3 Jaapis as background decoration in Agarwala's Joymoti

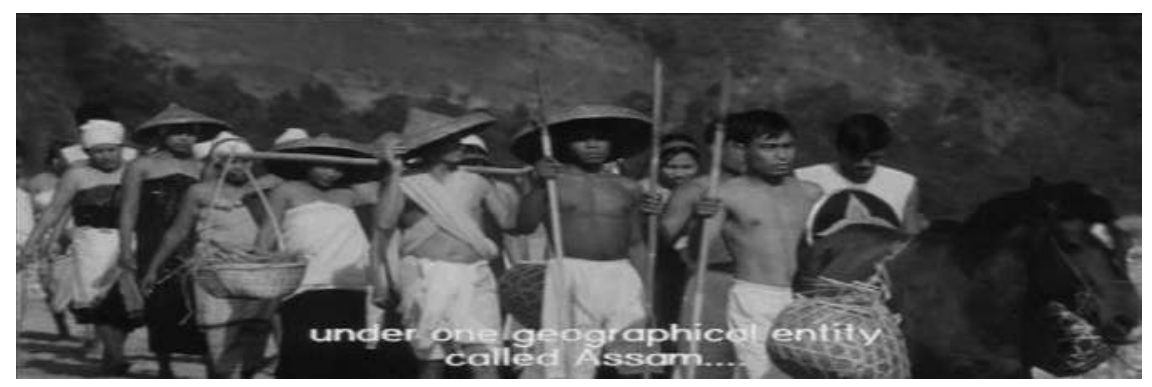

Figure 13.4 Jaapis as headwear in Borah's Joymati

decoration to the background in many scenes. Borah, by contrast, decorates the sets of her film with props that are more specifically symbolic; for example, the dragons shown in the background in the court scenes (see Figure 13.5). Dragons are commonly known to hold a significant place in the religious and cultural beliefs of people in China and other Asian countries like Thailand and Myanmar. By displaying dragons in the background, Borah once again makes a subtle link to the Ahoms' place of origin, underscoring their specific ethnic identity and reminding viewers of their migrant history. Significantly, a dragon is the centrepiece of the 


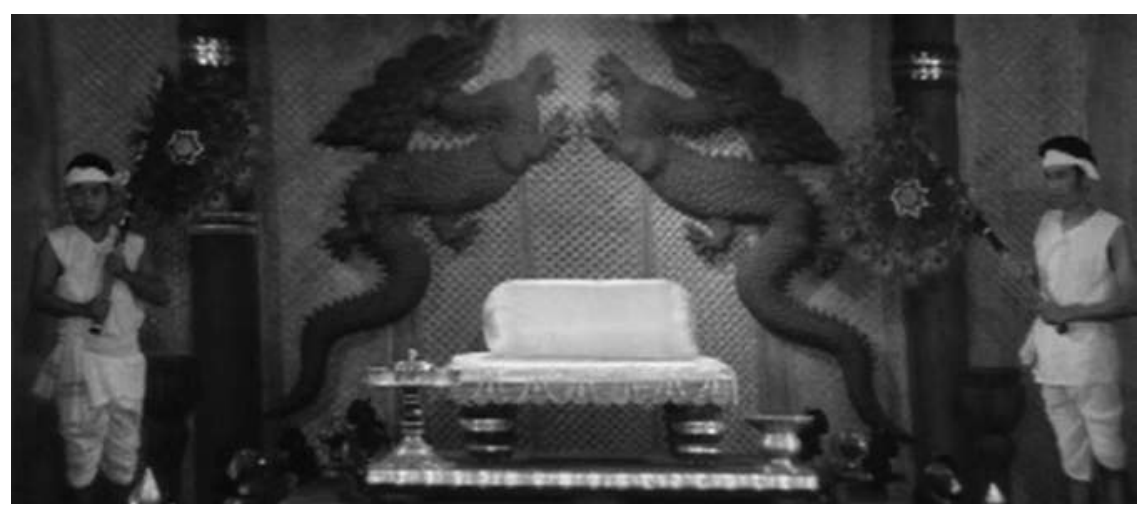

Figure 13.5 Dragons as background decoration in Borah's Joymati

Ahom flag that has been created during the Tai-Ahom identity movement. Saikia observed at a Tai-Ahom ceremony in 1995:

The newly made-up Ahom flag in white cloth had a dragon symbol across it. The dragon is not an Indian symbol, but is widely used in Tibet and China as well as in many parts of northeast Thailand. The dragon symbol of the TaiAhom flag was a way of asserting a non-Indic background and a connection with Asian cultures.

(Saikia 2004, 191)

A further Assamese cultural item, gamosa (also spelled gamocha/gamusa), is a cloth that is used for various purposes including as clothing, as an offering to express respect, and for covering venerated places such as platforms for worship. It is a very important part of Assamese cultural life. In Borah's film, male soldiers wear gamosa as wrap-around clothing; in Figure 13.6 a gamosa is offered before the priests as a part of the religious rituals. Such practices signify respect to the gods, the ancestors, and the elders.

In the past, Ahom soldiers were known to wear the gamosa wrapped around their lower bodies when they went to war. This type of gamosa worn by soldiers is called kabach (also referred to as tangali), and it used to be woven by soldiers' wives the night before a battle. The Ahoms believed that a kabach would protect their husbands from any fatal attack. This was a non-Aryan Ahom belief. By dressing her soldiers in gamosas worn as kabach on the battlefield, Borah references the culture and belief systems of the Ahoms.

The female characters in Agarwala's Joymoti wear mekhela-sador (a wrap-around two-piece dress for women), which is commonly worn by women across Assam and is similar in appearance to female attire in the state of Kerala and to imagery on the walls of the Ajanta caves (Das and Rajbanshi 2006, 28). The costumes worn by 


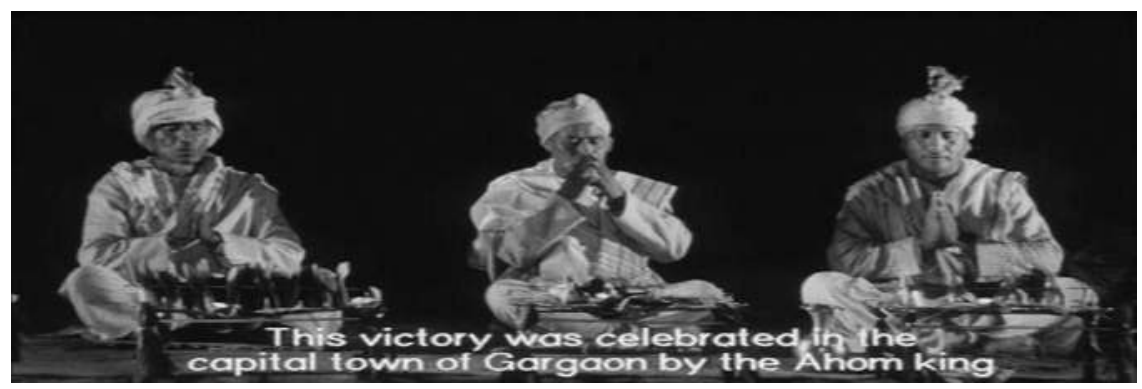

Figure 13.6 Gamosa offered before the priests in Borah's Joymati

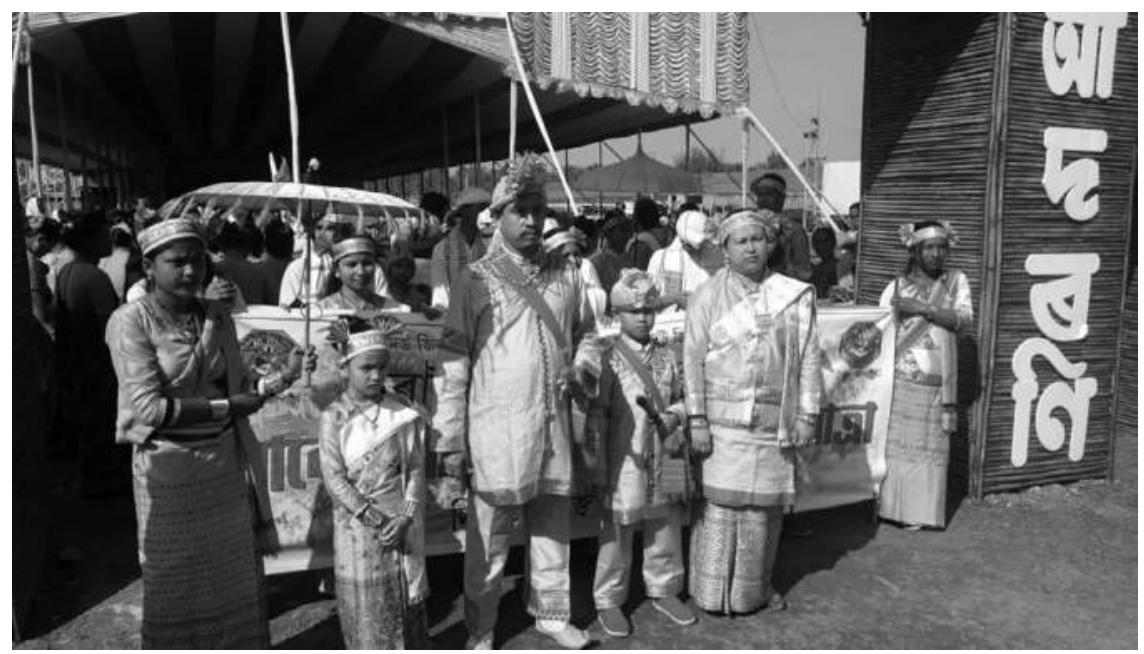

Figure 13.7 Clothing worn by members of the Tai-Ahom community during a cultural event in Sonari, Chraideo, Upper Assam

Source: Photograph by Raktim Gogoi

women in Borah's Joymati, by contrast, are recognisably similar to clothing worn by members of Tai-Ahom organisations, as shown in Figure 13.7. This traditional dress bears similarity to that of many other Asiatic communities in Northeast India.

As she walks towards the king's court, Joymati in Borah's film wears a particular type of sador (a lightweight shawl) that is known to have been worn in the past by royal and upper class Ahom women. Thus, Borah uses costumes in order to evoke a historical setting, while at the same time drawing parallels to clothing that is specific to the contemporary Tai-Ahom community and is worn by its members as a marker of ethnic identity.

Differences between the male costumes in the two films are also noteworthy. In Agarwala's film, Joymati's husband Godapani wears a dhoti (wrapped around the 
lower body) with a short kurta (a type of shirt known as sola suria), which is an outfit considered typical of the Ahoms (based upon depictions in murals, paintings, statues, and other sources). These days, so-called Ahom dress is worn at political demonstrations and during revivalist activities at which the Ahom/Tai-Ahom identity is asserted, as can be seen in Figures 13.8 and 13.9. Similarities can be

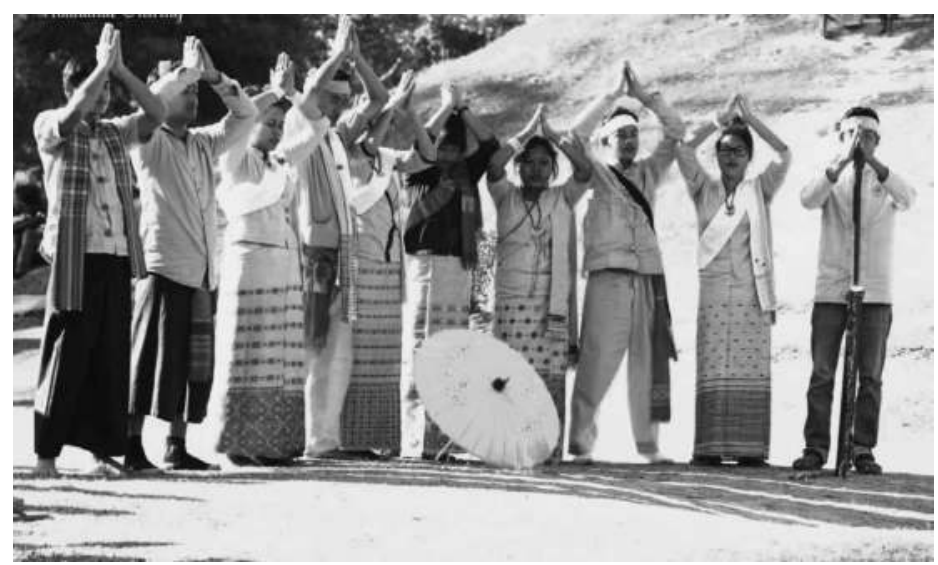

Figure 13.8 Clothing worn by members of the Tai-Ahom community at a religious event in Patsako, upper Assam region

Source: Photograph by Ichangdaw Boruah

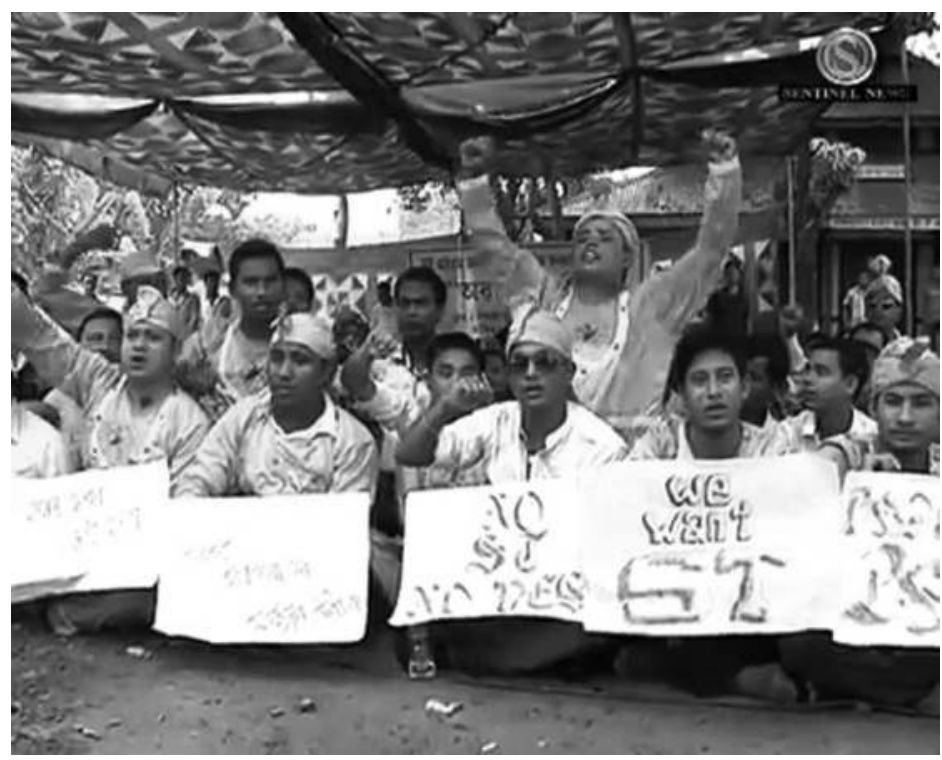

Figure 13.9 Video still from a video posted on YouTube showing a Tai-Ahom demonstration to demand ST status; demonstrators wear traditional clothing as a marker of identity ${ }^{6}$ 


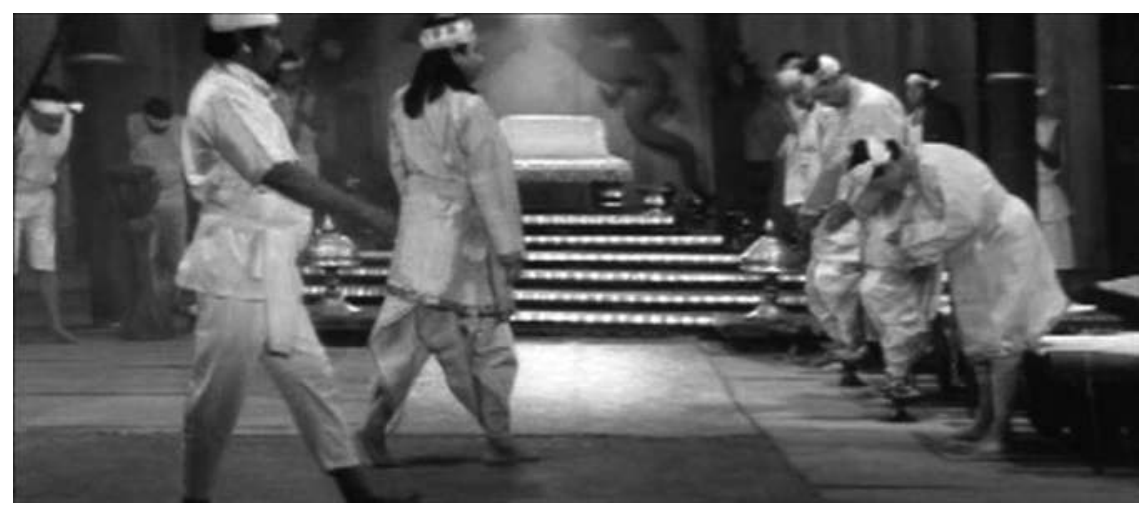

Figure 13.10 Costumes in Borah's Joymati

identified between the clothing worn on such occasions and the costumes in Borah's Joymati shown in Figure 13.10. Thus, Borah's choice of costumes not only identifies her characters as Ahoms, but also reinforces the idea that the clothing worn by Tai-Ahoms on political occasions is specific to Ahom culture and has historical roots. The clothing itself incorporates elements found in male attire from mainland India, Thailand, and Myanmar. This bears tribute to the Ahoms' history of migration, Aryanisation, and assimilation, as well as to recent moves to claim a unique identity in the face of such assimilation.

\section{Situating Joymati}

All of these examples show that Borah's version of the legend more explicitly references Ahom culture than does Agarwala's film, which clearly evokes Assam but is culturally less specific. Needless to say, Agarwala was more restricted technically than Borah. He was obliged to shoot in a (somewhat makeshift) studio rather than on location, so everything that appears in front of his lens was brought especially for the movie - nothing appears by chance in the background. He may have been less cautious of the specific differences between Ahom cultural traits and those of other groups in Assam; Agarwala grew up within the culturally mixed Assamese community of his time. I would like to suggest, however, a political explanation: released during the colonial period in 1935, Agarwala's film Joymoti displayed the props of an Assamese people and culture and did not strive to portray the Ahoms as a unique ethnic group. As an Indian patriot and freedom fighter, Agarwala's principle aim was to present an 'Assamese' cultural identity rooted in history. Even in the 1930s, India's independence movement was not united. As the movement brought them together with communities from other parts of India, Assamese Hindus came to realise how they were seen from the mainland: "as depraved, low-caste Hindus who were polluted due to associations with tribal and 
other religious and ethnic groups of the northeast" (Saikia 2006, 41). Agarwala's priority, then, was to highlight the commonalities (e.g., Hindu and Vaisnavite elements) of Assamese and mainland Indian culture, rather than drawing attention to distinctively Ahom traits. The props and markers of a composite or generic 'Assamese' identity served his needs to invoke a nationalist sentiment that was panIndian and anti-British. Furthermore, Agarwala's narrative focused on the intense relationship between Joymati and her husband Godapani, emphasising how Joymati's sacrifices save Godapani from Syulikfa. Parallels can be drawn between the story of absconding Godapani and events in Agarwala's own life. Agarwala advocated non-violent Gandhian protest that involved self-sacrifice. Agarwala was a follower of Mahatma Gandhi and was arrested and jailed for his involvement in the non-cooperation movement. In his 2006 article, "Filming a Classic", Manoj Barpujari emphasises the political significance of Agarwala's film:

Joymoti actually symbolised the nonviolent resistance of people against the tyranny of the ruler. It was a film of protest, the young princess representing mass disapproval of a tyrannical king. None of his contemporaries in celluloid dared take a dig,-- however symbolic, indirect and draped in historical facts,at the colonial rulers. Thus, the most uncommon attribute of Joymoti should make Jyotiprasad recognized as the first politically conscious film-maker in the history of Indian cinema.

(Barpujari 2006)

Babul Tamuli notes Agarwala's meticulous attention to mise-en-scène:

The set was artistically designed by Jyotiprasad himself using bamboo mats, japis of different sizes, deer horns, buffalo horns, Naga spears, etc. To decorate the Ahom court, he used various royal utensils such as, maihang, hengdang, bhogjara, sarai, bata, saryia, banbata, lota, etc. appropriately.

(Tamuli 2002) ${ }^{7}$

Barpujari (ibid.) sees such attempts on the part of the director as a result of his "conscious effort" to create a "regional realism". He maintains that the film "exploits the historical and traditional nuances peculiar to Assam":

Jyotiprasad not only recreated a very crucial period in the lives of Assamese people, but also the turmoil gripping the 17 th century Ahom kingdom. He took genuine and painstaking efforts to utilise specific Assamese speech-patterns, local idioms; even took into account various religious scripts, myths and legends, consulted eminent persons including those who were closely associated with the Satras - the Vaisnavite sanctuaries, to create his sets and social milieu.

Altaf Mazid, who has produced a digital version of the film from the reels that survived, claims, "Above all else, Joymoti is a nationalist film in its attempt to create a cultural world using the elements of Assamese cultural society" 
(Mazid 2006). ${ }^{8}$ This assertion of culture and heritage coincided with agitation against the British rule, which was seen to be just as despotic as the rule of the Lora Raja. Mazid relates the film's narrative to the patriotic zeal of India's independence movement: "The oppression and passive resistance of the film's story paralleled the situation prevalent in India during 1930s British rule. Thus the realistic depiction in the film was a political approach" (ibid).

By 2006, when Borah's version of Joymati was released, identity politics in Assam had moved on. In 1967, various Ahom community groups had come together to form the 'Ahom Tai Mongolia Parishad', demanding the formation of a separate Mongolian state in Upper Assam "in which Ahom-Tais and the various other tribes would enjoy social recognition and all political rights" (Ahom-Tai Rajya Parishad, Assam Tribune, 3 June 1967, cited in Saikia 2006, 42). Emphasis on the Ahoms' migrant history had led to intensified focus on their Eastern origins and the categorisation of their language within the Tai languages. As what is now known as the Tai-Ahom movement gained force in the 1980s, historical research was conducted to aid the reconstruction of the indigenous identity of the Tai-Ahom community, focusing on cultural elements that distinguished it from other communities in Assam. More than language or territorial identity, ethnicity, indigeneity, and origins became the basis of this constructed identity. In this context, Borah's Joymati appears as an assertive narrative that uses visual media and symbolically loaded props to portray the cultural history of the Tai-Ahom community. I believe that generically 'Assamese' props referencing Aryanised aspects of Assamese culture, like those in Agarwala's film, may not be acceptable to a contemporary Tai-Ahom audience. To clarify the implications of this, I will now offer some insights into contemporary politics of identity in Assam.

\section{From 'Assamese' to 'Tai-Ahom'}

What characterises an 'Assamese' identity is a matter of contentious debate, often based upon vague assumptions and populist notions. Attempts to define such an identity are sometimes based on territory and sometimes on language. On the basis of territory, every resident of Assam could be considered Assamese - but how long should they have lived there in order to qualify as 'resident'? Bengali-speaking Muslims are just one of the groups that has lived there for generations and yet still been accused of being 'outsiders' and subjected to extreme discrimination. Nor can linguistics offer a clear definition: the language known as Assamese or Asamiya/Ôxômiya reflects the name of the state, but it is just one of several official languages and many other languages that are spoken by members of different linguistic (and ethnic) communities in Assam. These communities have migrated to and settled in Assam over centuries, resulting in the diversity that characterises the state today. Who arrived first might appear to be a matter only relevant to the past, but in the context of demands for ST status, the assignment of which are often related to notions of territorial indigeneity, it is an issue that generates a great deal of research, debate, and conflict. In seeking aspects of 'Assameseness', it may be more fruitful to consider cultural practices that are shared across different 
communities in Assam. For example, disparate groups celebrate the quintessentially Assamese festival of Bihu (an agrarian festival held three times a year with different rituals), engage in other specific agrarian practices (like praying to the land for a good harvest), use jaapi and xorai, chew betel nut and leaf, and share a 'common heritage'. Authors such as Yasmin Saikia and Lipi Ghosh argue that the idea of an 'Assamese' identity is a colonial construct and was an "instrumentalist identity" constructed solely for the administrative purposes of the British. Saikia elaborates:

In the margins of Assam, colonials "found" Tai-Ahoms but could not fit them into the established categories of known castes and religious groups. Thus they dismissed them as an "unknowable" community and soon declared them "dead." For convenience, a new category, "Assamese" was devised, and everyone in the region of Assam was christened with this new name.

(Saikia 2004, 20)

Ghosh (2005) adds:

An important landmark in the history of the Ahoms happened in 1931 when the term 'Ahom' was deliberately dropped from the official Census by the colonial British rulers in India to destroy the identity of the former ruling class people of Assam. Since then, all Ahoms in India have been referred to as 'Assamese'.

Ghosh (2005)

According to these arguments, the colonially constructed 'Assamese' identity became a composite one that glossed over differences of history, religion, and ethnicity. However, this multi-ethnic composite identity gave way to vicious identity politics with the "Bangal-Kheda" ("drive away the Bengali migrants") agitations in the 1980s, which stoked up anti-Bengali sentiment by emphasising linguistic differences. Until the 1980s, many people who now identify themselves as Tai-Ahom had been proud to call themselves 'Assamese', referencing the idea of a composite Assamese identity. Since the late 1970s, however, TaiAhoms have begun demanding classification as a Scheduled Tribe. ${ }^{9}$ In order to back up their claims, they have drawn attention to the fact that Tai-Ahoms share numerous cultural traits with other janajatis/tribes in Assam. The current status of many sub-groups within the Ahom community is that of OBC (Other Backward Classes). Tai-Ahoms today may identify themselves as Assamese/Ôxômiya, and/or they can focus on ethnic difference, identifying exclusively as Tai-Ahom. At times they may strategically emphasise similarities between their culture and that of other recognised Scheduled Tribes, at other times differences are highlighted. Along with political demands and agitations, a revivalist movement has been inciting participation in cultural festivals such as Me-Dem-Ma-Phi or Sukafa Day and has promoted a Tai-Ahom religion called Phra-Lung " "for establishing the Tai-Ahom as separate from the Assamese and by extension 
Indians" (Saikia 2006, 38). Saikia draws a connection between these revivalist activities and the Tai-Ahoms' demand for Scheduled Tribe status: "Tai-Ahom leaders who see the confirmation of ST status as a possibility for gaining several benefits and privileges were willing to put on a display of worship if it would help them make claims of tribalism" (ibid, 49).

A recent trend of changing surnames provides a further example of the processes at large here. In recent years, Hindu Brahmin upper classes have been adopting their gotra names ${ }^{11}$ as surnames (for example Kaushik, Bhardwaj, Garg, etc.), in order to highlight their connection to mainland India, whereas members of TaiAhom communities have been following Tai-Ahom naming traditions (e.g., using Tai as a surname, and the prefix Chao for males and Nang for females) - as a way of drawing attention to their background. By contrast, many members of the subnationalist group ULFA (United Liberation Front of Assam) ${ }^{12}$ have adopted the common surname "Asom" in place of other surnames that reveal ethnic background. This is apparently a strategic move intended to foreground a composite 'Assamese' identity over ethnic and linguistic differences. This is just one example of the fluidity and, at times, apparently contradictory nature of ethnic and cultural identity politics in Assam and other states in India.

As mentioned above, Ahoms came to Assam as migrants; present-day TaiAhoms do not claim to be indigenous to the territory. Their origins in Southeast Asia, China, and Burma add a transnational dimension to their identity movement. In recent years, growing interest in the connections between Tai-Ahoms resident in Assam with those in Thailand, Myanmar, and China has sparked research that seeks to confirm migration theories based on racial features. At the same time, non-Aryan/non-Hindu aspects of Tai-Ahom culture are emphasised, as seen, for example, in the promotion of the Phra Lung religion and in the distinctive clothing worn by participants in Tai-Ahom festivities in upper Assam: the dress is clearly unlike the usual Assamese attire. As they focus on their 'roots', Tai-Ahoms draw on the narratives and handed-down memories that recount the advent of the Ahoms and the 'Golden age of Ahom rulers'. The Buranjis (Royal Chronicles) are referred to as authoritative texts in the revival/construction of this Tai-Ahom identity, which is pitted against that of the wider composite 'Assamese' community. In Borah's version of the Joymati legend, Joymati is portrayed as an empowered and visionary Ahom woman:

A woman who is regarded as the paragon of self-sacrifice had changed the course of Ahom history with her great political foresight. She was Joymati the intelligent and farsighted Ahom princess who had sacrificed her life so that the chaotic and tumultuous political upheavals of the period of self-centred officials, like Laluksola Borphukan, might end restoring stability and peace in the kingdom. ${ }^{13}$

In her adaptation of the legend, the feminist and activist filmmaker Borah chose to explore the politics of the state and Joymati's role in it, unlike Agarwala, who had focused on the relationship between Godapani and Joymati. Borah's emphasis 
on fighting for political empowerment presents a narrative guaranteed to resonate with the Tai-Ahom identity movement, which has been fuelled by a sense of deprivation and marginalisation because of 'neo-colonial' policies in the post-independence period. Tai-Ahoms are just one group among many that are dissatisfied with the political situation in Assam. Northeast India as a region is well known for calls of separatism and instances of violent insurgency, which have frequently been countered by institutional violence from police and armed forces. ${ }^{14}$

The language spoken in both Agarwala's Joymoti and Borah's Joymati is Assamese (Asamiya/Ôxômiya), which is the most widely claimed first language in Assam, spoken by over 14 million native speakers, and used by many others in the wider Northeast region. Assamese is classified as an Indo-Aryan language that has not only absorbed influences from Sanskrit, but also from Tibeto-Burman and Tai languages since the 5th century A.D. (Saikia 2004, 5; referencing Medhi 1988, 42). Like all languages, Assamese has evolved and been adapted over history, as its speakers encountered the speakers of other languages (e.g., the Ahom invaders) as well as new situations and contexts.

A parallel can be drawn to the symbolic language of cultural props established by Agarwala and Borah in their films: culturally significant objects are imbued with different meanings according to the context in which they are viewed. Agarwala's film was a celebration of 'Assamese' culture, and a successful one, as reflected in the praise it received from Gopinath Bordoloi, the then Prime Minister of undivided Assam and later the state's Chief Minister following Independence:

The artistic skill of the people of Assam in the past, the grandeur of the King's temples, etc. and the costumes of the king, the nobleman and the common people, the weapons used etc have been so well displayed that anybody who does not see this film will be poorer in his knowledge and appreciation of the life and times of Assam of the bygone days..$^{15}$

In a newspaper article about his visit to Agarwala's studio during production, Harinarayan Barua wrote that the film

would uphold the advanced culture of the people of ancient Assam when compared to the cultures of the other communities and also uphold the political power of the Ahom ministers in the eyes of the rest of the world. This will also be matter of great pride for the Assamese community. At the same time, it would also help the Assamese community to recollect their ancient culture. ${ }^{16}$

According to Barua, Assamese and Ahom "ancient culture" were one and the same: a source of "great pride for the Assamese community". Hence, as discussed above, the xorai that features in Agarwala's film is primarily an Assamese object, used to make a religious offering in a practice that dates back to pre-colonial times and is first and foremost indigenous to India - and not to any sub-group. The way that xorais are used in Borah's film, by contrast, references a practice more 
specifically associated to the exact period that Borah takes pains to represent as precisely as possible: the golden age of the Ahom kingdom. Whereas Agarwala places jaapi in the background of his sets to evoke an Assamese setting, Borah strategically sets jaapi on the heads of arriving Ahom migrants, inspiring her audience to link the headwear to its Eastern origins. This is supported by the very specific way that the male soldiers in her film are shown to wear gamosa as kabach, not referencing just any aspect of the Ahoms' belief system, but one that relates to their pre-eminence in warfare. The costumes of her female characters take a step further along this symbolic path: they confirm (or establish) a link between the clothing worn by contemporary members of the Tai-Ahom community and that worn by their ruling class ancestors.

My analysis has shown, then, that the meanings attached to individual objects of cultural significance are not fixed but can vary across time and context. To infer such meanings it is therefore necessary to pay close attention to the practices that accompany the objects. In this way, the effects of macro-political contexts can be identified even at a micro level of detail in the way that individual props are staged within individual films. Moreover, meanings are not fixed: viewers' perceptions of films, their narratives and mise-en-scène are not inscribed in the films themselves, but rather brought forth anew with every viewing, as different viewers interpret what they see in relation to their own knowledge, experiences, associations - and aspirations.

\section{Notes}

1 See, among others, Goswami (2014).

2 'Props' (abbreviated from 'property') on film sets are the moveable objects - including furniture, electronic devices, vehicles, and so on - which, in addition to sets and locations, are the responsibility of the art department. Such objects effectively 'prop up' or support the atmosphere created by a film's mise-en-scène. Although costumes and background decoration are usually considered separately, I will include them in my analysis here, as they also contribute significantly to a film's visual impact.

3 The original print of Agarwala's Joymoti is lost. It is partly digitised by Altaf Mazid with the footage of the films from the documentary "Rupkonwar Jyoriprasad aru Joymoti", which was produced by Hridayananda Agarwalla and directed by Bhupen Hazarika in 1976.

4 While Europeans generally associate it with Nazism, the term 'Aryanisation' in the Indian context refers to the adoption/assimilation of cultural traits associated with speakers of Indo-Aryan languages. This often includes acceptance of Hinduism or Hinduistic religious practices, since Indo-Aryan languages are rooted in Sanskrit, the language of the oldest Hindu texts.

5 The Ahoms' exact place of origin is a matter of ongoing debate. On her website, Borah states that the first Ahom king, Sukafa, originated from the Yunan province of China and came to invade Assam via Upper Myanmar/Burma. (https://manjuborah.com/ joymati/ [accessed on 30.1.2017]). Saikia $(2006,36)$ notes that the Buranjis (premodern chronicles from the region) trace Sukapha's family to Upper Burma.

6 www.youtube.com/watch?v=IXw1qY34oUQ [accessed on 28.3.2016]

7 Tamuli (2002): "The Making of Joymoti" article originally published in The Assam Tribune in 2002.

8 Mazid (2006) "Joymoti: The First Radical Film of India" article originally published by himalmag.com. 
9 Enshrined in the Indian Constitution is the allocation of certain privileges (e.g., 'reserved' seats in government establishments and institutions) to members of communities deemed to have been historically repressed and hence in need of 'upliftment'/ positive discrimination. Such communities include Scheduled Tribes (STs), Scheduled Castes (SCs), and Other Backward Classes (OBCs) and are designated by individual states according to criteria that are not necessarily clear-cut and are often fiercely contended. See The Constitution of India: http://lawmin.nic.in/ld/subord/rule9a.htm [accessed on 30.1.2017].

10 See Saikia (2006) on the Tai-Ahoms" "production" of the Phra Lung religion.

11 "'[A] caste 'surname,' e.g. the name of a subcaste or gotra or some other name associated with a particular caste" (Vatuk 1969, 256).

12 See "ULFA Mandates ASOM as Common Surname", Times of Assam, 20 January 2012. The ULFA is one of the most prominent political organisations calling for Assamese independence from India. The Government of India classifies it as a terrorist organisation.

13 Borah, Manju. n.d. “Joymati”. https://manjuborah.com/joymati/ [accessed on 30.1.2017].

14 Despite decades of protests and campaigning, the AFSPA (Armed Forces (Special Powers) Act) has been in force since 1958 in many parts of Northeast India as a so-called counter-insurgency measure. Human rights' organisations continue to criticise the legislature, which allegedly provides police and armed forces immunity for extrajudicial killings. See, for example, Human Rights Watch's World Report 2017, India.

15 Bordoloi (1935), published in the bi-weekly newspaper Assamiya (or Asomiya), quoted in Sharma (2008).

16 Barua (1934): "Chitrabonot Erati-Chalachitra Jagatot Assamiyar Uddyam" ("A night in Chitrabon - Effort of an Assamese in the cinema world"), article published in the Teenidiniya Assamiya, quoted in Sharma (2008).

\section{References}

Ahom-Tai Rajya Parishad. 1967. The Assam Tribune, June 3. n.p.

Barpujari, Manoj. 2006. "Filming a Classic." Originally published in The Assam Tribune, September. https://web.archive.org/web/20091027150751/www.geocities.com/bipuljyoti/ cinema/joymoti/joymoti02.html. Accessed on 30 January 2017.

Borah, Manju. n.d. "Joymati." https://manjuborah.com/joymati/. Accessed on 30 January 2017. Bose, Ashish. 1998. Demographic Diversity of India: 1991 Census, State, and District Level Data: A Reference Book. New Delhi: B.R. Publishing.

The Constitution of India. http://lawmin.nic.in/ld/subord/rule9a.htm. Accessed on 30 January 2017.

Das, Narayan, and Rajbanshi Paramananda (eds.). 2006. Axomiya Sanskritir Kanika. (Elements of Assamese Culture). Guwahati: Chandra Prakash.

Dutta, Dilip Kumar. 1981 [2014]. Bhupen Hazarikar Geet aru Jibon Rath. Guwahati. Ananta Hazarika of M/S. Banalata on behalf of Bhupen Hazarika Foundation.

Ghosh. 2005. "Tai Cultural Heritage in Northeast India: A Study of the Tai-Ahoms." www. rauz.net.cn/bbs/dv_rss_xhtml_38_11248_10.html. Accessed on 30 January 2017.

Goswami, Uddipana. 2014. Conflict and Reconciliation: The Politics of Ethnicity in Assam. New Delhi and Abingdon: Routledge.

Human Rights Watch. 2017. World Report 2017: India. www.hrw.org/world-report/2017/ country-chapters/india. Accessed on 30 January 2017.

Mazid, Altaf. 2006. "Joymoti: The First Radical Film of India." Originally published by himalmag.com. https:/web.archive.org/web/20091027150749/www.geocities.com/ bipuljyoti/cinema/joymoti/joymoti03.html. Accessed on 30 January 2017. 
Medhi, Kaliram. 1988. Assamese Grammar and Origin of the Assamese Language. Guwahati: Publication Board, Assam.

Saikia, Yasmin. 2004. Fragmented Memories: Struggling to Be Tai-Ahom in India. Durham and London: Duke University Press.

Saikia, Yasmin. 2006. "Religion, Nostalgia, and Memory: Making an Ancient and Recent Tai-Ahom Identity in Assam and Thailand." In The Journal of Asian Studies 65 (1): 33-60.

Sharma, Bobbeeta. 2008. "Joimoti: A Cultural Statement." Originally published in The Assam Tribune, March. https://web.archive.org/web/20091027150754/www.geocities. com/bipuljyoti/cinema/joymoti/joymoti05.html. Accessed on 30 January 2017.

Tamuli, Babul. 2002. "The Making of Joymoti." Originally published in The Assam Tribune.www.reocities.com/Athens/Parthenon/4526/cinema/joymoti/joymoti.html. Accessed on 30 January 2017.

Times of Assam Bureau. 2012. "ULFA Mandates ASOM as Common Surname." Times of Assam, January 20. www.timesofassam.com/headlines/ulfa-mandates-asom-as-commonsurname/. Accessed on 25 November 2018.

Vatuk, Sylvia. 1969. "Reference, Address, and Fictive Kinship in Urban North India." Ethnology 8 (3): 255-272.

\section{Filmography}

Agarwala, Jyoti Prasad. 1935. Joymoti. Chitralekha Movietone.

Borah, Manju. 2006. Joymati. Guwahati: AAAS Productions. 


\title{
14 Polyandry, sexuality and the (mis)representation of indigenous women on Indian screens. The film Sonam: The Fortunate One
}

\author{
Mara Matta
}

\section{Introduction}

In the last few decades, a growing number of international film festivals have given space to the output of South Asian cinemas, often showcasing films from the Indian subcontinent. Yet the homogenising national label of Indian films often glosses over a complex history of filmmaking at the margins of the nation-state, in regions far from the centre of political power, where indigenous people often constitute the majority of the population. One such region is India's Northeast, known for its tremendous ethnic and linguistic diversity, but perhaps less famous for its outstanding literary, theatrical and cinematic productions. ${ }^{1}$ There, a polyphonic indigenous cinema ${ }^{2}$ is developing alongside a newly found awareness of the importance of strategically deploying oral, literary and visual narratives as a means to construct thought-provoking and inspiring indigenous oratures, literatures and cinemas. Filmmaking has a special role to play along the lines of what bell hooks has called an "oppositional gaze" (1992; 1999), a programme of active resistance that engages the visual arts in a social and political battle to reclaim and reframe voice, space and images.

Notwithstanding the growing interest in indigeneity, subaltern history and processes of identity formation in South Asia, the issue of the visual representation of the indigenous peoples and the diverse cultures of India's Northeast has remained largely overlooked, and little has been written so far on the region's cinematic output. Much needs to be done to fully apprehend the role of indigenous cinema as a cultural and political strategic field capable of sustaining forms of counterhegemonic discourses. Films and documentaries by indigenous filmmakers - and by others willing to ethically engage with the complex histories and sensitive issues that characterise the discourses around the image of the Northeast - may be instrumental in developing oppositional gazes that can effectively address, contrast and possibly even subvert biased narratives of race, ethnicity, class and gender. If, on one hand, the problem of prejudiced and stereotyped representations of indigenous people in Indian cinema can be linked to Bollywood as a powerful meaningmaking machine that generates and nurtures tropes and discourses that do not simply reflect a hegemonic perspective, but rather help create one - producing 
what we might call a voyeuristic Indian spectator - then, on the other hand, it would be reductive to put all the blame on commercial Hindi films for inventing and disseminating stereotyped images of the exoticised, eroticised, wild and childlike tribal. ${ }^{3}$ India's parallel cinemas ${ }^{4}$ have also supported the reification of the image of the tribal woman as a highly sexualised creature, charmingly distant from civilisation. Validating the portrayal of indigenous women as creatures of untamed female sexuality, even independent films often offer disturbingly simplistic portrayals of the indigenous woman as a figure whose carnal instincts titillate the voyeuristic eye of the spectator. In this regard, what Elise Marubbio points out in her book Killing the Indian Maiden (2006) - in which she addresses the problematic representation of Native American women in US-American films - can also be applied to the context of Indian cinematic representations of indigenous women. In the preface to her book, Marubbio argues that the relevance of her work "lies in its dedication to understanding the ways in which our culture utilizes racialized, gendered, and sexualized bodies, especially female bodies, as sites for inscribing difference" (Marubbio 2006: x). Looking at films as powerful cultural texts informed by "the complex web of power relations that exists in the cultural arena" (ibid.), Marubbio offers her take on cinema as a male-dominated industry, in which films, "as a voyeuristic medium, offer a lens through which to analyze the psychological and sociological structures created through representations of subservient, simplistic, self-destructive Others" (ibid.). This last statement on voyeurism reminds us of Norman Denzin's powerful résumé of the current postmodern era: as "a visual, cinematic age" in which the "voyeur is the iconic, postmodern self" $(1995,1)$. Denzin goes so far as to implicate all of us: as "voyeurs all" floating in a sea of symbols, "products of the cinematic gaze" (ibid.).

In this cinematic context, I posit that the film Sonam: The Fortunate One (2005) by the Assamese director Ahsan Muzid offers an interesting case study of an independent Indian auteur film that, despite claiming to portray the life of the Brokpa tribes that live in the West Kameng and Tawang Districts of Arunachal Pradesh, ends up exposing its own rather neo-colonial and voyeuristic gaze as it feasts on the private and intimate lives of a little-known indigenous group. The story revolves around the fate of Sonam, a young Brokpa woman of the Monpa tribe of Arunachal Pradesh, which is culturally and religiously affiliated to the Tibetosphere. Sonam, despite her auspicious name, ${ }^{5}$ ends up meeting a very unfortunate and premature death, portrayed as a karmic punishment for her 'sinful' life. ${ }^{6}$ Shot in the Monpa language with a cast of non-professional actors, the film, according to filmmaker Ahsan Muzid, aimed to portray "polyandry in a small community called Brokpas, the yak shepherds of Arunachal Pradesh" (Ghosh 2007). However, misrepresenting polyandry as a sort of whimsical cicisbeism $^{7}$ and encouraging a voyeuristic viewing perspective by apparently using the camera as a peephole to pry on the intimate moments of Sonam's and other Brokpa women's lives, the film ultimately fails to show the complex social and cultural practices of the Brokpas and instead simply reinforces the stereotypical exotic/erotic images of indigenous women ${ }^{8}$ familiar from other Indian screens. Projecting women like Sonam as instances of debauchery, unbridled sexuality and untamed "celluloid maidens" 
(Marubbio 2006), this film offers its viewers a cultural text with a very biased political message: the demise of certain cultural practices, portrayed as morally questionable and hence in need of suppression, is simplistically but effectively symbolised by the death of the 'deviant woman' who indulged in them. Her fetishized body, initially portrayed as an object of exoticised and racialised desire, is ravaged by illness and ultimately destroyed, making way for the virginal yet maternal body of the good celluloid princess, the tribal and Indian maiden whose virtuosity and controlled sexuality comply with the national (patriarchal) ideal of a sublimated femininity, capable of upholding the hegemonic social, political and moral order. The juxtaposition of sequences depicting 'real' life in ethnographic detail - with representation of religious rituals, dance performances and other stereotypical images of singing and dancing, drinking and flirting happy-go-lucky tribals - and the fictional construction of a story of love and betrayal against the backdrop of the Himalayas result in a film that uses the intrusive eye of the camera to lure the audience into a faraway world where frequent sexual encounters and dangerous liaisons seems to constitute the main activity in Brokpa women's lives.

If, as Denzin has stated, “[t]he voyeur's perverse desire to look and see what others are unable, or unwilling, to see is always directed to a valued, cultural end and structured by personal and social motives" $(1995,1)$, we may wish to ask what these motives are in the context of contemporary India's (mis)representations of indigenous women on screen. In particular, why is it that even an independent Assamese filmmaker such as Ahsan Muzid, whose film was lauded for being the first feature film in the Monpa language, does not challenge the stereotypical image of the 'loose tribal woman' found repeatedly in more mainstream Indian films? Is Thongchi's novel - as the main text of reference - to be blamed for such a onedimensional film, by providing justification for a non-indigenous filmmaker to shoot [at] tribal cultures from his privileged position? Is this project a further example of the cultural practices of inner orientalism that characterise the portrayal of subaltern groups in the context of contemporary India? What "valued, cultural end" does the film strive for? And in what ways do some indigenous intellectuals support certain moralistic undertones, which collude in validating neo-colonial and neo-orientalist representations of indigenous people and cultures on Indian screens?

\section{Of biased prefaces and misleading premises}

To address these important questions, we must necessarily begin with the novel Sonam by Yeshe Dorjee Thongchi, which provided the inspiration for Ahsan Muzid's cinematic adaptation. The novel revolves around the story of a young and beautiful Brokpa woman, Sonam, who is happily married to a loving and affectionate husband, Lobsang. Lobsang is a shepherd who divides his time between working hard on the mountain farm, where he is accompanied by his friend Tikoro and his loyal dog Dambu, and leisure at his home in the village, where he is cared for by his pretty wife Sonam. During one of Lobsang's long stays at the mountain 
farm, Sonam gives in to the sexual advances of another man, the good-for-nothing Pema Wangchu. Upon discovering the romantic relationship between Sonam and Pema, Lobsang is saddened but decides to take Sonam's lover into his family, making Pema a co-husband. This decision, instead of saving their relationship, ruins their familial harmony and ultimately destroys Sonam, who dies of illness. The novel (in its second edition) ends with Sonam's death and Lobsang's decision to take their children to Tawang monastery, which is averted by the intervention of Sonam's sister Dholma, who becomes a loving mother to the kids and a new wife to Lobsang.

Thongchi's note to the first English translation (2001) of the novel offers some insights into the background to the story. Rather than being the product of the author's direct experience of life among the Brokpas, it is based on an "anecdote on the plight of men amongst the shepherds living on the high mountainous regions of the Himalayas who shared a common wife" (Thongchi 2001, 7). Yeshe Dorjee Thongchi is a Sherdukpen ${ }^{9}$ and is not directly acquainted with the customs of the semi-nomadic Brokpa pastoralists that live in the West Kameng and Tawang Districts of Arunachal portrayed in the novel. Thongchi started to write Sonam at the beginning of the 1970s. The story began appearing in serialised form in 1976-1977 in the Assamese magazine Manoranjan, gaining "immense popularity amongst the readers" (ibid.) The book was then translated into English by Mridula Borooah, a lecturer of English at a girls' college in Guwahati and herself a writer in the Assamese language. The translated version was published in 2001 with a translator's note in which Borooah introduced the book with some noteworthy comments. Beginning with a rather clichéd description of the novel's setting and its inhabitants, Borooah describes Arunachal Pradesh as a "land of down-lit mountains, lush green forests, deep river valleys and breathtaking plateaus" (Borooah, in Thongchi 2001, 9), with "an endless variety of scenic beauty, people and culture forms" (ibid.). Referring to the indigenous groups (more than 25) that live in the region, she writes,

By nature they are simple and warm hearted. Untouched and yet, unspoiled by the rigors of modernity and present day existence, the people of Arunachal have been left to their own lot, thus preserving their rich cultural heritage in pristine form. Things are however changing rapidly.

(ibid., 9-10)

While conflating the natural beauty of the place and the people with the usual Shangri-La stereotype of an unspoiled Paradise on Earth that has coloured much of the literature related to the Tibetosphere,$^{10}$ Borooah is quick to take a certain 'progressive view' of the changes that are taking place in Arunachal Pradesh, commending the role of literature and translation in "breaking cultural barriers, and bringing far-flung areas closer to each other" (ibid., 10). She praises Thongchi's "strong sense of social commitment" (ibid.), expressed in his novel Sonam as a charming story rooted in the indigenous culture of the Monpa tribes, which notwithstanding retains a universal appeal due to its main theme of love and betrayal. 
Up to this point, the reader does not sense any disturbingly moralistic undertone, despite the rather patronising description of the Brokpas as naturally simpleminded; a recurrent representation of indigenous people as child-like and intrinsically close to Nature that smacks of colonial tones. Far more alarming is the subsequent judgemental and deeply problematic reading of the custom of polyandry among the Brokpas, described as a deviant behaviour which, according to Borooah, causes social conflict:

The roots of social conflict in the families can be traced to their insolubility with prevalent social customs. The individual becomes the victim in such societies where polygamy and polyandry are socially permissible. The universal truth about man-woman relationships is that one is complementary to the other, and this unique bond is essentially biological in nature. According to this rule of nature, living together in pairs and not allowing the entry of a third one, is discernible also in the animal kingdom. Even if social customs lawfully allow the involvement of a third person or if somebody succumbs temporarily to an emotional fallibility, the foundation of a man-woman relationship is bound to re-establish itself.

(ibid., 10-11; emphasis mine)

While there are plenty of reasons to challenge Mridula Borooah's definitions of what is 'natural' or 'unnatural' when it comes to relationships among human beings - quite apart from her recourse to biology to justify what she sees as the 'universal truth' of heterosexual monogamous marriage - it is truly unfortunate that an intellectual and an educator such as Ms Borooah limits her analysis of polyandry to a simple rejection. Ignoring all the possible historical, socioeconomic and religious factors that influence complex and heterogeneous practices, she presents her own moralistic view of the practice of khor dekpa: it is a deviant phenomenon that produces 'social conflict'. While she could have found good reasons to question the viability of the practice in contemporary times - many young people nowadays are less inclined to follow it - I find her critique patronising and problematic. Borooah is clearly in favour of the demise of the custom - with the reinstatement of some sort of "rule of nature" as the "foundation of a man-woman relationship" (ibid.) - simply because she judges it to be unnatural and flawed from her own moral perspective.

Perhaps Thongchi had not so consciously intended the novel to be read as a moralistic tale denouncing 'unnatural practices'. He knew little of the customs of the Brokpas before writing the novel (Dutta 2011); hence, when preparing a second edition, he felt the need to revise it. In the revised edition of Sonam (2005), Thongchi decided not only to add some Monpa words, but also to change the end of the story, supposedly to convey a more emic view. However, writing in a regionally hegemonic language such as Assamese and simply inserting some Monpa words to add ethnic flavour to the story has not resulted in a more authentic portrayal of the lives and practices of the Brokpas. The new ending of the novel suggests that Thongchi was catering to a general readership that he assumed would be largely 
unacquainted with the Brokpas' way of life and customs, yet nonetheless fascinated by their sexual and matrimonial practices, such as polyandry, which is not unheard of in India but certainly less common than monogamy or polygamy.

Thongchi takes it upon himself to chastise the immorality of this customary practice, constructing his female Brokpa characters as either the epitome of mischievous and treacherous womanhood - in the figure of the beautiful but unrestrained Sonam - or a model of religiously sanctioned behaviour - personified by Sonam's sister Tsering Dholma. It is modest and chaste Dholma that the novel consecrates as the new progressive woman, so perfect that she can nurture and breastfeed her dead sister's children despite being an unmarried girl with no children of her own. Her religious devotion is such that she can be a virgin mother, capable of persuading Lobsang that she is his rightful and loyal companion. As she resolves in the revised ending of the novel:

My sister warned me not to repeat the mistake made by her. She advised me not to get involved with another man to encourage khor dekpa. ${ }^{11}$

[...]

We won't live as Brokpas anymore. We will go to Tawang and buy some land to cultivate. If we remain Brokpas, I will not always be able to accompany you. I will be compelled to perform khor depka again with someone else.

(Thongchi 2005, 128; cited in Dutta 2011, 242)

Whereas in the first edition of Sonam, Lobsang chose to take his children to the Tawang monastery to make them a monk and a nun, fulfilling a religious promise and vowing to dedicate his entire life to the worship of Lord Buddha, in the new edition, as Dutta aptly observes, there is "a new urge in Thongchi to reform society" $(2011,243)$. Written by an author who belongs to the same Tibetan cultural and religious sphere, but not to the ethnic group portrayed, the novel Sonam betrays an agenda that is disturbingly in line with that of educational and developmental projects carried out in such areas, where the emphasis is always on reforming and leading indigenous people 'to progress', that is, towards the ethos of an increasingly mono-cultural Indian state that needs more than a token plurality of voices if it is to embrace cultural pluralism. Despite the shield of self-representation that protects indigenous authors who claim to write along ethnic and emic lines, it remains unclear whose voices we keep hearing through their works. Offering the character Dholma as a 'new model' of a progressive Brokpa woman, the Sherdukpen writer Yeshe Dorjee Thongchi apparently feels justified to shoot [at] indigenous cultures from his own rather privileged and structurally empowered position.

The film adaptation of the novel by Assamese director Ahsan Muzid goes even further, casting more than 20 local Brokpa men and women (and one Sikkimese actor in the role of Pema Wangchu) in a movie that ultimately mocks their culture and practices in a one-dimensional representation of debauchery, infidelity and unbridled sexuality. As Sanjib Baruah (2005b) has rightly pointed out, the "role of visuality in the politics of race" should not be underestimated: the questions to ask, 
then, in analysing a film like Sonam, are principally related to the key role of cinema as a meaning-making machine that employs audiovisual strategies to forge its own symbolic realities, and the pitfalls and the challenges of fighting visual and narrative regimes that, as Baruah (2005b) argues, often translate into pernicious battles over images.

\section{Of internalised stereotypes and biased premises: indigenous and exogenous voyeurs}

From video-recording and archiving ancient stories as cultural heritage and counter-hegemonic social history, to the production of text and films by means of older and newer media, to the dissemination of such cultural and artistic products via blogging and vlogging, indigenous people in India are experimenting with the entire range of media available today - not only in order to connect with others and join the global movement for indigenous rights, but also to communicate new models of expression, creativity, art and agency. I locate indigenous literatures and cinemas in India in the frame of what Floya Anthias (2001) has called "narratives of location", or of "dislocation", in which the telling of individual or collective stories aims to rearticulate narratives of belonging/insiderness. As Anthias posits, such narratives privilege processes of identification to avoid cultural determinism and the sublimation of fixed identities. "Narratives of belonging (and its disclaimers)" - she writes - "may then be seen as forms of social action, that is, as actively participating in the very construction of subject positionalities" (Anthias 2001, 633). In this way, indigenous films and arts engage dialectically and dialogically with historical and cultural contexts and, by doing so, appear to "interpellate location and position (social place and hierarchy)" (ibid.).

The film Sonam offers very little that contrasts with mainstream perceptions of indigenous cultures in India. It seems that as a filmmaker exogenous to the ethnic, religious and linguistic group he strives to represent, Muzid is not keen to engage in any kind of "battle over images". Presenting his feature as the first film in the Monpa language and claiming to portray the real life of the Brokpa shepherds of Arunachal Pradesh who still practice polyandry, Muzid's film exploits Thongchi's supposed insider's claim to authenticity and manages to appeal to national and international audiences looking for an ultra-exotic India. His insider's view, which allegedly "attempts to capture participants' indigenous meanings of real-world events" (Yin 2010, 11) or "looks at things through the eyes of members of the culture being studied" (Willis 2007, 100), betrays a condescending perspective disturbingly reminiscent of orientalist and colonial readings of 'tribal cultures'. Despite the use of a nuanced language that spices literary Assamese with the zest of Monpa words, Thongchi's symbolic frame of reference and the set of values that accompanies it remain heavily exogenous to the Brokpas' worldview, ultimately producing a simplistic portrayal that obscures the cultural and economic reasons that have made polyandry a preferable sexual and matrimonial practice.

Theorising representation and the impact of media on the politics of signification, Stuart Hall (1997) has repeatedly highlighted how representation, far from 
merely reflecting the object represented, is in itself an act of creation: a formulation of meaning:

Representation is a very different notion from that of reflection. It implies the active work of selecting and presenting, of structuring and shaping; not merely the transmitting of an already-existing meaning, but the more active labour of making things mean.

(Hall 1997, 25)

Commenting on this, the Indian scholar Harindranath Ramaswami (2006) has pointed out the ambivalent status of representations as something constructed, forged, and yet, "at the same time, [. . .] so natural that they become transparent, and appear to reflect reality" (Harindranath 2006, 49). At the core of this problem is the fact that works of the imagination, rather than being constantly questioned and challenged for their assumptions, are all too often raised to the level of truth, nurtured by biased images of the Other that are devised by people in power in order to retain certain privileges and rights. We must remember, then, that representations are not mere reflections of reality but rather constructions of a certain set of social and cultural practices that we end up considering as 'reality' (Hall), that such representations are necessarily pitted against "discursive regimes that have social and political consequences" (Harindranath 2006, 49), and that recognising the role of the imagination in reinforcing or challenging such regimes of power is crucial to understanding the role of literature and cinema as potential tools of social change. All this is facilitated by a re-apprehension of cinema as a system of signs, a codified language. As De Lauretis posits,

The argument begun by feminism is not only an academic debate on logic and rhetoric [. . . . That argument is also a confrontation, a struggle, a political intervention in institutions and in the practices of everyday life. That the confrontation is itself discursive in nature - in the sense that language and metaphors are always embedded in practices, in real life, where meaning ultimately resides - is implicit in one of the first metaphors of feminism: the personal is political. For how else would social values and symbolic systems be mapped into subjectivity if not by the agency of the codes (the relations of the subject in meaning, language, cinema, etc.) which make possible both representation and self-representation?

(De Lauretis 1984, 3-4).

De Lauretis goes on to subtly comment,

The unholy alliance of feminism, semiotics, and film is of long standing. In cinema the stakes for women are especially high. The representation of woman as spectacle - body to be looked at, place of sexuality, and object of desire - so pervasive in our culture, finds in narrative cinema its most complex expression and widest circulation. 
De Lauretis offers a valuable critique of cinematic practices and reminds us of the filmic construction of woman as a "distillate from diverse but congruent discourses" (ibid., 5), which transforms real women from historical beings into a "metaphor of woman as image and bearer of the look". In this process, gender intersects with class and ethnicity, situating indigenous or black women in another frame of discourse, where the voyeuristic male gaze theorised by Laura Mulvey is further obfuscated by racist and sexist lenses. ${ }^{12}$

The complexity of unpacking seemingly 'natural' images of a projected reality and the challenge posed by inferential racist premises that support many stereotypes have not gone unnoticed by scholars studying indigenous media. Ella Shohat and Robert Stam, addressing the issue of racism in the representation of indigenous peoples, have identified racism as "adept at the art of the false or boomerang compliment, two forms of which are primitivism and exoticism" (1994, 18). Showing wild and violent male practices, on one hand, and displaying the eroticised beauty (and availability) of indigenous women, on the other, are easy ways to fall back upon a racist essentialism that consumers are familiar with. Such images have heavily impacted the representation of indigenous people in the social and political spaces of India. Portrayed by Indian cinema as "the ultra-subaltern in all ways" (Sawhney 2009, 104), indigenous people have often been pushed into a linguistic and visual ghetto, either misrepresented and talked about, or made invisible and silenced, sometimes depicted as charming exotic/erotic people, as primitive and superstitious simpletons, sometimes as violent and untameable terrorists. These cinematic representations cannot be dismissed as simply an innocent by-product of the entertainment industry. As Vasudevan (2001) has pointed out in an essay on the relationship between cinema and citizenship in post-colonial India, the cinema screen occupies a crucial position as a site for the reflection and refraction of political concepts constructed during colonial times that need to be debunked or reformulated in the post-independence era:

This is a screen that speaks to its audience, often in ways that engage us in a purposeful political address and a raucous fabrication of community. It is a significant space, I would suggest, to think about the productive imperfection of political subjects.

(Vasudevan 2001, 66)

This "fabrication of community" and of political subjects in mainstream Indian cinema, however, tends to push Indian citizens belonging to minority groups such as the scheduled castes and the scheduled tribes - to the margins of the screen, at best utilising them to add symbolic variety to the regimented image of Indian culture and Indian/Hindu values and thus limiting, if not completely impeding, the use of cinema as a significant space - artistic as well as political - to reclaim agency and the exercise of full citizenship for the whole population of India.

Biased but powerful lenses are often worn by tribal men who, in reclaiming their right to gaze, position themselves in the role of the spectator entitled to look, inheriting with this privileged position the glasses of hegemonic discourse and 
internalising it as 'natural' and 'real'. Thongchi's novel Sonam, in which Brokpa indigenous women are presented as naturally inclined to indulge in sexual intercourse with multiple partners, and the filmic rendition by Muzid, who repeatedly exploits the camera's eyes to peep into frequent erotic sequences, both resort to a phallogocentric narrative which posits men as the main reader/spectator of the text and women as the object of their voyeuristic desire. Even though the title Sonam - might suggest that the main protagonist of the story is a woman, she is ultimately just a prop: an image on paper and on screen for the male character (or reader/viewer) to projects his emotions upon, thereby reinforcing his subjectivity and reaffirming the patriarchal system of values. As Ahsan Muzid stated in an interview, his film "deals with love, hatred and jealousy that can breed between two husbands of a Monpa woman" (Nofil 2007). There is no reference to the feelings of the Brokpa female protagonist, no reference to her experience of polyandrous marriage or other customary practices. Both the Sherdukpen author and the Assamese filmmaker seem to share the opinion that Brokpa women succumb to their primitive instincts when they indulge in such practices. Rather than providing critical tools for the reader/spectator to understand the complexity of polyandry and the debates surrounding such marriage systems, the two male authors limit themselves to an androcentric view that is blinkered by their moral judgement of a practice that they deem improper, alien to their cultural ethos and hence deservedly destined to die out. The death of Sonam symbolically opens the way for the virtuous practice of heterosexual monogamy, sanctioned by the marriage of Lobsang and Tsering Dholma. It is difficult to ignore the sexist and racist premises of such a conclusion: both the novel and the film draw the reader/spectator into a spiral of Sonam's debauched behaviour at the expense of her virtuous and naïve husband Lobsang. At the end of the film, the child-like but brave Lobsang is held up as the ultimate hero both for his courage in killing the snowleopard that has been terrorising the shepherds for years, and for his integrity in patiently tolerating such a wife, who finally repents and dies, leaving the good Lobsang in the caring hands of Dholma. The film goes a step further than the novel by adding another female character, a widowed young woman, who spends her time flirting and having sex with Lobsang's friend and colleague Tikoro. The sequences showing this parallel affair are interwoven into the film to give an overall impression of the carefree nature of the Brokpa women, married or widowed, who cannot bear being alone and desire men to the point of hunting them down in any possible situation, much like the ferocious snow-leopard that hunts their yaks and cattle. The analogy between the bestiality of the animal that creates havoc among the Brokpas and even kills Lobsang's loyal dog Dambu and the insatiable lust of the Brokpa women, who do not hesitate to betray even such a caring and devout husband as Lobsang, is made clear in more than one sequence of the film. The scene in which we see Sonam falling prey to the seductive moves of Pema Wangchu is cross-cut, quite abruptly, with a sequence showing the snowleopard slowly climbing up the slope of the mountain. As Sonam allows Pema Wangchu to take the place of Lobsang in her bed, so the beast slowly enters the idyllic scene of the pasturelands, where up to that moment we had witnessed the 
happy-go-lucky Brokpas singing, playing and generally amusing themselves like carefree children.

Monogamy and religion are presented as the solution offered by a process of civilising and taming, with Dholma occupying the closing pages of the novel and the last sequences of the film. She takes centre stage after the deaths of both Sonam, who contracts an illness that sucks dry her beauty and sensuality, and the young widowed woman, who is devoured by the snow-leopard while trying to allure Tikoro among the bushes. It is reasonably clear that these are karmic deaths, the direct result of the women's sinful actions. Products of a purely male gaze, the questions that the film raises are multiple and far-reaching, echoing the doubts raised by many women intellectuals and feminist scholars of cinema studies. In The Witch's Flight, Kara Keeling, taking the interrelationships between cinema, racism and sexism as a critical starting point, discusses this nexus as "the crucible in which cinematic reality takes form and maintains itself" $(2007,11)$. She further elaborates,

An appeal to the visual is not uncomplicated or innocent. As theorists we have to ask how vision is structured, and, following that, we have to explore how difference is established, how it operates, how and in what ways it constitutes subjects who see and speak in the world. This we must apply to the ways in which black women are seen and not seen by the dominant society and to how they see themselves in a different landscape. But in overturning the "politics of silence" the goal cannot be merely to be seen: visibility in and of itself does not erase a history of silence nor does it challenge the structure of power and domination, symbolic and material, that determines what can and cannot be seen.

(Keeling 2007, 11)

This is particularly pertinent to the politics of representation of indigenous people, whose images are embedded in a history of oppressive strategies of silencing their voices. The visibility - and audibility - offered by films like Sonam, rather than countering the "politics of silence", actually further obscure indigenous perspectives, particularly those of women and subaltern individuals within the tribal group. If Thongchi, and then Muzid, wished to 'give voice' to the grievances of men in polyandrous relationships, they might have at least taken the trouble to ask what Brokpa women thought of it, instead of reiterating sexist and misogynist interpretations of the practice. Scenes in the film such as that in which Sonam undertakes a painstaking pilgrimage to Tawang to ask for forgiveness at the feet of the Buddha, or the one in which Lobsang's discovery of her extra-marital affair wins her a harsh thrashing, are all the more disturbingly 'violent' because they position the spectator as the one who chastises the woman for her immorality. These are just two blatant examples of how the androcentric narrative uses the 'natural (patriarchal)' authority of the Buddha or the husband to pass judgement upon Sonam, guiding the viewer to share the verdict that Lobsang is a victim of her deviant ways. In this way, rather than challenging hegemonic mainstream moralities, the film reinforces and sustains them. 
The imperatives that Indian intellectuals shortly after independence proposed for Indian artistic productions (including cinema), such as "the re-invention and re-connecting of cultural knowledge and memory suppressed or fetishized under colonial rule" (Vasudevan 2001, 66), are crucial ones for the indigenous artists and filmmakers of India today. In such a complex political frame, in which the Indian state is often seen as an inner coloniser that suppresses indigenous peoples' rights, the role of indigenous intellectuals such as Thongchi - who works in the civil service - cannot be understated. Helping to implement culturally alienating policies of education, or sustaining imported cultural practices, suggests a form of internalised colonisation of the mind that should be cause for concern. This is not to accuse Thongchi of being a writer subservient to a hegemonic political agenda, but rather to highlight how even an indigenous writer like him, whose works in the Assamese language have been highly praised (Misra 2007; 2013), can use the tropes of a condescending discourse that serves to reinforce certain neo-colonial images of race and gender. At the same time, a growing number of indigenous artists are calling for more thought-provoking and counter-hegemonic cultural practices. These "dissident traditions" (Gilroy 2000, 13) are very important for understanding the positionality of the "black intellectual" (hooks 1992). Commenting on a statement by the African filmmaker Ousmane Sembene, who has repeatedly encouraged black artists to create their own models in order to "rethink everything", bell hooks underlines how "insurgent black intellectuals and/or artists are looking at new ways to write and talk about race and representation, working to transform the image" $(1992,2)$. The creation of "oppositional gazes" remains one of the crucial duties of committed indigenous filmmakers, she argues, as it is "within the realm of the image" (ibid.) that the filmmaker can fight against such forms of (mis)representations. By creating new intellectual spaces where unreported histories can be revealed and hegemonic gazes deconstructed or even annihilated - more complex and layered, even contradictory, narratives can be told.

Caught as it is between multiple languages (both in terms of lexicon and visuality), the film Sonam does not offer an "oppositional gaze" upon the localised religious and cultural practices of the indigenous people living along the contested border between India and China (Tibet). The custom of polyandry, once fairly common among ethnic Tibetan groups, is portrayed as an 'immoral' practice that is deservedly destined to die out. Sonam, who is shown over-indulging in a double relationship with her two husbands, meets a punishing end. The flat depiction of the younger Brokpa woman is offered through the lenses of a camera that betrays a voyeuristic, unconcealed pleasure in peering into the private lives of indigenous people. Ultimately, what could have become a fascinating film offering insights into life in a Brokpa village resulted instead in a normative moralising and biased representation of a 'backward tribe'. This is an unfortunate outcome for a film that has been showcased at many international festivals and has won several awards and special mentions in India and abroad; a result that further highlights what is at stake when indigenous people are (mis)represented on Indian screens. 


\section{Conclusion: Of polyandry and polyamory in contemporary times}

Sonam has largely been marketed as a film about polyandry, a custom that used to be considered perfectly acceptable in the Tibetosphere alongside other forms of marriage. Usually the Brokpas practised what has been termed fraternal polyandry, whereby a group of brothers shared a common wife. Although this tradition has received criticism in Tibet and in other areas that today fall inside China's geopolitical borders and its neo-Confucian values, fraternal polyandry continues to be practised in a few Tibetan communities, not only in the Indian states of Arunachal Pradesh, Ladakh and Sikkim, but also in other countries such as Bhutan and Nepal. Often motivated by economic factors such as the scarcity of land and the advantage of avoiding dividing inherited property between the sons of one family, which would result in ever smaller plots, fraternal polyandry was often seen as the best choice, with the elder brother ceremoniously marrying a woman who, eventually, would also become the wife of his other male siblings. The practice appears to be becoming increasingly uncommon, in part because of growing opposition from young generations who have been brought up with a different education and influenced by ideas of love, companionship and the nuclear family as the ideal way of 'doing family'. Changes in how people earn their livelihoods and exposure to different systems of values have also been seen as reasons why polyandry is slowly being abandoned in favour of other relationship patterns.

As social practices sanctioned by tradition meet new ways of imagining life, family and society, discord is inevitable between groups that uphold old traditions in the name of preserving culture and movements that call for change and the abandoning of 'anachronistic' practices as the only way towards genuine progress and modernity. What concerns us here is that such crucial issues are not adequately addressed by the film Sonam, which instead makes a moral judgement based upon a phallogocentric system of values that marks the women portrayed as deviant and sacrifices them in order to establish a new era of virtue based on monogamous liaisons sanctioned by secular and religious patriarchal figures. In this sense, the story is far from accurate in its portrayal of the customary practices of the Brokpas, as indeed some Brokpa people pointed out when shown the edited version. Muzid, defending the choices he made when making the film, has stated that "Sonam is the simple story of a simple man. [...] They are only for a select audience" (Nofil 2007). Betraying a certain patronising attitude towards the Brokpas, whom he obviously does not expect to find among the select audiences that attend film festivals and art venues, he does not even seem concerned by criticisms that his portrayal shows the system of non-fraternal polyandry, which is not even practised by the Brokpas of Arunachal. As Muzid himself clarifies, "The Monpas still practice polyandry where brothers have one common wife and cohabit together, some people opposed my film for showing two men, not related to each other, for living with one woman" (ibid.) Scholars of polyandry have repeatedly claimed that it is difficult to ascertain the origins of this practice, but they too may have been 
hampered in their efforts by the die-hard androcentric bias that has been highlighted by Levine and Sangree:

[W]e would like to call attention to the notable difficulty that western anthropologists have had in accepting polyandry as such and fitting it into comprehensive theories of marriage. Widespread disbelief in the existence of polyandry has not, however, managed to preclude a prevailing fascination with the subject. Berreman [. . .] has attributed the latter to exotic and androcentric biases and we feel that the apparently paradoxical skepticism about polyandry also can be accounted for by reference to such factors.

$(1980,388-389)$

Ahsan Muzid seems to share this "fascination with the subject", which he exploits to his own advantage, regardless of the inaccuracy of his portrayal of associated polyandry in a context where fraternal polyandry is the norm. Equating polyandry to some sort of whimsical cicisbeism, then proceeding to depict some form of polykoity (Fischer 1952), which is then resolved by a polyandrous marriage - these are problematic blurrings that weaken an otherwise potentially insightful film. The ultimate denouncement of any possibility of sincere polyamory among the three main characters seems to cater to the (assumed) prevailing expectations of a general spectator, who is perhaps not inclined to approve of polyamory - and even less polyandry - in any possible form, especially one that opens space for some kind of sexual freedom for women. As Levine and Sangree have pertinently highlighted,

the Western Judeo-Christian, Islamic and South Asian Indic traditions are all antithetical to marriage systems which condone or approve of plural sexual unions for women [...]

Those societies which strongly oppose polyandry or plural sexual unions for women also, not surprisingly, resist perceiving women's sexual and reproductive capacities as separable, while they show little or no resistance to accepting the separability of men's sexual and procreative attributes. And it may well be a fundamental feature of the ideological system of polyandrous peoples that they recognize such a distinction for both men and women.

(1980, 389; emphasis original)

This is indeed an important consideration as, in the film, Sonam often tells Lobsang that his children are not his own but are Pema Wangchu's, which seems not to bother Lobsang at first but then seems to slowly deplete his affection for his wife. In studies on Pahari and Tibetan systems of polyandry, such as those by Berreman $(1962,1975)$ and Goldstein $(1971,1976,1978)$, co-resident brothers jointly wed a single woman and share some solidarity, something which has often been remarked upon by scholars and observers who have expressed surprise at the apparent absence of jealousy among the men involved (Levine and Sangree 1980,396). Yet the relationship between Sonam and Lobsang is deeply 
disrupted by the arrival of a third party, Pema Wangchu, who is portrayed as a lazy, obnoxious and spoilt young man. The film bears little resemblance to the day-to-day lived experience of the majority of Brokpas, where women actually share the hardships of a semi-nomadic life with their men, moving with their yak herds according to the season and dividing their time between hard work with the yaks and the exhausting job of trading yak products and other goods in the valley's markets. The lives of these pastoralists are far from idyllic, and it is a real pity that a potentially very interesting film set amongst the Brokpas of the Monpa tribes turned out to be a very biased representation of an indigenous group portrayed as backward and needing to progress towards the supposed moral high ground of monogamous heteronormativity. Perhaps my disappointment with the film stems mostly from two considerations: first, I expected an indigenous Sherdukpen writer like Yeshe Dorjee Thongchi and an accomplished Assamese director like Hasan Muzid to take into more serious consideration the politics of (mis)representation that have affected India's Northeast, particularly regarding the way tribal women are portrayed on screens. Second, I also expected to see a different take on Tibetan cultural practices in a country like India - which has always valued its pluralism - in comparison to biased representations of 'ethnic minorities' that are common in China. In both cases, racist and phallogocentric premises result in men being portrayed as justified in committing violence against women who are presented as 'lacking' in both moral and cultural standing. ${ }^{13}$

In Sonam, the issues of gender and race are superficially addressed and subjected to an apparatus of straitlaced norms, moralising stereotypes and titillating images, which end up making its main female Brokpa character into an icon of depravity and an example of deviant femininity. Ultimately, rather than opening a much needed space in which to reappraise stereotypical images of indigenous people and moving beyond the restrictive ethnic frame of films shot in tribal areas, the film is symptomatic of dangerous neo-colonial mind-sets and inner orientalism which, especially in the frame of contemporary India, should be carefully examined and analysed rather than upheld as models of independent filmmaking. The struggle that indigenous filmmakers and intellectuals have to fight to overturn such biased images must begin by avoiding the internalisation of certain discursive practices and implicit racist and sexist premises, which are some of the pitfalls of the perfunctory ethnicisation and mystification of indigenous lives. This challenge is not to be underestimated, especially the need to create a more historicised - and less romanticised or demonised - space within visual and cinematic landscapes, beyond the ethnicised and exoticised frames of reference that all too often trap indigenous people in anachronistic representations as alien cultures. The volatile double-edged sword of the "idea of tradition" (Gilroy 2000, 14) looms over everyone who dares to challenge external or internalised stereotypes: as a Sardinian, I am all too familiar with the dilemma of wanting to preserve distinctive cultural trends without falling into the trap of self-exoticising or creating false fixed identities devoid of cultural viability. The offensive and distorted lenses of films that 
portray Sardinians either as bandits or simple-minded shepherds who mate with women as they do with sheep have created well-known tropes that fail to amuse any of us on the receiving side of these biased representations. ${ }^{14}$ Hence, advocating "dissident traditions" (Gilroy 2000, 14) as a way to disrupt "race-thinking" (ibid.) is indeed an important call for all of us, as filmmakers, writers and scholars, to challenge "raciology" (ibid.) and to pursue more complex, layered and fluid concepts of identification and representation.

\section{Notes}

1 I use the term 'Northeast' as a functional label that has come to identify a specific geographical and geopolitical area of India: the seven states of Assam, Meghalaya, Tripura, Nagaland, Mizoram, Manipur and Arunachal Pradesh. This label has acquired different meanings in different contexts: in the popular imaginary in India, it may denote both an area of exotic and wild beauty and a place of unrest and potential ethno-nationalist struggles. In both cases, the Northeast appears to occupy a 'liminal space' in the Indian imagination, with cinema and mainstream media often reflecting a rather homogenised representation of the 'region'. To gain a more comprehensive and differentiated understanding of the political and cultural contexts of the region of India known as the 'Northeast', Sanjib Baruah's works remain a relevant source of information. See, among his works, Baruah (2005a; 2005b; 2007).

2 The cinema in different languages and among the numerous indigenous communities of Northeast India has yet to be comprehensively researched and discussed. Besides historically relevant films such as Joymoti (J. Agarwala, Assam 1935), recently restored by the late Assamese filmmaker Altaf Mazid (see Chapter 13, this volume), numerous new trends are emerging from the area, both in terms of commercial films and independent cinema. See Hasan (2010); Matta (2015b).

3 The use of the word 'tribal' is falling into disuse in academic writing due to its semantic and historic inheritance, which dates back to colonial times. For this reason, it has been highly problematised in the last few decades and is slowly being abandoned. Scholars of South Asia and local activists are increasingly adopting the terms 'indigenous' or $\bar{a}$ divās $\bar{\imath}$ as more politically correct terms, signalling their desire to distance themselves from colonial and neo-colonial perspectives. However, none of these words are truly 'neutral' and none can be left unquestioned. With a growing movement that has been bringing together many diverse indigenous groups inhabiting the Indian subcontinent, the term a a divāsi has gained popularity, especially when deployed in a highly politicised manner. In the contest of India's Northeast, however, not everybody welcomes the label and many people resist it, preferring to be identified by the name of their specific community (Khasi, Monpa, Bodo, etc.) rather than being subsumed under another homogenising label that may be used to conceal dangerous calls for eliminating 'aliens' or for creating forms of "geographical apartheid" (van Schendel 2011, 29). See van Schendel, W. (2011).

4 For a discussion of some parallel cinema films by Bengali authors in which eroticised indigenous women are key to the narrative, see Matta (2015a).

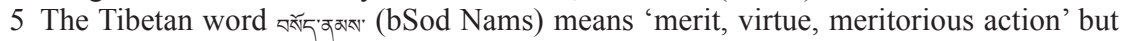
also 'good fortune, luck, meritorious karma'. It is often used as a proper name, implying an auspicious meaning, but also a moral one. A girl named Sonam is meant to be a 'virtuous' woman, hence accumulating 'meritorious karma' and bringing good luck and fortune to herself and the people around her. For other meanings of the term bSod Nams, see the THL Online Dictionary at www.thlib.org/reference/dictionaries/tibetandictionary/translate.php 
6 The Sanskrit word karma (tib. Las) can be broadly translated as 'action'. As J.B. Wilson elucidates in an article that discusses the relationship between individual actions and Tibetan Buddhist ethics,

In the technical terminology of scholastic Buddhist ethics, "karma" refers, narrowly, to an action performed by a sentient being [...]. However, the term "karma" often implies, more broadly, a sense of the relationship between an action intentionally performed and its effect, an effect experienced usually, but not necessarily, in a future lifetime by an entity who is in a significant way a continuation of the performer of the action.

(Wilson 1996, 381)

In the Buddhist tradition, there has been a lot of debate seeking to define what 'moral actions' might impact on the karma of a sentient being and the role of intentionality in making such actions 'immoral' and conducive to the accumulation of negative karma. As we shall see, in the narrative of the novel and film, it is the repeated intentional performance of certain actions that mark Sonam as a woman who defies the religiously sanctioned rules of the community. Her illness and premature death are presented as the natural (I prefer to say 'karmic') result of her conduct.

For an interesting discussion of the Buddhist categories of virtuous or wholesome actions and non-virtuous or unwholesome actions, see Wilson, J.B. (1996).

7 The term 'cicisbeism' refers to the custom, practised in certain areas of 18th century Italy, of a married woman keeping another man as her lover outside the bond of marriage. This 'man in attendance', whose role was usually known by the woman's legal husband, was called a 'cicisbeo'. The term has been employed by some anthropologists and researchers working among specific indigenous groups across Asia and Africa to refer to practices that differ from what is perceived as the normative marriage custom. Besides cicisbeism, other practices that are listed as 'deviant' from the norm are the levirate, polykoity ('multiple mating') and various forms of polyandry or polygyny. Forms of polyandry have sometimes been described as forms of cicisbeism, overlooking the specificities of various polyandrous customs across the world, which constitute alternative forms of 'marriage'. See, among others, Raha (2007); Mann, K. (1987); H.R.H. Prince Peter of Greece and Denmark (1980); Mann, R. S. (1996).

8 Colonial and neo-colonial representations have often resorted to stereotyping and exoticising the Other, particularly focusing on the body of the woman as a contested site of negotiation. As Suren Lalvani $(1995,263)$ has aptly put it,

Since the colonial representation of Otherness operates in a manner analogous to the psychoanalytic fetish, the discursive construction of Otherness is neither fixed nor continuous but ambivalent. The multiple and reciprocal interaction of the twin modes of differentiation - the racial and the sexual - enables the erotic recognition of the Other/the threat of difference to be displaced into alternative fields of power/ knowledge relations and into an economy of desire productive of power.

9 The Sherdukpens are recorded as belonging to one of the 12 'notified scheduled tribes' of Arunachal Pradesh in the Census of India $(1961 ; 2011)$ and differ from the Monpas in language and customs. Sometimes called the Mey, there is little detailed information regarding their culture. See Nongkynrih (2010).

10 Many important publications, starting with the praiseworthy collection of articles edited by Peter Bishop in 1989 with the title The Myth of Shangri-La, have tried to deconstruct the representation of Tibet and Tibet-related people and cultures as the custodians of mystical secrets and the inheritors of mythical histories. Discussing the same idea of the 'uniqueness' of the natural and human landscapes of Northeast India, Sanjoy Hazarika has pointed out that "There are no Shangri-La left". See Hazarika (2011).

11 The Monpa language expression khor depka is used to indicate the custom of polyandry. Even though it is cited in its original form in the revised version of the novel, Thongchi 
does not provide a literal translation of the specific practice, but simply uses it as a synonym for 'polyandry'.

12 See, in particular, the article by Mulvey (1989).

13 Sexist and phallocentric narratives on 'loose women' belonging to 'minority groups' has had very serious consequences in many countries around the world. In Canada and the US, for instance, violence against indigenous women is directly linked to colonising practices, memories of domination and histories of racism and oppression. Indigenous women in Canada, as a recent report states, have been subjected to violence and sexual abuse to the point that the Canadian government has set up an inquiry to investigate a scourge of violence against indigenous women and girls, many of whom have disappeared and never been found. For a history of the connection between colonialism and violence against women, see Etienne and Leacock (1980). To access the Canadian national inquiry's reports, visit the website www.mmiwg-ffada.ca

14 Sardinia is one of Italy's two large islands, the other of which is Sicily. It lies in the middle of the Mediterranean Sea and has a long history of cross-fertilisation between languages and cultures. However, it has often been presented as just a land of backward shepherds, poor farmers and uncultured fishermen. One recent - and successful - film that brought Sardinia onto national and international screens was Ballo a tre passi (Three steps dance, Italy 2003), by the Sardinian filmmaker Salvatore Mereu. The film attracted a great deal of attention, and won numerous awards, for its portrayal of Sardinia as some sort of exotic and wild heterotopia. Some Sardinians, however, were critical, particularly of the film's representation of a love affair between a Sardinian shepherd and a French girl. Unable to communicate with words, she condescendingly allows him to make love to her 'as sheep do', since she apparently assumes that he knows no better. The scene was deemed offensive and criticised for its misrepresentation of Sardinian shepherds. For more on Sardinian cinema, see Urban (2013).

\section{References}

Anthias, Floya. 2001. "New Hybridities, Old Concepts: The Limits of Culture." Ethnic and Racial Studies 24 (4): 619-642.

Baruah, Sanjib. 2005a. Durable Disorder: Understanding the Politics of Northeast India. New Delhi: Oxford University Press.

Baruah, Sanjib. 2005b. "India and Its Northeast: A New Politics of Race." IIC Quarterly, New Delhi, India International Centre 32 (2-3): 165-176.

Baruah, Sanjib. 2007. Postfrontier Blues: Toward a New Policy Framework for Northeast India. Policy Studies, No. 33. Washington, DC: East-West Center.

Berreman, Gerald Duane. 1962. "Pahari Polyandry: A Comparison." American Anthropologist 64: 60-75.

Berreman, Gerald Duane. 1975. "Himalayan Polyandry and the Domestic Cycle." American Ethnologist 2: 127-138.

De Lauretis, Teresa. 1984. Alice Doesn't. Feminism, Semiotics, Cinema. London: Palgrave Macmillan.

Denzin, Norman K. 1995. The Cinematic Society: The Voyeur's Gaze. London: Sage.

Dutta, Juri. 2011. "Reading Yeshe Dorjee Thongchi's Sonam: A New Historicist Perspective." Journal of Literature, Culture and Media Studies 3, 5-6 January-December: 231-243.

Etienne, Mona, and Leacock, Eleanor Burke. 1980. Women and Colonization. New York: Praeger Publishers.

Fischer, Henri Théodore. 1952. "Polyandry." International Archives of Ethnography 46: 106-115. 


\section{Mara Matta}

Ghosh, Avijit. 2007. "Bollywood is 99 per cent non-cinema." Times of India, April 13, 2007. https://timesofindia.indiatimes.com/edit-page/Bollywood-is-99-per-cent-noncinema/articleshow/1900371.cms

Gilroy, Paul. 2000. Against Race: Imagining Political Culture Beyond the Color Line. Cambridge: The Belknap Press of Harvard University Press.

Goldstein, Melvyn C. 1971. "Stratification, Polyandry and Family Structure in Tibet." Southwestern Journal of Anthropology 27 (1): 64-74.

Goldstein, Melvyn C. 1976. "Fraternal Polyandry and Fertility in a High Himalayan Valley in Northwest Nepal." Human Ecology 4 (3): 223-233.

Goldstein, Melvyn C. 1978. "Pahari and Polyandry Revisited." Ethnology 17: 325-337.

Hall, Stuart. 1997. Representation: Cultural Representations and Signifying Practices. London: Sage.

Harindranath, Ramaswamy. 2006. Perspectives on Global Cultures. New York: Open University Press (Issues in Cultural and Media Studies).

Hasan, Daisy. 2010. "Talking Back to 'Bollywood': Hindi Commercial Cinema in NorthEast India." In South Asian Media Cultures: Audiences, Representations, Contexts, edited by Shakuntala Banaji, 29-50. London: Anthem Press.

Hazarika, Sanjoy. 2011. "There Are No Shangri-La Left.” In The Oxford Anthology of Writings from North-East India (Vol. II, Poetry and Essays), edited by Tilottoma Misra, 157-163. New Delhi: Oxford University Press.

hooks, bell. 1992. "The Oppositional Gaze: Black Female Spectators.” In Black Looks: Race and Representation, 115-131. Boston: South End Press.

hooks, bell. 1999. Yearning: Race, Gender, and Cultural Politics. Boston: South End Press.

H.R.H. Prince Peter of Greece and Denmark. 1980. "Comments on the Social and Cultural Implications of Variant Systems of Polyandrous Alliances." Journal of Comparative Family Studies 371-375.

Keeling, Kara. 2007. The Witch's Flight: The Cinematic, the Black Femme, and the Image of Common Sense. Durham, NC: Duke University Press.

Lalvani, Suren. 1995. "Consuming the Exotic Other." Critical Studies in Media Communication 12 (3): 263-286.

Levine, Nancy E., and Walter H. Sangree. 1980. "Conclusion: Asian and African Systems of Polyandry." Journal of Comparative Family Studies 11 (3), Summer: 385-410.

Mann, K. 1987. "Polyandry, Cicisbeism and the Status of Tribal Women." Eastern Anthropologist (The) 40 (4): 331-336.

Mann, Rann Singh. 1996. Aspects of Indian Social Anthropology. New Delhi: Concept Publishing Company.

Marubbio, M. Elise. 2006. Killing the Indian Maiden: Images of Native American Women in Film. Lexington, KY: University Press of Kentucky.

Matta, Mara. 2015a. "Womanizing' Nature in India: A Few Considerations on the Politics of Representation of Tribal Women in Bengali Fiction." Rivista degli Studi Orientali (New Series) 88: 181-196.

Matta, Mara. 2015b. "The Khasi New Wave: Addressing Indigenous Issues from a Literary and Cinematic Perspective." Anglistica 19 (1): 51-67.

Misra, Tilottoma. 2007. "Crossing Linguistic Boundaries: Two Arunachali Writers in Search of Readers." Economic and Political Weekly 3653-3661.

Misra, Tilottoma. 2013. The Oxford Anthology of Writings from North-East India Poetry and Essay. New Delhi: Oxford University Press.

Mulvey, Laura. 1989. Visual and Other Pleasures. London: Palgrave Macmillan. 
Nofil, Zafri M. 2007. "Sonam: A Film That Transcends Heights, Boundaries.” https:// zafrimn.wordpress.com/2011/12/16/sonam-a-film-that-transcends-heights-boundaries/.

Nongkynrih, Aurelius Kyrham. 2010. "Scheduled Tribes and the Census: A Sociological Inquiry." Economic and Political Weekly 43-47.

Raha, Manis Kumar. 2007. "Marriage in India with Special Reference to Arunachal Pradesh." In Marriage in Tribal Societies: Cultural Dynamics and Social Realities, edited by Tamo Mibang and M C Behera, 21-54. New Delhi: Mittal Publications.

Sawhney, Rashmi. 2009. "Cinema and the Adivasis of India." Moving Worlds 9 (1): 102-115.

Shohat, Ella, and Robert Stam. 1994. Unthinking Eurocentrism. Multiculturalism and the Media. London and New York: Routledge.

Thongchi, Yeshe Dorjee. 2001. Sonam. Guwahati, Delhi: Spectrum Publications.

Thongchi, Yeshe Dorjee. 2005. Sonam. Guwahati, Delhi: Spectrum Publications.

Urban, Maria Bonaria. 2013. Sardinia on Screen: The Construction of the Sardinian Character in Italian Cinema. Series Studia Imagologica, Volume: 21. Amsterdam: Brill/ Rodopi.

van Schendel, Willem. 2011. "The Dangers of Belonging: Tribes, Indigenous Peoples and Homelands in South Asia." In The Politics of Belonging in India: Becoming Adivasi, edited by Daniel J. Rycroft and Sangeeta Dasgupta, 19-43. London: Routledge.

Vasudevan, Ravi S. (ed.). 2001. Making Meaning in Indian Cinema. New Delhi, India: Oxford University Press.

Willis, Jerry W. 2007. Foundations of Qualitative Research: Interpretive and Critical Approaches. Thousand Oaks, CA: Sage.

Wilson, Joe Bransford. 1996. "The Monk as Bodhisattva: A Tibetan Integration of Buddhist Moral Points of View.” The Journal of Religious Ethics 24 (2): 377-402. www.jstor.org/ stable/40015215.

Yin, Robert K. 2010. Qualitative Research from Start to Finish. New York: The Guilford Press. 


\title{
15 Afterword
}

\section{Meditations on media in digital times}

\author{
Robin Jeffrey
}

Three engaging pieces of research crossed my mind as I read the essays in this book: Hugh Trevor-Roper's "The Invention of Tradition" (1983), Peter Manuel's book Cassette Culture (1993), and Ratnakar Tripathy's "Music Mania in Smalltown Bihar" (2012). ${ }^{1}$ All are about the impact of new technologies of communication on relatively small, isolated groups - the Highlands of Scotland in Trevor-Roper's case, speakers of Hindi dialectics in northern India in Manuel's and Tripathy's. Trevor-Roper argues that bagpipes, tartan and the kilt were inventions of the late 18th century, propelled by the conquest of the Highlands after 1745 , improved communications, readier availability of printing and publishing and a growing textile industry hungry for marketable products, including 'tartans' for new Scottish regiments in British armies. For a growing Scottish middle class, the printers and publishers produced tales, mostly fabricated, about a glorious Highland-Scottish past. Making 'tartan' cloth helped the mechanized textile industry to grow. ${ }^{2}$ For those who have read about India and the "objectification" of "caste" and processes of "Sanskritization," these examples from Scotland echo in the published "caste histories" and "caste claims" presented to census officials in India from the $1890 \mathrm{~s}^{3}{ }^{3}$

In the background of these processes was the printing press and its requirements. Technically, printing required paper, ink, types, a press and skilled workers. Financially, these items had to be paid for, either by vain, ambitious authors and their backers or by audiences eager to pay for the publication. From a printer's and a publisher's point of view, the ideal combination was both - a no-risk subvention leading to a best-seller. Trevor-Roper does not explore the printing side of the manufactured "Highland tradition." But he might have done. His essay dates from 1983, the year Benedict Anderson published Imagined Communities: Reflections on the Origin and Spread of Nationalism, one of the most quoted academic books for 40 years, which put "print capitalism" into scholarly vocabulary.

The work of Peter Manuel and Ratnakar Tripathy explored the rapid transformation of communications and media and its effects on populations largely untouched by previous methods of communication. Manuel's admirable research recognized powerful, fleeting change, at a time (1989) when practitioners themselves were imperfectly aware of the extent and implications of their activities. He saw technology (the audio cassette) providing "a decentralized structure [of media] 
affording a responsiveness to community values and aesthetics." But - and this 'but' has grown mightily since 1993 - he also saw "enhanced possibilities for abuse and subversion of the very potential for liberation and democracy that centralization can bring."4 Manuel had seen the effects of audio cassettes' carrying the Khalistan message of Jarnail Singh Bhindranwale around the world in the 1970s and 1980s, and the power of videocassettes to escalate riot and murder after Indira Gandhi's assassination in $1984 .^{5}$

Tripathy's essay explores "the phenomenal rise of vernacular music in Bihar . . . and its likely contributions to Bihari identity." It also identifies the capacity of cheap technologies to enable smaller, less wealthy, more isolated groups to make and disseminate their own music, and make enough money in various ways to sustain a business - or to lose so little that the effort is more than worth it for a musician's or producer's status and fame. The 'feature phone' and the smartphone have made this music-making and video-making even easier, and dissemination has become fast, cheap and potentially global.

\section{$* * *$}

For me, the essays in this book carry on these explorations of the way human beings use technologies that potentially let every person share their feelings with the world. What is the appropriate word for it? "Democratization" of media? But "democratization" sounds too positive, a happy word that virtually every dictator in the modern world has wanted to claim. ${ }^{7}$ Perhaps "the individualization of mass communication" is closer to what I mean. Today, even a poor individual can make a show-and-tell presentation and send it to the world.

The essays in this book demonstrate how rapidly, even in some of India's most isolated areas, technologies have moved from the choke point represented by inkon-paper to a stage where anyone with a few thousand rupees can tell a story visually and disseminate it globally. In such developments, India has not been a leader; but it provides some of the most stunning examples and contrasts.

When India became independent in 1947, it had a literacy rate of about 17 per cent - 60 million people out of 360 million could read and write. It had 100,000 telephones (about one phone for every 3,500 people) and 256,000 radios (one for every 1,400 people). Its daily newspapers in most of the major languages sold about 2 million copies a day, of which about 30 per cent were in English. Its most extensive forms of mass media were the movie industry and the "postcard" delivered by Indian Posts and Telegraph. Close to two billion pieces of mail circulated each year (six pieces for every person), and sending a postcard cost only six pies or 1/32 of a rupee. The country had 3,000 cinema halls, more than a quarter of which were mobile, and produced close to 300 feature films a year. ${ }^{8}$

Radio, post, telegraph and telephone were all government monopolies. Radio and telephone were rare and expensive. And the post and telegraph services required reading and writing. Under the British, newspapers laboured under the threat of censorship and closure if they stepped out of line. Films were subject to censorship, but the film industry was profitable, and its innovative backers found 
ways to both please their audiences and keep the censors mostly at bay. But filmmaking was long-winded, complex and expensive; making and distributing prints was difficult. ${ }^{9}$

After independence, not a great deal changed, in terms of either technology or government policy. Elected politicians, influenced by 'socialist' ideas of the time, bemoaned the control of print media by 'big capitalists.' Governments tried occasionally to foster smaller newspapers, which were thought to 'speak for the people' more legitimately. ${ }^{10}$ Radio, tightly controlled, often by puritanical politicians, grew very slowly and failed to capture the hearts of a vast public. And radios needed electricity or expensive batteries. Television was a state monopoly and regarded as foolish frippery, a diversion to be avoided and, if it were occasionally experimented with, to be tightly controlled by government. ${ }^{11}$

Technologies began to offer possibilities for change. The first was the arrival of the transistor radio, which had become a fad by the late 1960s and made radiolistening, especially through shortwave services, more accessible and popular. Even All India Radio, the government monopoly, began to respond with more popular programming. In 1963, there were 3.6 million licensed radios; by 1972, there were 12.9 million, which was still only about one radio for every 40 people. ${ }^{12}$ Indian companies began manufacturing offset presses in the mid-1970s, and by 1981, desktop publishing software programs had become available in Hindi, Kannada, Telugu and Malayalam. ${ }^{13}$ In the ten years from 1976 to 1985 , the circulation of daily newspapers doubled from 9.3 million to 19.7 million, and the share of English newspapers fell from about 25 per cent to 16 per cent. ${ }^{14}$ The cassette taperecorder enabled cheap recording and duplicating. Manuel's Cassette Culture identified "the advent of a new medium . . . with dramatically different patterns of ownership and control," which presented "remarkable possibilities for new, diverse forms of expression." 15

These more effective ways of disseminating information and entertainment allowed owners of publications and ambitious music makers to find larger audiences and new revenues. For newspapers, this meant enlivening and localizing content - telling the stories of people who would become new consumers of print and purchasers of products advertised in these newspapers. For music makers, the change was more dramatic. Local musical practices, which had seemed to constitute too small a market for producers of vinyl records in the old days, could now be cheaply and easily recorded and distributed.

As the digital world's giant corporations such as Facebook have shown yet again, human beings like few things better than to see and talk about themselves. Local newspapers had already known for more than a hundred years that stories and pictures featuring their advertisers and readers were guarantees of commercial success. As the saying goes, people want media to provide a mirror, not a window.

The contrast between the slow, uncoordinated changes of the 1980s and the stories in this book are striking. Today, even in eastern India, often thought of as remote and underdeveloped, ordinary citizens produce audio and visual media themselves. The 'masses,' even when their languages and their locations are barely 
known to the mainstream, can increasingly talk back. The seven small Northeastern states have a population of close to 60 million. They had 12.8 million mobile phone subscribers in 2017, and the third fastest rate of increase in mobile subscriptions in the country. ${ }^{16}$

Of the 13 essays in this book, at least five (Wagner, Mukherjee, Kumar, de Maaker and Wettstein) illustrate remarkable new-found capacities of small groups to reach expanding audiences. Another six (Chandra, Borde, Hasan, Brandt, Ara and Matta) draw attention to the problems that arise when the ability to talk back - with few of the financial and technical limitations of earlier times - is (a) co-opted by a single voice, perhaps that of an outsider, and/or (b) creates a 'tradition.' Such 'traditions' are in fact frozen moments, which in the past would have vanished with the dawn. Any time an event or ceremony was performed, the practices could well have changed substantially. Now, however, captured on video and widely distributed, a single version can be presented as a permanent archetypal record of 'traditional' practice. Perhaps the earliest, most striking example of this in India was the television series of the Ramayana broadcast in the late 1980s. "The broadly distributed videocassettes tapes" of the series gained wide "acceptance as the version of the epic [emphasis original]." 17

There was nothing new about this process. Printing had long allowed 'texts' to become the 'source' of 'traditions.' The essays in The Invention of Tradition captured various examples of fluid customs plucked from their roots and preserved as 'traditions' like pickles in a jar. The contests described in this book over whether a video or other recording in a particular region in India faithfully represents aspects of a local culture recall these processes. But the novelty is the ease with which almost anyone can make and disseminate their interpretations, grievances and views.

In the past, the expansion of print-based media depended on investment, potential reward and advanced skills. Printers, whether in Korea, China, Japan or Europe, had to make money by selling their wares, having patrons or being rewarded by governments for assisting the state. In the new digital world, the central element in the media equation is no longer the institution that assembles the product. The writer doesn't need to own a printing press; the actor, a stage or a film studio; or the newscaster, a radio or television station. The only mediator of messages is the telecom provider - the company that builds the transmission network and sells access to it. In theory, the provider of these services has no interest in what is being transmitted. In practice, governments are keenly interested in (at least) monitoring transmissions.

Essays in this book vividly illustrate the capacity of individuals to use digital media to do things that governments - and others - may not like. In the 1980s, for example, old elites deplored the colloquial languages and local stories that were given space by the growing circulation of Indian-language publications. ${ }^{18}$ Akshaya Kumar in this book points out similar criticisms of small-scale Bhojpuri films. 
Such films appeal to audiences because they are earthy and recognizable. The people who make them do so partly to develop a reputation for themselves. The technology now enables such productions to be polished enough to engage audiences and cheap enough to fund.

Who is "authorized" to make such works? If films are to be distributed through formal channels in India, they must be certified by the Central Board of Film Certification. ${ }^{19}$ With the arrival of feature phones in about 2010, however, it became possible to make and distribute videos of all kinds to eager audiences without troublesome formalities. ${ }^{20}$ There is no need to get a licence, and nowhere to apply for permission. A number of the essays in this book focus on the long-standing question that increasingly arises: 'Who may tell my story and how should they tell it?'

The ease and economy of shooting and distributing video now makes it possible for any social worker, scientist or activist to record the people they work with and transmit a visual interpretation of people's practices and interests. Uday Chandra tells us that "the adivasi voices" that he spoke to were "surprisingly, sceptical of how they are represented in the video [We Shall Not Leave our Village]" (Chandra, this volume, 115). Critics, Chandra writes, may well view the film as the work of well-meaning external activists producing "mediatised indigeneity activism" (Chandra, this volume, 118). Radhika Borde, discussing her experience of producing videos for an NGO together with a talented Adivasi, points to the possibility that Adivasis "become the puppets of hegemonic ventriloquists" (Borde, this volume, 130). Daisy Hasan detects similar tendencies in Northeast India: an "indigenous political elite ... have often colluded with narratives of "primitivism"' (Hasan, this volume, 133). But the making and disseminating of mediatised images has also had the effect, she argues, of fostering "the idea of a shared 'Northeastern' identity" among people from the Northeast living elsewhere in India, even while "affiliations within the region are more localised and fragmented" (Hasan, this volume, 146). She argues, "social media interactions influence the creation of indigenous subjectivities and identities, and generate affective forms of citizenship" (ibid.).

Anja Wagner emphasizes the "comparatively low barriers to consumption and production" of VCDs (Wagner, this volume, 39). A small "tribal" community in Himachal Pradesh can produce and disseminate audiovisual material that gives people the satisfaction of seeing recognisable likenesses of themselves and at the same time make that vision part of an all-India conversation. Himachal Pradesh has the highest density of mobile phones of any state in India - an amazing 150 mobile-phone subscriptions for every 100 Himachalis. ${ }^{21}$

Madhuja Mukherjee notes a similar capacity in a single district - Purulia - of West Bengal. Film-length features made in very local conditions get viewed far beyond the locality and "become a powerful tool for indigenous people to express a range of political-cultural dissatisfactions" (Mukherjee, this volume, 55). She sees in these productions "the mobilisation of marginal cultures - specifically those of the "backward' castes/classes" and "attempts to reclaim and redefine indigenous cultures" (Mukherjee, this volume, 45).

What makes such audiovisual creations so popular that it becomes worthwhile to invest in them? Markus Schleiter suggests that their audiences relish the experience of being together while seeing representations of themselves - hence the 
popularity of the village video night that he describes. "[P]eople confirm, negate, or rework ideas about culture" when they watch films in which they see representations of themselves (Schleiter, this volume, 72). In the old days of movie making, producing films required heavy financial investment. In the digital world, film is no longer the physical medium, and today, anyone with a fourth-generation mobile phone can make video. "Small people" can now make Big Pictures as well as "big sounds." 22

As visual story-telling becomes easier and more common among people who may have skipped the newspaper, landline telephone and big-cinema experience, bewilderment is sometimes expressed. 'What does all this mean?' is a question asked by puzzled locals as well as scholars of media. Erik de Maaker discusses the ambivalence among the Garo Christian elite in Meghalaya about films made about 'Garo culture.' While the focus of such films on a pre-Christian past was troubling, leaders welcomed the emphasis on Garo distinctiveness (de Maaker, this volume, 198). de Maaker was intrigued by the ways in which moving images could be interpreted - people were willing to view footage of embarrassing situations that he had shot during past legal disputes. Seeing oneself on screen appeared to be more compelling than any embarrassment about one's behaviour in the past.

The state of media in the second decade of the 21 st century enables a constant game of ping-pong between makers of audiovisual stories, their subjects and their consumers. Marion Wettstein's account of the presentations of dances of the Rai people of Nepal via YouTube illustrates "how both the dance and the video clips are linked to the agenda of Rai ethnic activist organisations" (Wettstein, this volume, 214). Similar processes appear to be at work in the two Assamese films Arzuman Ara describes. They draw on the legend of a princess and use "symbolically loaded props that are familiar to specific audiences" (Ara, this volume, 230). The technical possibility of making low-budget, specifically tailored works is what enables the emotional power of visual media to be deployed for relatively small audiences - for "small markets" in the terminology of old-fashioned makers of movies. The strategy of filmmakers in these circumstances is to reinforce or create a sense of identity where such identities were ill-defined before. Among the potential pitfalls of such capacities is that colonial era stereotypes may be reinforced, resulting in films that may prove more symptomatic of "inner orientalism" than "models of independent filmmaking", as Mara Matta argues in her essay on a film made with the Monpa people of Arunachal Pradesh (Matta, this volume, 260).

The resourcefulness and energy that have gone into researching the essays in this book draw attention to the unsettling power of digital media. The processes are old and obvious. In print-on-paper times, practices that were frozen in books and reports acquired an authority and permanence that had previously been inconceivable. In the age of paper and film, printing presses and processing labs were costly choke points. In digital times, however, only the telecom provider stands between individuals and their audiences. From one angle, this may look admirably democratic. From another, it may appear frightening in three ways. First, users of mobile devices are never private or alone; the provider of a network can track them down. Second, anyone can readily record me, interpret me and present me to the world without my consent. Third, superstition, rumour, lies and hate can be easily 


\section{Robin Jeffrey}

circulated..$^{23}$ But the democratic possibilities - to improve health and services, to reveal injustice and to inform and educate - are also immense. The essays in this book are remarkable for demonstrating the power of digital media in places where it would once have been hard to find a newspaper. ${ }^{24}$

\section{Notes}

1 Hugh Trevor-Roper, "The Invention of Tradition: The Highland Tradition of Scotland," in Eric Hobsbawm and Terence Ranger (eds.), The Invention of Tradition (New York: Cambridge University Press, 1983), pp. 15-41. Peter Manuel, Cassette Culture: Popular Music and Technology in North India (Chicago: University of Chicago Press, 1993); Ratnakar Tripathy, "Music Mania in Small-Town Bihar: Emergency of Vernacular Identities," Economic and Political Weekly, vol. 47, no. 22 (June 2, 2012), pp. 58-66.

2 Stephen Foster, A Private Company (Sydney: Pier 9, 2010), pp. 67-72. There are Indian connections. The author of one of these popular texts about Scotland's glory was James Macpherson, a wheeler-dealer parliamentarian and influence-pedlar at East India House, headquarters of the East India Company.

3 Bernard S. Cohn, "The Census, Social Structure and Objectification in South Asia," in Bernard S. Cohn (ed.), An Anthropologist among the Historians and Other Essays (New Delhi: Oxford University Press, 1994), pp. 224-254, is a good place to start.

4 Peter Manuel, Cassette Culture: Popular Music and Technology in North India (Chicago: Chicago University Press, 1993), p. xv.

5 Robin Jeffrey, What's Happening to India? (London: Macmillan, 1986), pp. 12-15, 91-92.

6 Ratnakar Tripathy "Music Mania in Small-Town Bihar," Economic and Political Weekly (June 2, 2012), p. 58.

7 For example, the Democratic People's Republic of Korea.

8 For radio, cinemas, telephones, newspapers and post office, India: A Reference Annual 1953 (New Delhi: Ministry of Information and Broadcasting, 1953), pp. 315-318, 330-331. For phone, Robin Jeffrey and Assa Doron, The Great Indian Phone Book (London: C. Hurst, 2013), p. 28. For newspapers, Robin Jeffrey, India's Newspaper Revolution (London: C. Hurst, 2000), p. 27.

9 K. P. Jayasankar and Anjali Monteiro, A Fly in the Curry: Independent Documentary Film in India (New Delhi: Sage Publications, 2016), pp. 4-9.

10 Jeffrey, India's Newspaper Revolution, p. 189.

11 Nalin Mehta, India on Television (New Delhi: HarperCollins, 2008), pp. 27-55; Sevanti Ninan, Through the Magic Window: Television and Change in India (New Delhi: Penguin, 1995); Arvind Rajagopal, Politics after Television (Cambridge: Cambridge University Press, 2001).

12 India: A Reference Annual 1964 (New Delhi: Ministry of Information and Broadcasting, 1964), p. 125; India: A Reference Annual 1953 (New Delhi: Ministry of Information and Broadcasting, 1974), p. 107.

13 Jeffrey, India's Newspaper Revolution, pp. 39-42.

14 Press in India (New Delhi: Ministry of Information and Broadcasting, Annual Report of the Registrar of Newspapers for India, for Relevant Years).

15 Manuel, Cassette Culture, p. 10.

16 Telecom Regulatory Authority of India, Highlights of Telecom Subscription Data as on 30th June 2017, Press Release No. 60/2017, 14 August 2017, pp. 9, 15. The Northeastern region for telecommunications purposes consists of the state of Assam, Arunachal Pradesh, Meghalaya, Nagaland, Manipur, Mizoram and Tripura.

17 Paul Richman, "Introduction: The Diversity of the Ramayana Tradition," in Paul Richman (ed.), Many Ramayanas: The Diversity of a Narrative Tradition in South Asia (New Delhi: Oxford University Press, 1992), p. 4. Rajagopal, Politics after Television, pp. 12-17. 
18 Jeffrey, India's Newspaper Revolution, p. 101.

19 Jayasankar and Monteiro, Fly in the Curry, p. 30.

20 Jeffrey and Doron, Great Indian Phone Book, pp. 191-197.

21 Telecom Regulatory Authority of India, Highlights of Telecom Subscription Data as on 30th June 2017, p. 3. The National Capital Territory of Delhi had a teledensity of 261 per cent.

22 Roger Wallis and Krister Malm, Big Sounds from Small People: The Music Industry in Small Countries (New York: Pendragon Press, 1984).

23 See, for example, "How WhatsApp Helped Turn an Indian Village into a Lynch Mob," $B B C$ News, July 19, 2018, www.bbc.com/news/world-asia-india-44856910, Accessed 23 November 2018.

24 At independence in 1947, there was one daily newspaper in Assamese. It is fairly certain there were none in the other languages of the Northeast. India: A Reference Annual 1953 , p. 316. 


\section{Index}

access to communication resources 146

Achchha thik geya 74

acquisition of Adivasi land 123

ActionAid 107

activist documentary films 125

activist simplification 118

Adivasi 91, 108-109, 110-113; communities 117; culture 125

Adivasi cultural traditions 76

Adivasi (first people) in India 3, 51

adivasi village community 113

adivasi village life 113

Adivasis in Jharkhand 129

Adivasis of India 129

affective forms of citizenship 147

affirmative action policy, in South Asia 5

Agarwala, Jyotiprasad 230-238

agents of: state and MNCs 123

age of cinema 82

Ahom 229, 230-243

All India Santali Film Association

(AISFA) 11

Andean chichi 94

angir bapla ("marriage by elopement") 79

AnSI fieldwork activity 187

anthropological knowledge 178

anthropological research 177

Anthropological Survey of India 179, 186-189, 191

anthropological visual representation 180

anthropologising gaze 197

anthropologists 175

anti-colonialism (implicit) 19

anti-mining movements 122

apparatus of distribution 90

Arth 96

Asamiya/Ôxômiya 239, 242

Asian culture 234

Assamese 229, 240
Assamese language 249, 257

audiovisual media: documentation 17; material 187; provides projections surfaces 8

audiovisual music production 93

audiovisual research footage 198

authorship in filmmaking 176

auto-ethnographic case study 123

Awami League 159

backward: caste and class 46

backwardness 41

Badkagaon, Jharkhand 127

Bagalwali jaan mareli 93

Baingabandhu [bongobond ${ }^{\mathrm{h}} \mathrm{u}$ ] ('friend of Bengal') 159

Bangladeshi film industry 151

Bangladeshi government 153

Bangladeshis 153

Bangladeshi state's self-positioning 163

Bangladeshi war of independence in 1971 160

Bangladesh Nationalist Party (BNP) 160

Bangladesh's cultural richness 155

Bangladesh's national identity 159

Benarasis 99

Bengali cinema 13, 46

Bengali cultural products 50

Bengali 'folk' cultures 58

Bengali literature 158

Bengali Muslims 159

Bengaliness 159

Bhadralok 47

Bhadrota (civility) 60

bhasha (dialect) 53

Bhojpuri: cinema 52, 90-94; culture 90; film industry 98; films 96-97; media 92-96; music videos 93

Bhojpuri indigeneity 90-99 
Bhojpuri media 99; audiences 91; industry 91-99; production, distribution and exhibition 90

Bhojpuri music economy 93

Bidesia 97

Bidesini - From Bangladesh with Love (movie) 14, 151

Bihu festival 240

Birhor 72; indigenous group 66; people 66 Birmingham Centre for Contemporary Cultural Studies 55

Bluetooth 1

bodily movement 213-215, 222

Bollywood 10, 220-223; dance scenes 32; movies 40; productions; stereotypes 40

British colonial rule 162

Brokpa (Arunachal Pradesh) 19, 249, 254

Buranji 241

\section{cable TV 9}

capitalist world economy 107

carnivalesque energy in comedy 58

cassette culture 90-92

cassette technology 9

caste group (jāti $) 34$

casteless global citizenship 98

caste privileges 98

Chando Likhon 74

Chhaprahiyas 99

Chhath Pooja 99

Chhatiar ceremony 69

chinki 137

Chittagong Hill Tracts (CHT) 162

Choice Videos 50

Chorok Chikan 74

Chronique d'un Été 178

Chuar ('tribe') revolts 47

cinema: Tamil 81

Cinema in India 186

cinema vérité (cinema-truth) 177

cine-technician 187

civilisation, notion of $1-2$

claimed indigeneity 92, 101

claims to indigeneity 99

classical linear narrative structures 49

classic documentary film domain 179

cinephilia 49

citizen journalists 139

classifications: academic and administrative 37

coalitional indigeneity 99

colā and dorā (Gaddi male attire) 31-32

colonial academic practice 179

colonial anthropology 182 colonial forms of 'othering' 180

colonial powers 16

colonial practices of representation 188

colonised societies 164

comic mode 58

common identity projects 132

communicative ecology 143

communities: Birhor 70; exoticising 18;

Ho 70; Munda 70; national 43; othering

18; supra-national 43

Company Raj (East India Company) 116

composite Indian culture 133

concepts of culture 72

connections: television and landline phones 39

contemporary: media practices 47 ; South

Asia 118

contemporary anthropologists 187

contemporary art practices 178

contemporary Bangladesh's identity 160

contemporary India 109-118, 191

Contemporary Pashto [pornographic] film and Cinema Culture 52

cornerstones of Bangladesh's identity 155

cosmopolitanism (shared North-eastern

identity) 16

counter-hegemonic discourses 16

counter-hegemonic voices 130

CRPF [state paramilitaries] 114

Cuban timba 94

cultural: affirmation 17; distinctiveness

18-19, 37; evolutionalism 17; hierarchy

16 ; margin 71 ; minorities 19 ; practices

72 ; production 3 ; stereotypes 17 ;

vignettes 4

cultural authenticity 118

culturalisation of media 9, 10-19

cultural loss 199, 200

cultural margin of film circulation 71 , 80-83

cultural otherness 122

cultural self-determination 165

cultural stereotypes 198, 210

culture industry 71

culture of consumption 134

custom 198, 207-209, 210-211

customary practices 4

Dabangg 113

Das Kapital 107

decentralised or small media 9-10

Delhi International Ethnographic Film

Festival (DIEFF) 173, 182, 191

Delhi-Mumbai-Delhi 173 
Democratization" of media 267

demographic distribution 99

deshvāsi (fellow countrymen) 112

devaluation of local identifications 43

Dhauladhar mountain range 42

dhoti (wrap) 125, 231, 235-236

diasporas 17, 213-214, 217-219, 220-225; national and global 19

dichotomies: cosmopolitan vs. local 40; male $v s$. female 40 ; modern civilization $v s$. tradition 40

digital files 10

digital revolution 7

digital technology and connectivity, availability at lower prices 1

digital video films 52

discourse of national integration 139

dissemination of video-making technology 130

Diwali 39

documentary: filmmakers 17 ; films 17 ; practitioners 175

documentary studies 176

dominant popular culture 40

Dong 69

Doordarshan 39

double indigenization 30-31, 41

Dumi Rai 214-215

Durdura 66, 70-76, 83-84

East Pakistan 159, 160

ecological guardians 6

economic capital 98

economic ramifications of cultural products 46

economies of scale 2

eco spiritual custodians 14

educational films 190

Edwards (2012) 204

Ekuśe ('the 21st [of February]') 160

Elwin, Verrier 7

emergent video cultures 47

empirical findings 72

established cartography of India 50

ethnic minorities 151, 162

ethnic self-assertion 139

ethnographic: audiovisual practices

176; charge 61; classification 36;

differentiation 71; fieldwork 29, 30; film

festival 173; filmmakers 17; filmmaking

16, 176; filmmaking practices 176 ; films

16, 173-179, 191; literature 72

ethnographic image-making practices 178 ethnographic interest 188

ethnographic sensibility 188

ethnolinguistic homogeneity 159

European forms of entertainment 81

evolutionary perspectives on culture 202

evolutionary theory of culture 16

evolutionist perspective 204

experiences: dalit and adivasi 57

far-Left guerrilla movements 47

federated political structure 137

female: gender 19; sexuality 19

festivals 4, 33, 213-218, 221, 240, 257-258

fiction films 17

fictive kinship 111

film: genre 191; Hindi 75; practices 176;

Santali 80; Tamil and Telegu 75

filmic image 49

filmmaker-anthropologist 178

filmmaker in India 188

filmmaking practices 175

films as mirrors 72

fluidity of cultures 49

folk dance 213-218, 221-222

folk humour 55-58

folk music: qawwali, ghazal, birha, rasiya, kajri and chaiti 93

Frankfurt School 71

fringe communities 47

Gaddi: celās (oracles) 31; community 8 , 12 ; dialect 29 ; folk dances 32 ; identity 30 ; music videos 29; people 29;

religious practice 31,40 ; representations 30 ; songs 29 ; tribal culture 41

gamchha 101/gamosa 243

Gandhi Foundation International Peace Award 129

Gaon Chodab Nahin (We Shall Not Leave Our Village) (political video) 14, 107

Garo: community 18, 196-198, 200-209, 210; culture 18; customs 18 ; modernity 18

Garo community religion, Songsarek 197, 203

Gesture 215-217, 222-225

Ghurye, G.S. 7

Ginsburg, Faye 7

global activism 109

global cultural flows 71

globalisation theory 71

global marketing 40 
government servants 187

grassroots-level activist 126

grotesque realism 55, 60

hanriā (rice beer) 113,125

Hausa 71

Hazarika, Bhupen 229

hegemonic ventriloquists 130

heterogeneous processes of filmmaking 49

hilli 78

Himachali: folk music 29; indigeneity 43; music videos 30

Himachal Pradesh tourism 42

Himal Southasian 180

historical complexities 51; Purulia 47

historically oppressed castes 133

historico-political orientation 91

histories of oppression 165

histories of social marginalization 53

historiography of cinema 52

history of anthropology 176

Hindi cinema 13, 95-99

Hindi film market 101

Hindi film music 94

Hindi films 94

Hindutva or Hindu nationalism 204

Ho community 15

Hollywood films 10

homogeneity 36

Huchke niye puchke dili re 59

human rights violations 162

HuM HiMacHali HaI YaaR (We are

Himachali, dude) 42

Hundred Drums Wangala festival 196-199

hyper-energetic cultural universe 92

identity 213-217, 223-225; Nepali and

Gorkha 52; politics 19, 98, 166

identity politics $229,230,240-241$

identity projects 134

ideological schemas 116

If It Rains 173

illegal immigrants 139

image analysis 176

independent artists 179

independent 'ethnographic' films 175

independent filmmaker 173, 180, 190

independent image-makers 179

independent Indian filmmakers 173

Indian cinema industries 73

Indian Directorate of Film Festivals 200

Indian Documentary 190

Indianised: satellite TV 39
Indian mainstream 123, 137

Indian media landscape 91

Indian Mutiny of 1857 (or first war of Indian Independence) 4

Indian National Trust for Art and Cultural Heritage (INTACH) 189

Indian news television 39

Indian state 114

Indian subcontinent 176, 190

India's mediascape 37

indigenous cinema 246

indigenous communities of Northeast India 132

indigenous cultural production 91

indigenous documentary filmmaker 122

indigenous inhabitants 165

indigenous media 7-9, 40; industry 92

indigenous musical patterns 50

indigenous people from Northeast India 131

indigenous peoples 122

indigenous self-representation 146

Indira Gandhi National Centre for the Arts 198,200

Indology 151

industrial capitalism 107

Info Change 180

information and communications

technology (ICT) 135

Institut National d'Histoire de l'Art 180

'insurgent' movements 133

intergenerational conflicts 113

internal migrants of India 137

international academic world 182

International ādibāsī Day 150

international film festivals 179. 180

International Labour Organization 122

intertextual network of images 41

Irani Restaurant Instructions 173

IT revolution 135

jaapi 230-232, 240-243

janajati (nation) in Nepal 3

Jangal Mahal 47

Jayanti Mata Cassette label (JMC) 31

Jhalda town 48

Jharkhand Cine Award 11

jhum cultivation 199

Jhumur 53

Joymati (Assamese legend) 19

Karbala: narratives 52

Kashipur, Odisha 107

Khunti district 112 
kino-pravda (cinema-truth) 177

Kirat 213-218, 221-224

Kora Rajee/Land of the Diggers 173

Kshatriya varna (social stratum) 34

kșudra nrgoșțīs [minor ethnic sects] 150

Kumar, Uttam 53

larāi (fighting) 113

lathi (long bamboo stick) charges 14

Lavani (erotic dance performance from the Marathi Tamasha) 99

Le samla sadher tomato 55

liberalisation of markets 39

liminality of borders 49

linguistic fragmentation 38

local language(s): Garo, Assamese, and

Bengali 1; newspapers 39; production 39

local musical forms (Tusu, Bhadu,

Jhumur) 50

logic of primitive accumulation 109

Loizos (1993) 203

Lok Rāmāyan (Folk Ramayana) 32-37, 40

Lok Sabha (House of Commons) elections 145

lungi (wrap) 60

\section{machchuāre 112}

mahua 66-68

mainstream film industries 90

mainstream media industries 40

mainstream normativity 19

Manbhum 46; video industry 46, 53

Manbhum videos 52-58, 60-61; production and consumption 49; West Bengal 8, 12-13

Mani Mahesh Yatra (large annual pilgrimage to the seat of Lord Shiva: Mount Kailash in the Bharmaur subdistrict of Chamba) 31-32, 42

Manju Borah 230

Maoist movement 116

Maoists 15

Maovād (Maoism) 114

marginalization 122

marginal media practices 49

Marxist teleology 108

mass media: in elite hands 9

master narratives: of evolution 40; of progress 40

media: anticipation 206; portrayals 8; practices 29; producers 19

mediatisation of Himachali indigeneity 43 mediatisation of indigeneity $29,30,40-43$ mediatised indigeneity activism 107-118

mediatising Himachali indigeneity 40

Meghalaya: sale of movies and music

videos in 1

mekhela-sador 234

melas (fairgrounds) 48

melting pot 58

memory cards 1

methodological tool (film) 176

migrant Northeastern communities 136

migration of Santals 74

militant particularisms 109

Ministry of Culture (India) 198

Mirza \& Juuliet 76

mobilisation of marginal cultures 46

modernisation 200

modern nation-state 165

modern South Asian languages 161

modern state 165

Moi, un Noir 178

Monpa 258, 260

Mujra dance video CDs 52

multi-focal narrative structures 49

Multimedia Messaging Service (MMS) 138

Mumbai International Film Festival

(MIFF) 180

Musée de l'Homme's Committee 173

museum representations 177

music VCDs: Himachali and Gaddi 40

music video: economy 94; production of $11-13$

Muslim Bengalis 159

MVM (Malati Video Movies) 50

nagāda drum 109

nagārā (battle drums) 112

Nanook of the North (Flaherty's film) 16

narrative pattern 49

narratives of discontents 52

national Bangladeshi identity 158

Nationalist Socialist Council of Nagaland 134

National Thermal Power Corporation 124

nation state 50

Naxalism [Maoism] 116

neo-Bhadralok cinema 57

neo-liberal capitalism 14

Nepal 213-218, 221-224

Nepali films 52

new and digital media 132

new digital media platforms 139

new media $7,19,40-43,71$ 
new media environment 139 newspaper revolution 9, 19 new voices: politically engaged and culturally committed 1

niche audiences 3,17

Nigerian јuju 94

Niyamgiri Movement 5, 129

non-academic practitioners 176

non-Bengali ethnolinguistic groups 161

non-governmental organization 112

non-indigenous communities 144

non-linear story-telling 49

non-professional videographers 17

non-visual anthropologists 187

Northeast India 200-206

Notes on Man Capture 173

nuāla (a Gaddi worship ritual for the god Shiva) 29, 31-37

nuāncari (a long dress with a tight bodice and a flowing, red, flower-printed skirt) 32

'Occident'-'Orient' dichotomy 166

Odiya films 76

O go bideśinī 155

ojha 111

orientalist perspectives 133

other Backward Classes (OBC) 21, 256

other media 72

pahan (village priest) 111

pahari (hill people) or upojati (those

outside the nation) in Bangladesh 3

pan-Assamese nationalism 18

pan-Indian nation 133

pan-Northeastern regional identity 149

pan-regional identity 149

parallel modernities 61

participant observation 72

Pee/Shit 173

Photo Wallahs 189

Phra Lung 240-241

'primitivising' (inaccurate representation of community) 15

police oppression 125

political activism 51

political agitations in the hills 52

political-cultural dissatisfactions 53

political idealism 116

political marginalisation 51

political mobilization 146

political uprising: Purulia 47

politics of representation 256 polyandry $19,250-255$

popular culture 177

popular films 72

postcolonial critique of the colonial foreign gaze 180

postcolonial India 107

post-colonial Indian state 132

postcolonial world 108

pre-cassette: recording and film industry

38-39

preferential discrimination 137,202 ; in

India 5

pre-marital relationships 79

Press Information Department (PID) of the

Bangladeshi state 150

Primitivised 197

problems of cultural re-presentation 51

professional activism 128

professional anthropologists 178

progressive social change 115

Project Cinema City 180

proliferation of regional news channels 39

propaganda materials 114

protection of Adivasi land 123

provincialise the female body 97

public discourse 190

public nudity 197

Purulia 46

puzzle films 49

Rabelais and His World 58

racial marginalisation 141

Rajbangsi: communities 51; video industry 51; videos 46, 50

Ray, Bappa 198, 203

regimes of victimisation and exploitation 112

regional cinema 61

regional film productions 74

regionalisation: of language and audience

40; of media 10; of VCD market 38

regional language-based cinemas 51

repeat viewing 82

Republic Day parade 133

resources: marginalised minorities 14

rickshaw-wallahs 95

rights of ethnic minorities 150

rìti-riwāz (customs) 33

river: Yamuna, Narmada, Subarnarekha,

Ganges, Krishna 110

Royal Anthropological Institute in London 188

rural hinterlands 19 
Sadher Tomato 5, 55-57, 60

Śahid Minār ('martyr monument') 160 sakela dance 18, 213-219, 220-225

sal (Shorea robusta) 111

salvār-kamīz (trousers and shirts worn across India) 33

sangart 79

Sanskrit neologism 161

Santal 72

Santali: culture 51; film industry $72-73$; film production companies 73 ; film script 73; films 66-67, 73, 70; indigenous group 70; language 50-51, 70; music video albums 70; music videos 46; people 70; script 51; VCDs 66; writers 73

Sasaram 99

satellite TV channels 9

Scheduled Castes (SCs) 5

Scheduled Tribes (STs) 5, 29, 35-37, 40, 123, 137, 202, 210, 240-241, 254 self-determined group identities 163 self-representation by Adivasis 129 semi-structured interviews 72 shared 'Northeastern' identity 149 Sherdukpen 251-255, 260

Shia Muslim communities 52 Shillong Chamber Choir (SCC) 144 Short Message Service (SMS) 138 Singham 76

South Asian: cinema audiences 81-82; educated urban audiences 14; media enterprises 92; popular films 70-71; 'pre-modern' cultures 82

South Asian countries: dominated by hegemonic majorities 1 ; indigeneity and nation in 3-7; media as cultural fields of production $9-11$

South Asian studies 151

small scale movies, production of 11-13

small-scale production networks 46 social mobility 98

social patterns of communication 39 societal change 72

society: Birhor and Santal 76-79

socio-economic development 123

socioeconomic disadvantages 163

socio-political discontents 46

socio-political discourse 39

song-and-dance sequences 49

South Asia: communities 78; popular films 74

special constitutional guarantees 137 state-corporate nexus 107

state-funded producers of documentary

films 190

state-produced documentary films 180

State-sponsored 'Bengalisation' 162

Still, The Children Are Here (documentary film) 200, 208-209, 210

strategies: ethnographic and documentary 173

subaltern 122,130

subaltern fringes of metropolises 92

subalternity 130

subaltern voice (the lack of it) 15

subcontinental modernity 118

subcultural forms 47

subcultures 47

Sukafa/Sukapha 240

Sur Sangeet Films 2

Survival International 14

Syulikfa 230-238

Tai-Ahom 240-242

Tai-Ahom identity 19

Tamil cinema 13

television soaps 8

Thai-Malay shadow puppetry 94

thāli-ghad̄a (brass plate on a clay pitcher) 32

Thiruvithamkoor, Malabar, Kerala:

Speculations on the Regions in

'Regional Cinema 50

threat of indigenous rights 14

Tibetosphere 249, 258

tola: Birhor 66, 72-76; Santal 66-69

traditional anthropological 'Other' 178

traditional medicine 157

traditional social anthropology 178

transhumant: migrations 35; pastoralists 33

Transparency International 157

tribal communities or groups 2, 4;

organisations demand for original

inhabitants for 5-6

tribal homelands 201

tribal middle classes 202

tribal studies 36

Triund (a famous hiking destination above Dharamshala) 42

Tsing (2005) 209

tushu songs 47

typical Bengali narratives 47

underprivileged urban and rural Others 83

Unity in Diversity 133, 141

universal logic of capitalism 108 
University of Delhi 173

upajāti [tribe] 150

VCDs 17; consumption 39; recorders 39

Vedanta (bauxite mining company) 14

Ventriloquism 128

vernacular 92; languages and dialects 92; music 92

vernacularisation (music cassettes) 19

vernacular media industries 91

video: narrative and feature-length 46

video clip 214, 220-225

video dissemination via YouTube 14

videographic expressions 125

video narratives 12

vikshipt mansikta 90

village life in South Asia 83

violent resistance 116

"virtual" after-lives of celluloid films 49

virtual explosion of communication 139

virtual indigeneity: Gaddi and

Himachali 41
Virtual Life of Film 49

virtual public spheres 115

virtual Sherpas 33

visual: anthropologist 175; anthropology 173-179, 188, 190-191

Visual Anthropology Bulletin 189

visual anthropology in India 188

Visual Anthropology in India and Its Development 188

visualist bias 39

voyeurism 247

vulgarisation of Manbhum music and songs 53

Wahhabisation of Islam 157, 165

Wangala, A Garo Festival 196-197

Warli paintings 111

West Pakistan 159

wireless transfer of data 1

Word Within the Word 173

World Happiness Survey 156

Xorai 231, 240 